Universidade de São Paulo - USP Escola de Engenharia de São Carlos - EESC Departamento de Engenharia Elétrica e de Computação

DANILO LUIZ ALVES NEGRÃO

\title{
Metodologia Para a Coordenação e Seletividade da Proteção Direcional de Sobrecorrente em Sistemas de Transmissão de Energia Elétrica
}

São Carlos

2015 



\section{DANILO LUIZ ALVES NEGRÃO}

\section{Metodologia Para a Coordenação e Seletividade da Proteção Direcional de Sobrecorrente em Sistemas de Transmissão de Energia Elétrica}

Dissertação apresentada à Escola de Engenharia de São Carlos da Universidade de São Paulo como parte dos requisitos para obtenção do título de Mestre em Ciências, Programa de Engenharia Elétrica

Área de Concentração: Sistemas Elétricos de Potência

Orientador: Prof. Dr. José Carlos de Melo Vieira Júnior

São Carlos

2015 


\section{AUTORIZO A REPRODUÇÃO TOTAL OU PARCIAL DESTE TRABALHO, POR QUALQUER MEIO CONVENCIONAL OU ELETRÔNICO, PARA FINS DE ESTUDO E PESQUISA, DESDE QUE CITADA A FONTE.}

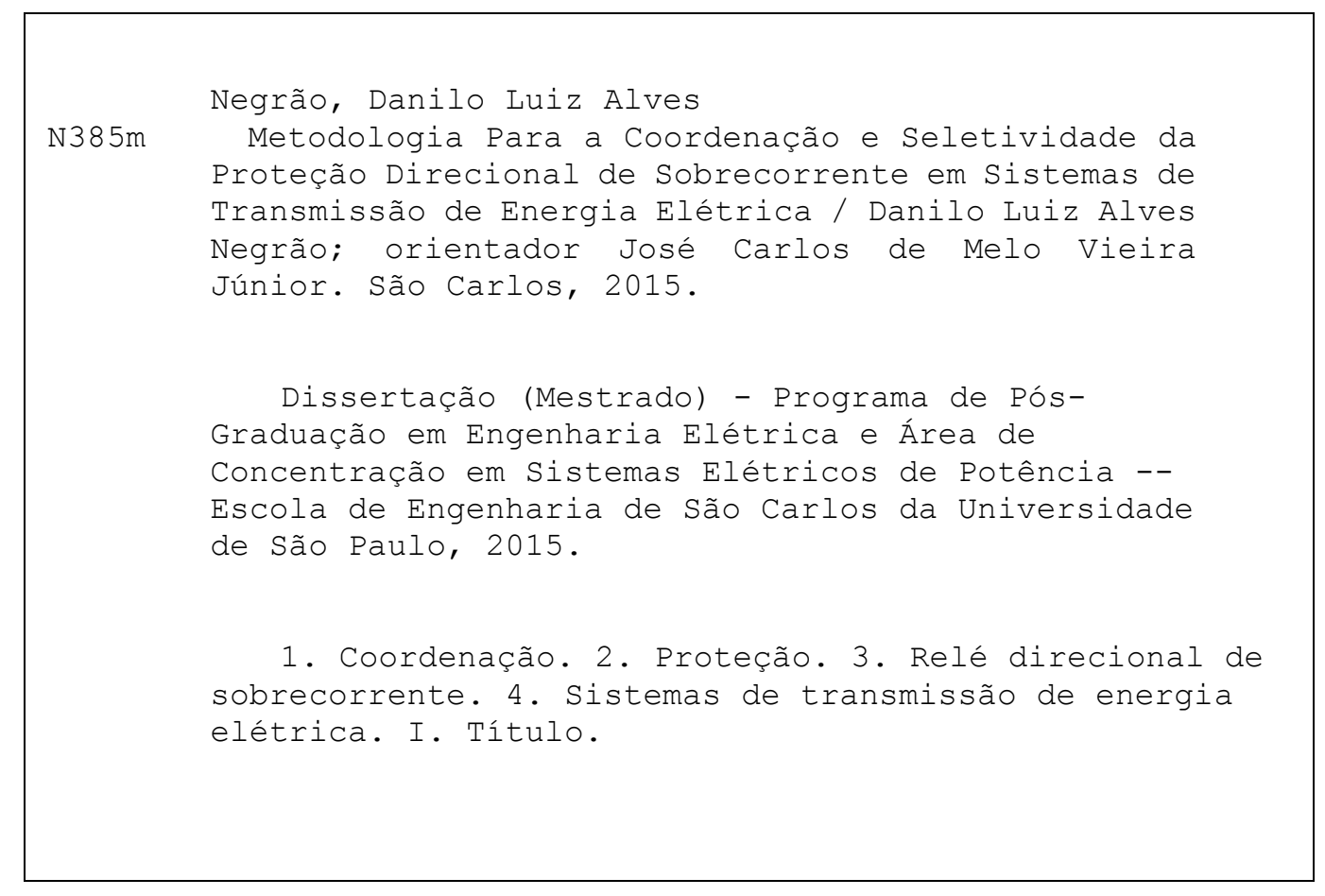




\section{FOLHA DE JULGAMENTO}

Candidato: Engenheiro DANILO LUIZ ALVES NEGRÃO.

Título da dissertação: "Metodologia para a coordenação e seletividade da proteção direcional de sobrecorrente em sistemas de transmissão de energia elétrica".

Data da defesa: 31/03/2015

Comissão Julgadora:

Resultado:

Prof. Dr. José Carlos de Melo Vieira Júnior (Orientador) APROVADO

(Escola de Engenharia de São Carlos/EESC)

Prof. Dr. Eduardo Nobuhiro Asada

PROVADO

(Escola de Engenharia de São Carlos/EESC)

Dr. Silvio Aparecido de Souza

(Companhia de Transmissão de Energia Elétrica Paulista/CTEEP)

Coordenador do Programa de Pós-Graduação em Engenharia Elétrica:

Prof. Associado Luis Fernando Costa Alberto

Presidente da Comissão de Pós-Graduação:

Prof. Associado Paulo César Lima Segantine 



\section{AGRADECIMENTOS}

Um trabalho que agrega conhecimentos só pode ser realizado através do apoio de companheiros e conselheiros.

Agradeço a minha família pela disposição e força diante dos desafios superados. Aos colegas do Laboratório de Sistema de Energia Elétrica pelas discussões construtivas que esclarecem dúvidas e permitem o crescimento de todos. Aos professores Dr. Eduardo N. Asada, Mário Oleskovicz e Dr. Denis V. Coury pela paciência e auxílio no desenvolvimento desse trabalho. A todos os membros do Departamento de Engenharia Elétrica e Computação, em especial aos funcionários da secretaria de pósgraduação de Engenharia Elétrica.

Agradeço à Companhia de Transmissão de Energia Elétrica Paulista - CTEEP e aos engenheiros da Divisão de Análise da Operação pelos dados e informações do sistema. Aos integrantes do projeto de Pesquisa e Desenvolvimento PD-0068-0020/2011 por proporcionarem o desenvolvimento de conhecimento e pensamento crítico. À Coordenação de Aperfeiçoamento de Pessoas de Nível Superior CAPES pelo apoio financeiro.

Por último, ao professor Dr. José Carlos de Melo Vieira Jr., meu orientador, sem o qual esse trabalho nunca seria possível, agradeço pela amizade, paciência, conselhos e dúvidas criadas e solucionadas, obrigado. 



\section{RESUMO}

\section{NEGRÃO, D. L. A. Metodologia Para a Coordenação e Seletividade da Proteção Direcional de} Sobrecorrente em Sistemas de Transmissão de Energia Elétrica. 2015. 145p. Dissertação (Mestrado em Ciências, Programa de Engenharia Elétrica) - Escola de Engenharia de São Carlos, Universidade de São Paulo, São Carlos, 2015.

Este trabalho propõe uma nova metodologia para a solução do problema de coordenação de relés direcionais de sobrecorrente em sistemas de transmissão em malha. São utilizadas informações sobre a atuação do relé como dispositivo de proteção principal (ou retaguarda local no caso de se considerar o relé de distância) e também de sua atuação como proteção de retaguarda remota, fornecendo uma base mais sólida para definição dos ajustes. A partir de uma série de critérios determinados de acordo com a instalação, define-se uma área de ajuste do relé, diretamente sobre sua curva de atuação. Sobre esta área, aplica-se um método de otimização capaz de encontrar o melhor ajuste possível para o dispositivo em análise. A metodologia é aplicada sem a necessidade de uma análise topológica do sistema, sendo que as informações da localização do relé e sua integração com os outros dispositivos de proteção são resumidas durante o estudo de curto-circuito, que fornece os dados de entrada para a metodologia. O algoritmo resume os critérios de coordenação em pontos de referência, de modo que a análise é feita relé a relé, eliminando assim problemas comuns como o de tratamento de banco de dados e ganhando em agilidade e simplicidade no tratamento do problema. A resposta fornecida é bastante intuitiva, sendo fácil entender os resultados obtidos e quais seriam as implicações caso na prática sejam necessárias adequações à instalação.

Palavras-Chave: Coordenação; proteção; relé direcional de sobrecorrente; sistemas de transmissão de energia elétrica. 


\section{ABSTRACT}

\section{NEGRÃO, D. L. A. Methodology for the Coordination and Selectivity of Directional Overcurrent} Protection in Electrical Power Transmission Systems. 2015. 145p. Dissertation (Master Degree, Electrical Engineering Program) - Engineering School of São Carlos, University of São Paulo, São Carlos, 2015.

This work proposes a new methodology to solve the problem of coordination of directional overcurrent relays in meshed transmission systems. Using information about the operation of the directional relay as primary protection (or local backup, in the case of considering the distance relay) and also its role as remote backup protection, the methodology provides a more solid basis for defining settings. Based on a series of criteria determined in accordance with the installation, an area of relay feasible settings is defined directly over their time-overcurrent curve. On this area, an optimization method is applied to find the best possible setting for the device under analysis. The method is applied without the need for topological analysis of the system, and the information of the relay location and its integration with other protective devices are summarized during the short circuit study, which provides the input data for the methodology. The algorithm summarizes the criteria of coordination in landmarks and the analysis is performed relay by relay, thus common problems are eliminated, such as database treatment, gaining agility and simplicity in treating the problem. The answer provided is extremely intuitive, making it easy to understand the results and what would be the implications in case of, in practice, be necessary to perform adjustments to fit with the installation.

Keywords: Coordination; directional overcurrent relay; electric power transmission systems; protection. 


\section{SUMÁRIO}

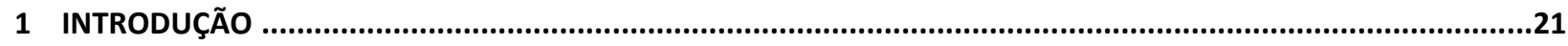

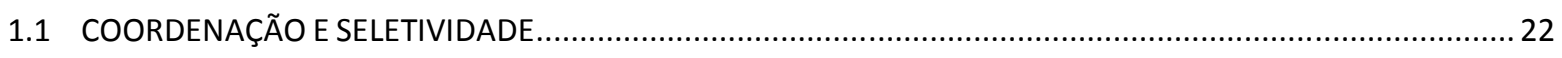

1.2 OBJETIVOS

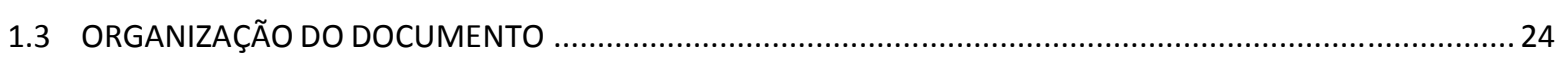

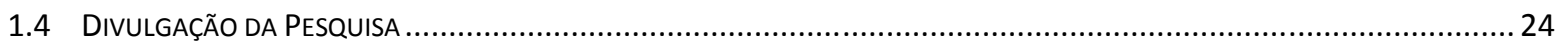

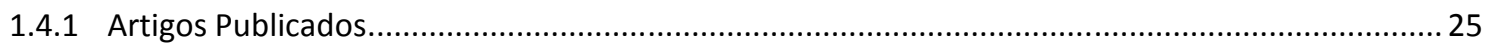

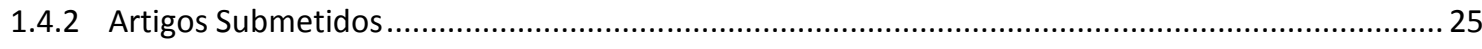

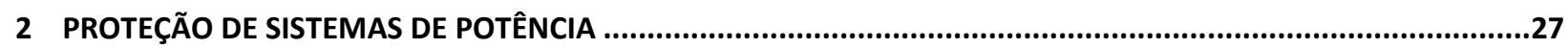

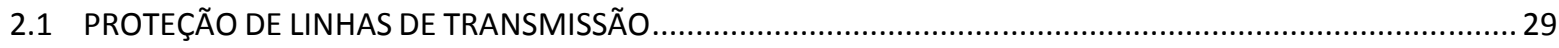

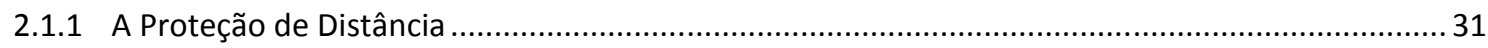

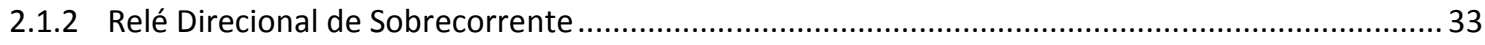

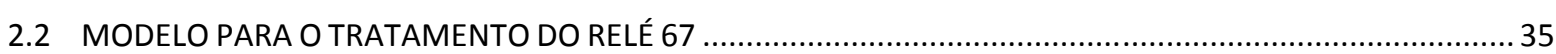

2.2.1 Modelo para o Tratamento de Relés com Curvas Padronizadas .................................................... 35

2.2.2 Modelo para o Tratamento de Relés com Curvas não Padronizadas ................................................ 37

3 MÉTODOS PARA COORDENAÇÃO DE RELÉS DIRECIONAIS DE SOBRECORRENTE ……....................................49

4 METODOLOGIA: COORDENAÇÃO DE RELÉS DIRECIONAIS PELO MÉTODO DO MENOR ERRO ………………....57

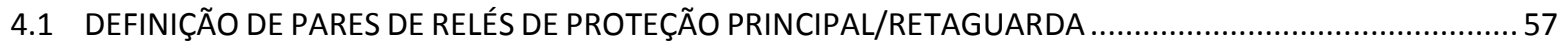

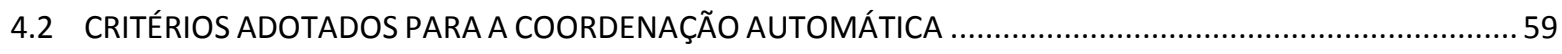

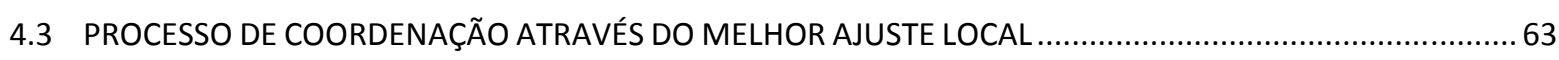

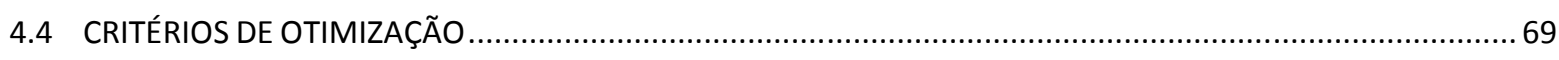

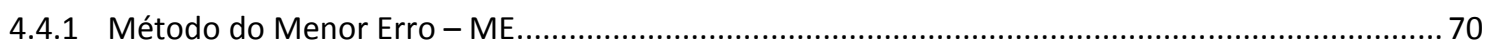

4.4.2 Método da Integral Logarítmica Ponderada Linearmente - ILL .................................................. 71

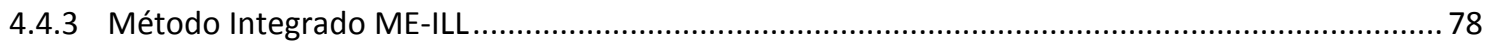

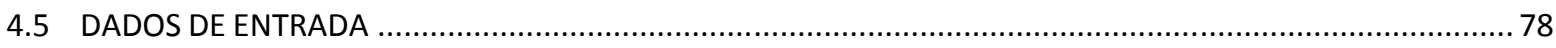

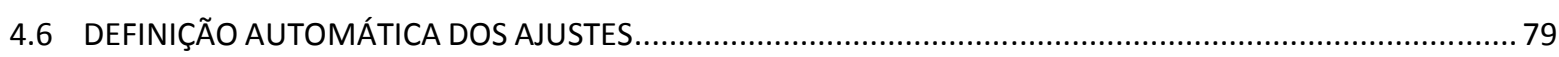

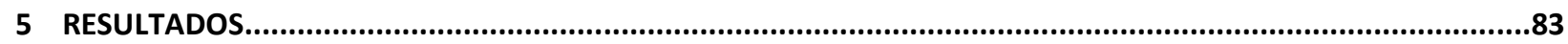

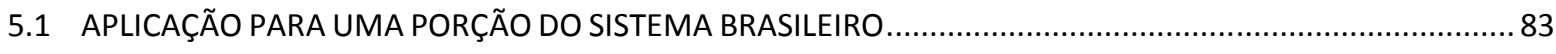

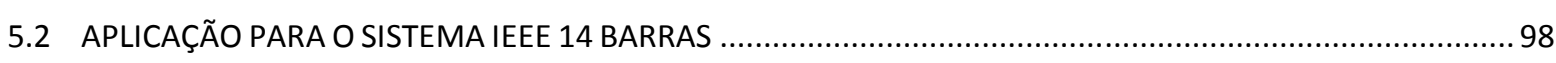

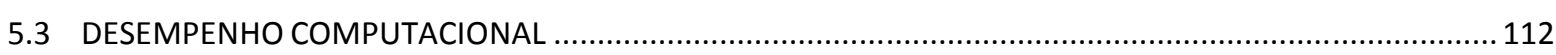

6 ANÁLISE DA COORDENAÇÃO DOS RELÉS DIRECIONAIS FRENTE A ALTERAÇÕES TOPOLÓGICAS.......................115

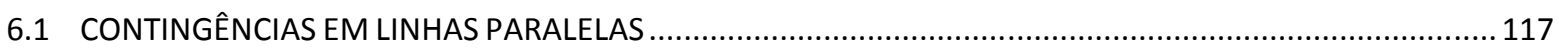

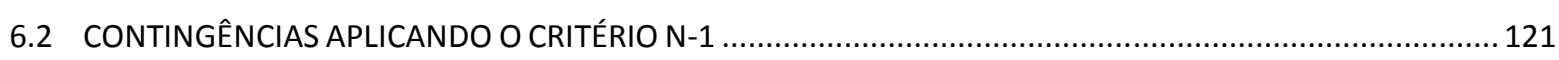




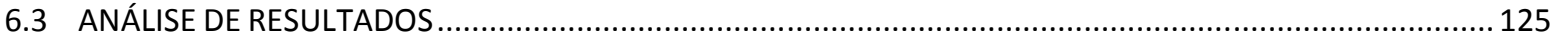

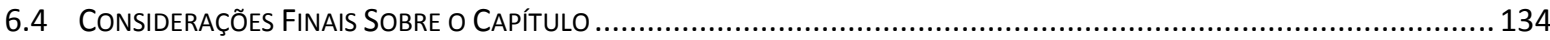

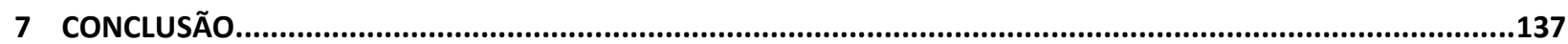

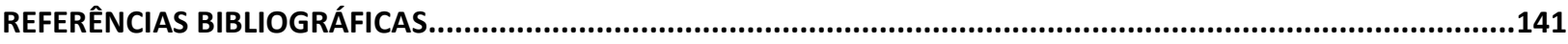

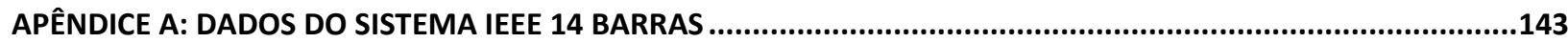

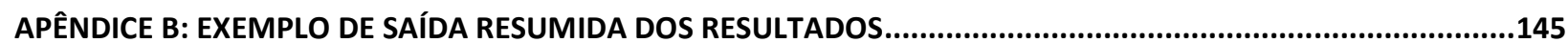




\section{LISTA DE FIGURAS}

Figura 2.1 - Subsistemas de um sistema de proteção (COURY; OLESKOVICZ; GIOVANINI, 2007).

Figura 2.2 - Exemplo de zonas de proteção (PHADKE; THORP, 1990)..........................................................228

Figura 2.3 - Exemplo de sistema radial, em que é indicado o sentido da corrente................................................ 29

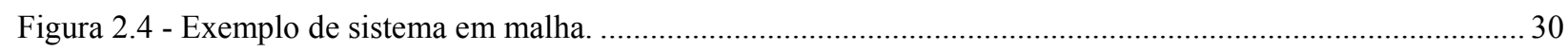

Figura 2.5 - Exemplo de um sistema em malha com falta na linha entre os relés R4 e R5................................... 30

Figura 2.6 - Exemplo de SEP em malha com correntes de curto-circuito nos relés de acordo com a localização da falta.

Figura 2.7 - Características do relé de distância (COURY; OLESKOVICZ; GIOVANINI, 2007). 32

Figura 2.8 - Relés direcionais aplicados a um sistema em malha. 33

Figura 2.9 - Conexões para diferentes conjugados do relé direcional. a) Conexão para $30^{\circ}$;

b) Conexão para $60^{\circ}$; c) Conexão para $90^{\circ}$. 34

Figura 2.10 - Exemplo de curva de atuação do relé e como os ajustes a afetam....... 37

Figura 2.11 - Curvas para o relé CO-8. Relação entre valores estimados e valores de catálogo. 42

Figura 2.12 - Curvas para o relé CDG-13. Relação entre valores estimados e valores de catálogo. 45

Figura 4.1 - Exemplo de sistema não-radial. 58

Figura 4.2 - Considerações sobre o intervalo de coordenação do relé direcional levando em consideração o relé de distância. a) zonas de proteção e locais de instalação dos relés.

b) resumo dos critérios.

Figura 4.3 - Situação em que o primeiro ponto de referência é obtido. 64

Figura 4.4 - Situação em que o segundo ponto de referência é obtido. 65

Figura 4.5 - Situação em que o terceiro ponto de referência é obtido.

Figura 4.6 - Situação em que o quarto ponto de referência é obtido. 68

Figura 4.7 - Definição das áreas de ajuste e restrição.

Figura 4.8 - Exemplo de resultado não satisfatório pelo método ME. 72

Figura 4.9 - Ilustração do método dos trapézios. 73

Figura 4.10 - Diferença entre o detalhamento da característica inversa nas escalas a) linear e b) logarítmica.......... 73

Figura 4.11 - Função de ponderação sobre a área abaixo da curva do relé. 75 
Figura 4.12 - Fluxograma do método ILL.

Figura 4.13 - Exemplo de solução pelo método ME, com apenas uma corrente de referência sensibilizada pelo relé

Figura 4.14 - Exemplo de solução pelo método ILL, com apenas uma corrente de referência sensibilizada pelo relé 77

Figura 4.15 - Fluxograma geral da metodologia.

Figura 5.1 - Diagrama unifilar reduzido de parte do sistema brasileiro, com foco no estado de São Paulo. 86

Figura 5.2 - Curva de atuação obtida para o relé R1

Figura 5.3 - Coordenação entre os relés R1 e R4 de fase. 90

Figura 5.4 - Coordenação entre os relés R1 e R4 de neutro.

Figura 5.5 - Curvas de atuação dos relés R15, R18, R16 e R17 de fase. .92

Figura 5.6 - Curvas de atuação dos relés R15, R18, R16 e R17 de neutro.

Figura 5.7 - Curvas de atuação dos relés R9 e R7 de fase, sendo o relé R7 retaguarda remota do relé R9. .95

Figura 5.8 - Curvas de atuação dos relés R9 e R7 de neutro, sendo o relé R7 retaguarda remota do relé R9............96

Figura 5.9 - Coordenação entre os relés R1 e R4 de neutro, sem considerar relé 21 como proteção principal...........97

Figura 5.10 - Representação do sistema IEEE 14 barras.............................................................................. 98

Figura 5.11 - Sistema IEEE 14 barras para a aplicação da metodologia .......................................................... 99

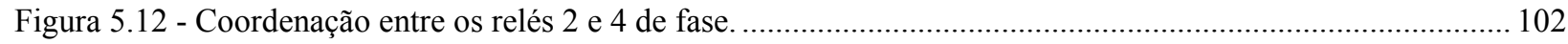

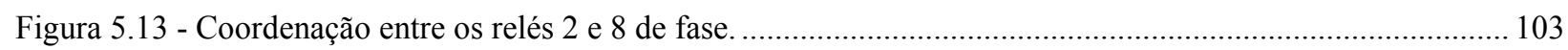

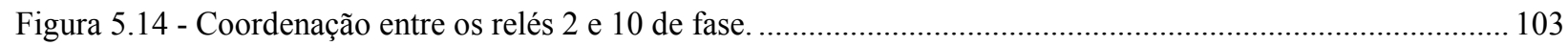

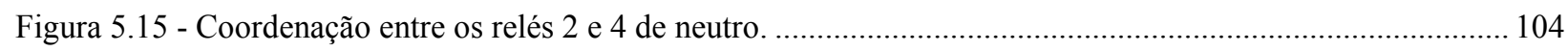

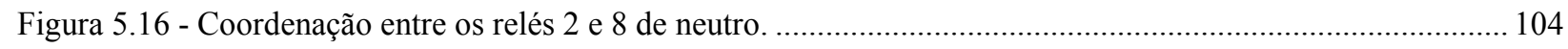

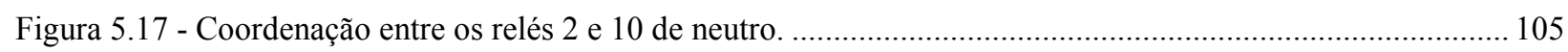

Figura 5.18 - Intervalos de coordenação para o sistema IEEE 14 barras para a proteção de fase a) e de neutro b)

Figura 5.19 - Comparação entre resultados para o relé 1 com (a) e sem (b) unidade instantânea......

Figura 5.20 - Imagem da interface do programa desenvolvido.

Figura 6.1 - Coordenação de fase entre os relés R24 e R15 considerando a análise para o caso base.

Figura 6.2 - Coordenação de fase entre os relés R24 e R15 considerando a análise de linhas paralelas.

Figura 6.3 - Coordenação de fase entre os relés R24 e R15 considerando a análise N-1. 
Figura 6.4 - Coordenação de neutro entre os relés R22 e R24 considerando a análise para o caso base. 133

Figura 6.5 - Coordenação de neutro entre os relés R22 e R24 considerando a análise de linhas paralelas. 133

Figura 6.6 - Coordenação de neutro entre os relés R22 e R24 considerando a análise N-1. 134 


\section{LISTA DE TABELAS}

Tabela 2.1 - Coordenação entre os dispositivos de proteção para o sistema da Figura 2.8..................................... 34

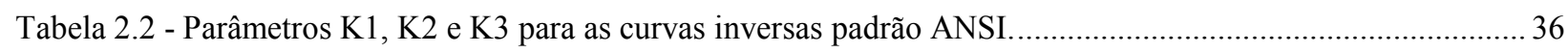

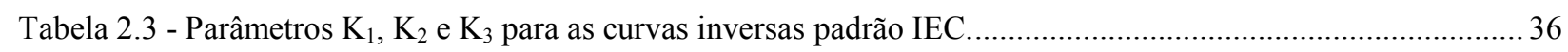

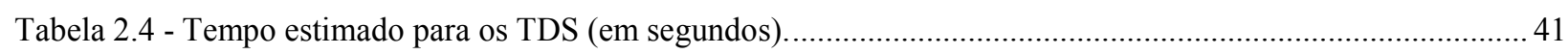

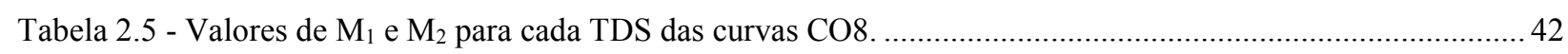

Tabela 2.6 - Valores de $\alpha$ e $\beta$ para todos os diais do relé CO8 ................................................................... 42

Tabela 2.7 - Erro relativo ponto-a-ponto do método descrito para o relé CO-8 ................................................. 43

Tabela 2.8 - Erro absoluto ponto-a-ponto do método descrito para o relé CO-8. ................................................4 43

Tabela 2.9 - Tempo estimado para os diais de tempo (em segundos). ................................................................ 44

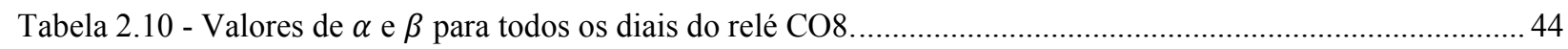

Tabela 2.11 - Erro relativo ponto-a-ponto do método descrito para o relé CDG-13...........................................45

Tabela 2.12 - Erro absoluto ponto-a-ponto do método descrito para o relé CDG-13......................................... 46

Tabela 2.13 - Resumo dos erros relativos obtidos pela aplicação do método para os relés

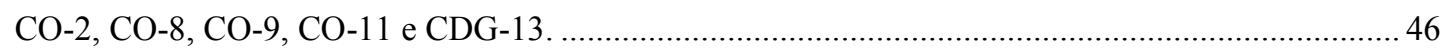

Tabela 4.1 - Pares de proteção principal/retaguarda do sistema da Figura 4.1 ...................................................5 58

Tabela 5.1 - Dados de entrada para os relés de fase do sistema da Figura 5.1 .................................................. 84

Tabela 5.2 - Dados de entrada para os relés de neutro do sistema da Figura 5.1 ............................................ 85

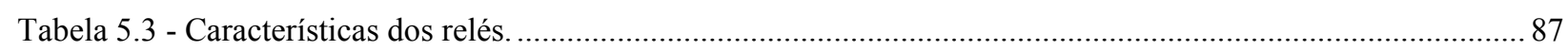

Tabela 5.4 - Corrente de curto-circuito sobre R1 para sua atuação como proteção de retaguarda remota................. 87

Tabela 5.5 - Resultados para R1 e R4 como proteção de neutro, sem considerar relé 21 como proteção principal... 97

Tabela 5.6 - Dados de entrada para os relés de fase do sistema da Figura 5.11 ........................................... 100

Tabela 5.7 - Dados de entrada para os relés de neutro do sistema da Figura 5.11 ........................................... 101

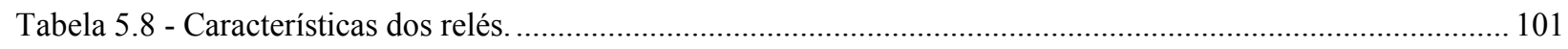

Tabela 5.9 - Tempos de referência para a coordenação utilizados no sistema da Figura $5.11 \ldots \ldots \ldots \ldots \ldots \ldots \ldots \ldots \ldots \ldots . . . . . . . . . . . . . .102$

Tabela 5.10 - Resultados de fase do sistema IEEE 14 barras: correntes sobre os relés e respectivos tempos de atuação. 106

Tabela 5.11 - Resultados de neutro do sistema IEEE 14 barras: correntes sobre os relés e 
Xviii

respectivos tempos de atuação 107

Tabela 5.12 - Ajustes de fase obtidos para o sistema IEEE 14 barras 109

Tabela 5.13 - Ajustes de neutro obtidos para o sistema IEEE 14 barras. 110

Tabela 6.1 - Localização dos relés em estudo e as respectivas linhas com trechos paralelos. 119

Tabela 6.2 - Resultados de fase da análise de curto-circuito trifásico considerando circuitos paralelos 120

Tabela 6.3 - Resultados de neutro da análise de curto-circuito monofásico-terra considerando circuitos paralelos.

Tabela 6.4 - Resultados de fase da análise de curto-circuito considerando o critério N-1

Tabela 6.5 - Resultados de neutro da análise de curto-circuito considerando o critério N-1 124

Tabela 6.6 - Comparação dos resultados entre o critério de linhas paralelas e o caso base.

Tabela 6.7 - Comparação dos resultados entre o critério N-1 e o caso base. 126

Tabela 6.8 - Comparação dos resultados entre o critério N-1 e o critério de linhas paralelas. 126

Tabela 6.9 - Casos em que o critério N-1 fornece resultados mais realistas do que o critério de linhas paralelas, para a proteção de fase.

Tabela 6.10 - Casos em que o critério N-1 fornece resultados melhores do que o critério de linhas paralelas, para a proteção de neutro. 


\title{
LISTA DE ABREVIAÇÕES E SÍMBOLOS
}

\author{
ANSI - American National Standards Institute. \\ BPS - Conjunto de abertura e laço (Break Point Set). \\ CAPE - Software Computer-Aided Protection Engineering.
}

Função ANSI 21 - Relé de distância.

Função ANSI 67 - Relé direcional de sobrecorrente.

IEC - International Electrotechnical Commission.

IEEE - Institute of Electrical and Electronics Engineers.

Icc - Corrente de curto-circuito.

$\mathrm{Icc}_{\text {cin_Bn }}$ - Corrente de curto-circuito medida pelo relé em análise para uma falta close-in na linha em que Rn é proteção principal.

Icc $80 \_B n$ - Corrente de curto-circuito medida pelo relé em análise para uma falta a $80 \%$ da linha em que Rn é proteção principal.

$\mathrm{I}_{\text {cinP }}$ - Corrente medida pelo relé para um curto-circuito close-in, trifásico (para proteção de fase) ou monofásicoterra (para a proteção de neutro), para o relé atuando como proteção principal, ou retaguarda local no caso de se considerar o relé 21 .

$\mathrm{I}_{80 \mathrm{P}}$ - Corrente medida pelo relé para um curto-circuito a $80 \%$ da linha, trifásico (para proteção de fase) ou monofásico-terra (para a proteção de neutro), para o relé atuando como proteção principal, ou retaguarda local no caso de se considerar o relé 21.

$\mathrm{I}_{\mathrm{cinB}}$ - Corrente medida pelo relé para um curto-circuito close-in, trifásico (para proteção de fase) ou monofásicoterra (para a proteção de neutro), para o relé atuando como proteção de retaguarda remota.

$\mathrm{I}_{80 \mathrm{~B}}$ - Corrente medida pelo relé para um curto-circuito a $80 \%$ da linha, trifásico (para proteção de fase) ou monofásico-terra (para a proteção de neutro), para o relé atuando como proteção de retaguarda remota.

ID - Identificação.

$\mathrm{I}_{\text {inst }}$ - Corrente de ajuste da unidade instantânea do relé.

$\mathrm{I}_{\mathrm{P}}$ - Corrente de pick-up do relé.

$\mathrm{I}_{\mathrm{P}_{-} \text {min }}$ - Valor mínimo admitido para a corrente de pick-up.

$\mathrm{I}_{P_{-} \max }$ - Valor máximo admitido para a corrente de pick-up. 
$\mathrm{I}_{\text {up }}$ - Corrente de pick-up da unidade a tempo definido do relé de sobrecorrente.

$\mathrm{K}_{1}, \mathrm{~K}_{2}, \mathrm{~K}_{3}$ - Constantes de declividade da curva.

M - Múltiplo da corrente de ajuste.

ME - Menor soma dos erros relativos percentuais.

P/R - Par de relés Principal/Retaguarda (ou retaguarda local/retaguarda remota).

PIB - Programação Inteira Binária.

PIM - Programação Inteira Mista.

R - Resistência em ohms $(\Omega)$.

S.P.E - Soma ponderada dos erros relativos.

S.R. - Soma dos erros relativos.

TC - Transformador de Corrente.

$\mathrm{t}_{\text {cinP }}$ - Tempo de atuação do relé para a corrente $\mathrm{I}_{\text {cinP. }}$.

$t_{80 P}-$ Tempo de atuação do relé para a corrente $\mathrm{I}_{80 \mathrm{P}}$.

$t_{\text {cinB }}$ - Tempo de atuação do relé para a corrente $I_{\text {cinB }}$.

$\mathrm{t}_{80 \mathrm{~B}}-$ Tempo de atuação do relé para a corrente $\mathrm{I}_{80 \mathrm{~B}}$

$\mathrm{TC}_{\text {Prim }}-$ Corrente no primário do $\mathrm{TC}$.

$\mathrm{TC}_{\mathrm{Sec}}$ - Corrente no secundário do TC.

TDS - Multiplicador do ajuste de tempo do relé (Time Dial Setting).

$\mathrm{T}_{\mathrm{op}}$ - Tempo de operação do relé.

TP - Transformador de Potencial.

$\mathrm{T}_{\text {up }}$ - Tempo de atuação da corrente de pick-up da unidade a tempo definido.

V - Tensão do equipamento em Volts.

X - Reatância em ohms $(\Omega)$. 


\section{INTRODUÇÃO}

Os sistemas de energia elétrica estão sujeitos a perturbações e anomalias devido a vários fatores, tais como:

- Erros de manobras: causados por operações indevidas;

- Erros técnicos: equipamentos defeituosos ou de má qualidade, ajustes indevidos, erro do sistema de comunicação de dados, etc.;

- Faltas devidas a deterioramento de equipamentos;

- Fatores ambientais: situações de descargas elétricas e condições naturais extremas, como ventos fortes, tornados, gelo, dentre outros.

Para otimizar o funcionamento de um sistema de potência é necessário um planejamento da operação, assim como a apropriada interconexão de sistemas, necessitando sempre de um conjunto de proteções adequado.

A maioria das faltas ocorre em linhas de transmissão, devido a certas condições (descargas atmosféricas, aquecimento anormal do ar devido a queimadas, etc.) que ionizam o ar proporcionando um caminho da corrente para a terra. Dentre as faltas em linhas de transmissão, 67\% delas envolvem um só condutor e a terra (faltas fase-terra), $25 \%$ são faltas bifásicas, $5 \%$ trifásicas e $3 \%$ são bifásicas-terra (TLEIS, 2008).

Um sistema de potência deve ser projetado de modo a atender tanto a demanda atual quanto a futura. Para promover o máximo de retorno do grande investimento que é necessário em um sistema de potência, todo o sistema precisa se manter em operação contínua com o mínimo de interrupções possível. Como não é viável economicamente projetar um sistema resistente a todo tipo de falhas, projeta-se um sistema que pode rapidamente determinar condições anormais e tomar as devidas providências (ANDERSON, 1999).

Um sistema de proteção tem três funções principais (HEWITSON; BROWN; BALAKRISHNAN, 2004):

- Proteger todo o sistema para manter a continuidade do fornecimento de energia;

- Minimizar os danos e custos de reparos em casos de ocorrência de faltas;

- Promover a integridade física do pessoal envolvido.

A proteção também deve possuir as seguintes qualidades essenciais (HEWITSON; BROWN; BALAKRISHNAN, 2004):

- Seletividade: para detectar e isolar somente a porção do sistema sob condição de falta; 
- Estabilidade: para manter todo o restante do sistema intacto e permitir a continuidade do suprimento de energia;

- Sensibilidade: para detectar toda e qualquer condição anormal, por menor que ela seja, e operar corretamente antes que a falta cause danos irreparáveis;

- Agilidade (ou rapidez): para operar rapidamente, evitando a propagação dos danos pelo sistema.

Além disso, o sistema de proteção também deve ser confiável, devendo atuar quando for requerido, e seguro, não podendo atuar indevidamente.

O custo do sistema de proteção determina o grau de proteção destinado a ele. Muitos equipamentos podem ser adicionados de modo a tornar o sistema mais confiável, seletivo e preciso, mas aumentam consideravelmente o custo do projeto. Por outro lado, instalando a proteção em seu quesito mínimo pode levar a um funcionamento insatisfatório, o que resultará em altos custos por paralisações. Outro fator que deve ser levado em consideração é o de que quanto mais o distúrbio se propagar, mais equipamentos serão comprometidos, de modo que uma das filosofias principais, que é a da preservação da integridade dos equipamentos, será desrespeitada.

Assim, um projeto que isole o distúrbio com o mínimo de consequências negativas para o sistema elétrico se torna mais confiável, justificando os custos de implantação, tanto localmente quanto em relação ao sistema como um todo.

\subsection{COORDENAÇÃO E SELETIVIDADE}

Um sistema elétrico deve ser equipado com dispositivos de proteção devidamente posicionados e dimensionados para uma proteção efetiva contra qualquer situação indesejada. A rede elétrica possui vários dispositivos distintos de proteção e estes devem estar relacionados uns com os outros, de modo que uma falha no sistema possa ser isolada sem que as outras partes sejam afetadas, ou seja, os dispositivos de proteção devem ser coordenados para uma operação seletiva.

Desse modo, a finalidade da coordenação dos dispositivos de proteção é (ANDERSON, 1999):

- Restringir interrupções do sistema apenas aos componentes sob condição de falta;

- Realizar o isolamento da falha no menor tempo possível, visando redução dos danos.

Diz-se que dois dispositivos estão coordenados se seus ajustes permitem que aquele que se situa mais distante do ponto falta possa eliminar a condição indesejada caso o dispositivo que estiver mais próximo da falta falhe na atuação. Deve-se ter em mente que a coordenação deve visar a melhor relação entre fatores de segurança, custo, previsão de expansão do sistema, flexibilidade, dentre outros. 
Em grandes sistemas de energia não-radiais a complexidade do problema de coordenação aumenta, pois há a necessidade da detecção do sentido do fluxo da corrente nos locais de instalação dos relés, sendo necessários relés de sobrecorrente com unidades direcionais para a solução do problema. Assim, a definição dos ajustes destes relés demanda muito esforço e tempo do engenheiro de proteção, sendo ainda que os resultados obtidos podem não ser otimizados, deixando de atender alguns requisitos de proteção.

Há diferentes métodos para a coordenação de relés direcionais de sobrecorrente (67), porém eles podem ser divididos entre quatro grandes classes de acordo com a abordagem:

- Como um problema de otimização não linear com formulação clássica;

- Como um problema de otimização linearizado;

- Como um problema de otimização utilizando técnicas heurísticas e meta-heurísticas;

- Através de heurísticas que determinam os ajustes dos relés fora do escopo da teoria de otimização.

Em geral as abordagens atuais possuem alguns pontos fracos, sendo difícil manter ao mesmo tempo uma resposta otimizada do ponto de vista da teoria de proteção, obtenção de resultados intuitivos, flexibilidade nos estudos e ainda um esforço computacional baixo. Desse modo, verifica-se a necessidade do desenvolvimento de uma ferramenta para a definição automática dos ajustes de relés direcionais de sobrecorrente, facilitando o trabalho de análise, e que ainda, preencha os requisitos não cumpridos pelas metodologias atuais, fornecendo resultados confiáveis e intuitivos, para que o engenheiro possa entender o resultado obtido com base na teoria de proteção.

\subsection{OBJETIVOS}

Conforme o exposto justifica-se a necessidade de uma metodologia eficiente, simplificada e precisa para a determinação dos ajustes dos dispositivos de proteção. Uma vez que a maior quantidade de faltas ocorre em linhas de transmissão e que o problema de realizar a coordenação entre os diferentes equipamentos de proteção instalados é complexo, o objetivo deste trabalho é desenvolver uma nova metodologia que permita realizar a coordenação de relés direcionais de sobrecorrente de forma simples e intuitiva. A metodologia deve considerar as restrições impostas pela coordenação entre relés direcionais e relés de distância, podendo ser aplicada em sistemas radias e não-radiais. A nova metodologia conta com a proposição do método do Melhor Ajuste Local, otimizado pelos critérios ME - Menor Erro e ILL Integral Logarítmica ponderada Linearmente, que utilizam informações de determinadas correntes de curto-circuito do sistema e dos tempos de atuação desejados para estas correntes, de forma que o ajuste obtido seja, para o método ME, aquele que apresente a menor soma do erro relativo percentual entre os 
pontos de análise e, para o método ILL, aquele que apresente a menor integral logarítmica sobre a curva de atuação do relé.

A proposta culminou no desenvolvimento de uma ferramenta computacional capaz de analisar sistemas de transmissão e subtransmissão, fornecendo automaticamente os ajustes para relés direcionais de sobrecorrente, respeitando a coordenação com relés de distância, de modo que o sistema de proteção resultante seja seletivo e atenda a requisitos pré-determinados. Como características da ferramenta, podese citar:

- Agilidade na análise de sistemas de grande porte e/ou grande área de atuação;

- Precisão e flexibilidade na resolução do problema de coordenação de relés direcionais de sobrecorrente;

- Obtenção de coordenogramas de proteção, mostrando os resultados finais dos ajustes em forma de gráficos de atuação dos relés.

\subsection{ORGANIZAÇÃO DO DOCUMENTO}

Esta dissertação está organizada como se segue:

- No capítulo 2 apresenta-se a teoria básica sobre proteção em sistemas de potência, contemplando dispositivos de proteção, definição de coordenação e seletividade, proteção de linhas de transmissão e um aprofundamento em relés direcionais de sobrecorrente (67);

- No capítulo 3 apresenta-se uma revisão bibliográfica a respeito da coordenação ótima da proteção de sistemas de transmissão utilizando relés direcionais de sobrecorrente;

- No capítulo 4 é apresentada a metodologia proposta. Nele é descrito em que se baseia a ferramenta, quais os critérios utilizados e o funcionamento da metodologia em si;

- No capítulo 5 são apresentados os resultados obtidos;

- No capítulo 6 é apresentada uma análise de coordenação frente a alterações topológicas de um sistema;

- No capítulo 7 apresentam-se as conclusões deste trabalho.

\subsection{DIVULGAÇÃO DA PESQUISA}

Em decorrência deste trabalho foram produzidos quatro artigos, sendo dois publicados e dois submetidos. 


\subsubsection{ARTIGOS PUBLICADOS}

1. Título: Metodologia Automática para a Coordenação e Seletividade da Proteção Direcional de Sobrecorrente em Sistemas de Transmissão de Energia de Energia por Detecção do Melhor Ajuste Local. Autores: Danilo L. A. Negrão, José C. M. Vieira. Apresentado no XX Congresso Brasileiro de Automática - CBA 2014.

2. Título: Methodology for Modeling Overcurrent Relays with Non-Standard Curves by Using Logarithmic-Linear Correction. Autores: Danilo L. A. Negrão, José C. M. Vieira, Silvio A. de Souza. Apresentado no IEEE Power \& Energy Society General Meeting 2014.

O artigo (1) expõe parte da metodologia de coordenação automática descrita neste trabalho, enquanto o artigo (2) expõe uma metodologia para o tratamento de dados de relés eletromecânicos que é descrita no tópico 2.2.2.

\subsubsection{ARTIGOS SUBMETIDOS}

1. Título: The Best Local Fit Method for Coordinating Directional Overcurrent Relays. Autores: Danilo L. A. Negrão, José C. M. Vieira. Submetido para a revista IEEE Transactions on Power Delivery.

2. Título: Ferramenta Computacional para a Determinação dos Ajustes da Proteção Direcional de Sobrecorrente de Linhas de Transmissão Através do Método do Melhor Ajuste Local. Autores: Danilo L. A. Negrão, José C. M. Vieira. Submetido para o XXII Seminário Nacional de Produção e Transmissão de Energia Elétrica - SNPTEE 2015.

O artigo (1) expõe de uma forma mais completa a metodologia descrita neste trabalho, enquanto que o artigo (2) foca na ferramenta desenvolvida com base na metodologia. 


\section{PROTEÇÃO DE SISTEMAS DE POTÊNCIA}

Um sistema de proteção é composto de vários subsistemas que contribuem para o processo de extinção da falta. A Figura 2.1 mostra estes subsistemas.

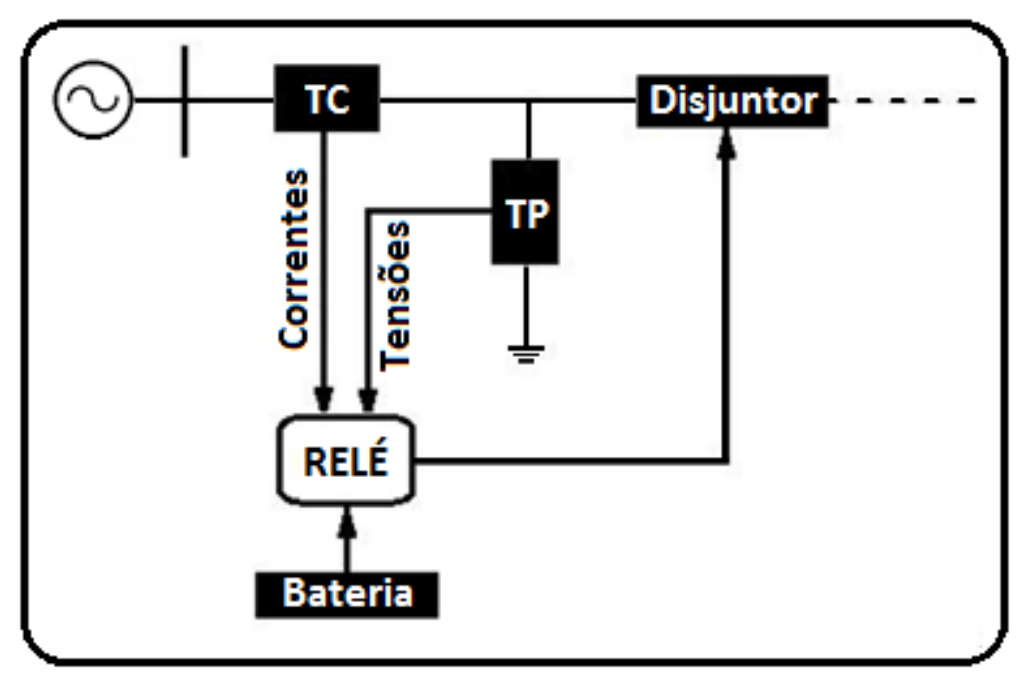

Figura 2.1 - Subsistemas de um sistema de proteção (COURY; OLESKOVICZ; GIOVANINI, 2007).

O disjuntor é o elemento que realmente extingue a falta. Os disjuntores normalmente são capazes de interromper faltas da ordem de $100 \mathrm{kA}$ em sistemas com tensões de até $800 \mathrm{kV}$, com mecanismos de extinção de arco e de sincronização para que o circuito seja aberto no momento em que a corrente passar pelo zero (PHADKE; THORP, 1990).

Para o monitoramento de grandezas pelos relés, são utilizados transformadores de potencial (TPs) e transformadores de corrente (TCs), que têm a função de reduzir valores de tensão e corrente, respectivamente, para adequá-los aos valores suportáveis pelo relé. O sinal analógico é filtrado, visando retirar as componentes harmônicas de alta frequência que viriam a interferir nos resultados, e em seguida amostrado, resultando em um sinal digital que é processado pelo relé.

O relé propriamente dito é composto por uma unidade de tomada de decisão que, a partir de uma lógica interna e das medições realizadas pelos transdutores (TP e TC), comanda o funcionamento do disjuntor enviando, quando solicitado, um sinal de trip (abertura). Um banco de baterias alimenta o relé, e também fornece energia para a operação do disjuntor a comando do relé.

A responsabilidade pela proteção de uma porção do sistema é definida pela chamada zona de proteção, que é uma região bem definida no diagrama unifilar do sistema. Para cada zona de proteção, os equipamentos ligados a ela são responsáveis por eliminar faltas que ocorrem em seu domínio. As zonas de proteção são geralmente definidas pelos disjuntores instalados no sistema, mas há casos em que o sistema de proteção pode acionar algum disjuntor remoto por meio de um canal de comunicação (PHADKE; THORP, 1990). 
A Figura 2.2 mostra um sistema de potência qualquer em que podem ser observadas cinco zonas de proteção, indicadas pelos números e delimitadas por áreas tracejadas, enquanto as letras denotam os barramentos. Percebe-se que as zonas de proteção se sobrepõem, sendo esta uma característica desejável para que o sistema não possua regiões desprotegidas.

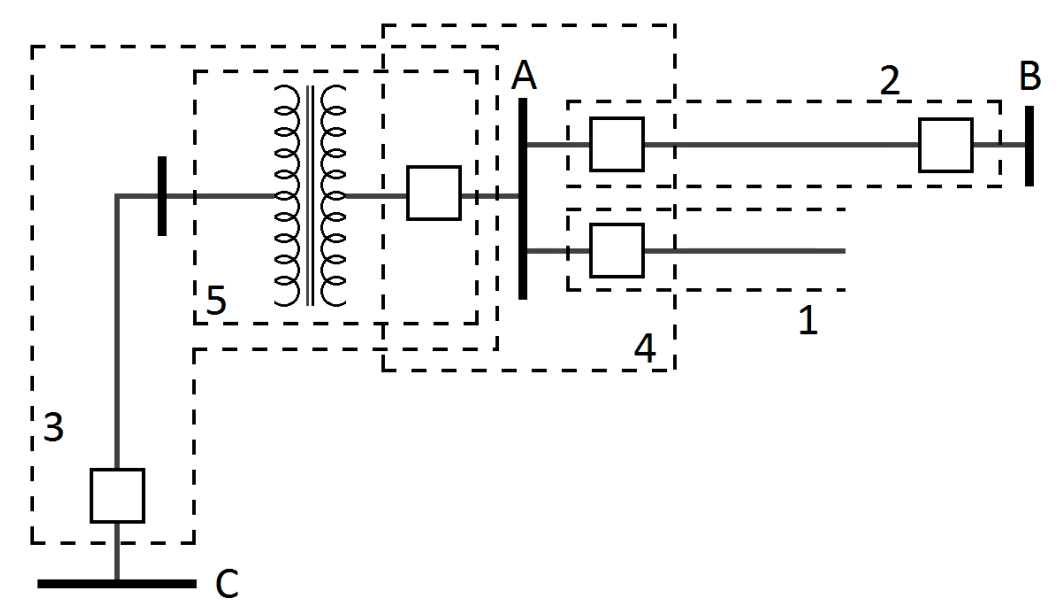

Figura 2.2 - Exemplo de zonas de proteção (PHADKE; THORP, 1990).

É necessário promover uma proteção adicional ao sistema caso a proteção principal falhe. Esta proteção adicional é chamada de proteção de backup ou de retaguarda (HEWITSON; BROWN; BALAKRISHNAN, 2004). Assim, a proteção principal atua logo que uma condição anormal é detectada dentro de sua zona de proteção, enquanto a proteção de retaguarda somente atua caso a principal falhe. A situação de falha é determinada por um intervalo de tempo em que se aguarda a atuação da proteção principal. Caso não haja atuação da mesma durante este intervalo, a proteção de retaguarda deverá atuar.

Os tipos de relés utilizados em sistemas de proteção podem ser classificados como a seguir (PHADKE; THORP, 1990):

- Relés de magnitude: respondem à magnitude dos valores de entrada, tais como os relés de sobrecorrente e de sobretensão;

- Relés direcionais: respondem ao ângulo de fase entre duas entradas, geralmente à corrente de análise e a uma grandeza de polarização, que pode ser a tensão ou a corrente de uma das fases. É possível assim distinguir a direção do fluxo da corrente (à frente ou reversa) em relação a sua localização física;

- Relés de razão: respondem à razão entre dois sinais de entrada. Os relés deste tipo mais comuns são os relés de impedância e o relé de distância;

- Relés diferenciais: respondem à soma das magnitudes de dois ou mais sinais. Normalmente estes relés respondem à soma de correntes entrando e saindo de uma zona de proteção. Caso o valor das correntes que entram seja diferente do valor das correntes que saem o relé detectará uma falta interna à área de monitoramento; 
- Relés com canal piloto ou com mídia de comunicação: estes relés utilizam informações de comunicação de locais remotos como sinal de entrada. Geralmente a tomada de decisão é feita por um dos quatro tipos de relés citados anteriormente e então uma comunicação informa ao relé nos terminais remotos o que fazer.

Um sistema de proteção é composto por diversos equipamentos, porém os dispositivos de proteção devem estar relacionados entre si, de modo que uma falha no sistema possa ser isolada sem que as outras partes sejam afetadas. Ou seja, os dispositivos de proteção devem ser coordenados para uma operação seletiva. É chamado de tempo ou degrau de coordenação o intervalo entre a falha de um dispositivo até a atuação do que está em sua retaguarda.

O intervalo de coordenação depende do tipo de dispositivo de proteção. Normalmente, o intervalo utilizado para relés eletromecânicos é de 300 a 400ms, enquanto para relés microcontrolados é da ordem de 100 a 200ms (MANSOUR et al, 2007).

\subsection{PROTEÇÃO DE LINHAS DE TRANSMISSÃO}

Grande parte das faltas em sistemas de potência ocorre em linhas de transmissão, sendo a maioria faltas fase-terra, causadas por descargas atmosféricas, queimadas, defeitos em isoladores, falta de manutenção, etc.

Em um sistema radial de transmissão, como no exemplo da Figura 2.3, na ocorrência de uma falta na linha L1, o dispositivo de proteção 1 deverá atuar, retirando L1 de operação. Caso o dispositivo 1 falhe, o dispositivo 4 deverá atuar como proteção de retaguarda, retirando as linhas L1, L2, L3 e L4 de operação. Neste caso, simples relés de sobrecorrente seriam suficientes para realizar a proteção de forma seletiva e adequada, pois a corrente só flui em um sentido.

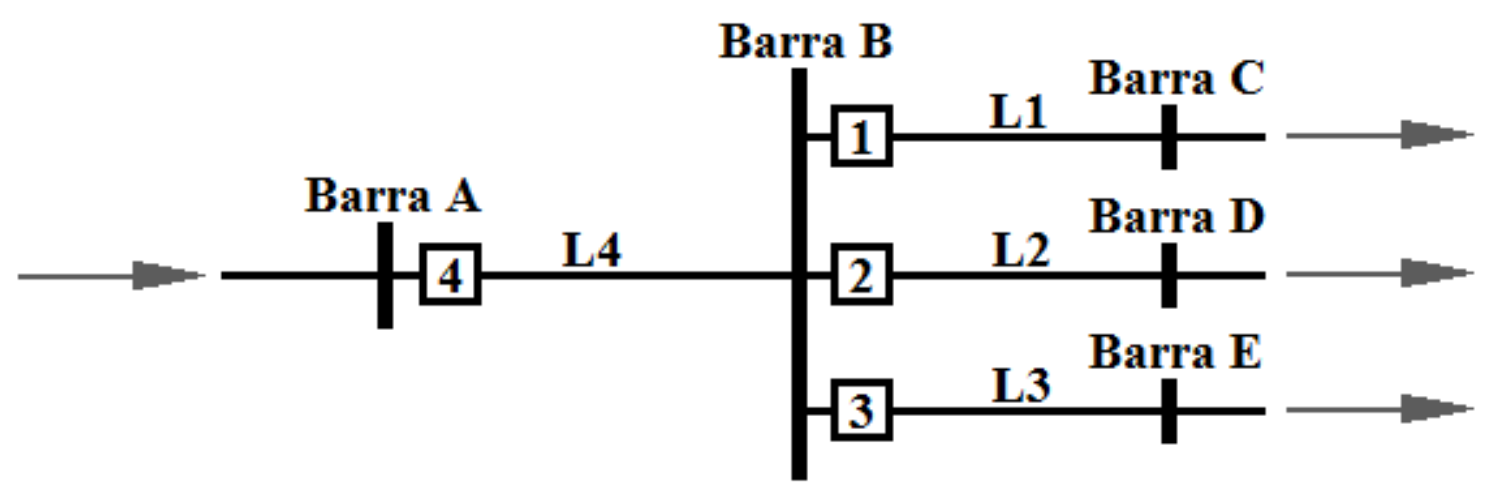

Figura 2.3 - Exemplo de sistema radial, em que é indicado o sentido da corrente.

Porém, a maioria dos sistemas de transmissão de energia elétrica encontrados é não-radial, para se tornarem mais confiáveis (TLEIS, 2008). Desta forma, seja o sistema em malha da Figura 2.4. 


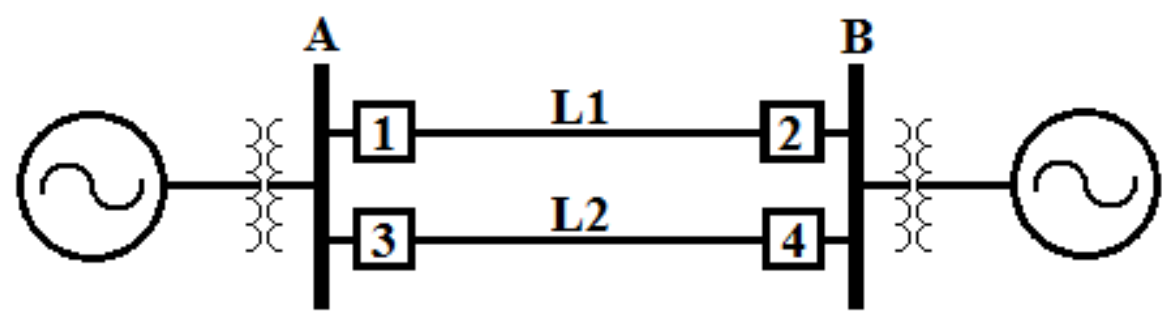

Figura 2.4 - Exemplo de sistema em malha.

Caso ocorra uma falha na linha L1, espera-se que os tempos de abertura dos dispositivos se relacionem do seguinte modo (ANDERSON, 1999):

$$
t_{1}<t_{3} \quad t_{2}<t_{4}
$$

Do mesmo modo, caso ocorra uma falta na linha L2, os tempos de abertura dos dispositivos deverão ser tais que:

$$
t_{3}<t_{1} \quad t_{4}<t_{2}
$$

Percebe-se que estas afirmações são conflitantes, de modo que este problema, apesar de simples, não pode ser resolvido com o uso de relés de sobrecorrente, sendo necessário distinguir o sentido da corrente. Normalmente a proteção de linhas é realizada utilizando-se relés de distância, relés direcionais e ainda teleproteção. Esta última consiste em um sistema em que um terminal da linha envia informações sobre uma situação de falta remotamente para o outro, através de uma interface de comunicação via fibra ótica, micro-ondas, carrier, ou ainda via telefonia.

Para um determinado sistema de potência, quanto mais próximo da falta maior será o valor da corrente de defeito. Logo, todos os relés próximos à falta serão sensibilizados, porém a magnitude da corrente de curto-circuito em cada relé será diferente, possuindo um maior valor para equipamentos instalados mais próximos à falta. Como exemplo, seja um sistema como o da Figura 2.5, no qual uma falta é aplicada na linha entre os relés R4 e R5.

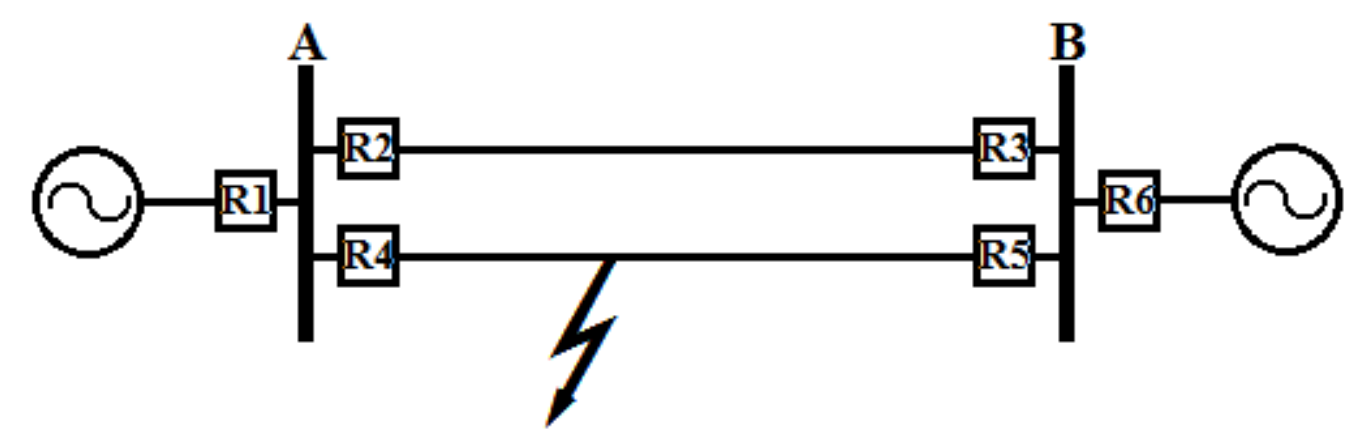

Figura 2.5 - Exemplo de um sistema em malha com falta na linha entre os relés R4 e R5.

A falta sensibiliza todos os relés do sistema, com magnitude da corrente variando de acordo com a localização do mesmo. Se o local de falta for variado, partindo do relé R4 até R5, as correntes de curtocircuito (Icc) que circulam por cada relé são apresentadas no gráfico da Figura 2.6. Nele percebe-se que 
para uma falta muito próxima de R5, a corrente medida pelos relés R2 e R3 inverte de sentido, confirmando a necessidade da utilização de relés direcionais em sistemas em malha.

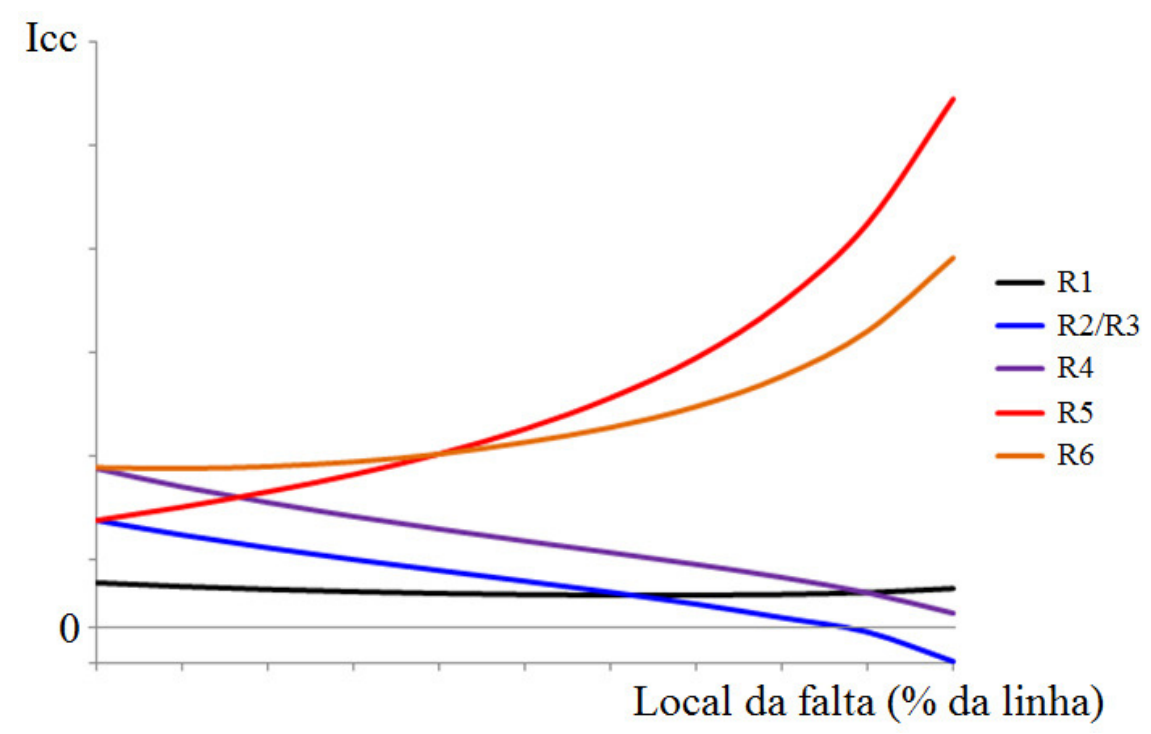

Figura 2.6 - Exemplo de SEP em malha com correntes de curto-circuito nos relés de acordo com a localização da falta.

Portanto, a coordenação da proteção deve também levar em consideração a sensibilidade do relé atuando como proteção de retaguarda. Ou seja, na ocorrência de uma falta na zona em que um relé é proteção principal, a corrente medida pelo respectivo relé de retaguarda deve ser levada em consideração no estudo de coordenação.

Nos tópicos seguintes serão explicadas as proteções de distância e direcional de sobrecorrente. A teleproteção não será tratada neste trabalho.

\subsubsection{A PROTEÇÃO DE DISTÂNCIA}

Relés de distância, representados pelo código ANSI 21, recebem esta denominação pela capacidade de determinar a distância entre o local de instalação do relé e o ponto de falta na linha. A partir das medições de tensão e corrente no terminal da linha, o relé determina o tipo de falta incidente e calcula a impedância aparente da linha (COURY; OLESKOVICZ; GIOVANINI, 2007). A impedância de uma linha é proporcional ao comprimento da mesma. Portanto, conhecida a impedância característica da linha e a impedância registrada no relé, pode-se estimar se o valor registrado corresponde a uma condição normal ou de falta, além de uma estimativa do local da falta na linha.

A impedância aparente da linha possui componentes de resistência e reatância elétrica, de modo que a característica de operação do relé pode ser definida por diagramas R-X. Os tipos de relés classificados de acordo com o formato de suas zonas de operação são os definidos na Figura 2.7. 


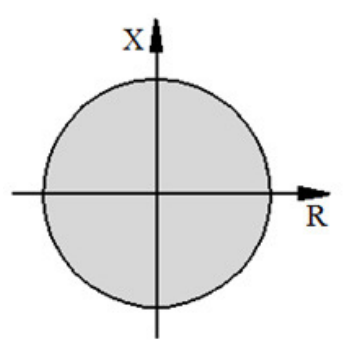

Impedância

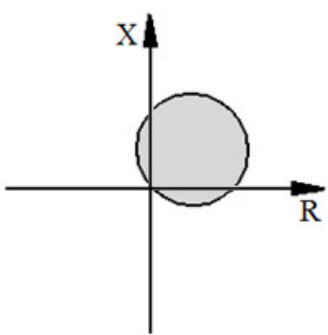

Admitância

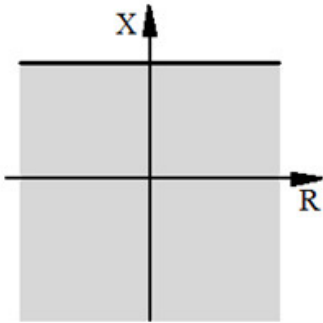

Reatância

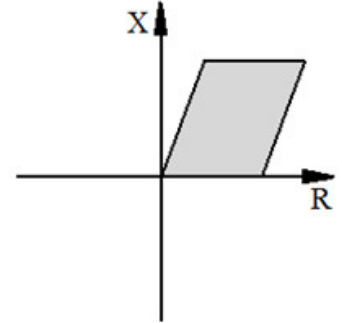

Quadrilateral

Figura 2.7 - Características do relé de distância (COURY; OLESKOVICZ; GIOVANINI, 2007).

O relé de impedância enxerga uma zona de proteção na forma de um círculo, podendo ou não haver unidade direcional, que limitaria a atuação do relé apenas para uma direção de corrente de falta. O relé de admitância, ou MHO, possui uma característica circular que é tangente ao plano R-X, sendo mais seletivo do que o relé de impedância. O relé de reatância considera apenas a parte reativa da impedância aparente, possuindo uma faixa de atuação para qualquer impedância aparente que varie a reatância característica da linha. Relés com característica quadrilateral são os que melhor descrevem a situação de falta da linha, podendo ser programados para características específicas da linha.

Para cada tipo de relé é definido um limiar de disparo. Caso o valor medido de impedância aparente se situe na região de atuação, o relé atuará. Como a impedância característica da linha é constante, não variando com as condições do sistema, trata-se de uma proteção bem eficaz.

Para a proteção de distância são definidas zonas de proteção como se segue:

- Primeira zona: opera sem atraso de tempo, compreendendo a atuação instantânea. É ajustada para cobrir de 80 a $90 \%$ da linha protegida (ANDERSON, 1999). O tempo de operação é composto por:

Tempo de operação do disjuntor, que varia de 2 a 4 ciclos (ABB, 2009; SIEMENS, 2012);

Tempo de operação do relé, que varia entre 15 e 30 ms para relés digitais e entre 25 e 80 ms para relés eletromecânicos (ZIEGLER, 2008).

- Segunda zona: é ajustada para cobrir $100 \%$ da linha protegida além de até $50 \%$ da linha adjacente mais próxima (ANDERSON, 1999). Esta zona possui atuação temporizada e deve respeitar a atuação da primeira zona. Possui um tempo de operação usualmente ajustado em 400 ms (KLOCK JR., 2002). Este tempo é composto por:

Tempo de atuação da primeira zona, como descrito anteriormente;

Tempo de restabelecimento (reset) do relé de distância, que tem o valor de aproximadamente $20 \mathrm{~ms}$ para relés digitais e varia de 60 a $100 \mathrm{~ms}$ para relés eletromecânicos (ZIEGLER, 2008); 
Erro dos temporizadores internos do relé, que possui valor usual de $10 \mathrm{~ms}$ para relés digitais e entre 60 e 100 ms para relés eletromecânicos (ZIEGLER, 2008);

Algum outro fator de segurança definido de acordo com a experiência prática do engenheiro.

A maioria das linhas de transmissão trifásicas possuem um sistema solidamente aterrado, pois há predominância de faltas que envolvem a terra. Durante a operação normal do sistema não há componentes de sequência zero significativas fluindo no sistema, somente aquelas devido ao desbalanceamento das fases, e estas são, em geral, bem menores do que a magnitude das correntes de falta (ANDERSON, 1999). No entanto, toda falta envolvendo a terra contém componentes de sequência zero, desse modo, a maioria dos relés de terra depende da detecção destas correntes.

As correntes de sequência zero do sistema estão diretamente relacionadas com as impedâncias de sequência zero, que não dependem das condições de carregamento do sistema, variando apenas quando há alterações topológicas como entrada e saída de geradores e linhas. Desse modo, em condição de falta há uma grande alteração nas impedâncias de sequência zero quando comparadas com a operação normal. A proteção de neutro por relés de distância verifica a impedância de sequência zero do sistema, através da análise de correntes de linha compensadas (ANDERSON, 1999; PHADKE; THORP, 1990).

A seguir, será abordada a proteção via relé direcional, que é o foco deste trabalho.

\subsubsection{RELÉ DIRECIONAL DE SOBRECORRENTE}

Como visto na seção anterior, não é possível coordenar relés de sobrecorrente em sistemas em malha. Este problema pode ser solucionado inserindo um elemento direcional nos relés. Os relés direcionais, representados pelo código ANSI 67, distinguem o sentido da corrente através da análise de ângulos entre fasores. Para isso, usa-se o ângulo de fase entre a corrente de falta e alguma referência, como uma tensão. O relé então consegue identificar qual a defasagem entre a tensão e a corrente, estabelecendo qual é o sentido positivo da corrente de acordo com tensão tomada como referência (ANDERSON, 1999; PHADKE; THORP, 1990). Adicionando a direcionalidade dos relés, o mesmo sistema da Figura 2.4 pode ser resolvido como na Figura 2.8.

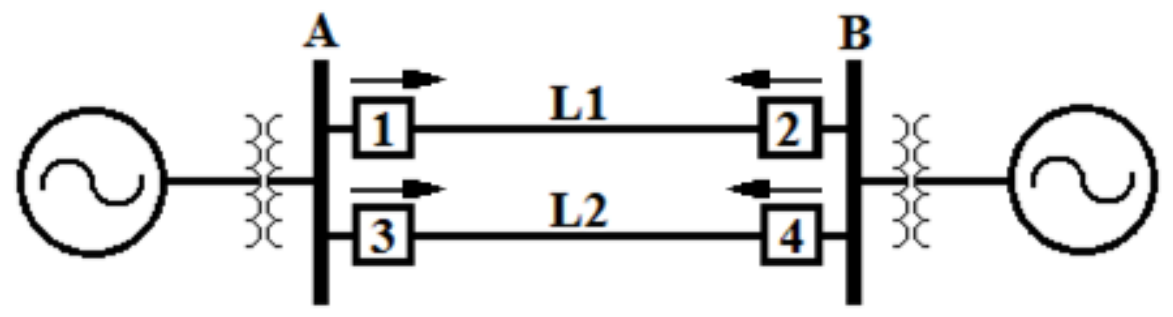

Figura 2.8 - Relés direcionais aplicados a um sistema em malha.

Neste sistema, os relés indicados pelos números somente verificam correntes nos sentidos indicados. Os dispositivos de proteção formam um laço em que a coordenação é possível. Caso ocorra 
uma falta na linha L1, o relé 1 estará coordenado com o relé 4, e o relé 2 estará coordenado com o relé 3 . A Tabela 2.1 resume os conceitos de coordenação para faltas nas linhas L1 e L2 do circuito da Figura 2.8.

Tabela 2.1 - Coordenação entre os dispositivos de proteção para o sistema da Figura 2.8.

\begin{tabular}{|c|c|c|c|c|c|}
\hline \multicolumn{3}{|c|}{ Falta em L1 } & \multicolumn{3}{c|}{ Falta em L2 } \\
\hline $\begin{array}{c}\text { Proteção } \\
\text { Principal }\end{array}$ & $\begin{array}{c}\text { Proteção } \\
\text { Retaguarda }\end{array}$ & $\begin{array}{c}\text { Sentido da } \\
\text { Corrente } \\
\text { de Falta }\end{array}$ & $\begin{array}{c}\text { Proteção } \\
\text { Principal }\end{array}$ & $\begin{array}{c}\text { Proteção } \\
\text { Retaguarda }\end{array}$ & $\begin{array}{c}\text { Sentido da } \\
\text { Corrente } \\
\text { de Falta }\end{array}$ \\
\hline 1 & 4 & A-B & 3 & 2 & A-B \\
2 & 3 & B-A & 4 & 1 & B-A \\
\hline
\end{tabular}

Relés direcionais são conectados para serem polarizados por uma tensão de um circuito. As conexões de corrente e as características do relé são escolhidas tal que o conjugado máximo ocorra quando uma carga com fator de potência unitário percorre o circuito. Para que o relé direcional contemple estas condições de falta, são geralmente utilizados três tipos arranjos de conexões no relé, produzindo ângulos de $90^{\circ}, 60^{\circ}$ e $30^{\circ}$ (ELMORE, 1994). A Figura 2.9 mostra esses arranjos para a corrente de referência na fase $a$.

a)

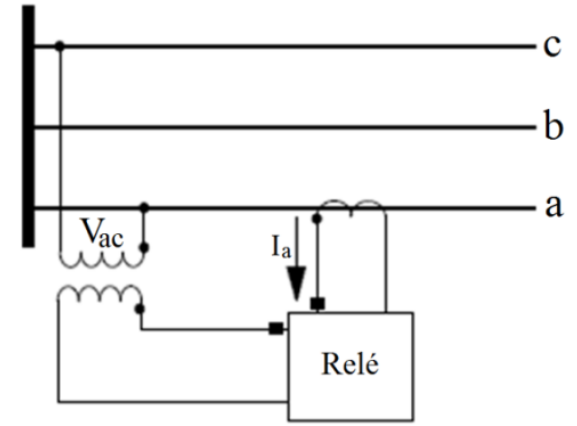

b)

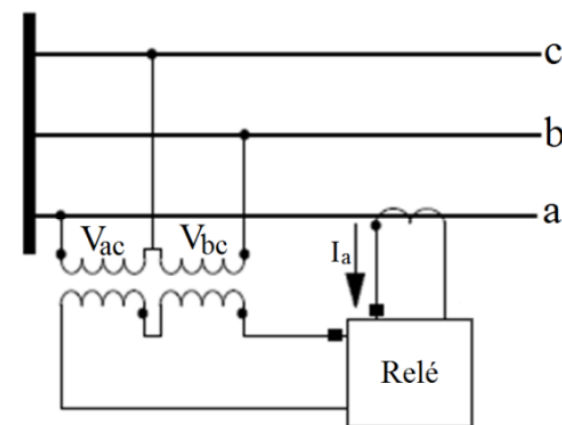

c)

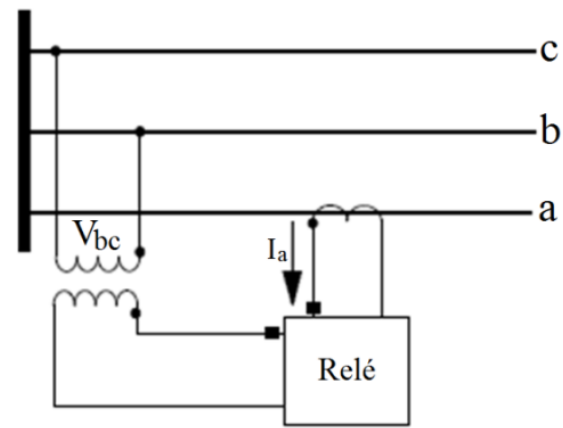

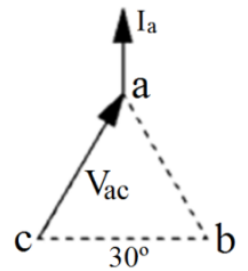
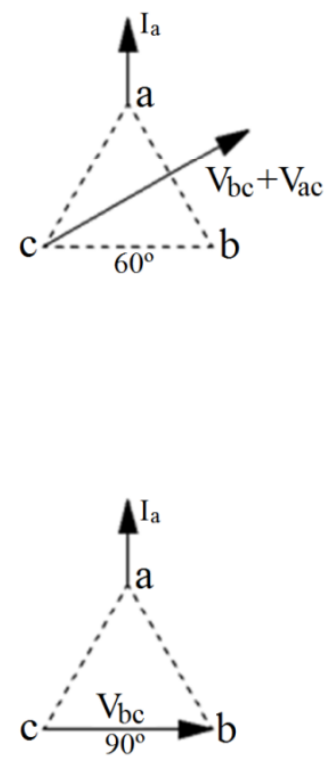

Figura 2.9 - Conexões para diferentes conjugados do relé direcional. a) Conexão para $30^{\circ}$; b) Conexão para $60^{\circ}$; c) Conexão para $90^{\circ}$. 
Considerando que as faltas em linhas de transmissão são em sua maioria indutivas, a corrente de falta se atrasa da tensão em quase $90^{\circ}$. Ângulos factíveis para faltas se localizam em torno de $-\pi / 2$ para faltas na direção direta e em torno de $\pi / 2$ para faltas em direção reversa. Se o ângulo entre o fasor de referência (tensão) e a corrente de falta é de $\theta$, então o princípio de operação do relé pode ser descrito como (PHADKE; THORP, 1990):

$$
\left\{\begin{array}{c}
-\pi \leq \theta \leq 0, \text { o relé opera } \\
0 \leq \theta \leq \pi, \text { o relé bloqueia }
\end{array}\right.
$$

Para a proteção de faltas entre fase e terra são utilizados relés de sobrecorrente direcionais de neutro $(67 \mathrm{~N})$. Estes possuem as mesmas características dos relés de fase, com a diferença que operam verificando correntes de sequência zero, que estão presentes predominantemente em faltas envolvendo a terra.

\subsection{MODELO PARA O TRATAMENTO DO RELÉ 67}

O relé de sobrecorrente direcional possui três unidades de atuação:

- Atuação instantânea: o relé atua instantaneamente se o valor da corrente medida for maior que um valor predeterminado;

- Atuação a tempo definido: são ajustados valores de tempo e corrente. O relé irá então disparar para qualquer corrente acima da especificada $\left(I_{u p}\right)$ desde que permaneça por um determinado tempo acima do especificado $\left(T_{u p}\right)$;

- Atuação de tempo inverso: para esta unidade, o tempo de atuação do relé é inversamente proporcional à corrente, ou seja, quanto maior a corrente, menor o tempo de atuação do relé. Esta característica é desejada, pois favorece a seletividade do sistema.

A atuação a tempo inverso do relé 67 pode ser descrita por curvas padronizadas através de equações bem definidas, ou ainda através de curvas não padronizadas que variam por fabricante. A seguir serão apresentadas as modelagens de ambos casos.

\subsubsection{MODELO PARA O TRATAMENTO DE RELÉS COM CURVAS PADRONIZADAS}

Existem várias famílias de curvas de atuação de tempo inverso, sendo que serão utilizadas neste trabalho as curvas padronizadas pelo instituto ANSI (American National Standards Institute) e pelo IEC (International Electrotechnical Comission) (IEEE Std. C37.112, 1996).

A equação que descreve o tempo de atuação do relé é definida como:

$$
T_{o p}=T D S \cdot\left(K_{1}+\frac{K_{2}}{M^{K_{3}-1}}\right)
$$


Em que:

Top: Tempo de atuação do relé, em segundos;

TDS: Multiplicador de tempo do relé;

$M$ : Múltiplo da corrente de ajuste, sendo este definido como $M=I / I_{P} ; I$ é a corrente de falta e $I_{P}$ a corrente de pick-up do relé;

$K_{1}, K_{2}$ e $K_{3}$ : Constantes que determinam o tipo (grau de declividade) da curva.

As curvas de atuação de tempo inverso de relés de sobrecorrente do padrão ANSI são definidas na IEEE Std. C37.112 (1996). Há cinco tipos de curva inversa: moderadamente inversa, inversa, muito inversa, extremamente inversa e inversa de tempo curto. Para cada uma destas curvas, os valores das constantes $\mathrm{K}_{1}, \mathrm{~K}_{2}$ e $\mathrm{K}_{3}$ variam. Estes valores podem ser vistos na Tabela 2.2. O multiplicador de tempo (TDS) desloca verticalmente a curva de atuação, sendo que, normalmente, este parâmetro varia de 0,5 a 15.

Tabela 2.2 - Parâmetros K1, K2 e K3 para as curvas inversas padrão ANSI.

\begin{tabular}{|c|c|c|c|}
\hline Curva & K1 & K2 & K3 \\
\hline Moderadamente Inversa (U1) & 0,02260 & 0,01040 & 0,0200 \\
\hline Inversa (U2) & 0,18000 & 5,95000 & 2,0000 \\
\hline Muito Inversa (U3) & 0,09630 & 3,88000 & 2,0000 \\
\hline Extremamente Inversa (U4) & 0,03520 & 5,67000 & 2,0000 \\
\hline Inversa de Tempo Curto (U5) & 0,00262 & 0,00342 & 0,0200 \\
\hline
\end{tabular}

Para as curvas de atuação pelo padrão IEC, os valores $\mathrm{K}_{1}, \mathrm{~K}_{2}$ e $\mathrm{K}_{3}$ variam de acordo com a Tabela 2.3. No padrão IEC, o multiplicador de ajuste de tempo do relé (TDS) varia de 0,05 a 1 (IEC 60255-3, 1989).

Tabela 2.3 - Parâmetros $\mathrm{K}_{1}, \mathrm{~K}_{2}$ e $\mathrm{K}_{3}$ para as curvas inversas padrão IEC.

\begin{tabular}{|c|c|c|c|}
\hline Curva & K1 & K2 & K3 \\
\hline Inversa (C1) & 0 & 0,14 & 0,02 \\
\hline Muito Inversa (C2) & 0 & 13,50 & 1,00 \\
\hline Extremamente Inversa (C3) & 0 & 80,00 & 2,00 \\
\hline Inversa de Tempo Longo (C4) & 0 & 120,00 & 1,00 \\
\hline Inversa de Tempo Curto (C5) & 0 & 0,05 & 0,04 \\
\hline
\end{tabular}

Para exemplificar uma curva de atuação do relé de sobrecorrente, a Figura 2.10 mostra uma curva padrão ANSI muito inversa. Nela verifica-se a atuação dos ajustes. A corrente de partida ou de pick-up $\left(I_{P}\right)$ move a curva horizontalmente. O multiplicador de tempo do relé TDS move a curva verticalmente. A 
alteração dos parâmetros $\mathrm{K}_{1}, \mathrm{~K}_{2}$ e $\mathrm{K}_{3}$ muda a declividade da curva. A corrente de ajuste da unidade instantânea $I_{\text {inst }}$ descreve a função de sobrecorrente instantânea, sendo que qualquer valor acima de $I_{\text {inst }}$ fará o relé atuar instantaneamente. Para o exemplo da Figura 2.10, utilizou-se como referência uma curva padrão ANSI muito inversa, com TDS $=2,1 ; I_{p}=1 \mathrm{~A}$ e $I_{\text {inst }}=30 \mathrm{~A}$ (valores de corrente meramente ilustrativos para este caso).

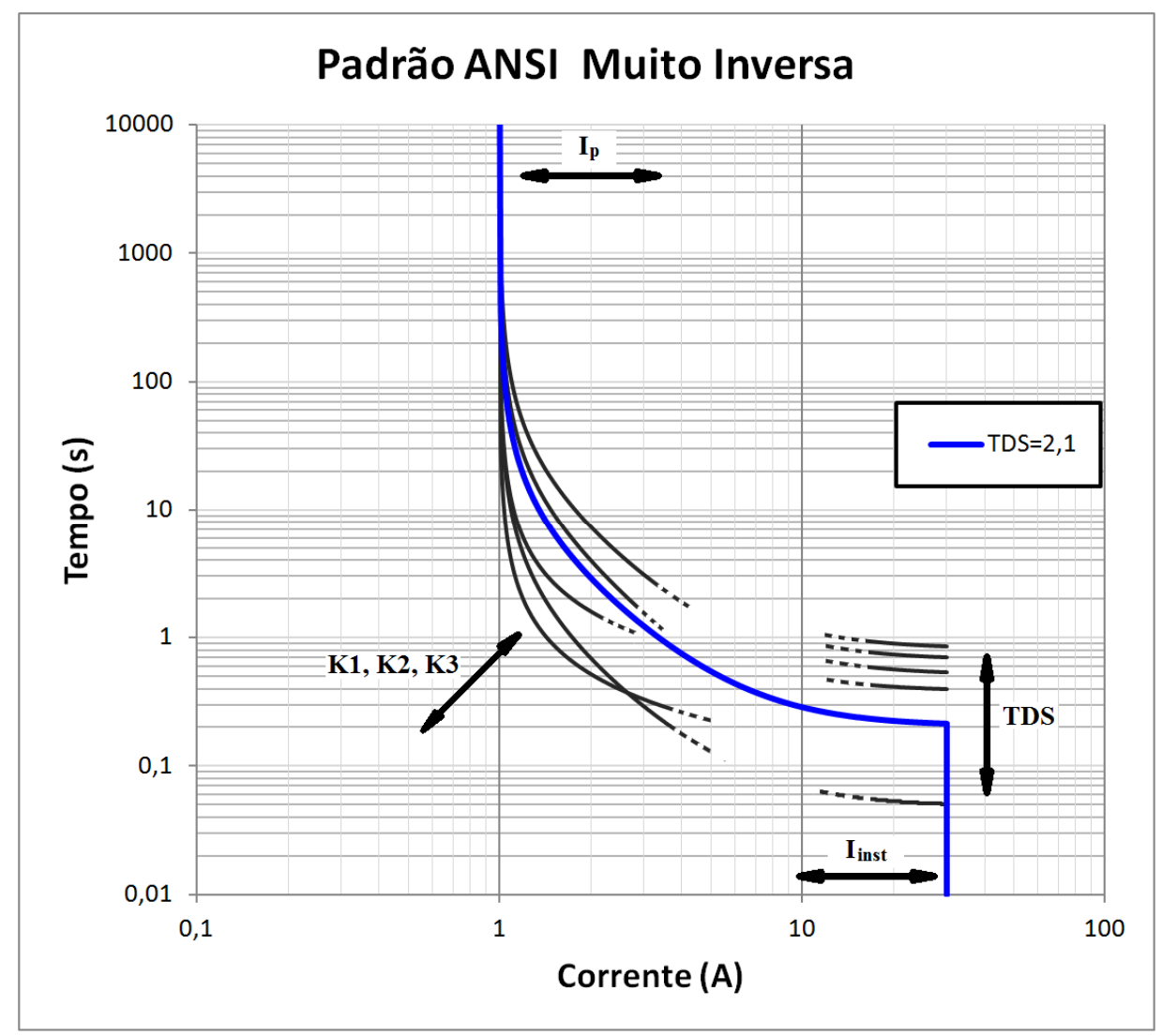

Figura 2.10 - Exemplo de curva de atuação do relé e como os ajustes a afetam.

A metodologia de coordenação automática de relés direcionais de sobrecorrente apresentada neste trabalho não se limita à aplicação apenas em relés com curvas padronizadas ou com curvas caracterizadas pela equação (2.4), porém, a fim de simplificação e clareza da exposição do método, os relés padronizados pela equação (2.4) serão o foco desta dissertação.

\subsubsection{MODELO PARA O TRATAMENTO DE RELÉS COM CURVAS NÃO PADRONIZADAS}

Apesar de que o uso de relés eletromecânicos e/ou com equações não padronizadas esteja cada vez menor, ainda existem instalações em que estes equipamentos compreendem uma parte considerável do sistema de proteção e, portanto, devem ser levados em consideração. O tratamento computacional de relés com curvas não padronizadas pode ser complicado, principalmente no que diz respeito ao levantamento e tratamento dos dados necessários. Pensando nisto, foi desenvolvida uma metodologia complementar para o tratamento de relés com curvas não padronizadas, que pode ser utilizada para 
obtenção da característica inversa no tempo de relés os quais se possui apenas dados de catálogo, compreendendo curvas de atuação impressas.

A modelagem de relés eletromecânicos foi discutida por muitos pesquisadores no passado e também recentemente. Por exemplo, uma modelagem detalhada utilizando a teoria dos Elementos Finitos é proposta em HENROTTE et. al. (1994). Em aplicações práticas, como no caso de operação de relés eletromecânicos, o eletromagnetismo é utilizado para promover forças de movimento, mas estes movimentos geralmente não são levados em consideração na modelagem dos dispositivos. Pensando nisso os autores desenvolveram um método para modelagem numérica de relés eletromecânicos que leva em consideração equações clássicas de relés, além de equações de circuitos elétricos e equações de movimento de corpos, utilizando para isto o método dos Elementos Finitos acoplado ao método do Elemento de Contorno. Usa-se o método do Elemento de Contorno para magnetismo linear e meios dielétricos onde partes rígidas podem se mover. O método dos elementos finitos é utilizado para toda a modelagem restante, em especial meios sujeitos à saturação magnética. $\mathrm{O}$ método se demonstra bastante preciso, fornecendo uma equação final para a atuação do relé. Porém, são necessários vários levantamentos e análises em laboratório, inviabilizando sua aplicação prática.

DARWISH et. al. (1995) mostra uma modelagem da curva de atuação de relés, propondo uma equação que descreve o tempo de atuação da seguinte forma:

$$
T_{p}=c_{0}+c_{1}(T D S)+c_{2}(T D S)^{2}+\cdots+c_{n}(T D S)^{n}
$$

Em que $T_{p}$ é o tempo de atuação do relé e $c_{0}, c_{1}, c_{2}, \ldots c_{n}$ são constantes determinadas através de uma curva de ajuste, sendo esta a curva de atuação do relé para um dos dias tomado como referência. O método necessita de dados das curvas de todos os TDS para se encontrar a melhor delas para ser tomada como referência. É relativamente simples, mas também não resolve o problema da quantidade de entrada de dados para cada relé.

Visando a modelagem de relés eletromecânicos, no trabalho de WU et. al. (2012) é exposto um método que, por meio da aplicação de matrizes de Hankel e de decomposição em valores singulares, obtém-se uma solução em espaços de estados, através da qual é obtida uma equação polinomial com ordem de até 40 termos. O erro relativo encontrado é da ordem de 1\%, o que é bastante satisfatório. Porém para a sua aplicação são necessários muitos pontos de corrente versus tempo, demandando um grande esforço de coleta de dados, além de que a solução encontrada não é geral, sendo que o processo deve ser repetido para cada relé encontrado. Esta metodologia é a mais utilizada por programas comerciais.

Para resolver os obstáculos mencionados, nesta dissertação também foi proposto um método sistemático para a modelagem de relés eletromecânicos e/ou com curvas não padronizadas, necessitando de uma quantidade reduzida de dados de entrada e permitindo o uso dos modelos em métodos 
computacionais. O método foi desenvolvido e validado pela análise de diferentes tipos de relés eletromecânicos e os resultados são bem promissores, conforme pode se observar nos itens a seguir.

\subsubsection{DESCRIÇÃO DO MÉTODO PROPOSTO}

Curvas padronizadas de corrente inversa no tempo são definidas pela equação (2.4). No entanto, para relés com curvas não padronizados a equação (2.4) já não é válida, pois várias características não lineares influenciam sua modelagem. Não há uma relação simples entre as curvas de atuação de diferentes diais e os valores de TDS como em relés padronizados, sendo que para modelar as não linearidades seria necessário um levantamento de dados das curvas de todos os TDS, necessitando um grande esforço.

O método proposto utiliza informações de uma curva específica tomada como referência para encontrar as curvas dos outros TDS. Como há muitas não linearidades, a relação entre os diversos TDS é corrigida através de dois pontos que devem ser tomados das curvas de cada um deles. Ou seja, contrariamente a outros métodos que necessitam uma quantidade significativa de pontos (20 ou mais) das curvas de cada TDS, este trabalho propõe um método que necessita apenas de pontos de uma curva tomada como referência e mais dois pontos de cada um dos outros TDS, sendo que por meio de um tratamento matemático recuperam-se as informações das curvas dos outros TDS.

A aplicação do método é dada pelos seguintes passos:

1. Admite-se a curva de um TDS como referência. Esta curva é geralmente indicada nos catálogos como a curva utilizada para calibração. Em casos em que não for especificada pelo fabricante, deve-se utilizar a curva com o TDS mais mediano possível dentre as opções.

2. Tomam-se pontos de tempo versus $M$ (múltiplo da corrente de pick-up) da curva de referência. A quantidade de pontos deve ser escolhida de modo a descrever o mais bem possível a não linearidade da curva.

3. Após obter os pontos do passo 2 , é necessário fazer uma estimativa inicial do tempo de operação das curvas dos outros TDS. Para cada TDS e para cada $M$ da curva de referência, calcula-se o tempo estimado com base na curva de referência. Para o cálculo utiliza-se a fórmula (2.6):

$$
t_{e}^{i}=\frac{T D S}{T D S_{\text {ref }}} t_{r e f}^{i} \quad i=1,2, \ldots, n_{M}
$$

em que $t_{e}^{i}$ é o tempo estimado para o i-ésimo múltiplo, $T D S_{r e f}$ é o ajuste do multiplicador de tempo da curva de referência e $t_{r e f}^{i}$ o tempo de atuação para o i-ésimo M na curva de referência.

4. Para curva de TDS, toma-se $\mathrm{M}_{1}$ (explicado mais a diante) e encontra-se um $\alpha$ (com precisão adequada) que satisfaça a relação (2.7): 


$$
t_{r_{-} M_{1}}=t_{e_{-} M_{1}}+10^{\left[\log \left(t_{e_{-} M_{1}}\right)-\alpha\right]}
$$

em que $t_{r_{-} M_{1}}$ é o tempo real de atuação (dado pelo manual do relé) da curva do TDS em análise para $\mathrm{M}_{1}, t_{e_{-} M_{1}}$ é o tempo estimado para o múltiplo $\mathrm{M}_{1}$ (calculado no passo 3), e $\alpha$ é um número real positivo. Caso não seja possível encontrar um $\alpha$ tal que $0<\alpha \leq 6$ (pois o valor numérico de $10^{\left[\log \left(t_{e_{-} M_{1}}\right)-\alpha\right]}$ para $\alpha>6$ geralmente não possui valor significativo) que satisfaça a relação (2.7), deve-se encontrar $\alpha$ que satisfaça a seguinte relação:

$$
t_{r_{-} M_{1}}=t_{e_{-} M_{1}}-10^{\left[\log \left(t_{e_{-} M_{1}}\right)-\alpha\right]}
$$

Deve-se notar que $\alpha$ varia para cada TDS.

5. Para cada TDS, toma-se $\mathrm{M}_{2}$ (explicado abaixo) e encontra-se $\beta$ que satisfaça a seguinte relação:

$$
t_{r_{-} M_{2}}=t_{e_{-} M_{2}} \pm 10^{\left[\log \left(t_{e_{-} M_{2}}\right)-\alpha\right]}+\beta
$$

em que $t_{r_{-} M_{2}}$ o tempo real de atuação da curva do TDS em análise para $\mathrm{M}_{2}, t_{e_{-} M_{2}}$ é o tempo estimado para o múltiplo $\mathrm{M}_{2}$, é o tempo e $\beta$ é um número real. O sinal na relação (2.9) deve ser o mesmo selecionado no tópico anterior através das relações (2.7) ou (2.8).

6. Para cada TDS deve-se calcular o tempo de atuação corrigido para todos os múltiplos da corrente de pick-up através da relação abaixo.

$$
t_{c a l c}=t_{e} \pm 10^{\left[\log \left(t_{e}\right)-\alpha\right]}+\beta
$$

Na prática, $\mathrm{M}_{1}$ é o valor de $\mathrm{M}$ até o qual a curva do relé apresenta grandes valores de derivada (grandes variações no tempo de operação com pequenas variações do múltiplo da corrente), enquanto $\mathrm{M}_{2}$ é o valor de $\mathrm{M}$ a partir do qual o tempo de operação pode ser considerado constante ou com pequenas variações. Desse modo, a escolha dos valores de $\mathrm{M}_{1}$ e $\mathrm{M}_{2}$ não é necessariamente fixa, porém a seguinte regra mostrou bons resultados:

$\mathrm{M}_{1}$ : O múltiplo da corrente de pick-up utilizado como referência em correntes baixas. Para curvas em que o menor $M$ inteiro significativo ( $M$ cujo valor numérico seja um inteiro e seja o menor dentre os válidos para a curva em análise) é menor que 4, deve-se utilizar $\mathrm{M}_{1}$ como sendo o segundo menor $M$ inteiro significativo. Em curvas em que o menor $M$ inteiro significativo for maior ou igual a $4, \mathrm{M}_{1}$ deve ter o valor do terceiro menor $\mathrm{M}$ inteiro significativo.

$\mathrm{M}_{2}$ : O múltiplo da corrente de pick-up utilizado como referência em correntes altas. $\mathrm{M}_{2}$ deve ser igual ao quarto maior $\mathrm{M}$ inteiro significativo da curva a qual se deseja obter o valor corrigido. 
A escolha de $\mathrm{M}_{1}$ e $\mathrm{M}_{2}$ ficará mais clara a partir dos exemplos a seguir.

\subsubsection{EXEMPLOS DE APLICAÇÃO}

\subsection{Relé CO-8 (ABB TYPE CO, 1984)}

Para este relé, a curva tomada como referência é a referente ao TDS $=6$. Após tomar os pontos de catálogo para os múltiplos da corrente de pick-up da curva de referência, deve-se estimar o tempo de atuação para todos os outros TDS de acordo com a fórmula (2.6). A Tabela 2.4 mostra esta etapa, sendo que a coluna destacada refere-se à curva de referência.

Tabela 2.4 - Tempo estimado para os TDS (em segundos).

\begin{tabular}{c|c|c|c|c|c|c|c|c|c|c|c|c}
\hline $\boldsymbol{M}^{\backslash \boldsymbol{T D S}}$ & 0,5 & 1 & 2 & 3 & 4 & 5 & 6 & 7 & 8 & 9 & 10 & 11 \\
\hline 2 & 1,11 & 2,23 & 4,45 & 6,68 & & & & & & & & \\
\hline 3 & 0,44 & 0,88 & 1,77 & 2,65 & 3,53 & 4,42 & 5,30 & 6,18 & & & & \\
\hline 4 & 0,27 & 0,55 & 1,09 & 1,64 & 2,19 & 2,73 & 3,28 & 3,83 & 4,37 & 4,92 & 5,47 & 6,01 \\
\hline 5 & 0,21 & 0,42 & 0,83 & 1,25 & 1,67 & 2,08 & 2,50 & 2,92 & 3,33 & 3,75 & 4,17 & 4,58 \\
\hline 6 & 0,17 & 0,34 & 0,69 & 1,03 & 1,37 & 1,72 & 2,06 & 2,40 & 2,75 & 3,09 & 3,43 & 3,78 \\
\hline 7 & 0,15 & 0,30 & 0,60 & 0,90 & 1,20 & 1,50 & 1,80 & 2,10 & 2,40 & 2,70 & 3,00 & 3,30 \\
\hline 8 & 0,14 & 0,27 & 0,54 & 0,81 & 1,08 & 1,35 & 1,62 & 1,89 & 2,16 & 2,43 & 2,70 & 2,97 \\
\hline 9 & 0,13 & 0,25 & 0,50 & 0,76 & 1,01 & 1,26 & 1,51 & 1,76 & 2,01 & 2,27 & 2,52 & 2,77 \\
\hline 10 & 0,12 & 0,24 & 0,47 & 0,71 & 0,94 & 1,18 & 1,41 & 1,65 & 1,88 & 2,12 & 2,35 & 2,59 \\
\hline 11 & 0,11 & 0,23 & 0,45 & 0,68 & 0,91 & 1,13 & 1,36 & 1,59 & 1,81 & 2,04 & 2,27 & 2,49 \\
\hline 12 & 0,11 & 0,22 & 0,43 & 0,65 & 0,87 & 1,08 & 1,30 & 1,52 & 1,73 & 1,95 & 2,17 & 2,38 \\
\hline 13 & 0,11 & 0,21 & 0,42 & 0,63 & 0,84 & 1,05 & 1,26 & 1,47 & 1,68 & 1,89 & 2,10 & 2,31 \\
\hline 14 & 0,10 & 0,20 & 0,41 & 0,61 & 0,81 & 1,02 & 1,22 & 1,42 & 1,63 & 1,83 & 2,03 & 2,24 \\
\hline 15 & 0,10 & 0,20 & 0,40 & 0,60 & 0,80 & 1,00 & 1,20 & 1,40 & 1,60 & 1,80 & 2,00 & 2,20 \\
\hline 16 & 0,10 & 0,20 & 0,39 & 0,59 & 0,78 & 0,98 & 1,17 & 1,37 & 1,56 & 1,76 & 1,95 & 2,15 \\
\hline 17 & 0,10 & 0,19 & 0,38 & 0,58 & 0,77 & 0,96 & 1,15 & 1,34 & 1,53 & 1,73 & 1,92 & 2,11 \\
\hline 18 & 0,09 & 0,19 & 0,38 & 0,57 & 0,75 & 0,94 & 1,13 & 1,32 & 1,51 & 1,70 & 1,88 & 2,07 \\
\hline 19 & 0,09 & 0,19 & 0,37 & 0,56 & 0,75 & 0,93 & 1,12 & 1,31 & 1,49 & 1,68 & 1,87 & 2,05 \\
\hline 20 & 0,09 & 0,19 & 0,37 & 0,56 & 0,74 & 0,93 & 1,11 & 1,30 & 1,48 & 1,67 & 1,85 & 2,04 \\
\hline
\end{tabular}

Para cada TDS deve-se escolher $\mathrm{M}_{1}$ e $\mathrm{M}_{2}$. Como exposto, para $\mathrm{M}_{1}$, caso o menor $\mathrm{M}$ inteiro significativo for menor que $4, \mathrm{M}_{1}$ deve ser o segundo menor $\mathrm{M}$ inteiro significativo. Caso for maior que 4, deve-se escolher o terceiro $\mathrm{M}$ inteiro significativo. Para $\mathrm{M}_{2}$, deve ser escolhido o quarto maior $\mathrm{M}$ inteiro significativo. Com isto em mente, a Tabela 2.5 resume os valores escolhidos para $\mathrm{M}_{1}$ e $\mathrm{M}_{2}$ para cada TDS. $O$ menor $M$ inteiro significativo para os diais menores que 6 é $M=4$, pois o menor $M$ inteiro da curva de referência (TDS =6) é $M=3$. Logo, escolhe-se o segundo menor M inteiro significativo. 
Tabela 2.5 - Valores de $\mathrm{M}_{1}$ e $\mathrm{M}_{2}$ para cada TDS das curvas CO8.

\begin{tabular}{c|c|c|c|c|c|c|c|c|c|c|c|c}
\hline TDS & 0,5 & 1 & 2 & 3 & 4 & 5 & 6 & 7 & 8 & 9 & 10 & 11 \\
\hline $\mathrm{M}_{1}$ & 4 & 4 & 4 & 4 & 4 & 4 & - & 4 & 6 & 6 & 6 & 6 \\
\hline $\mathrm{M}_{2}$ & 17 & 17 & 17 & 17 & 17 & 17 & - & 17 & 17 & 17 & 17 & 17 \\
\hline
\end{tabular}

Definidos $\mathrm{M}_{1}$ e $\mathrm{M}_{2}$, o próximo passo é encontrar valores de $\alpha$ para cada TDS. Para os TDS maiores do que 6, a função de correção deve ser do tipo da relação (2.7), enquanto que para os menores que 6, a correção deve ser feita através da equação (2.8). A seguir, deve-se encontrar o valor de $\beta$ que satisfaça a relação (2.9). A Tabela 2.6 mostra os valores encontrados de $\alpha$ e $\beta$ para todos os TDS.

Tabela 2.6 - Valores de $\alpha$ e $\beta$ para todos os diais do relé CO8.

\begin{tabular}{c|c|c|c|c|c|c|c|c|c|c|c|c}
\hline TDS & 0,5 & 1 & 2 & 3 & 4 & 5 & 6 & 7 & 8 & 9 & 10 & 11 \\
\hline$\alpha$ & 0,571 & 0,915 & 1,31 & 1,62 & 1,4 & 1,9 & - & 1,715 & 1,72 & 1,34 & 1,31 & 1,068 \\
\hline$\beta$ & $-0,013$ & 0,0016 & 0,0055 & 0,019 & 0,014 & 0,004 & - & $-0,028$ & $-0,013$ & $-0,033$ & 0,005 & $-0,008$ \\
\hline
\end{tabular}

Com os valores de $\alpha$ e $\beta$ pode-se calcular os valores corrigidos dos pontos de todos os TDS utilizando-se a equação (2.10). A Figura 2.11 mostra as curvas do relé CO-8. As curvas pontilhadas são os valores obtidos pelo manual do relé, enquanto as curvas sólidas representam valores calculados pelo método proposto. A curva de referência também é apresentada.

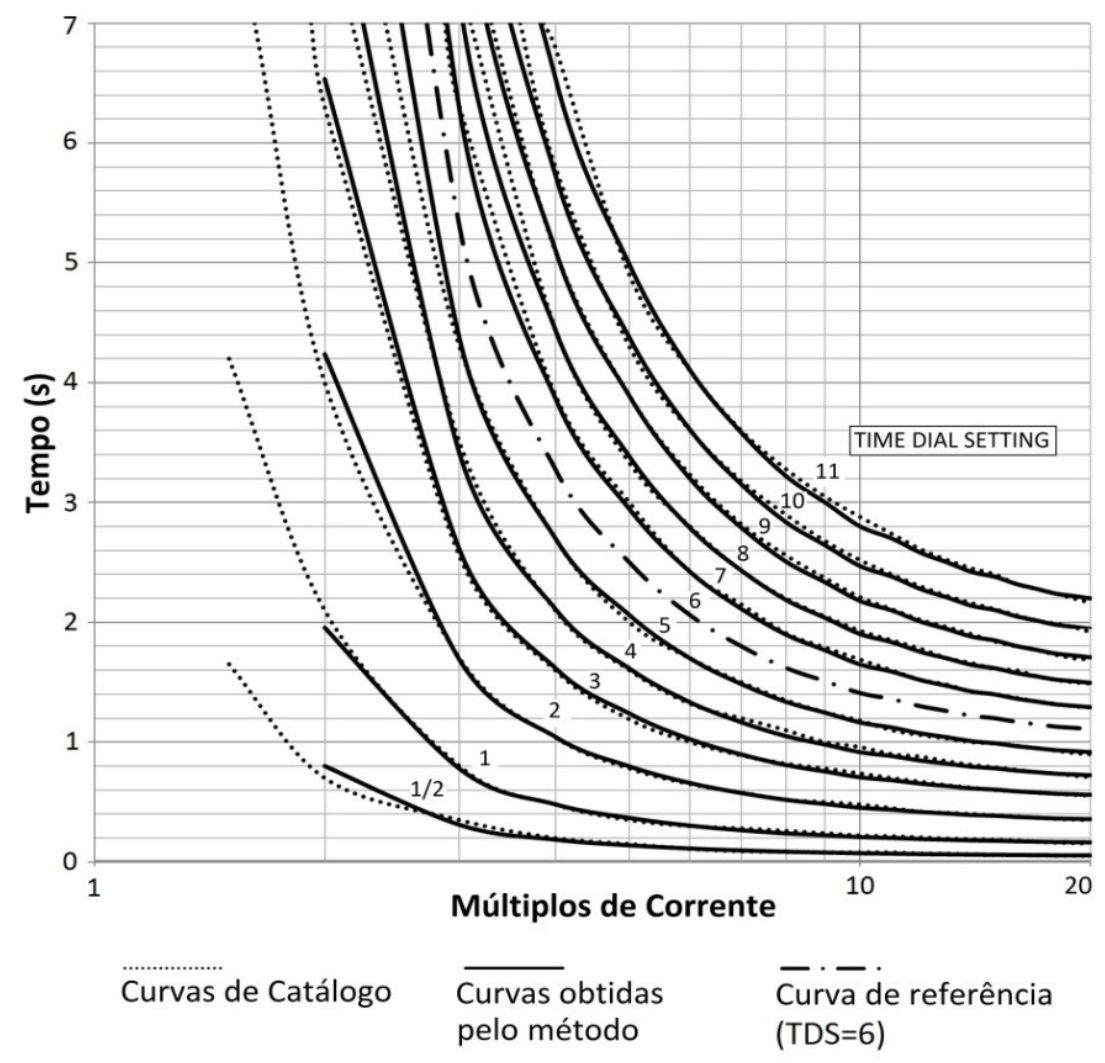

Figura 2.11 - Curvas para o relé CO-8. Relação entre valores estimados e valores de catálogo.

A Tabela 2.7 mostra os erros relativos entre os valores obtidos pelo método proposto e os valores de catálogo, enquanto a Tabela 2.8 mostra os erros absolutos para o mesmo relé. 
Tabela 2.7 - Erro relativo ponto-a-ponto do método descrito para o relé CO-8.

\begin{tabular}{c|c|c|c|c|c|c|c|c|c|c|c|c}
\hline $\boldsymbol{M}^{\text {TDS }}$ & 0,5 & 1 & 2 & 3 & 4 & 5 & 6 & 7 & 8 & 9 & 10 & 11 \\
\hline 3 & $-11,4 \%$ & $-2,8 \%$ & $-0,8 \%$ & $2,2 \%$ & $-2,7 \%$ & $1,5 \%$ & - & $-0,4 \%$ & & & & \\
\hline 4 & $-6,6 \%$ & $0,4 \%$ & $0,5 \%$ & $1,2 \%$ & $0,6 \%$ & $0,1 \%$ & - & $-0,7 \%$ & $-0,1 \%$ & $0,2 \%$ & $-1,0 \%$ & $-3,7 \%$ \\
\hline 5 & $-7,1 \%$ & $5,0 \%$ & $2,3 \%$ & $4,1 \%$ & $0,9 \%$ & $3,1 \%$ & - & $-1,8 \%$ & $1,6 \%$ & $0,0 \%$ & $1,8 \%$ & $1,8 \%$ \\
\hline 6 & $2,2 \%$ & $1,1 \%$ & $1,3 \%$ & $2,4 \%$ & $1,0 \%$ & $-0,1 \%$ & - & $0,1 \%$ & $-0,5 \%$ & $-1,0 \%$ & $0,2 \%$ & $0,1 \%$ \\
\hline 7 & $7,4 \%$ & $-5,3 \%$ & $-0,7 \%$ & $0,8 \%$ & $-2,8 \%$ & $-1,0 \%$ & - & $-1,7 \%$ & $0,1 \%$ & $-1,0 \%$ & $-0,9 \%$ & $-0,5 \%$ \\
\hline 8 & $0,8 \%$ & $-8,2 \%$ & $-0,2 \%$ & $-1,3 \%$ & $-4,5 \%$ & $-1,0 \%$ & - & $-0,6 \%$ & $-0,5 \%$ & $-2,0 \%$ & $-2,2 \%$ & $-1,8 \%$ \\
\hline 9 & $-1,3 \%$ & $-7,2 \%$ & $-3,2 \%$ & $-3,1 \%$ & $-1,9 \%$ & $-0,3 \%$ & - & $-1,3 \%$ & $-0,6 \%$ & $-1,5 \%$ & $-1,3 \%$ & $-1,6 \%$ \\
\hline 10 & $-8,9 \%$ & $-5,4 \%$ & $-5,7 \%$ & $-4,4 \%$ & $-4,5 \%$ & $-1,3 \%$ & - & $-2,4 \%$ & $-1,4 \%$ & $-1,4 \%$ & $-2,0 \%$ & $-2,7 \%$ \\
\hline 11 & $-12,8 \%$ & $-6,7 \%$ & $-3,0 \%$ & $-2,5 \%$ & $-1,7 \%$ & $2,1 \%$ & - & $-0,7 \%$ & $-0,8 \%$ & $-0,5 \%$ & $-0,7 \%$ & $-1,4 \%$ \\
\hline 12 & $-5,5 \%$ & $-6,4 \%$ & $-0,6 \%$ & $-2,5 \%$ & $-3,8 \%$ & $1,3 \%$ & - & $-0,1 \%$ & $-1,5 \%$ & $-0,7 \%$ & $-1,0 \%$ & $-1,1 \%$ \\
\hline 13 & $-9,0 \%$ & $-4,6 \%$ & $-1,2 \%$ & $-1,0 \%$ & $-2,3 \%$ & $1,0 \%$ & - & $-0,7 \%$ & $-0,1 \%$ & $-0,8 \%$ & $-0,5 \%$ & $-0,8 \%$ \\
\hline 14 & $-2,8 \%$ & $-5,2 \%$ & $-1,9 \%$ & $-0,9 \%$ & $-1,9 \%$ & $0,8 \%$ & - & $0,2 \%$ & $-0,9 \%$ & $-1,0 \%$ & $-1,0 \%$ & $-1,2 \%$ \\
\hline 15 & $-1,6 \%$ & $-4,2 \%$ & $-1,0 \%$ & $0,8 \%$ & $-1,0 \%$ & $0,1 \%$ & - & $-0,1 \%$ & $0,5 \%$ & $0,5 \%$ & $-0,3 \%$ & $-0,8 \%$ \\
\hline 16 & $0,4 \%$ & $-4,0 \%$ & $-0,9 \%$ & $0,0 \%$ & $-0,9 \%$ & $-0,3 \%$ & - & $-0,5 \%$ & $-1,5 \%$ & $0,1 \%$ & $-0,5 \%$ & $0,0 \%$ \\
\hline 17 & $0,0 \%$ & $0,0 \%$ & $0,0 \%$ & $0,0 \%$ & $0,0 \%$ & $0,0 \%$ & - & $0,0 \%$ & $0,0 \%$ & $0,0 \%$ & $0,0 \%$ & $0,0 \%$ \\
\hline 18 & $1,4 \%$ & $3,1 \%$ & $1,0 \%$ & $0,1 \%$ & $-0,4 \%$ & $0,4 \%$ & - & $-0,3 \%$ & $0,2 \%$ & $0,5 \%$ & $-0,5 \%$ & $0,0 \%$ \\
\hline 19 & $2,2 \%$ & $4,8 \%$ & $1,6 \%$ & $1,0 \%$ & $1,5 \%$ & $1,7 \%$ & - & $0,3 \%$ & $0,6 \%$ & $1,4 \%$ & $0,2 \%$ & $0,9 \%$ \\
\hline 20 & $4,9 \%$ & $5,9 \%$ & $2,1 \%$ & $1,0 \%$ & $2,0 \%$ & $1,9 \%$ & - & $0,2 \%$ & $0,3 \%$ & $1,1 \%$ & $1,3 \%$ & $1,6 \%$ \\
\hline
\end{tabular}

Tabela 2.8 - Erro absoluto ponto-a-ponto do método descrito para o relé CO-8.

\begin{tabular}{c|c|c|c|c|c|c|c|c|c|c|c|c}
\hline $\boldsymbol{M}^{\boldsymbol{T} \boldsymbol{T D S}}$ & 0,5 & 1 & 2 & 3 & 4 & 5 & 6 & 7 & 8 & 9 & 10 & 11 \\
\hline 3 & $-0,040$ & $-0,022$ & $-0,014$ & 0,055 & $-0,093$ & 0,065 & - & $-0,025$ & & & & \\
\hline 4 & $-0,013$ & 0,002 & 0,005 & 0,020 & 0,014 & 0,003 & - & $-0,028$ & $-0,006$ & 0,012 & $-0,061$ & $-0,250$ \\
\hline 5 & $-0,011$ & 0,018 & 0,018 & 0,049 & 0,014 & 0,061 & - & $-0,055$ & 0,054 & $-0,002$ & 0,076 & 0,086 \\
\hline 6 & 0,002 & 0,003 & 0,009 & 0,024 & 0,013 & $-0,001$ & - & 0,002 & $-0,014$ & $-0,032$ & 0,006 & 0,004 \\
\hline 7 & 0,007 & $-0,015$ & $-0,004$ & 0,007 & $-0,034$ & $-0,015$ & - & $-0,038$ & 0,003 & $-0,030$ & $-0,028$ & $-0,017$ \\
\hline 8 & 0,001 & $-0,021$ & $-0,001$ & $-0,010$ & $-0,049$ & $-0,013$ & - & $-0,012$ & $-0,012$ & $-0,052$ & $-0,063$ & $-0,058$ \\
\hline 9 & $-0,001$ & $-0,017$ & $-0,016$ & $-0,024$ & $-0,019$ & $-0,004$ & - & $-0,022$ & $-0,011$ & $-0,034$ & $-0,035$ & $-0,048$ \\
\hline 10 & $-0,007$ & $-0,012$ & $-0,028$ & $-0,033$ & $-0,043$ & $-0,016$ & - & $-0,041$ & $-0,027$ & $-0,031$ & $-0,050$ & $-0,079$ \\
\hline 11 & $-0,010$ & $-0,014$ & $-0,013$ & $-0,017$ & $-0,015$ & 0,023 & - & $-0,011$ & $-0,015$ & $-0,010$ & $-0,017$ & $-0,039$ \\
\hline 12 & $-0,004$ & $-0,013$ & $-0,002$ & $-0,017$ & $-0,034$ & 0,014 & - & $-0,002$ & $-0,027$ & $-0,014$ & $-0,022$ & $-0,029$ \\
\hline 13 & $-0,006$ & $-0,009$ & $-0,005$ & $-0,006$ & $-0,019$ & 0,011 & - & $-0,010$ & $-0,001$ & $-0,017$ & $-0,012$ & $-0,019$ \\
\hline 14 & $-0,002$ & $-0,010$ & $-0,008$ & $-0,006$ & $-0,015$ & 0,008 & - & 0,003 & $-0,015$ & $-0,019$ & $-0,022$ & $-0,030$ \\
\hline 15 & $-0,001$ & $-0,008$ & $-0,004$ & 0,005 & $-0,008$ & 0,001 & - & $-0,001$ & 0,007 & 0,009 & $-0,007$ & $-0,020$ \\
\hline 16 & 0,000 & $-0,007$ & $-0,004$ & 0,000 & $-0,007$ & $-0,003$ & - & $-0,007$ & $-0,023$ & 0,002 & $-0,009$ & 0,000 \\
\hline 17 & 0,000 & 0,000 & 0,000 & 0,000 & 0,000 & 0,000 & - & 0,000 & 0,000 & 0,000 & 0,000 & 0,000 \\
\hline 18 & 0,001 & 0,005 & 0,004 & 0,000 & $-0,003$ & 0,004 & - & $-0,004$ & 0,002 & 0,009 & $-0,009$ & 0,000 \\
\hline 19 & 0,001 & 0,008 & 0,006 & 0,006 & 0,011 & 0,016 & - & 0,004 & 0,009 & 0,024 & 0,003 & 0,020 \\
\hline 20 & 0,003 & 0,009 & 0,007 & 0,006 & 0,015 & 0,017 & - & 0,002 & 0,005 & 0,018 & 0,026 & 0,035 \\
\hline
\end{tabular}

Percebe-se que o erro relativo para baixos valores de TDS é grande em algumas ocasiões. Porém esse erro é justificável, pois o erro absoluto é pequeno. Nos tópicos a seguir serão expostos outros 
exemplos. Nota-se que em alguns casos o erro é grande em pequenos múltiplos da corrente de pick-up, porém isso é aceitável, pois a própria característica de operação para relés eletromecânicos geralmente apresenta grandes erros para baixos valores de M, chegando a 10\% em alguns casos. Como consequência, na prática, os engenheiros de proteção evitam ajustes de relés com tais valores. Contudo, se for desejada uma maior precisão dos resultados, devem ser tomados quantos pontos forem necessários para definir as características de operação de acordo com o passo 2.

\subsection{Relé CDG-13 (GEC MEASUREMENTS CDG-13)}

O método foi aplicado na modelagem das características de operação do relé CDG-13. Para este caso, a curva de referência tomada foi a de $\mathrm{TDS}=0,5$. Este relé tem uma faixa contínua de ajustes de TDS, de modo que a modelagem apresenta menos não linearidades quando comparada ao do relé CO-8. Os resultados mostram erros bem baixos. Como no relé CO-8, primeiramente o método encontra o tempo estimado para todos os diais utilizando a equação (2.6). A Tabela 2.9 mostra os resultados. Para este caso, o valor de $M_{1}$ para todos os diais é 3, enquanto que o valor de $M_{2}$ para todos os TDS é 9.

Tabela 2.9 - Tempo estimado para os diais de tempo (em segundos).

\begin{tabular}{c|c|c|c|c|c|c|c|c|c|c}
\hline $\boldsymbol{M}^{\backslash \boldsymbol{T D S}}$ & 0,1 & 0,2 & 0,3 & 0,4 & 0,5 & 0,6 & 0,7 & 0,8 & 0,9 & 1 \\
\hline 2 & 1,68 & 3,36 & 5,04 & 6,72 & 8,4 & 10,08 & 11,76 & 13,44 & 15,12 & 16,8 \\
\hline 3 & 0,64 & 1,28 & 1,92 & 2,56 & 3,2 & 3,84 & 4,48 & 5,12 & 5,76 & 6,4 \\
\hline 4 & 0,376 & 0,752 & 1,128 & 1,504 & 1,88 & 2,256 & 2,632 & 3,008 & 3,384 & 3,76 \\
\hline 5 & 0,27 & 0,54 & 0,81 & 1,08 & 1,35 & 1,62 & 1,89 & 2,16 & 2,43 & 2,7 \\
\hline 6 & 0,22 & 0,44 & 0,66 & 0,88 & 1,1 & 1,32 & 1,54 & 1,76 & 1,98 & 2,2 \\
\hline 7 & 0,192 & 0,384 & 0,576 & 0,768 & 0,96 & 1,152 & 1,344 & 1,536 & 1,728 & 1,92 \\
\hline 8 & 0,176 & 0,352 & 0,528 & 0,704 & 0,88 & 1,056 & 1,232 & 1,408 & 1,584 & 1,76 \\
\hline 9 & 0,162 & 0,324 & 0,486 & 0,648 & 0,81 & 0,972 & 1,134 & 1,296 & 1,458 & 1,62 \\
\hline 10 & 0,152 & 0,304 & 0,456 & 0,608 & 0,76 & 0,912 & 1,064 & 1,216 & 1,368 & 1,52 \\
\hline 15 & 0,128 & 0,256 & 0,384 & 0,512 & 0,64 & 0,768 & 0,896 & 1,024 & 1,152 & 1,28 \\
\hline 20 & 0,116 & 0,232 & 0,348 & 0,464 & 0,58 & 0,696 & 0,812 & 0,928 & 1,044 & 1,16 \\
\hline
\end{tabular}

O próximo passo é encontrar os valores de $\alpha$ para cada TDS. Para diais maiores que 0,5 a equação (2.7) deve ser utilizada, caso contrário a equação (2.8) deve ser empregada. Em seguida, deve-se encontrar $\beta$ que satisfaça a relação (2.9). A Tabela 2.10 mostra os resultados obtidos.

Tabela 2.10 - Valores de $\alpha$ e $\beta$ para todos os diais do relé CO8.

\begin{tabular}{c|c|c|c|c|c|c|c|c|c|c}
\hline TDS & 0,1 & 0,2 & 0,3 & 0,4 & 0,5 & 0,6 & 0,7 & 0,8 & 0,9 & 1 \\
\hline$\alpha$ & 0,903 & 1,205 & 1,505 & 2,107 & - & 6 & 1,57 & 1,807 & 2,158 & 1,807 \\
\hline$\beta$ & 0,018 & 0,016 & 0,009 & 0,007 & - & $-0,002$ & $-0,044$ & $-0,016$ & $-0,023$ & $-0,025$ \\
\hline
\end{tabular}


A comparação entre valores calculados e os valores de catálogo são mostradas na Figura 2.12. A Tabela 2.11 mostra os erros relativos ponto-a-ponto e a Tabela 2.12 mostra os erros absolutos ponto-aponto para o relé CDG-13.
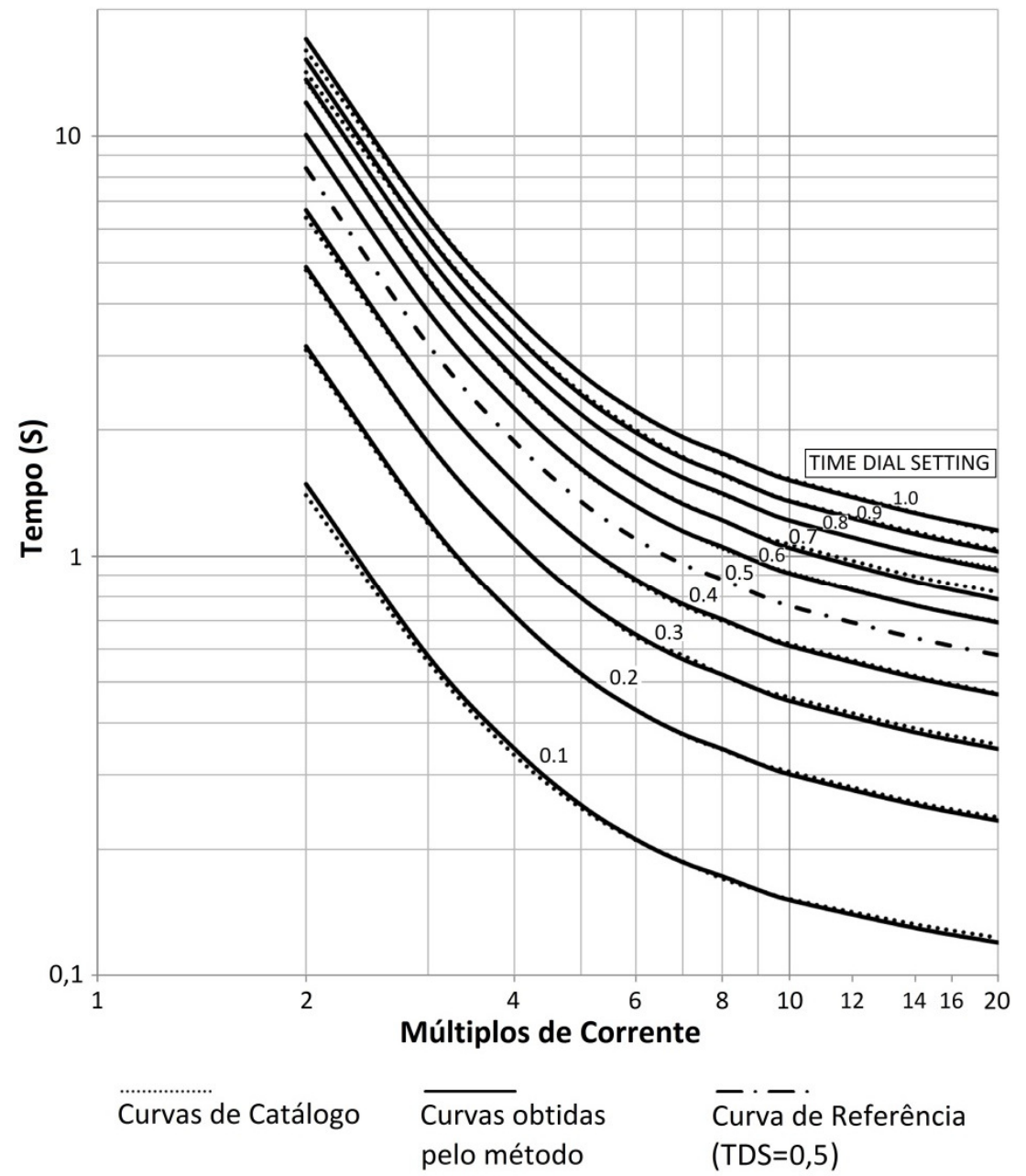

Figura 2.12 - Curvas para o relé CDG-13. Relação entre valores estimados e valores de catálogo.

Tabela 2.11 - Erro relativo ponto-a-ponto do método descrito para o relé CDG-13.

\begin{tabular}{c|c|c|c|c|c|c|c|c|c|c}
\hline $\boldsymbol{M}^{\backslash \boldsymbol{T D S}}$ & 0,1 & 0,2 & 0,3 & 0,4 & 0,5 & 0,6 & 0,7 & 0,8 & 0,9 & 1 \\
\hline 2 & $6,3 \%$ & $2,2 \%$ & $1,9 \%$ & $4,3 \%$ & - & $0,8 \%$ & $0,3 \%$ & $1,8 \%$ & $7,1 \%$ & $6,5 \%$ \\
\hline 3 & $3,3 \%$ & $1,4 \%$ & $0,5 \%$ & $0,3 \%$ & - & $-0,1 \%$ & $-1,0 \%$ & $-0,3 \%$ & $-0,4 \%$ & $-0,4 \%$ \\
\hline 4 & $3,7 \%$ & $0,2 \%$ & $0,2 \%$ & $-0,1 \%$ & - & $-0,7 \%$ & $1,1 \%$ & $-0,4 \%$ & $-0,5 \%$ & $-0,1 \%$ \\
\hline 5 & $1,8 \%$ & $0,5 \%$ & $-0,4 \%$ & $-0,1 \%$ & - & $1,1 \%$ & $-0,2 \%$ & $-0,1 \%$ & $-1,5 \%$ & $-0,1 \%$ \\
\hline 6 & $0,4 \%$ & $-0,3 \%$ & $1,3 \%$ & $1,2 \%$ & - & $-0,2 \%$ & $-0,2 \%$ & $-0,5 \%$ & $-1,5 \%$ & $0,4 \%$ \\
\hline 7 & $-0,4 \%$ & $0,4 \%$ & $-2,2 \%$ & $1,2 \%$ & - & $0,0 \%$ & $-0,4 \%$ & $0,2 \%$ & $-0,8 \%$ & $-0,2 \%$ \\
\hline 8 & $1,4 \%$ & $0,4 \%$ & $0,2 \%$ & $0,8 \%$ & - & $1,3 \%$ & $0,0 \%$ & $1,0 \%$ & $0,8 \%$ & $0,7 \%$ \\
\hline 9 & $0,0 \%$ & $0,0 \%$ & $0,0 \%$ & $0,0 \%$ & - & $0,0 \%$ & $0,0 \%$ & $0,0 \%$ & $0,0 \%$ & $0,0 \%$ \\
\hline 10 & $-0,5 \%$ & $-1,5 \%$ & $-1,9 \%$ & $-1,1 \%$ & - & $-1,1 \%$ & $-2,1 \%$ & $-0,1 \%$ & $-0,4 \%$ & $-0,7 \%$ \\
\hline 15 & $-2,0 \%$ & $-1,4 \%$ & $-2,2 \%$ & $-1,0 \%$ & - & $-0,5 \%$ & $-2,8 \%$ & $-0,7 \%$ & $-1,2 \%$ & $-0,4 \%$ \\
\hline 20 & $-2,6 \%$ & $-1,8 \%$ & $-2,4 \%$ & $-0,6 \%$ & - & $-0,9 \%$ & $-3,8 \%$ & $-1,5 \%$ & $-1,2 \%$ & $1,2 \%$ \\
\hline
\end{tabular}


Tabela 2.12 - Erro absoluto ponto-a-ponto do método descrito para o relé CDG-13.

\begin{tabular}{c|c|c|c|c|c|c|c|c|c|c}
\hline $\boldsymbol{M}^{\backslash \boldsymbol{T D S}}$ & 0,1 & 0,2 & 0,3 & 0,4 & 0,5 & 0,6 & 0,7 & 0,8 & 0,9 & 1 \\
\hline 2 & 0,088 & 0,067 & 0,090 & 0,274 & - & 0,078 & 0,032 & 0,236 & 1,004 & 1,041 \\
\hline 3 & 0,018 & 0,016 & 0,009 & 0,007 & - & $-0,002$ & $-0,044$ & $-0,016$ & $-0,023$ & $-0,024$ \\
\hline 4 & 0,012 & 0,001 & 0,002 & $-0,001$ & - & $-0,016$ & 0,028 & $-0,011$ & $-0,016$ & $-0,005$ \\
\hline 5 & 0,005 & 0,003 & $-0,003$ & $-0,002$ & - & 0,018 & $-0,004$ & $-0,003$ & $-0,036$ & $-0,002$ \\
\hline 6 & 0,001 & $-0,001$ & 0,009 & 0,010 & - & $-0,002$ & $-0,004$ & $-0,009$ & $-0,029$ & 0,010 \\
\hline 7 & $-0,001$ & 0,001 & $-0,013$ & 0,009 & - & 0,000 & $-0,005$ & 0,003 & $-0,013$ & $-0,005$ \\
\hline 8 & 0,002 & 0,001 & 0,001 & 0,005 & - & 0,014 & 0,000 & 0,013 & 0,012 & 0,013 \\
\hline 9 & 0,000 & 0,000 & 0,000 & 0,000 & - & 0,000 & 0,000 & 0,000 & 0,000 & 0,001 \\
\hline 10 & $-0,001$ & $-0,005$ & $-0,009$ & $-0,007$ & - & $-0,010$ & $-0,022$ & $-0,002$ & $-0,006$ & $-0,011$ \\
\hline 15 & $-0,003$ & $-0,004$ & $-0,009$ & $-0,005$ & - & $-0,004$ & $-0,025$ & $-0,007$ & $-0,013$ & $-0,005$ \\
\hline 20 & $-0,003$ & $-0,004$ & $-0,009$ & $-0,003$ & - & $-0,006$ & $-0,031$ & $-0,014$ & $-0,012$ & 0,013 \\
\hline
\end{tabular}

\subsubsection{CONSIDERAÇÕES FINAIS DO MÉTODO}

Os resultados mostram erros relativamente baixos, da ordem de 5\%. O método requer selecionar alguns pontos de múltiplo de corrente versus tempo da curva de um TDS tomado como referência e um par de pontos das curvas dos outros diais a serem analisados. Alguns estudos adicionais mostram que erros menores que $10 \%$ foram encontrados aplicando o método com apenas 5 pontos da curva de referência. Contudo, para maior precisão, recomenda-se empregar uma quantidade mínima de 10 pontos coletados. Desse modo tem-se uma redução de cerca de 10 vezes da quantidade de dados de entrada comparando-se com outros métodos.

O método foi aplicado também aos relés CO-2, CO-9 e CO-11 (ABB TYPE CO, 1984). A Tabela 2.13 mostra o resumo dos erros relativos dos relés testados. Estes erros foram obtidos pela comparação dos resultados da metodologia com as curvas dos manuais dos relés.

Tabela 2.13 - Resumo dos erros relativos obtidos pela aplicação do método para os relés CO-2, CO-8, CO-9, CO-11 e CDG-13.

\begin{tabular}{|c|c|c|c|c|c|c|}
\hline \multirow[t]{2}{*}{ Relés } & \multirow{2}{*}{$\begin{array}{l}\text { Erro } \\
\text { médio }\end{array}$} & \multirow{2}{*}{$\begin{array}{l}\text { Erro médio } \\
\text { apenas do } \\
\text { menor M }\end{array}$} & \multirow{2}{*}{$\begin{array}{c}\text { Erro médio } \\
\text { desconsiderando } \\
\text { o menor } \mathrm{M}\end{array}$} & \multirow{2}{*}{$\begin{array}{l}\text { Erro } \\
\text { máximo }\end{array}$} & \multicolumn{2}{|c|}{$\begin{array}{l}\text { Local de ocorrência } \\
\text { do erro máximo }\end{array}$} \\
\hline & & & & & $\mathrm{M}$ & TDS \\
\hline $\mathrm{CO}-2$ & $2,45 \%$ & $10,17 \%$ & $1,59 \%$ & $19,54 \%$ & $1,5\left(1^{\circ}\right)$ & 0,5 \\
\hline $\mathrm{CO}-8$ & $1,78 \%$ & $2,90 \%$ & $1,73 \%$ & $11,44 \%$ & $3\left(1^{o}\right)$ & 0,5 \\
\hline $\mathrm{CO}-9$ & $2,64 \%$ & $8 \%$ & $2,62 \%$ & $19,02 \%$ & $3\left(1^{\circ}\right)$ & 0,5 \\
\hline $\mathrm{CO}-11$ & $2,89 \%$ & $5,52 \%$ & $2,70 \%$ & $12,41 \%$ & $1,5\left(1^{\circ}\right)$ & 1 \\
\hline CDG-13 & $0,97 \%$ & $3,10 \%$ & $0,76 \%$ & $7,10 \%$ & $2\left(1^{o}\right)$ & 0,9 \\
\hline
\end{tabular}

A partir da Tabela 2.13 pode-se perceber que os maiores erros ocorrem para baixos valores de M, mas isso é aceitável como já foi justificado anteriormente. O desempenho geral do método é satisfatório, com erros médios da ordem de 3\%. Relés eletromecânicos já possuem um erro intrínseco, em alguns casos, como no relé CO-11, chegando de $+20 \%$ a $-5 \%$ sob o tempo médio de operação (ABB TYPE CO, 
1984). Desse modo, a redução na quantidade de dados de entrada comparada com a pequena perda de precisão é bem razoável.

A principal vantagem do método proposto é que não há necessidade de levantar grandes quantidades de pontos das curvas de todos os TDS, e o usuário pode facilmente modelar as características de relés não padronizados ele mesmo. Nota-se também que o método é passível de desenvolvimento em qualquer linguagem de programação. Após o tratamento pela metodologia, pode-se aplicar qualquer método computacional para obtenção de uma função do relé, como por exemplo, um dos citados durante a revisão bibliográfica. Porém, para uma maior simplificação do processo, foi desenvolvido um método que realiza uma interpolação logarítmica, tanto nos múltiplos da corrente quanto para os diais (para tratar casos em que se têm relés com variação contínua de diais, como, por exemplo, o relé CDG-13), sendo que o método resultante apresenta um erro final da ordem de $5 \%$. 


\section{MÉTODOS PARA COORDENAÇÃO DE RELÉS DIRECIONAIS DE SOBRECORRENTE}

O processo de determinação dos ajustes de relés direcionais de sobrecorrente pode ser bastante complicado, especialmente para sistemas de grande porte, sendo que vários trabalhos podem ser encontrados na literatura propondo diferentes abordagens e soluções. Em URDANETA et al. (1988) o problema de coordenação é estabelecido e resolvido no âmbito da teoria de otimização, levando-se em consideração que as dimensões envolvidas são muito grandes (sistemas acima de 30 barras) e que o objetivo é minimizar o tempo de atuação dos relés. A função objetivo do problema tem a seguinte forma:

$$
\min _{s \in S}[z(s, p)]
$$

Em que $z(s, p)$ é uma função que representa o melhor desempenho para a coordenação de acordo com os parâmetros dos relés $(s)$, dentro de todos os parâmetros disponíveis para os relés $(S)$, e das condições de falta $(p)$. Este é um problema de dimensões muito grandes, e uma solução é utilizar uma função de aproximação do tipo:

$$
\min _{s \in S}\left[\max _{p \in P} z(s, p)\right]
$$

Nesta aproximação P representa as condições de falta ou de perturbações. Os autores assumem que os parâmetros do relé (TDS e $I_{p}$ ) são variáveis contínuas e ao fim o resultado é arredondado para solução discreta mais próxima.

O problema de otimização é moldado inserindo-se restrições, tais como:

- Critérios de coordenação: há a necessidade de um intervalo de tempo entre a operação de relés de retaguarda e principais. Este intervalo depende do tempo de abertura de disjuntores, dos critérios de operação e de outros parâmetros operacionais;

- Limites dos ajustes dos relés e tempos de operação: limites de TDS e da corrente de pickup $I_{p}$

- Características dos relés: próprias características de atuação dos relés (curvas de atuação).

Formulado o problema, os autores buscam a minimização da função objetivo empregando um processo iterativo e calculando a corrente de pick-up $\left(I_{p}\right)$ até que a precisão desejada seja atingida.

Nesse mesmo trabalho, quando o sistema muda de configuração a solução não é mais válida. Desse modo, em condições de retirada ou inclusão de linhas, transformadores e geradores, em que a característica do sistema muda, é necessário recalcular a coordenação dos dispositivos. Outro destaque é 
que não se garante o ponto ótimo da coordenação, porém o método fornece uma solução que se aproxima da ótima. Por produzir um algoritmo que exige pouco esforço computacional, os autores sugerem que a metodologia seja utilizada em sistemas de controle on-line, apesar da não garantia da solução ótima.

Já em KAWAHARA et al. (1997), os autores propõem a aplicação de um sistema baseado em regras, em que estas regras são utilizadas para resolver o problema dos ajustes de relés de sobrecorrente direcionais e atraso de tempo para a coordenação da proteção. Com o objetivo de resolver o problema eficientemente, primeiramente os autores propõem um algoritmo para encontrar a ordem dos ajustes dos relés utilizando certas regras. Estas regras checam todos os pares de relés principal/retaguarda para detectar um laço específico para as configurações do sistema, identificando um conjunto mínimo de relés a serem ajustados inicialmente, que são chamados de conjunto de abertura de laço (BPS - breakpoint set). Então a ordem dos ajustes dos relés é identificada a partir deste conjunto inicial. O sistema proposto ainda tem a vantagem de trabalhar com ajustes discretos da corrente de pick-up para evitar problemas que surgem com o arredondamento de respostas contínuas. As regras são tomadas com a intenção de minimizar o tempo de coordenação entre os relés. Para atingir os objetivos propostos no trabalho, inicialmente são definidos pares de relés principais e retaguarda para um dado sistema em análise. Após uma escolha inicial dos ajustes de um relé, o relé de retaguarda correspondente pode ser ajustado, respeitando os tempos de coordenação. Mas a escolha dos relés que serão ajustados primeiramente deve seguir alguns critérios, caso contrário não será possível completar o laço de coordenação. Quanto menor o BPS mais fácil se torna a resolução do sistema, porém o BPS é proporcional ao número de interações requeridas para a coordenação, podendo ser difícil obter um valor mínimo do conjunto. As regras para a determinação do conjunto de abertura de laço são:

- Relés que não são retaguarda de nenhum outro relé são escolhidos como candidatos a BPS;

- Casos em que um relé é retaguarda de apenas um outro relé indicam que apenas um dos relés do par P/R é suficiente para ser candidato a BPS;

- Relés em linhas paralelas são candidatos a BPS;

- Em caso de mais de duas linhas sucessivas, os relés associados à proteção destas linhas não podem ser candidatos a BPS;

- Relés de linhas que possuem características de linhas paralelas, tais como linhas que apesar de possuir barramentos intermediários, possuem barramentos iniciais e finais iguais, são utilizados como candidatos adicionais a BPS;

- O conjunto BPS não pode conter dois relés que são pares $\mathrm{P} / \mathrm{R}$ em seu conteúdo.

Os autores desenvolvem um algoritmo de determinação de uma sequência de ajuste dos relés com base em regras heurísticas da seguinte forma: determinam-se os BPS. Estes serão os primeiros a serem 
ajustados. Estes relés são então adicionados a um conjunto "A". Na segunda iteração, o algoritmo procura quais relés do sistema são retaguarda dos relés do conjunto "A", sendo os encontrados os próximos a receber os ajustes. Na próxima iteração o algoritmo novamente procura relés do sistema, fora do conjunto "A", que são retaguarda dos relés do conjunto "A", sendo os encontrados os próximos a receber os ajustes. $\mathrm{O}$ algoritmo segue assim até determinar a ordem de ajuste de todos os relés.

Determinada a ordem de ajustes a ser seguida, a metodologia realiza os ajustes dos relés, o que significa encontrar valores da corrente de pick-up ( $\mathrm{I}_{\mathrm{p}}$ ) e do multiplicador de tempo (TDS) que satisfaçam determinadas condições. Estas condições dizem respeito a critérios de coordenação e limites operacionais do relé. Com o objetivo de minimizar o tempo de atuação dos relés, a metodologia varia Ip e TDS dentro de uma área de operação do relé para as regras de ajustes, e utilizando um processo de tentativa e erro direcionado por certos critérios que indicam se Ip e TDS devem ser incrementados ou decrementados, obtém-se o melhor tempo possível de atuação do relé em análise.

A metodologia então separa o problema de forma a tratar cada relé de uma só vez, desmembrando-o do sistema, porém insere regras para a realização destes ajustes que têm origem no sistema como um todo. Esta, portanto, se demonstrou uma forma bastante simplificada e eficaz de se resolver o problema de coordenação de relés direcionais.

PÉREZ et al. (1999) apresenta uma metodologia considerando-se a característica de tempo definido em relés de retaguarda na coordenação ótima de relés de sobrecorrente direcionais usando programação linear. O trabalho mostra que a influência da segunda zona de proteção de relés de distância e falha de disjuntores impõe requisitos importantes para a determinação dos ajustes dos relés direcionais, havendo a necessidade de formular soluções para coordenação ótima quando são inseridos outros tipos de relés diferentes do direcional. A maioria dos sistemas utiliza relés direcionais apenas como proteção secundária, sendo a proteção principal realizada por relés de distância. Os relés de distância são implementados segundo o princípio de atuação instantânea em zona primária e atuação temporizada em zona secundária. Esta zona secundária representa uma proteção de tempo definido, e seu tempo de operação é superior a 300ms. O artigo então propõe uma metodologia de solução ótima do problema de coordenação de relés direcionais de sobrecorrente incluindo as restrições impostas por relés de distância e relés de falha de disjuntor. Estas restrições dizem respeito ao tempo de atuação destes relés.

No trabalho de KLOCK JR. (2002), o autor propõe uma ferramenta computacional para a verificação e determinação da coordenação de relés de sobrecorrente direcionais de neutro, sendo que o objetivo da ferramenta não é a determinação automática dos ajustes dos relés, e sim auxiliar o engenheiro na verificação e determinação da coordenação e relés direcionais de sobrecorrente, analisando apenas um par de relés principal/retaguarda definido pelo usuário e não o sistema elétrico inteiro. A ferramenta inclui um módulo de cálculo de corrente de curto-circuito em que as simulações de contingência utilizam o método de compensação, produzindo assim dados de entrada para a metodologia. O módulo de cálculo de 
curto-circuito foi validado simulando o sistema elétrico da Companhia Paranaense de Energia ( 767 barras e 1432 linhas) e comparando-se o resultado com o programa de curto-circuito utilizado pela empresa. A verificação de coordenação é feita através da análise de pares de relés principal/retaguarda. Para um determinado ponto da curva de proteção do relé da zona primária, verifica-se qual o tempo de atuação da proteção de retaguarda e assim determina-se se os critérios de coordenação foram atendidos. Para esta verificação é realizada uma interpolação logarítmica linear nas curvas dos relés envolvidos. Caso os relés não estejam coordenados, um novo ajuste para o relé de retaguarda deve ser feito. Para isso, a metodologia incrementa o valor da corrente de pick-up do relé de retaguarda até que a coordenação entre os relés seja garantida (observando-se toda a faixa de valores de corrente da curva característica de ambos relés). Após isso, o ajuste de tempo do relé é diminuído sistematicamente até que se chegue a um ponto limite no qual a coordenação ainda é garantida. Para o ajuste da unidade instantânea a metodologia segue o critério de que a unidade instantânea deve ser ajustada em um valor $25 \%$ acima da corrente de curtocircuito vista pelo relé. Esta porcentagem denominada fator de sobrealcance transitório e é utilizada para garantir que não ocorra atuação do relé para curtos-circuitos fora da zona de proteção, devido à assimetria da forma de onda que aparece durante o curto-circuito.

ZEINELDIN et al. (2004) insere um novo tipo de abordagem do problema de coordenação, tratando os ajustes de corrente de pick-up discretamente, que é a condição real de ajuste dos relés existentes. Nesse trabalho foi utilizado o programa General Algebraic Modeling System (GAMS), para modelar, utilizando equações algébricas, as restrições do problema de otimização. O tratamento do problema de forma discreta introduz um ganho de precisão, pois em geral, o que se faz em termo de otimização é utilizar variáveis contínuas para a obtenção de Ip e depois arredondar para o inteiro mais próximo. Esta prática pode levar a soluções inviáveis, podendo invalidar o ponto ótimo obtido. Para tratar o problema de maneira discreta, os autores inserem uma variável binária no problema de otimização, sendo que a corrente de pick-up será admitida como uma soma de cada ajuste de corrente de pick-up possível nos relés multiplicada pela variável binária, fazendo com que Ip se mantenha como um valor discreto. Esta abordagem faz com que os resultados obtidos sejam confiáveis, devendo ser levada em consideração em métodos eficazes de coordenação ótima de relés direcionais.

Em ZEINELDIN et al. (2005), trata-se do problema de coordenação ótima de relés direcionais de sobrecorrente, sendo que estes constituem a opção mais adequada para proteger sistemas de potência interconectados e sistemas de distribuição em malha. Para tal, expõe métodos para obtenção de TDS e Ip que minimizam o tempo de operação dos relés e mantêm a seletividade do sistema. Caso a corrente de pick-up seja considerada fixa, tem-se um problema de programação linear. Caso Ip seja variável e contínuo, o problema será não linear. Se Ip for variável e discreto, o problema será caracterizado como não linear inteiro misto. Para este último método, tem-se a vantagem de que a corrente não é fixada a um valor pré-determinado, podendo-se contornar o problema de ajuste discreto da corrente de pick-up. O problema de coordenação de relés é originalmente um problema não linear inteiro misto, já que Ip é um 
valor discreto, TDS pode ser considerado contínuo e algumas restrições são não lineares. Assim, algumas técnicas de resolução podem resultar em soluções ótimas locais ao invés de soluções ótimas globais. Para obter soluções ótimas globais, os autores reformulam o problema, adicionando restrições e variáveis que evitam a não linearidade do sistema, evitando assim soluções ótimas locais. Ao fim, os autores comparam a programação linear, não linear inteira mista e a inteira mista, chegando à conclusão que a última possui melhores resultados, pois não precisa do conhecimento prévio da corrente de pick-up, evita a não linearidade do problema e obtém soluções ótimas globais, eliminando o problema de soluções ótimas locais.

Em EZZEDDINE et al. (2011), os autores apresentam um novo método de selecionar os ajustes de relés direcionais de sobrecorrente, tratando o problema de forma discreta. $\mathrm{O}$ algoritmo seleciona a corrente de pick-up inicial de acordo com os valores calculados da máxima corrente de carga e mínima corrente de curto-circuito local. Então o atraso de tempo do relé é calculado para respeitar a restrição que tem o maior intervalo de coordenação de cada par de relé principal/retaguarda. Em um segundo passo, a corrente de pick-up é incrementada de acordo com a restrição de tempo encontrada anteriormente. Testando a equação da curva do relé no ponto de corrente encontrado, obtém-se o ajuste de tempo (TDS) correspondente. Em um próximo passo, TDS é diminuído para satisfazer o intervalo de coordenação mínimo. O algoritmo continua aumentando Ip e diminuindo TDS até que o tempo encontrado seja o menor ou até que a restrição da corrente de pick-up seja atingida (mínima corrente de falta no local). A seleção do atraso de tempo segue dois princípios. Primeiramente, o valor inicial deve satisfazer somente as restrições de cada relé de retaguarda selecionado. Em seguida, estes valores iniciais são selecionados e gradativamente aumentados a fim de se obter um valor final que satisfaça todas as restrições de coordenação. Os valores de corrente de falta para referência do tempo de atuação do relé são de curtoscircuitos sentidos sobre o relé. Então, para um relé de retaguarda, o valor de referência será a corrente vista sobre o relé de retaguarda para um curto-circuito aplicado na zona primária de proteção. O método se demonstrou bastante eficaz quando comparado a métodos lineares em relação ao tempo de atuação dos relés. Porém foram obtidas correntes de pick-up maiores do que em métodos lineares, reduzindo a sensibilidade dos relés. A conclusão final é de que o método melhora os requerimentos de seletividade e rapidez da proteção, porém não garante que os ajustes tomados sejam os melhores possíveis.

O trabalho de CORRÊA (2012) visa otimizar a coordenação de relés de sobrecorrente direcionais microprocessados em sistemas de potência com o auxílio da Programação Inteira Binária (PIB). Propõe dois novos modelos matemáticos de PIB, sendo que o primeiro determina somente o multiplicador de tempo de cada relé, enquanto que o segundo determina simultaneamente o multiplicador de tempo e o multiplicador de corrente de cada relé. O trabalho considera a coordenação dos relés de sobrecorrente com e sem suas unidades instantâneas, com características de tempo definido. O modelo matemático desenvolvido para o problema de otimização tem a mesma forma que em URDANETA et al. (1988).

As restrições utilizadas pelo autor no modelo de otimização são: 
- Restrições do tempo de coordenação: não consideram viável a verificação da coordenação pelo simples critério de intervalo de coordenação para correntes de falta, pois devem ser verificadas todas correntes de curto-circuito decorrentes de todas as faltas que podem ocorrer na linha. Utiliza as seguintes restrições de intervalo de coordenação:

$>$ O tempo para atuação do relé de retaguarda deve ser maior que o tempo para atuação do relé na zona primária de $\Delta \mathrm{t}$ (tempo de coordenação), considerando-se curtos-circuitos em $0 \%, 85 \%$ e $100 \%$ da linha protegida;

$>$ O tempo para atuação do relé de retaguarda deve ser maior que $\Delta \mathrm{t}$ (tempo de coordenação), considerando-se um curto-circuito em $0 \%$ da linha protegida.

- Restrição de tempo de operação: o tempo de operação de um relé deve respeitar um intervalo mínimo para atuação. Esta restrição contempla casos em que o relé de sobrecorrente é considerado proteção secundária, como na proteção de linhas de grande porte, em que a proteção de distância é considerada principal;

- Restrições de limites operativos de relés: ajustes mínimos, máximos e o passo da corrente de pick-up e TDS.

Na modelagem há uma restrição indicativa de que o modelo é discreto. O algoritmo proposto é feito com programação inteira binária, em que são utilizadas variáveis binárias, tornando possível que os ajustes sejam determinados na forma discreta diretamente. As conclusões tomadas indicam que a velocidade do sistema de proteção aumenta quando utilizadas as unidades instantâneas dos relés para faltas até $85 \%$ da linha, e acima disso o relé passa a atuar temporizadamente. Apesar do baixo esforço computacional obtido mesmo para sistemas de grande porte, os tempos de atuação encontrados foram maiores do que os obtidos em uma análise não linear.

Um grande desafio no tratamento do problema de coordenação de relés de sobrecorrente direcionais se deve aos testes sucessivos entre pares de relés, levando a uma explosão combinatorial. Assim, técnicas inteligentes visam à implementação de metaheurísticas para contornar essa dificuldade. Como exemplo, através de uma metaheurística nomeada Discrete Particle Swarm Optimization-DPSO, no trabalho de BERNARDES (2013) o autor desenvolve um mecanismo de busca que é inspirado no comportamento social de animais em busca de alimento. Originalmente o PSO é utilizado em tarefas de otimização irrestrita, assim, para a aplicação no problema coordenação de relés direcionais é necessária a aplicação de algoritmos restritivos e penalizações na função objetivo que impeçam que as partículas se direcionem para regiões não factíveis. A inserção da modelagem discreta através de funções senoidal ou quadrática contribui para que as variáveis do problema sejam tratadas adequadamente de acordo com o problema de otimização não linear inteira mista. Os resultados foram satisfatórios, porém é necessária uma grande quantidade de parametrizações do algoritmo para a resolução do problema. O tempo computacional é razoável (de 1 a 6 segundos por relé), porém aumenta exponencialmente de acordo com 
a complexidade do problema. Como conclusão, a metodologia se demonstrou robusta, sempre oferecendo uma solução factível otimizada.

Uma outra variação do PSO é apresentada no trabalho de SANTOS (2013), em que o autor utiliza um algoritmo de enxame de partículas evolutivo (EPSO). O PSO clássico apresenta uma alta dependência à definição dos parâmetros que o regem, necessitando de uma análise exaustiva de tentativa e erro até que se obtenha resultados satisfatórios. O algoritmo EPSO permite a evolução do conjunto de busca que atuará sobre os pesos e parâmetros que regem o comportamento de cada partícula, melhorando a resposta do algoritmo permitindo sua auto-parametrização. Para abranger a natureza discreta do problema, as variáveis são arredondadas ao inteiro mais próximo a cada iteração, garantindo resultados factíveis. O autor compara os resultados entre o PSO clássico, PSO modificado, EPSO clássico e o EPSO modificado, chegando à conclusão que o PSO tem dificuldades de encontrar soluções de boa qualidade em sistemas malhados, sendo que o EPSO demonstra resultados mais consistentes e satisfatórios.

A formulação clássica do PSO é empregada em MORO (2014) com o objetivo de encontrar os ajustes de relés direcionais de forma a garantir a coordenação entre eles e entre a proteção de distância. Para isso, utiliza como referência correntes nos relés principal e retaguarda para faltas close-in, near-end, e também faltas a $80 \%$ da linha, de acordo com a parametrização do alcance da primeira zona do relé de distância. São realizados estudos avaliando o emprego de diferentes tipos de padrão de curvas da função de sobrecorrente: IEC - Normal inversa, IEC - Muito Inversa e IEC Extremamente Inversa, além de avaliação do emprego simultâneo das curvas Normal Inversa e Muito Inversa, cabendo ao algoritmo decidir o emprego de uma ou outra. Como a inicialização dos valores é aleatória, a detecção do melhor resultado é obtida após várias execuções do algoritmo (50, segundo o autor), o que torna o estudo demorado, pois o tempo computacional de cada execução é relativamente alto (em torno de 30 minutos para um sistema de 22 relés), considerando que a implementação foi feita em MATLAB. Ainda assim os resultados obtidos foram factíveis e a metodologia se demonstrou bastante útil, principalmente porque considera as restrições da proteção de distância, fornecendo o tempo de ajuste da segunda zona do relé.

Ainda na linha de metodologias inteligentes, em BOTTURA (2014) há a proposição de um método de otimização híbrido baseado na combinação da programação linear (LP) e Algoritmo genético (AG), permitindo a realização de diversos estudos de curto-circuito necessários para a avaliação da coordenação da proteção tanto na configuração original quanto na alteração topológica do SEP. Verificou-se que há casos em que a configuração de ajustes obtida para o caso de todas as linhas do sistema operando não atende os requisitos de seletividade para alguns casos de saída de linhas. Nestes casos a solução apontada pelo autor é a reaplicação do algoritmo e a obtenção de um novo conjunto de ajustes. São utilizadas apenas faltas do tipo close-in para a realização do estudo de coordenação e as variáveis são tratadas como valores contínuos, havendo um arredondamento dos valores encontrados pelo algoritmo. O tempo computacional para a aplicação do algoritmo (executado via MATLAB) é de 82 
minutos para a solução otimizada de um sistema com 22 relés, havendo necessidade de melhorias nesse quesito.

Em geral, a utilização de metaheurísticas esbarra na dificuldade de ajustar os parâmetros, que deve ser feita para cada sistema em análise, além de fornecer resultados não intuitivos, de difícil interpretação, e que permite violações das restrições do problema, já que é realizado através de uma função de otimização.

Como visto, as metodologias existentes definem uma série de critérios para a realização da coordenação da proteção de sobrecorrente, realizando testes sucessivos nos pares de relés de proteção principal e retaguarda remota, de maneira a verificar a cada iteração se os critérios definidos foram satisfeitos, utilizando algum método de otimização para guiar o processo. A metodologia proposta neste trabalho difere no sentido de que, a partir de um levantamento de dados conciso, os critérios são resumidos na definição de uma área factível de ajustes do relé. Desse modo, não é necessária a etapa de testes entre os pares de proteção, sendo os ajustes realizados relé a relé, ganhando-se em simplicidade. Nos capítulos a seguir serão apresentados os critérios adotados e a metodologia de coordenação da proteção. 


\section{METODOLOGIA: COORDENAÇÃO DE RELÉS DIRECIONAIS PELO MÉTODO DO MENOR ERRO}

Normalmente na proteção de linhas de transmissão, a proteção principal é realizada pelo relé de distância (ANSI 21). Desse modo, a atuação do relé 21 deve ser considerada na metodologia de coordenação de relés direcionais, para condizer com a real situação do sistema. O relé de distância será considerado com ajustes fixos de acordo com critérios consolidados na literatura. A metodologia tem o objetivo de determinar os ajustes da unidade temporizada do relé direcional de modo que ela respeite as restrições impostas pelo sistema elétrico, pelos critérios de operação e pela atuação do relé de distância. A respeito da operação instantânea do relé 67, entende-se que ela seja uma unidade adicional, configurada com critérios específicos e que não interfere nos ajustes da unidade temporizada calculados pela metodologia, não sendo levada em consideração neste trabalho.

O processo de busca pelo melhor conjunto de ajustes deve testar a curva de atuação do relé direcional de modo que ela respeite algumas restrições. A seguir será exposta a determinação dos pares de proteção principal/retaguarda, e, em seguida, serão apresentados os critérios e restrições adotados para a metodologia proposta.

\subsection{DEFINIÇÃO DE PARES DE RELÉS DE PROTEÇÃo PRINCIPAL/RETAGUARDA}

O processo de coordenação leva em consideração a atuação do relé como proteção principal ou como proteção de retaguarda, portanto primeiramente devem-se definir estes arranjos topológicos.

Considerando proteções entre diferentes zonas de proteção, a proteção de retaguarda situa-se eletricamente a montante (antes) da proteção principal. Em um sistema radial é fácil identificar as proteções principal e secundária, porém em sistemas não-radiais o processo é um pouco mais complicado. Para uma rápida e simples identificação dos pares de proteção principal/retaguarda foi desenvolvido o seguinte raciocínio:

- Na Figura 4.1, seja o dispositivo de proteção R1, proteção principal da linha L1 e instalado no barramento B1. Os dispositivos de proteção de retaguarda de R1 são aqueles instalados nas barras opostas das linhas que partem de B1 e que protegem estas linhas, exceto o dispositivo referente à própria linha L1. Ou seja, no exemplo citado, somente o dispositivo R6 é retaguarda de R1, pois ele está instalado na barra terminal (B4) de uma linha que parte de B1 e não é a linha em que R1 está instalado;

- Na Figura 4.1, o dispositivo de proteção R1 é proteção de retaguarda de todos os dispositivos instalados na barra B2 que protegem as linhas que partem de B2, excetuando o dispositivo que protege a linha L1 (relé R3). Ou seja, R1 é retaguarda de R4, R5 e R12, 
pois estes estão instalados na barra oposta da linha em que R1 é proteção principal e nenhum deles é proteção principal desta mesma linha.

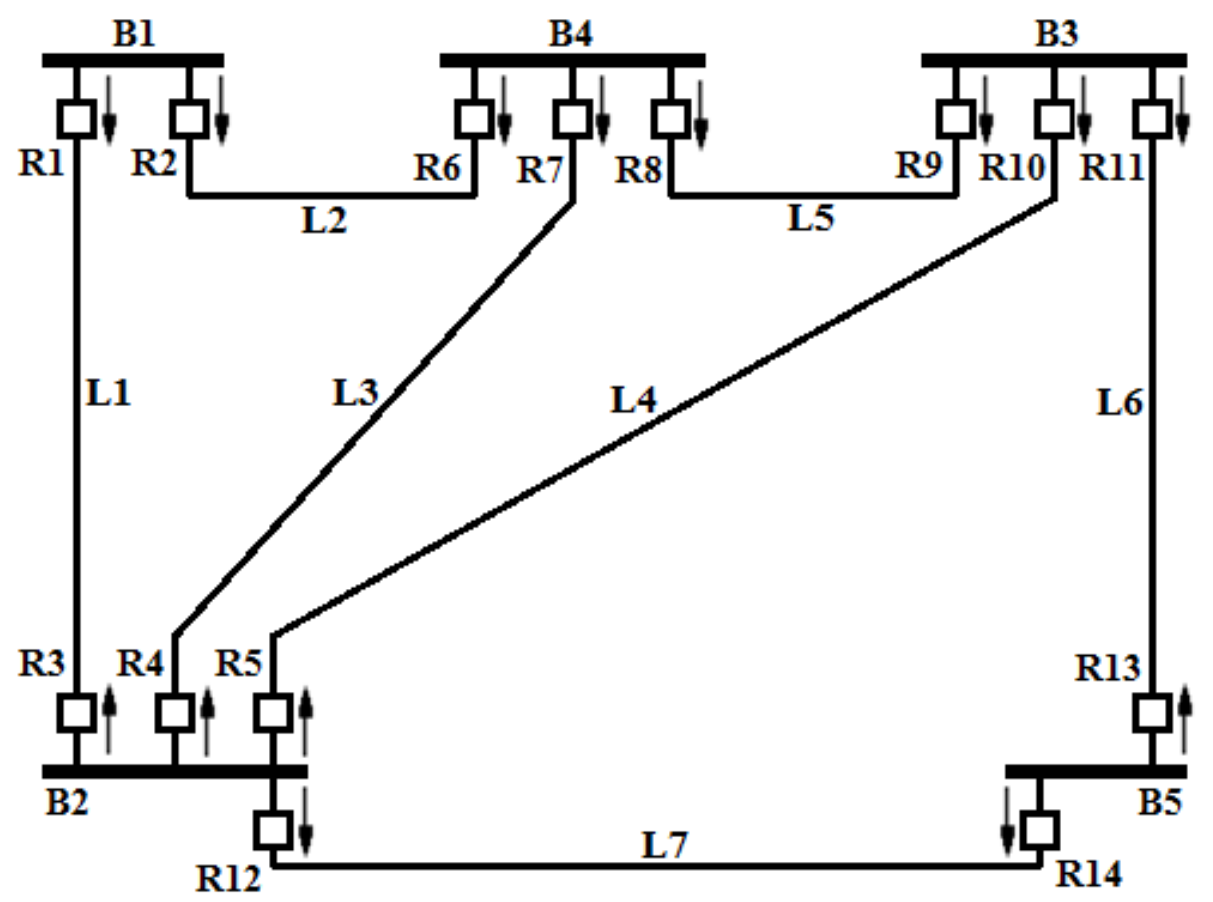

Figura 4.1 - Exemplo de sistema não-radial.

Seguindo esta mesma linha de raciocínio, todos os pares de proteção principal/retaguarda do sistema elétrico da Figura 4.1 são descritos na Tabela 4.1.

Tabela 4.1 - Pares de proteção principal/retaguarda do sistema da Figura 4.1.

\begin{tabular}{|c|c|c|c|c|c|c|c|c|c|c|c|c|c|c|}
\hline $\begin{array}{l}\text { Proteção } \\
\text { principal }\end{array}$ & $\mathrm{R} 1$ & R2 & R3 & R3 & R3 & R4 & R4 & R4 & R5 & R5 & R5 & R6 & R6 & R7 \\
\hline $\begin{array}{c}\text { Proteção de } \\
\text { retaguarda }\end{array}$ & R6 & R3 & R7 & R10 & R14 & R1 & R10 & R14 & R1 & R7 & R14 & R4 & R9 & R2 \\
\hline $\begin{array}{l}\text { Proteção } \\
\text { principal }\end{array}$ & R7 & R8 & R8 & R9 & R9 & R10 & R10 & R11 & R11 & R12 & R12 & R12 & & R14 \\
\hline $\begin{array}{l}\text { Proteção de } \\
\text { retaguarda }\end{array}$ & R9 & R2 & R4 & R5 & R13 & $\mathrm{R} 8$ & R13 & R8 & R5 & R1 & R7 & R10 & R12 & R11 \\
\hline
\end{tabular}

A proteção de retaguarda pode ser separada em retaguarda local e retaguarda remota. A proteção de retaguarda local está instalada juntamente com a proteção principal, podendo ser realizada por relés de tipos diferentes ou ainda uma duplicação da proteção principal. Já a proteção de retaguarda remota está instalada em outra zona de proteção, distante da proteção principal. Neste trabalho, o relé de sobrecorrente direcional instalado no mesmo local (e consequentemente protegendo a mesma linha) do relé de distância é considerado proteção de retaguarda local, enquanto o relé direcional instalado em outra zona de proteção é considerado proteção de retaguarda remota. Pela filosofia de proteção, a proteção de distância é considerada proteção principal e deve atuar antes da proteção de sobrecorrente. Desse modo, para que o sistema de proteção atue corretamente, retirando a menor porção do sistema possível, a sequência seletiva de atuação dos relés é a seguinte: 
1. Relé de distância instalado na zona em que ocorre a falta, funcionando como proteção principal;

2. Relé direcional de sobrecorrente cobrindo a região em que ocorre a falta, funcionando como proteção de retaguarda local;

3. Relé de distância instalado remotamente, verificando a falta em sua zona secundária e atuando como proteção de retaguarda;

4. Relé direcional de sobrecorrente instalado remotamente, atuando como proteção de retaguarda remota.

Para que sejam realizados ajustes corretos sobre os dispositivos de proteção e a sequência acima seja respeitada, alguns critérios devem ser seguidos. A seção a seguir define os critérios de coordenação empregados neste trabalho.

\subsection{CRITÉRIOS ADOTADOS PARA A COORDENAÇÃO AUTOMÁTICA}

Os critérios utilizados podem variar de acordo com a instalação, não interferindo na aplicabilidade do método. A Figura 4.2 a) mostra um sistema hipotético para entendimento das zonas de proteção, enquanto a Figura 4.2 b) resume as considerações a respeito do intervalo de coordenação.

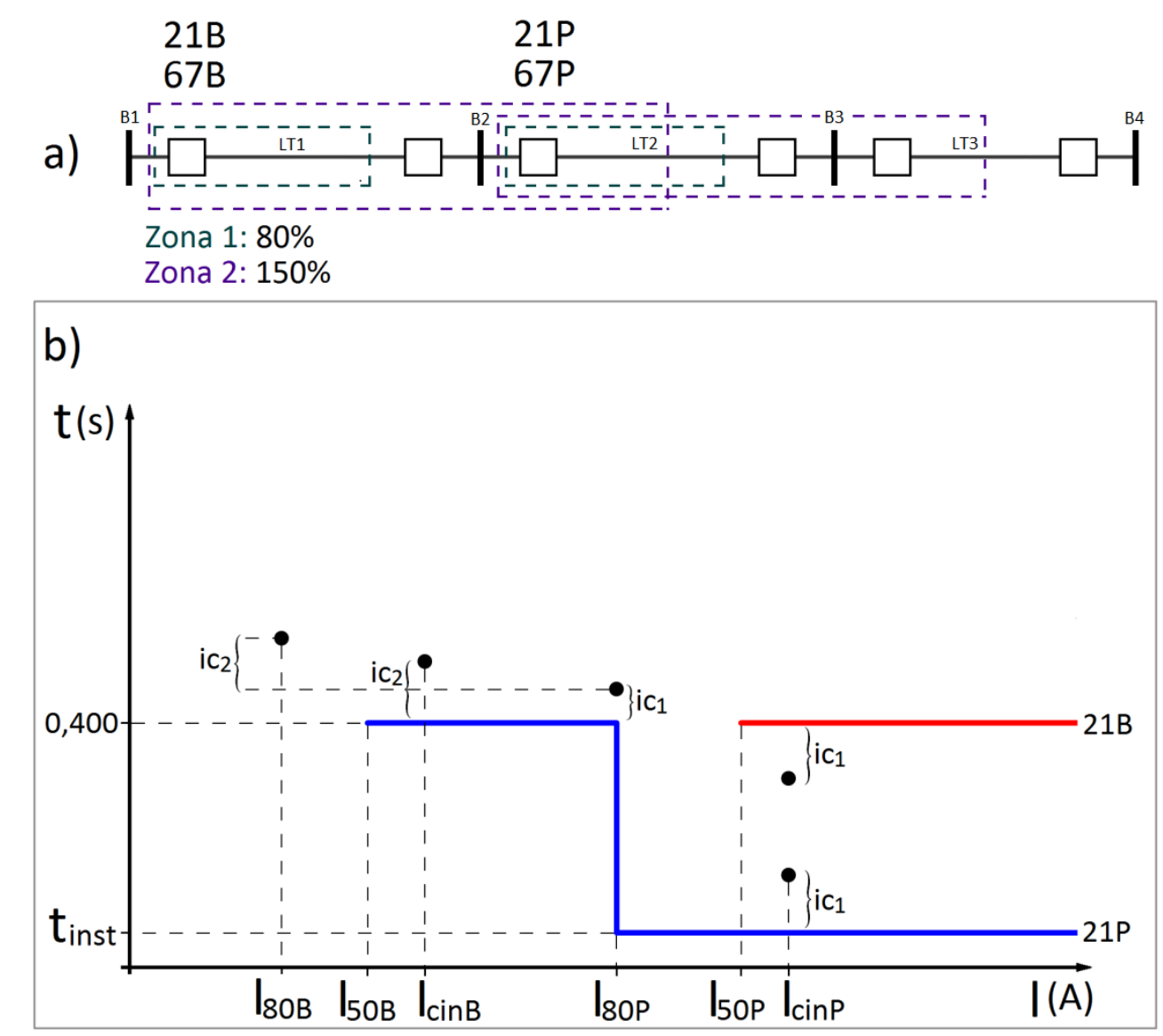

Figura 4.2 - Considerações sobre o intervalo de coordenação do relé direcional levando em consideração o relé de distância. a) zonas de proteção e locais de instalação dos relés. b) resumo dos critérios. 
A curva em azul na Figura 4.2 b) representa a atuação do relé de distância no local de análise, 21P, instalado na barra B2 sendo proteção principal da linha LT2. A curva em vermelho representa a atuação de um relé de distância 21B, instalado na barra B1 da linha LT1, de modo que 21B é retaguarda de $21 \mathrm{P}$. As correntes $\mathrm{I}_{\mathrm{cinP}}, \mathrm{I}_{50 \mathrm{P}}$ e $\mathrm{I}_{80 \mathrm{P}}$ representam, respectivamente, as correntes de curto-circuito trifásico para uma falta close-in, a $50 \%$ e a $80 \%$ da linha LT2 em que $21 \mathrm{P}$ é principal, enquanto $\mathrm{I}_{\text {cinB }}$, $\mathrm{I}_{50 \mathrm{~B}}$ е $\mathrm{I}_{80 \mathrm{~B}}$ representam, respectivamente, as correntes de curto-circuito trifásico para uma falta close-in, a $50 \%$ e a $80 \%$ da linha adjacente mais próxima, LT3, da qual 21P é proteção de retaguarda.

A primeira zona de atuação do relé de distância tem atuação instantânea e é geralmente ajustada para cobrir de $80 \%$ a $90 \%$ do comprimento da linha (ANDERSON, 1999), sendo que o valor padrão adotado neste trabalho foi de $80 \%$. O tempo de atuação instantânea do relé 21 é composto pelo tempo de operação do relé (entre 15 e 80 ms) (ZIEGLER, 2008) e o tempo de abertura do disjuntor (entre 33 e 67 ms) (ABB, 2009; SIEMENS, 2012). Desse modo, como pode ser visto na Figura 4.2, a atuação do relé 21 para primeira zona se dá para correntes acima de $\mathrm{I}_{80 \mathrm{P}} \mathrm{e}$ em um tempo $\mathrm{t}_{\text {inst }}$ entre 48 e $147 \mathrm{~ms}$, sendo o valor adotado neste trabalho de $100 \mathrm{~ms}$.

A segunda zona de atuação do relé de distância é temporizada, devendo respeitar a atuação instantânea da proteção da zona 1 e um intervalo de coordenação que tem valores entre 30 e $200 \mathrm{~ms}$ dependendo do tipo de relé utilizado (ZIEGLER, 2008), além de um fator de segurança. Usualmente utiliza-se um tempo de atuação para a segunda zona de $400 \mathrm{~ms}$ (KLOCK JR., 2002). Esta zona cobre a partir de $80 \%$ da linha em que o relé está instalado $\left(\mathrm{I}_{80 \mathrm{P}}\right)$ até $50 \%$ da linha adjacente mais próxima $\left(\mathrm{I}_{50 \mathrm{~B}}\right)$. $\mathrm{Na}$ Figura 4.2 pode-se verificar a atuação de segunda zona do relé $21 \mathrm{P}$ para correntes de $\mathrm{I}_{50 \mathrm{~B}}$ até $\mathrm{I}_{80 \mathrm{P}}$, em um tempo de $400 \mathrm{~ms}$, assim como a atuação de segunda zona do relé $21 \mathrm{~B}$, retaguarda de $21 \mathrm{P}$, cobrindo correntes acima de $\mathrm{I}_{50 \mathrm{P}}$.

O relé direcional de sobrecorrente, atuando como retaguarda local, deve respeitar a atuação instantânea do relé $21 \mathrm{P}$ para faltas em até $80 \%$ da linha. Assim, para a corrente de falta close-in $\left(\mathrm{I}_{\operatorname{cinP}}\right)$, a atuação do relé 67P deve possuir um intervalo de coordenação para com a atuação instantânea do relé 21P. O intervalo de coordenação considerado deve ser entre 100 a 200 ms (MANSOUR, 2007), sendo que o valor admitido para este caso foi de $100 \mathrm{~ms}$. Além disso, ainda para a corrente de falta close-in, deve-se levar em consideração a atuação do relé de distância de retaguarda (21B na Figura 4.2). Este relé tem tempo de atuação de $400 \mathrm{~ms}$ para $\mathrm{I}_{\operatorname{cinP}}$ e deve estar coordenado com a proteção direcional retaguarda local. Logo, a atuação do relé 67P deve estar limitada superiormente por um intervalo de coordenação com o relé $21 \mathrm{~B}$, considerado de $100 \mathrm{~ms}$. Para uma falta a $80 \%$ da linha $\left(\mathrm{I}_{80 \mathrm{P}}\right)$, a atuação do relé $67 \mathrm{P}$ deve respeitar a atuação temporizada do relé de distância (400 ms), além de um intervalo de coordenação, considerado como $100 \mathrm{~ms}$, pois esta é a região de transição da atuação instantânea para a temporizada do relé 21 . 
Atuando como retaguarda remota, para uma falta close-in na barra adjacente mais próxima $\left(\mathrm{I}_{\mathrm{cinB}}\right)$ o relé 67B deve respeitar a atuação de segunda zona do relé 21 (segunda zona do relé 21P na Figura 4.2), além de um intervalo de coordenação, admitido como 200 ms (MANSOUR, 2007). Para uma falta a 80\% da linha adjacente mais próxima $\left(\mathrm{I}_{80 \mathrm{~B}}\right)$, o relé $67 \mathrm{~B}$ de retaguarda remota deve respeitar a atuação do relé 67P de retaguarda local, além de um intervalo de coordenação, considerado de 200 ms.

De acordo com o exposto, a proteção de sobrecorrente direcional deve respeitar um intervalo de coordenação para com a atuação do relé de distância e também, atuando como retaguarda remota, deve respeitar um intervalo de coordenação para com o relé 67 de retaguarda local. Na Figura 4.2 estes intervalos são representados por $\mathrm{ic}_{1}$ e ic $\mathrm{ic}_{2}$, sendo considerados $\mathrm{ic}_{1}=100 \mathrm{~ms}$ e ic $\mathrm{c}_{2}=200 \mathrm{~ms}$, conforme justificado anteriormente. As faltas adotadas como referência são de curto-circuito trifásico franco para casos em que o relé é utilizado para proteção fase-fase.

Em um sistema equilibrado, as componentes de sequência zero só estão presentes em condições de faltas envolvendo a terra. Desse modo, considerações para coordenação da proteção de neutro (67N) são as mesmas para a de fase, com a diferença que a proteção de neutro utilizará como referência a corrente de curto-circuito fase-terra franco, sendo esta três vezes o valor das correntes de sequência zero, além disso, a corrente de pick-up pode ser ajustada para ser mais sensível do que nos relés de fase (PHADKE; THORP, 1990).

Foi considerado que o ajuste da corrente de pick-up deve se situar entre uma faixa, de acordo com os requisitos apresentados a seguir:

- O valor mínimo para o ajuste da corrente de pick-up para proteção fase-fase ( $\left.\mathrm{I}_{P_{-} f f \_m i n}\right)$ deve ser a corrente que limita o carregamento da linha multiplicada por um fator de segurança definido pela experiência do usuário. Neste trabalho o valor admitido foi de $120 \%$;

- O valor máximo para o ajuste da corrente de pick-up para a proteção fase-fase ( $\left.\mathrm{I}_{\mathrm{P}_{-} \mathrm{ff} \_ \text {max }}\right)$, é dado por uma porcentagem da corrente de curto-circuito trifásica na barra remota, produzindo uma ampla faixa de busca além de respeitar o critério de sensibilidade da proteção de modo que se garante que correntes acima de $\mathrm{I}_{\mathrm{P}_{f} \mathrm{ff} \text { max }}$ representem condições de falta. O valor adotado como padrão para o coeficiente de segurança foi de $80 \%$;

- O valor para o ajuste da corrente de pick-up para proteção de neutro deve ser uma porcentagem da corrente nominal do TC. Valores usuais são entre 10 e $30 \%$, sendo referente ao erro nominal da maioria dos TCs. A faixa admissível para o valor de pick-up da proteção de neutro varia de acordo com os critérios da instalação, sendo que para este

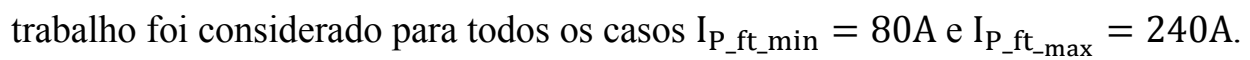


A faixa de ajuste definida considera apenas os dados do sistema, não sendo incluídas as restrições do próprio relé, que se admite serem adequadas para a instalação e contemplar em sua faixa de ajustes a faixa entre $I_{P_{-} f f \_m i n}$ e $I_{P_{-} f f \_m a x}$ para a proteção de fase e entre $I_{P_{-} f t \_m i n}$ e $I_{P_{-} f t \_m a x}$ para a proteção de neutro.

Vale a pena lembrar que os critérios apresentados foram apenas tomados como valores padrão, porém estes são dados de entrada, podendo ser alterados de acordo com as características da instalação, não afetando a funcionalidade da metodologia.

Para a proteção de linhas podem ser utilizados dois arranjos diferentes para tratar todos os tipos de faltas (PHADKE; THORP, 1990):

- Relé de distância para tratar faltas entre fases e relé de distância para tratar faltas entre fases e terra;

- Relé de distância para tratar faltas entre fases e relé direcional de sobrecorrente de neutro para tratar faltas entre fases e terra.

No caso do primeiro arranjo, os critérios tempos de atuação definidos até então valem tanto para a proteção de fase quanto para a de neutro. Já para o segundo arranjo, os critérios devem ser mantidos apenas para a proteção de fase, pois, como não há relé de distância para a proteção de neutro a coordenação será feita somente entre os relés direcionais e os tempos de referência mudarão. Com o intuito de seguir uma mesma tendência de ajuste para o segundo arranjo, os tempos de referência adotados para a proteção de neutro do relé $67 \mathrm{~N}$, conforme as correntes já citadas na Figura 4.2, são:

- Corrente de falta close-in $\left(\mathrm{I}_{\mathrm{cinP}}\right)$ : quando há relé de distância para faltas entre fases e terra, o relé direcional de sobrecorrente deve respeitar um intervalo de coordenação de 100 a 200 ms (valor considerado como padrão de $100 \mathrm{~ms}$ ) para com a atuação instantânea do relé 21, além de um limite superior de $300 \mathrm{~ms}$, respeitando um intervalo de coordenação de $100 \mathrm{~ms}$ para com a atuação da unidade temporizado do relé $21 \mathrm{de}$ retaguarda, conforme a Figura 4.2 e o exposto para a proteção de fase. Não havendo proteção de distância de neutro (segundo arranjo mencionado), o tempo de referência para $\mathrm{I}_{\text {cinP }}$ será dado de entrada da metodologia, sendo considerado como valor padrão $200 \mathrm{~ms}$, sem limite superior;

- Corrente de falta a $80 \%$ da linha $\left(\mathrm{I}_{80 \mathrm{P}}\right)$ : quando há relé de distância para faltas entre fases e terra, o relé direcional de sobrecorrente deve respeitar um intervalo de coordenação de 100 a $200 \mathrm{~ms}$ (valor considerado como padrão de $100 \mathrm{~ms}$ ) para com a atuação temporizada (considerada com tempo fixo em $400 \mathrm{~ms}$ ) do relé 21, conforme a Figura 4.2 e o exposto para a proteção de fase. Não havendo proteção de distância de neutro, o 
tempo de referência para $\mathrm{I}_{80 \mathrm{P}}$ será dado de entrada da metodologia, sendo considerado como valor padrão $300 \mathrm{~ms}$;

- Entra a atuação dos relés direcionais de sobrecorrente de neutro deve haver um intervalo de coordenação mínimo entre 100 e 200 ms, sendo considerado o valor padrão de 200 ms.

A metodologia desenvolvida contempla ambos os casos para a proteção de neutro, devendo o usuário selecionar se há ou não relé de distância tratando faltas entre fase e terra e quais os tempos de referência.

\subsection{PROCESSO DE COORDENAÇÃO ATRAVÉS DO MELHOR AJUSTE LOCAL}

Em sistemas não radiais, um mesmo relé pode atuar como proteção principal (ou retaguarda local, considerando o relé 21 como principal) de uma determinada área e como proteção de retaguarda remota de outra área. Métodos de coordenação convencionais utilizam informações e critérios para a operação do relé como proteção principal (ou retaguarda local, considerando o relé 21 como principal) e depois testam um a um os pares de relés principal/retaguarda (ou retaguarda local/retaguarda remota) verificando a correta coordenação e aplicando algum tipo de ferramenta de otimização para obter o melhor ajuste do relé. Porém pode-se facilmente obter informações de um relé atuando como retaguarda remota e incluir estes dados como restrição no método de otimização juntamente com os critérios de sua atuação como proteção principal (ou retaguarda local, considerando o relé 21 como principal). Assim elimina-se a etapa de testes sucessivos entre pares de relés retaguarda local/retaguarda remota (ou principal/retaguarda), simplificando o processo e aumentando a eficiência do método.

Tomando como base os critérios de coordenação descritos na seção 4.2, podem-se definir quatro pontos de referência para os ajustes dos relés de sobrecorrente:

\section{Ponto de Referência P1 $\left(\mathrm{I}_{\mathrm{cinP}}, \mathrm{t}_{\mathrm{cin} \mathrm{P}}\right)$ : Atuação do relé $67 / 67 \mathrm{~N}$ como proteção de retaguarda local para um curto-circuito close-in}

- Para a proteção de fase: assim como ilustrado na Figura 4.3, P1 diz respeito à atuação de um relé para uma falta close-in. Neste caso, para uma corrente de curto-circuito franco trifásico na linha do relé em análise, o tempo de atuação do relé direcional deve ser superior, porém o mais próximo possível, ao tempo de $200 \mathrm{~ms}$, que é o tempo de atuação da unidade instantânea do relé de distância, que foi considerado $100 \mathrm{~ms}$, adicionado de um intervalo de coordenação de $100 \mathrm{~ms}$. Além disso, a atuação do relé 67 para a corrente de falta trifásica franca close-in não pode chegar a $300 \mathrm{~ms}$ (limite superior de atuação de $300 \mathrm{~ms}$ ), que é o tempo de atuação da segunda zona do relé de distância (relé 21 de retaguarda, 21B na Figura 4.2) subtraído de um intervalo de coordenação de 100 ms. Logo, para a falta close-in, o relé 67 deve ter um tempo de atuação entre 200 e 300 ms; 
- Para a proteção de neutro: caso haja proteção de distância de neutro, utiliza-se o mesmo critério da proteção de fase, porém a corrente de referência é de uma falta fase-terra franca, ou seja, tempo de atuação entre 200 e $300 \mathrm{~ms}$ para uma corrente de falta monofásica-terra close-in. Caso não haja proteção 21 de neutro, o tempo de atuação deverá ser superior, porém o mais próximo, de 200 ms, sem limite superior.

Define-se $\mathrm{I}_{3 \mathrm{f} \text { cinP }}$ como sendo a corrente medida pelo relé em análise para um curto-circuito trifásico close-in na linha em que o relé 67 em análise é proteção de retaguarda local. Para uma falta monofásica-terra close-in, define-se $\mathrm{I}_{3 \mathrm{io} \_ \text {cinP }}$ como sendo a corrente medida pelo relé. Definem-se $\mathrm{t}_{3 \mathrm{f}_{-} \text {cinP }}$ e $t_{3 i o \_c i n P}$ como sendo:

$$
\mathrm{t}_{3 \mathrm{f}_{-} \mathrm{cinP}}=200 \mathrm{~ms} \quad \mathrm{t}_{3 \mathrm{io}_{-} \mathrm{cinP}}=200 \mathrm{~ms}
$$

Desse modo forma-se o ponto $\left(\mathrm{I}_{3 \mathrm{f}_{-} \text {cinP }}, \mathrm{t}_{3 \mathrm{f}_{-} \text {cinP }}\right)$ de referência para a proteção de fase e o ponto $\left(I_{3 i o \_c i n P}, t_{3 i o \_c i n P}\right)$ de referência para a proteção de neutro. Definem-se também $t_{3 f_{-} c i n P_{-} s}$ e $t_{3 i i_{-} c i n P_{-} s}$ como sendo os limites superiores para a atuação da proteção direcional de sobrecorrente para as correntes $I_{3 f_{-} \text {cinP }}$ e $I_{3 f_{-} \text {cinP }}$, respectivamente. Os valores padrões utilizados de $t_{3 f_{-} \text {cinP_s }}$ e $t_{3 i_{-} \text {cinP_s }}$ são:

$$
\mathrm{t}_{3 \mathrm{f}_{-} \text {cinP_s }}=300 \mathrm{~ms} \quad \mathrm{t}_{3 \mathrm{io} \_ \text {cinP_s }}=300 \mathrm{~ms}
$$

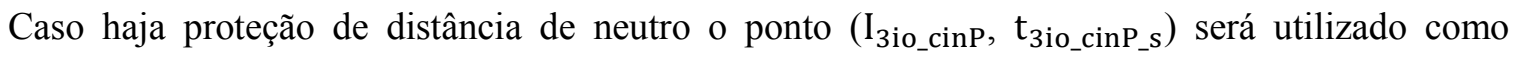
restrição de limite superior. Caso contrário, não haverá restrição de limite superior para o ajuste do relé $67 \mathrm{~N}$. A Figura 4.3 reproduz as condições de faltas para o primeiro ponto de referência de fase $\left(\mathrm{I}_{3 \mathrm{f}_{-} \text {cinP }}\right.$, $\left.t_{3 f \_c i n P}\right)$ e de neutro $\left(I_{3 i i_{-} \text {cinP }}, t_{3 i_{0} \text { cinP }}\right)$.

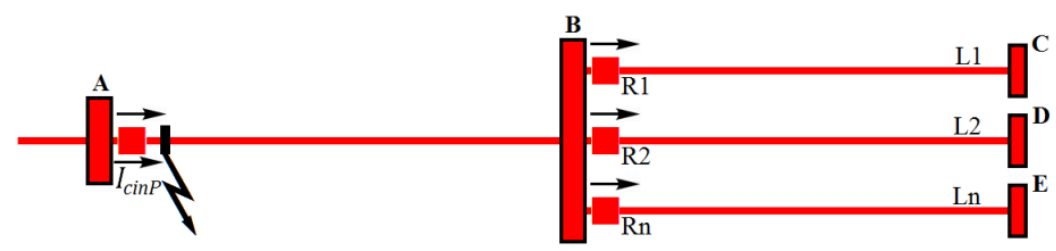

Figura 4.3 - Situação em que o primeiro ponto de referência é obtido.

\section{Ponto de referência P2 ( $\left.\mathrm{I}_{80 \mathrm{P}}, \mathrm{t}_{80 \mathrm{P}}\right)$ : Atuação do relé $67 / 67 \mathrm{~N}$ como proteção de retaguarda local para um curto-circuito a $80 \%$ da linha em análise}

- Para a proteção de fase: de acordo com a Figura 4.4, P2 diz respeito à atuação de um relé para uma falta a $80 \%$ da linha. Assim, para uma corrente de curto-circuito franco trifásico a $80 \%$ da linha a qual o relé 67 em análise é proteção de retaguarda local, o tempo de atuação do relé direcional deve ser superior, porém o mais próximo possível, ao tempo de $500 \mathrm{~ms}$, que é o tempo de atuação do relé de distância (proteção principal, 21P na Figura 
4.2) para a segunda zona (400 ms) adicionado de um intervalo de coordenação de 100 ms;

- Para a proteção de neutro: caso haja proteção de distância de neutro, utiliza-se o mesmo critério da proteção de fase, porém a corrente de referência é de uma falta fase-terra franca, ou seja, tempo de atuação acima de $500 \mathrm{~ms}$ para uma corrente de falta monofásica-terra a $80 \%$ da linha em análise. Caso não haja proteção 21 de neutro, o tempo de atuação deverá ser superior, porém o mais próximo, de $300 \mathrm{~ms}$.

Define-se $\mathrm{I}_{3 \mathrm{f} \_80 \mathrm{P}}$ como sendo a corrente medida pelo relé 67 em análise para um curto-circuito trifásico a $80 \%$ da linha em que o relé em análise é proteção de retaguarda local. Para uma falta monofásica-terra a $80 \%$ da linha, define-se $\mathrm{I}_{3 \mathrm{io} \_80 \mathrm{P}}$ como sendo a corrente medida pelo relé $67 \mathrm{~N}$. Definese $t_{3 f \_80 P}$ como sendo:

$$
\mathrm{t}_{3 \mathrm{f}_{-} 80 \mathrm{P}}=500 \mathrm{~ms}
$$

Caso haja proteção de distância de neutro, define-se $t_{3 i o \_80 P}=500 \mathrm{~ms}$. Caso contrário, o valor de referência tomado como padrão será $\mathrm{t}_{3 \text { io_80P }_{3}}=300 \mathrm{~ms}$.

Desse modo forma-se o ponto $\left(\mathrm{I}_{3 \mathrm{f}_{-} 80 \mathrm{P}}, \mathrm{t}_{3 \mathrm{f}_{-} 80 \mathrm{P}}\right)$ de referência para a proteção de fase e o ponto $\left(\mathrm{I}_{3 \mathrm{iio} \_80 \mathrm{P}}, \mathrm{t}_{3 \mathrm{iio} \_80 \mathrm{P}}\right)$ de referência para a proteção de neutro. A Figura 4.4 reproduz as condições de falta para o segundo ponto de referência de fase $\left(\mathrm{I}_{3 \mathrm{f}_{-} 80 \mathrm{P}}, \mathrm{t}_{3 \mathrm{f}_{-} 80 \mathrm{P}}\right)$ e de neutro $\left(\mathrm{I}_{3 \mathrm{io} \_80 \mathrm{P}}, \mathrm{t}_{3 \mathrm{io} \_80 \mathrm{P}}\right)$.

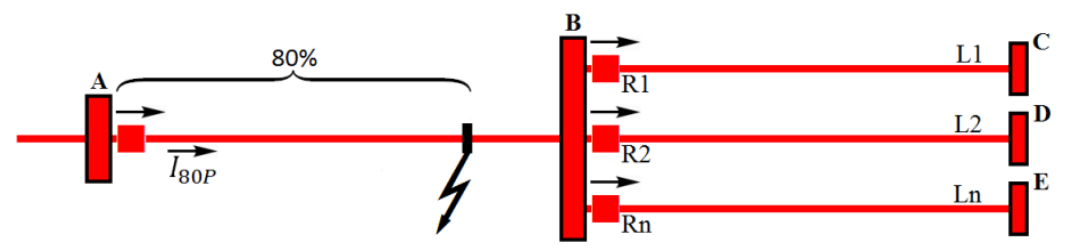

Figura 4.4 - Situação em que o segundo ponto de referência é obtido.

Ponto de referência P3 $\left(\mathrm{I}_{\mathrm{cinB}}\right.$, $\left.\mathrm{t}_{\mathrm{cinB}}\right)$ : Atuação do relé $67 / 67 \mathrm{~N}$ como proteção de retaguarda remota para um curto-circuito close-in na linha em que o relé principal está instalado

- Para a proteção de fase: tomando como R1, R2,..., Rn, os dispositivos que são proteção principal das linhas L1, L2,... Ln, respectivamente nessa ordem, tal como mostra a Figura 4.5. Seja $\mathrm{Rb}$ um dispositivo que é ao mesmo tempo proteção de retaguarda remota de todos os dispositivos $\mathrm{R} 1, \mathrm{R} 2, \ldots, \mathrm{Rn}$, sendo $n$ a quantidade de relés os quais $\mathrm{Rb}$ é retaguarda remota. Para uma corrente de falta franca trifásica close-in em L1 com relação a R1, a corrente de falta que irá sensibilizar o relé Rb é $I c c_{3 f_{-} c i n \_B 1}$. Para uma corrente de falta franca trifásica close-in em L2 com relação a R2, a corrente de falta que irá 
sensibilizar o relé $\mathrm{Rb}$ é $I c c_{3 f_{-} c i n_{-} B 2}$. Seguindo este raciocínio, as correntes medidas por $\mathrm{Rb}$ atuando como proteção de retaguarda remota serão $I c c_{3 f_{-} c i n_{-} B 1}, I c c_{3 f_{-} c i n_{-} B 2}, \ldots$, $I C c_{3 f_{-} c i n \_B n}$. Para todas estas correntes, $\mathrm{Rb}$ deve atuar em um tempo maior, porém o mais próximo possível, que $600 \mathrm{~ms}$, que é o tempo de atuação de segunda zona do relé de distância (segunda zona do relé de distância local, por exemplo o relé 21P na Figura 4.2) para uma falta close-in na linha adjacente $(400 \mathrm{~ms})$ adicionado de um intervalo de coordenação, que foi adotado como 200 ms. Portanto o ajuste de $\mathrm{Rb}$ deve respeitar a maior das correntes $I c c_{3 f_{-} c i n_{-} B 1}, I c c_{3 f_{-} c i n_{-} B 2}, \ldots, I c c_{3 f_{-} c i n \_B n}$ em um tempo de atuação de $600 \mathrm{~ms}$;

- Para a proteção de neutro: caso haja proteção de distância de neutro, utiliza-se o mesmo critério da proteção de fase, porém a corrente de referência é de uma falta fase-terra franca. Ou seja, para uma corrente de falta franca monofásica-terra close-in em uma linha Ln com relação a $\mathrm{Rn}$, a corrente de falta que irá sensibilizar o relé Rb é $I c c_{3 i o_{-} c i n \_B n}$. Assim, o ajuste de $\mathrm{Rb}$ deve respeitar a maior das correntes

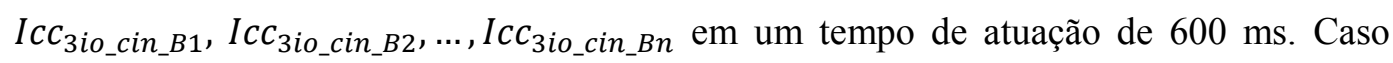
não haja proteção 21 de neutro, o tempo de atuação deverá ser superior, porém o mais próximo, de $400 \mathrm{~ms}$, que é o tempo de referência de atuação da proteção direcional

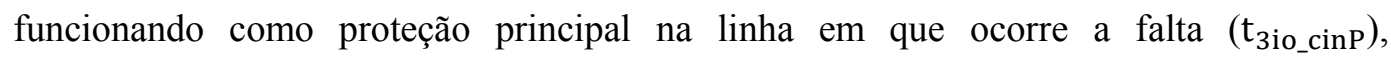
adicionado de um intervalo de $200 \mathrm{~ms}$.

Definem-se $\mathrm{I}_{3 \mathrm{f}_{-} \text {cinB }}, \mathrm{t}_{3 \mathrm{f}_{-} \text {cinB }}$ e $\mathrm{I}_{3 \mathrm{io}_{-} \text {cinB }}$ como sendo:

$$
\begin{aligned}
& \mathrm{I}_{3 \mathrm{f}_{-} \mathrm{cinB}}=\max \left\{I c c_{3 f_{-} c i n_{-} B 1}, I C C_{3 f_{-} c i n_{-} B 2}, \ldots, I C C_{3 f_{-} c i n_{-} B n}\right\} \\
& \mathrm{t}_{3 \mathrm{f}_{-} \text {cinB }}=600 \mathrm{~ms}
\end{aligned}
$$

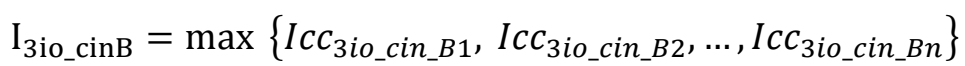

Caso haja proteção de distância de neutro, define-se $t_{3 i i_{c} \text { cinB }}=500 \mathrm{~ms}$. Caso contrário, o valor de referência tomado como padrão será $\mathrm{t}_{3 \text { io_cinB }_{1}}=400 \mathrm{~ms}$.

Desse modo forma-se o ponto $\left(\mathrm{I}_{3 \mathrm{f}_{-} \text {cinB }}, \mathrm{t}_{3 \mathrm{f}_{-} \text {cinB }}\right)$ de referência para a proteção de fase e o ponto $\left(I_{3 i o \_c i n B}, t_{3 i o \_c i n B}\right)$ de referência para a proteção de neutro. A Figura 4.5 reproduz as condições de falta para o segundo ponto de referência de fase $\left(\mathrm{I}_{3 \mathrm{f}_{-} \text {cinB }}, \mathrm{t}_{3 \mathrm{f}_{-} \text {cinB }}\right)$ e de neutro $\left(\mathrm{I}_{3 \text { io_cinB }}, \mathrm{t}_{3 \text { 3io_cinB }}\right)$, sendo mostrado como a corrente $I c c_{\text {cin_Bn }}$ (em faltas trifásicas ou monofásicas-terra) é obtida. 


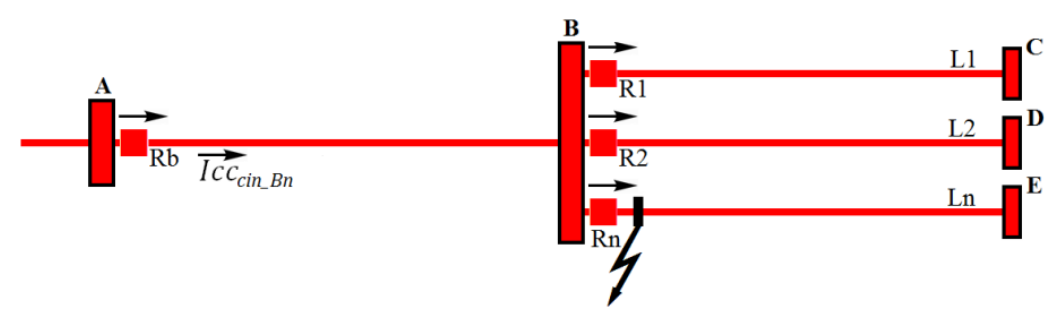

Figura 4.5 - Situação em que o terceiro ponto de referência é obtido.

\section{Ponto de referência $\mathrm{P4}\left(\mathrm{I}_{80 \mathrm{~B}}, \mathrm{t}_{80 \mathrm{~B}}\right)$ : Atuação do relé $67 / 67 \mathrm{~N}$ como proteção de retaguarda remota para um curto-circuito a 80\% da linha em que o relé principal está instalado}

- Para a proteção de fase: tomando como R1, R2,..., Rn, os dispositivos que são proteção principal das linhas L1, L2,.., Ln, respectivamente nessa ordem. Seja Rb um dispositivo que é ao mesmo tempo proteção de retaguarda remota de todos os dispositivos R1, R2,..., Rn, tal como mostra a Figura 4.6. Para uma corrente de falta franca trifásica a $80 \%$ de L1 com relação a R1, a corrente de falta que irá sensibilizar o relé Rb é $I c c_{3 f_{-} 80 \_B 1}$. Para uma corrente de falta franca trifásica a $80 \%$ de L2 com relação a R2, a corrente de falta que irá sensibilizar o relé $\mathrm{Rb}$ é $I c c_{3 f_{-} 80 \_B 2}$. Seguindo este raciocínio, as correntes medidas por $\mathrm{Rb}$ atuando como proteção de retaguarda remota serão $I C C_{3 f_{-} 80 \_B 1}, I c c_{3 f_{\_} 80 \_B 2}, \ldots, I c C_{3 f_{-} 80_{-} B n}$. Para todas estas correntes, $\mathrm{Rb}$ deve atuar em um tempo superior, porém o mais próximo possível, de $700 \mathrm{~ms}$, que é o tempo de atuação do relé direcional como proteção de retaguarda local em uma falta a $80 \%$ da linha em que a proteção principal está instalada (500 ms, como pode ser verificado no ponto P2) adicionado do intervalo de coordenação, que foi adotado como $200 \mathrm{~ms}$. Portanto, o ajuste de $\mathrm{Rb}$ deve respeitar a maior das correntes $I C c_{3 f_{-} 80_{-} B 1}, I c c_{3 f_{-} 80_{-} B 2}, \ldots, I c c_{3 f_{-} 80_{-} B n} \mathrm{em}$ um tempo de atuação de $700 \mathrm{~ms}$;

- Para a proteção de neutro: caso haja proteção de distância de neutro, utiliza-se o mesmo critério da proteção de fase, porém a corrente de referência é de uma falta fase-terra franca. Ou seja, para uma corrente de falta franca monofásica-terra a $80 \%$ de em uma linha Ln com relação a Rn, a corrente de falta que irá sensibilizar o relé Rb é $I c C_{3 i o_{-} 80_{-} B n}$. Assim, o ajuste de $\mathrm{Rb}$ deve respeitar a maior das correntes $I C C_{3 i o_{-} 80 \_B 1}, I C C_{3 i o_{-} 80 \_B 2}, \ldots, I C c_{3 i o \_80 \_B n}$ em um tempo de atuação de $700 \mathrm{~ms}$. Caso não haja proteção 21 de neutro, o tempo de atuação deverá ser superior, porém o mais próximo, de $500 \mathrm{~ms}$, que é o tempo de referência de atuação da proteção direcional funcionando como proteção principal na linha em que ocorre a falta $\left(\mathrm{t}_{3 \mathrm{iio} \_80 \mathrm{P}}\right)$, adicionado de um intervalo de $200 \mathrm{~ms}$.

Definem-se $I_{3 f_{-} 80 B}, t_{3 f_{-} 80 B}$ e $I_{3 i \text { io } 80 B}$ como sendo: 


$$
\begin{aligned}
& \mathrm{I}_{3 \mathrm{f}_{-} 80 \mathrm{~B}}=\max \left\{I C C_{3 f_{\_} 80_{-} B 1}, I C C_{3 f_{-} 80_{-} B 2}, \ldots, I C C_{3 f_{-} 80_{-} B n}\right\} \\
& \mathrm{t}_{3 \mathrm{f}_{-} 80 \mathrm{~B}}=700 \mathrm{~ms} \\
& \mathrm{I}_{3 \mathrm{io} \_80 \mathrm{~B}}=\max \left\{I C C_{3 i 0_{-} 80 \_B 1}, I C C_{3 i o \_80 \_B 2}, \ldots, I C C_{3 i o \_80 \_B n}\right\}
\end{aligned}
$$

Caso haja proteção de distância de neutro, define-se $t_{3 i{ }_{2} 80 B}=700 \mathrm{~ms}$. Caso contrário, o valor de referência tomado como padrão será $\mathrm{t}_{3 \mathrm{io}_{-} 80 \mathrm{~B}}=500 \mathrm{~ms}$. Desse modo forma-se o ponto $\left(\mathrm{I}_{3 \mathrm{f} \_80 \mathrm{~B}}\right.$,

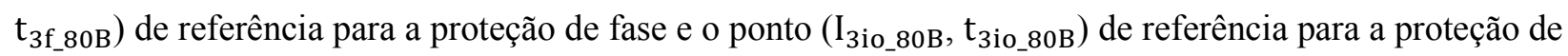
neutro. A Figura 4.6 reproduz as condições de falta para o segundo ponto de referência de fase $\left(\mathrm{I}_{3 \mathrm{f}_{-} 80 \mathrm{~B}}\right.$, $\left.\mathrm{t}_{3 \mathrm{f}_{-} 80 \mathrm{~B}}\right)$ e de neutro $\left(\mathrm{I}_{3 \mathrm{io \_} 8 \mathrm{~B}}, \mathrm{t}_{3 \mathrm{io} \_ \text {80B }}\right.$ ), sendo mostrado como a corrente $I c c_{80 \_B n}$ (em faltas trifásicas ou monofásicas-terra) é obtida.

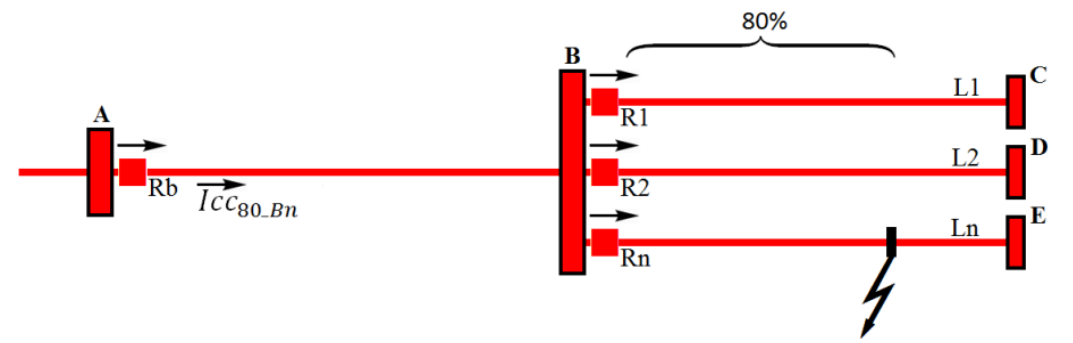

Figura 4.6 - Situação em que o quarto ponto de referência é obtido.

Novamente destaca-se que os tempos de referência de fase $\left(t_{3 f_{-} \text {cinP }}, t_{3 f_{-} c i n P_{-}}, t_{3 f_{-} 80 P}, t_{3 f_{-} \text {cinB }}\right.$, $\left.t_{3 f_{-} 80 B}\right)$ e de neutro $\left(t_{3 i o_{-} c i n P}, t_{3 i o_{-} c i n P_{-} s}, t_{3 i i_{-} 80 P}, t_{3 i o_{-} \text {cinB }}, t_{3 i o_{3} 80 B}\right)$ são dados de entrada da metodologia, podendo ser alterados de acordo com a filosofia de proteção adotada, desde que essas alterações sejam feitas de maneira coerente. Isto também se aplica ao tipo e ao local dos curtos-circuitos aplicados, podendo variar dependendo do critério adotado. Os quatro pontos de referência formados, $\left(I_{\text {cinP }}, t_{c i n P}\right),\left(I_{80 P}, t_{80 P}\right),\left(I_{c i n B}, t_{c i n B}\right)$ e $\left(I_{80 B}, t_{80 B}\right)$, tanto para a proteção de fase quanto para a de neutro, juntamente com o ponto de limite superior $\left(\mathrm{I}_{\text {cinP }}, \mathrm{t}_{\text {cinP_s}}\right)$, quando cabível, e a faixa de ajuste da corrente de pick-up, formarão uma área de referência, definindo um local de ajuste da curva de atuação do relé direcional. A Figura 4.7 mostra um exemplo de delimitação da área de ajuste do relé direcional, válido tanto para a proteção de fase quanto a de neutro. Na figura, $\mathrm{I}_{P_{-} \min }$ e $\mathrm{I}_{\mathrm{P}_{-} \max }$ são as correntes mínima e máxima de pick-up. 


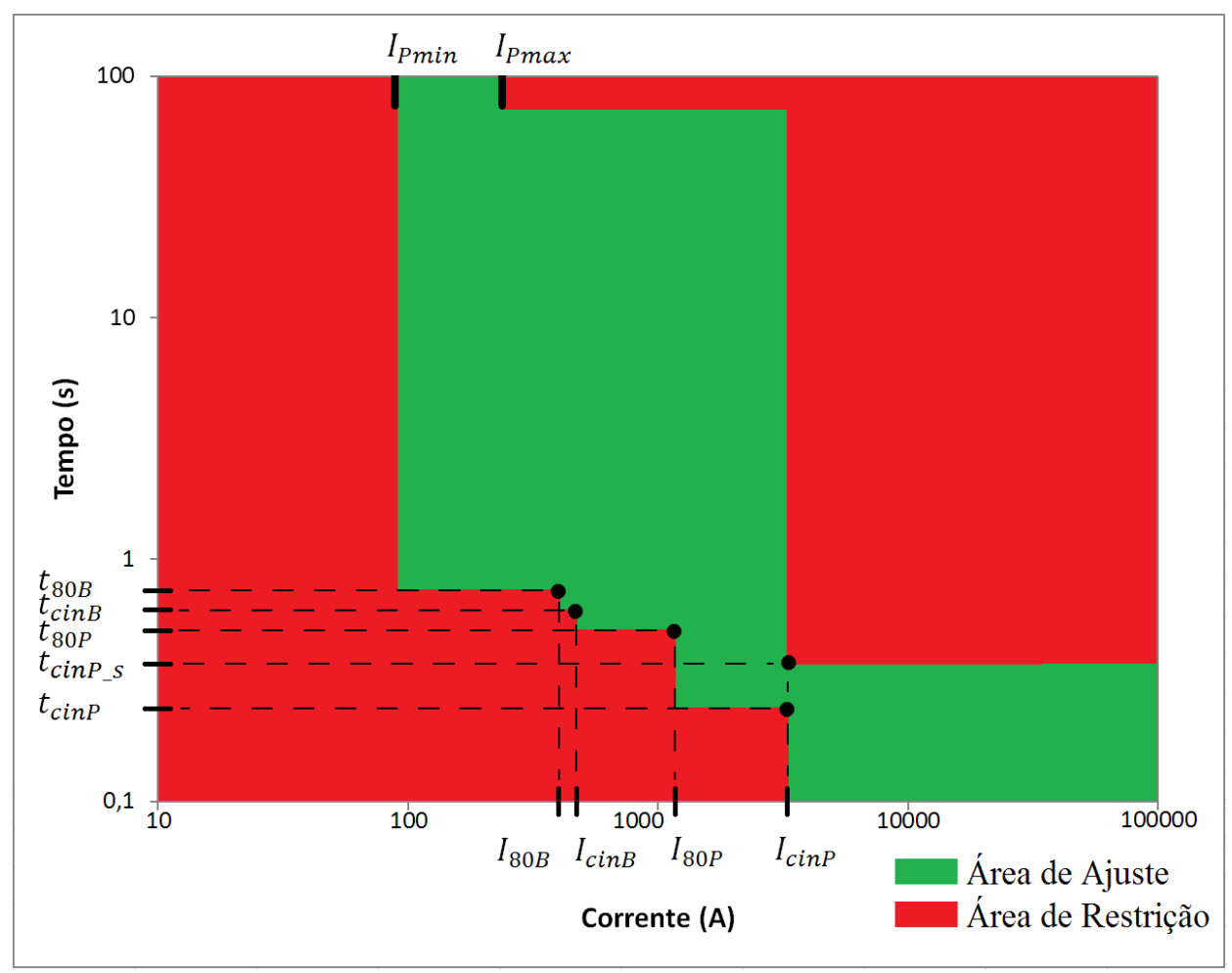

Figura 4.7 - Definição das áreas de ajuste e restrição.

A definição dos ajustes dos relés deve ter como base a Figura 4.7, de modo que as curvas candidatas a serem escolhidas devem estar dentro da área de ajuste definida. Assim, eliminadas as curvas que não estão nessa área, deve haver algum método de otimização para determinar qual dentre todas as configurações de ajustes produz a melhor característica de atuação para o relé de acordo com a teoria de proteção e os critérios da instalação.

\subsection{CRITÉRIOS DE OTIMIZAÇÃO}

Definida a área de ajustes dos relés na Figura 4.7, percebe-se que o melhor ajuste possível é aquele que produz uma curva de atuação que tangencia os quatro pontos de referência $\left(\mathrm{I}_{\operatorname{cinP}}, \mathrm{t}_{\operatorname{cinP}}\right)$, $\left(\mathrm{I}_{80 \mathrm{P}}, \mathrm{t}_{80 \mathrm{P}}\right),\left(\mathrm{I}_{\text {cinB }}, \mathrm{t}_{\mathrm{cinB}}\right)$ e $\left(\mathrm{I}_{80 \mathrm{~B}}, \mathrm{t}_{80 \mathrm{~B}}\right)$, válidos tanto para a proteção de fase (corrente de falta trifásica) quanto de neutro (corrente de falta monofásica-terra), definidos na seção anterior, e que possui uma corrente de pick-up o mais próximo possível do valo mínimo, resultando em uma proteção coordenada (pois respeita os pontos de referência, tanto para atuação como retaguarda local quanto para atuação como retaguarda remota), ágil (pois tem o menor tempo de atuação possível que respeita os critérios de atuação) e sensível (pois possui um baixo valor da corrente de pick-up). Idealmente as características do relé seriam tais que proporcionariam um ajuste que se adequaria perfeitamente sobre a área de ajuste definida na Figura 4.7, tangenciando os pontos. Visando aproximar a atuação do relé instalado à curva de atuação idealizada, foram desenvolvidos dois métodos: o método do Menor Erro 
(ME) e o método da Integral Logarítmica ponderada Linearmente (ILL), que visam encontrar o ajuste que produz a curva de atuação o mais próximo possível dos pontos de referência.

\subsubsection{MÉTODO DO MENOR ERRO-ME}

Pode haver uma grande diferença no que diz respeito à ordem de grandeza dos tempos de atuação do relé para as correntes $\mathrm{I}_{\mathrm{cinP}}, \mathrm{I}_{80 \mathrm{P}}, \mathrm{I}_{\mathrm{cinB}}$ e $\mathrm{I}_{80 \mathrm{~B}}$, principalmente em linhas longas, que implicam em situações em que o relé é pouco sensibilizado pelas correntes $\mathrm{I}_{\mathrm{cinB}}$ e $\mathrm{I}_{80 \mathrm{~B}}$. Desse modo, para minimizar o tempo de atuação do relé para todas as quatro correntes, deve-se analisá-los em uma mesma escala de ordem de grandeza. O cálculo do erro relativo percentual é uma solução simples e atrativa para este problema, pois, para uma determinada corrente, tem-se a relação entre o tempo de atuação desejado e do tempo de atuação da configuração atual do relé em análise, independente da ordem de grandeza desses tempos de atuação. Além disso, as correntes de maior magnitude possuem uma importância maior, o que deve ser levado em consideração durante a formulação matemática.

Desse modo, o método proposto determina o ajuste do relé de modo que ele seja o que produza a menor soma ponderada dos erros relativos do tempo de atuação para com quatro pontos de referência: $\left(I_{\text {cinP }}, t_{\text {cinP }}\right),\left(I_{80 P}, t_{80 P}\right),\left(I_{\text {cinB }}, t_{\text {cinB }}\right)$ e $\left(I_{80 B}, t_{80 B}\right)$. O ponto $\left(I_{\text {cinP }}, t_{c i n P_{-} s}\right)$ não é utilizado no critério de otimização, sendo apenas outra restrição (limite superior de atuação) a se levar em consideração. A expressão (4.10) define a base do método proposto.

$$
M E=\min \left[\mathrm{P}_{\operatorname{cinP}}\left(\frac{t_{1}-t_{\operatorname{cin} P}}{t_{\operatorname{cin} P}}\right)+\mathrm{P}_{80 \mathrm{P}}\left(\frac{t_{2}-t_{80 P}}{t_{80 P}}\right)+\mathrm{P}_{\operatorname{cinB}}\left(\frac{t_{3}-t_{\operatorname{cinB}}}{t_{\operatorname{cin} B}}\right)+\mathrm{P}_{80 \mathrm{~B}}\left(\frac{t_{4}-t_{80 B}}{t_{80 B}}\right)\right]
$$

Em que:

$M E$ : Menor soma dos erros relativos percentuais;

$t_{1}$ : Tempo de atuação do relé para a corrente $\mathrm{I}_{\text {cinP }}$;

$t_{2}$ : Tempo de atuação do relé para a corrente $\mathrm{I}_{80 \mathrm{P}}$;

$t_{3}$ : Tempo de atuação do relé para a corrente $\mathrm{I}_{\text {cinB }}$;

$t_{4}$ : Tempo de atuação do relé para a corrente $\mathrm{I}_{80 \mathrm{~B}}$;

$\mathrm{P}_{\text {cinP }}, \mathrm{P}_{80 \mathrm{P}}, \mathrm{P}_{\text {cinB }}$ e $\mathrm{P}_{80 \mathrm{~B}}$ : Ponderações para com os erros sob os tempos de atuação.

Os valores utilizados para ponderar os erros são definidos a critério do usuário, sendo que $P n_{1}$ deve ter o maior valor, pois indica a corrente de referência mais severa (curto-circuito do tipo close-in). Para este trabalho, para a proteção de fase foram utilizados $\mathrm{P}_{\text {cinP }}=4$ e $\mathrm{P}_{80 \mathrm{P}}=\mathrm{P}_{\text {cinB }}=\mathrm{P}_{80 \mathrm{~B}}=1$, indicando que um desvio de 1 segundo para a atuação do relé para uma falta close-in equivale a um desvio de 4 segundos para uma falta a $80 \%$ da linha ou para a atuação do relé como proteção de retaguarda remota, ou ainda, que uma atuação rápida para uma falta close-in é quatro vezes mais 
importante do que uma rápida atuação para as outras três correntes analisadas. Geralmente, para faltas envolvendo a terra, as correntes variam mais com a localização da falta do que para faltas entre fases (MASON, 1956). Com isso em mente, o valor de $P n_{1}$ da proteção de neutro deve ser menor do que a de fase, já que os valores das correntes estão mais distantes entre si, aproveitando melhor a característica inversa no tempo das curvas, de maneira que, como valor padrão para o ajuste de neutro neste trabalho, foram utilizados $\mathrm{P}_{\text {cinP }}=2$ e $\mathrm{P}_{80 \mathrm{P}}=\mathrm{P}_{\text {cinB }}=\mathrm{P}_{80 \mathrm{~B}}=1$. O engenheiro de proteção deve definir o grau de importância de $\mathrm{Pn}_{1}$ segundo sua experiência prática, sendo que deve levar em consideração que a tendência de um ajuste com uma atuação rápida pra altas correntes é de possuir altas correntes de pick-up e curvas com declividade acentuada, perdendo-se em sensibilidade.

De acordo com o comprimento da linha e a distribuição das cargas, as correntes de curto-circuito $\mathrm{I}_{80 \mathrm{P}}, \mathrm{I}_{\mathrm{cinB}}, \mathrm{e} \mathrm{I}_{80 \mathrm{~B}}$ podem apresentar valores menores do que o próprio ajuste da corrente de pick-up do relé. Estas correntes de referência podem ainda se situar entre os valores de $\mathrm{I}_{\mathrm{P}_{-} \text {mín }}$ e $\mathrm{I}_{\mathrm{P}_{-} \text {max }}$, apresentando um problema no momento de realizar a equação (4.10). Para exemplificar essa situação digamos que $\mathrm{I}_{\mathrm{P}_{-} \text {mín }}<\mathrm{I}_{80 \mathrm{~B}}<\mathrm{I}_{\mathrm{P}_{-} \text {max }}<\mathrm{I}_{\text {cinB }}<\mathrm{I}_{80 \mathrm{P}}<\mathrm{I}_{\text {cinP. }}$. Assim o método se inicia somando os erros relativos das quatro correntes de referência. Porém, quando $\mathrm{I}_{80 \mathrm{~B}}<\mathrm{I}_{\mathrm{P}}<\mathrm{I}_{\mathrm{P}_{-} \text {max }}$ o método irá realizar a soma dos erros de apenas três correntes, não havendo mais sentido na comparação entre os resultados de duas situações diferentes. Portanto, para garantir que toda a faixa das correntes de pick-up será analisada durante o processo de determinação automática dos ajustes, uma condição deve ser verificada a cada relé analisado, de modo que sejam desconsideradas as correntes de referência que possuírem amplitude menor do que o maior valor que corrente de pick-up pode assumir $\left(\mathrm{I}_{P_{\mathrm{P}} \max }\right)$. Estes casos indicam que o relé não foi sensibilizado para sua atuação como proteção de retaguarda remota, ou seja, o próprio decaimento da corrente de falta ao longo da linha de transmissão descarta a atuação da proteção de retaguarda remota. Assim, a otimização será feita utilizando apenas os pontos de referência que possuem amplitude de corrente maior do que o valor máximo da corrente de pick-up, $\mathrm{I}_{\mathrm{P}_{-} \max }$.

\subsubsection{MÉTODO DA INTEGRAL LOGARÍTMICA PONDERADA LINEARMENTE - ILL}

Em alguns casos de aplicação da metodologia, pode acontecer de algumas das quatro correntes de referência não sensibilizarem o relé em análise, ou seja, possuírem valores menores do que a corrente de pick-up do relé, como descrito na seção anterior. Nestes casos, na aplicação do método ME, ignoram-se as referências não sensibilizadas pelo relé. Como consequência, podem surgir alguns casos em que o resultado obtido produza uma curva de atuação como a da Figura 4.8. Nela percebe-se que o tempo de atuação para correntes abaixo de $I_{\operatorname{cinP}}$ é muito alto. Isto acontece, pois, havendo poucas correntes de referência e com a possibilidade de serem escolhidos diferentes tipos de curvas, a tendência do método ME é obter resultados com correntes de pick-up bastante elevadas e curvas com grande declividade, produzindo um tempo de atuação pequeno para altas correntes e ganhando-se em agilidade, porém perdese muito em sensibilidade, não sendo uma resposta otimizada segundo a teoria de proteção. 


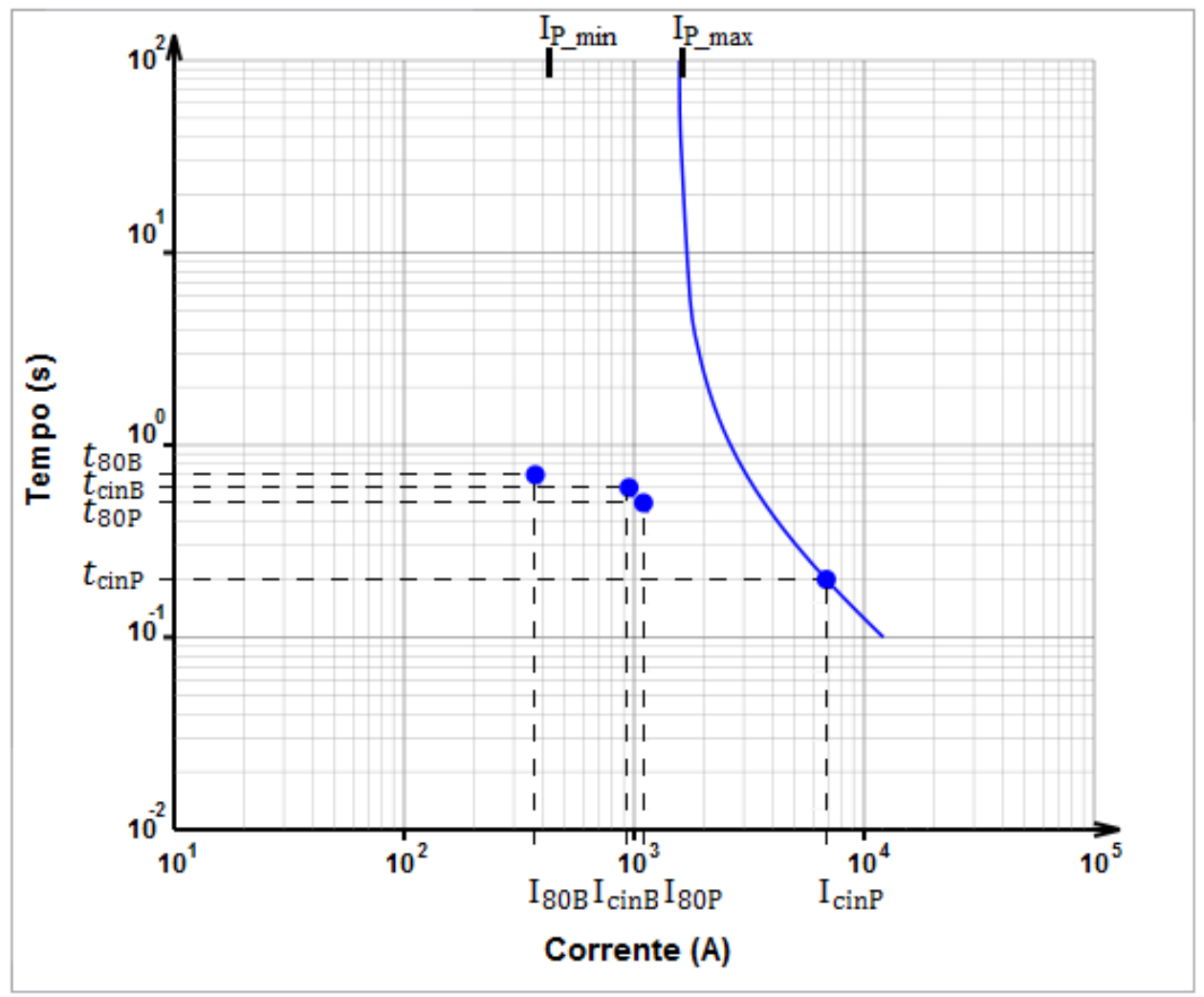

Figura 4.8 - Exemplo de resultado não satisfatório pelo método ME.

Para resolver este problema foi desenvolvido um método com base na menor área de integração do relé, o método da Integral Logarítmica ponderada Linearmente - ILL. Com a intenção de reduzir a área abaixo da curva de atuação do relé, este método compara a integral das diferentes curvas possíveis para o relé em análise e, seguindo critérios bem definidos, tem como resultado o ajuste que produz a curva cuja área é a menor dentre todas as possíveis. O método de integração numérica utilizado é o método dos trapézios, que pode ser resumido na Figura 4.9. Seu princípio é de aproximar a área de uma seção da curva para a área de um trapézio. Dividindo os limites de integração em vários segmentos pequenos, a área total se aproximará da soma das áreas dos trapézios. 


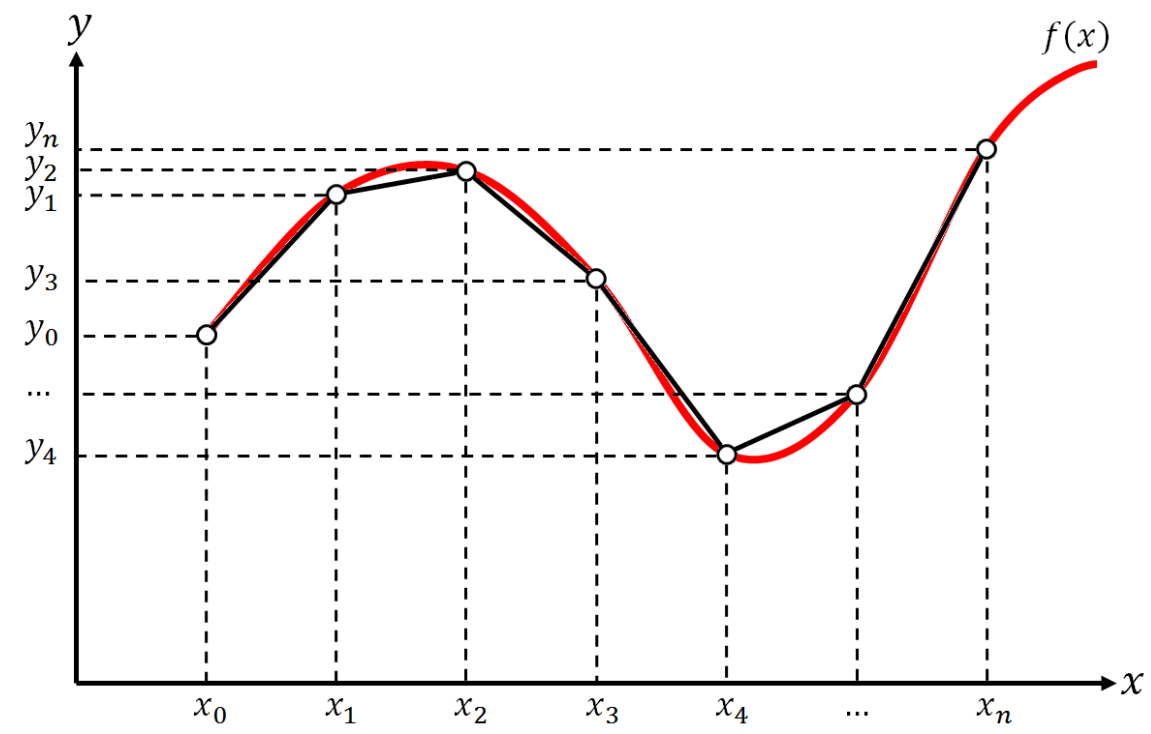

Figura 4.9 - Ilustração do método dos trapézios.

Desse modo, para a curva $f(x)$ da Figura 4.9, sendo $n$ o número de divisões, a área total será:

$$
\begin{gathered}
\int_{x_{0}}^{x_{n}} f(x) d x \cong \frac{1}{2}\left(y_{1}+y_{0}\right)\left(x_{1}-x_{0}\right)+\frac{1}{2}\left(y_{2}+y_{1}\right)\left(x_{2}-x_{1}\right)+\cdots+\frac{1}{2}\left(y_{n}+y_{n-1}\right)\left(x_{n}-x_{n-1}\right) \\
(k \in \mathbb{N} \mid 0 \leq k \leq n) \Rightarrow y_{k}=f\left(x_{k}\right)
\end{gathered}
$$

O critério de otimização deve ser capaz de analisar corretamente tempos de atuação e correntes que se situam em diferentes ordens de grandeza. No método ME isso é feito através do erro relativo dos tempos de atuação. Observando a curva de atuação do relé em uma escala linear, verifica-se que a área mais importante de atuação, a região em que a corrente varia inversamente com o tempo, é pouco valorizada. No entanto, em escala logarítmica esta região é mais bem detalhada, valorizando baixas correntes e baixos tempos de atuação, qualidade desejada para requisitos de agilidade e sensibilidade. A Figura 4.10 mostra estas considerações.
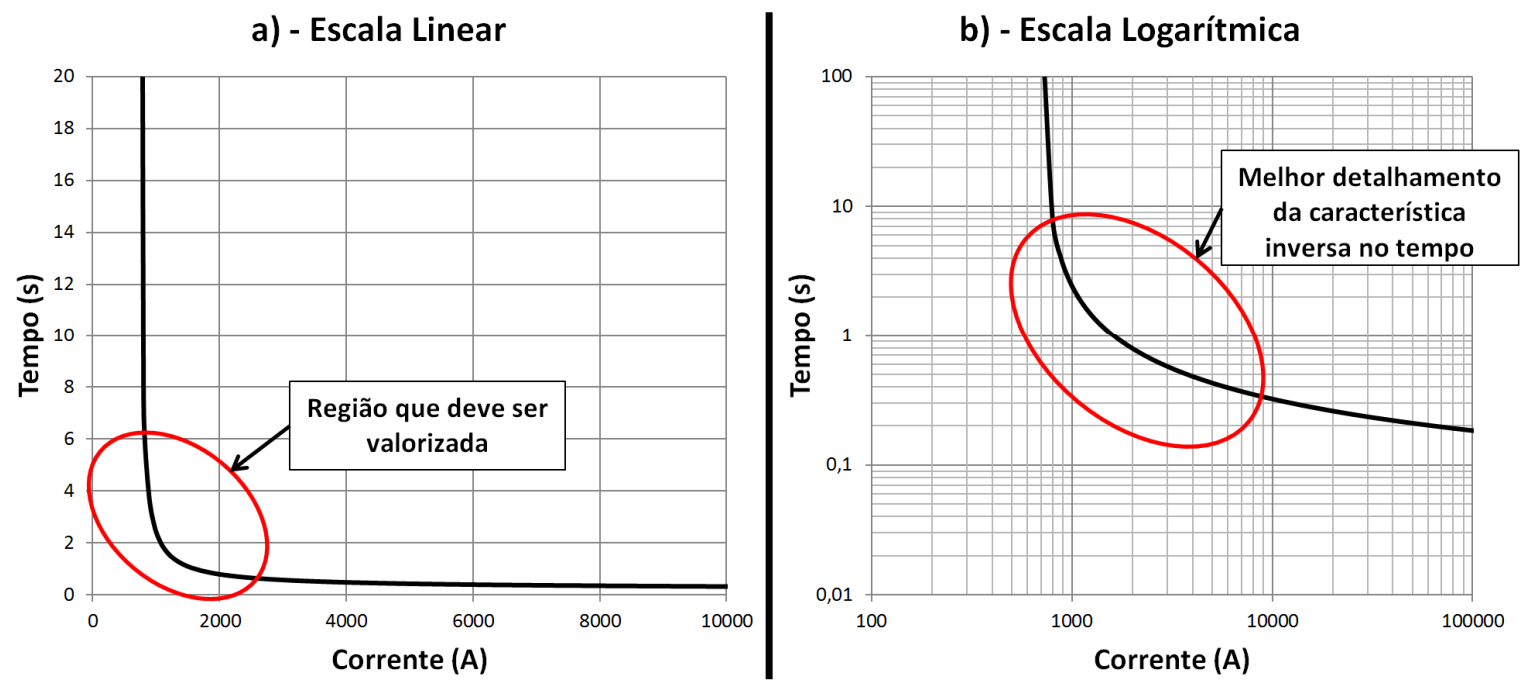

Figura 4.10 - Diferença entre o detalhamento da característica inversa nas escalas a) linear e b) logarítmica. 
Visando calcular a integral da curva do relé, porém em escala logarítmica, o método dos trapézios foi modificado de modo que, os passos são variáveis em escala linear, porém constantes em escala logarítmica. Isto é possível atualizando o passo $\mathrm{h}$ em cada iteração, para que a corrente varie logaritmicamente. Para a função da Figura 4.9, considerando $n$ divisões dos limites de integração, as etapas para o calculo da integral logarítmica I serão:

1. Calcular o passo de integração pela equação:

$$
h=\frac{1}{n}\left(\log \left(x_{n}\right)-\log \left(x_{0}\right)\right)
$$

2. Iniciar variáveis: $x_{b}=x_{0}, y_{b}=y_{0} ; k=1 ; \mathrm{I}=0$;

3. Calcular próximos valores de $x$ e $y$ :

$$
x_{a}=10^{k \cdot h+\log \left(x_{0}\right)}, y_{a}=f\left(x_{a}\right)
$$

4. Calcular a função logarítmica sob os valores de $x$ e $y$ :

$$
x_{a \_l o g}=\log \left(x_{a}\right), \quad y_{a_{-} l o g}=\log \left(y_{a}\right), \quad x_{b_{-} l o g}=\log \left(x_{b}\right), \quad y_{b_{-} l o g}=\log \left(y_{b}\right)
$$

5. Atualizar o valor da integral somando área do próximo trapézio:

$$
\mathrm{I}=\mathrm{I}+\frac{1}{2}\left(y_{a_{\_} l o g}+y_{b_{-}} \log \right)\left(x_{a_{-} l o g}-x_{b_{\_}} \log \right)
$$

6. Atualizar variáveis: $x_{b}=x_{a}, y_{b}=y_{a} ; k=k+1$;

7. Voltar à etapa 3 e repetir até que $k$ seja maior que $n$.

Ao final das etapas, I conterá o valor da integral logarítmica entre $x_{0}$ e $x_{n}$.

O critério de otimização também deve ser capaz de ponderar sobre as correntes de maior importância, aplicando um peso maior às correntes próximas de $\mathrm{I}_{\operatorname{cin} P}$. Como a comparação das curvas é feita sob diferentes áreas, a ponderação não pode ser pontual como no método ME, e sim ser distribuída sob a área calculada. Para este requisito foi desenvolvida uma ponderação distribuída linearmente sobre a área da curva do relé. Utilizando dois pesos de referência, $\mathrm{P}_{80 \mathrm{~B}}$ e $\mathrm{P}_{\text {cinP }}$, assim como no método $\mathrm{ME}$, constrói-se uma reta entre $\mathrm{I}_{80 \mathrm{~B}}$ e $\mathrm{I}_{\text {cinP }}$, passando pelos pontos $\left(\mathrm{I}_{80 \mathrm{~B}} ; \mathrm{P}_{80 \mathrm{~B}}\right)$ e $\left(\mathrm{I}_{\operatorname{cinP}} ; \mathrm{P}_{\text {cinP }}\right)$. A equação desta reta é:

$$
\mathrm{a}_{\mathrm{PL}}=\frac{\left(\mathrm{P}_{\operatorname{cin} \mathrm{P}}-\mathrm{P}_{80 \mathrm{~B}}\right)}{\left(\mathrm{I}_{\operatorname{cin} \mathrm{P}}-\mathrm{I}_{80 \mathrm{~B}}\right)}, \mathrm{b}_{\mathrm{PL}}=\mathrm{P}_{\operatorname{cin} \mathrm{P}}-\mathrm{a}_{\mathrm{PL}} \cdot \mathrm{I}_{\mathrm{cin} \mathrm{P}} \Rightarrow f_{\mathrm{PL}}(\mathrm{I})=\mathrm{a}_{\mathrm{PL}} \mathrm{I}+\mathrm{b}_{\mathrm{PL}}
$$

$f_{P L}(I)$ é a função de ponderação que deve ser utilizada a cada passo de integração sobre as correntes analisadas. Para uniformizar a comparação entre os diferentes tipos de curvas, o limite de integração inferior será a corrente correspondente ao tempo de atuação de 10 segundos, visto que para um sistema de proteção, atuações acima desse tempo não fariam nenhum sentido em se tratando da estabilidade e segurança do sistema de potência. Além disso, para comparar áreas de curvas com diferentes correntes de pick-up e valorizar aquelas com baixos valores, ou seja, com maior sensibilidade, 
será calculada a área até a origem do gráfico. Em suma, a área tomada será aquela abaixo da curva de atuação do relé até $t=0$, entre as correntes 0 e $\mathrm{I}_{\mathrm{cinP}}$ e limitada superiormente por $t=10$ segundos. A Figura 4.11 mostra a função de ponderação $f_{P L}(I)$ sobre a área da curva do relé.

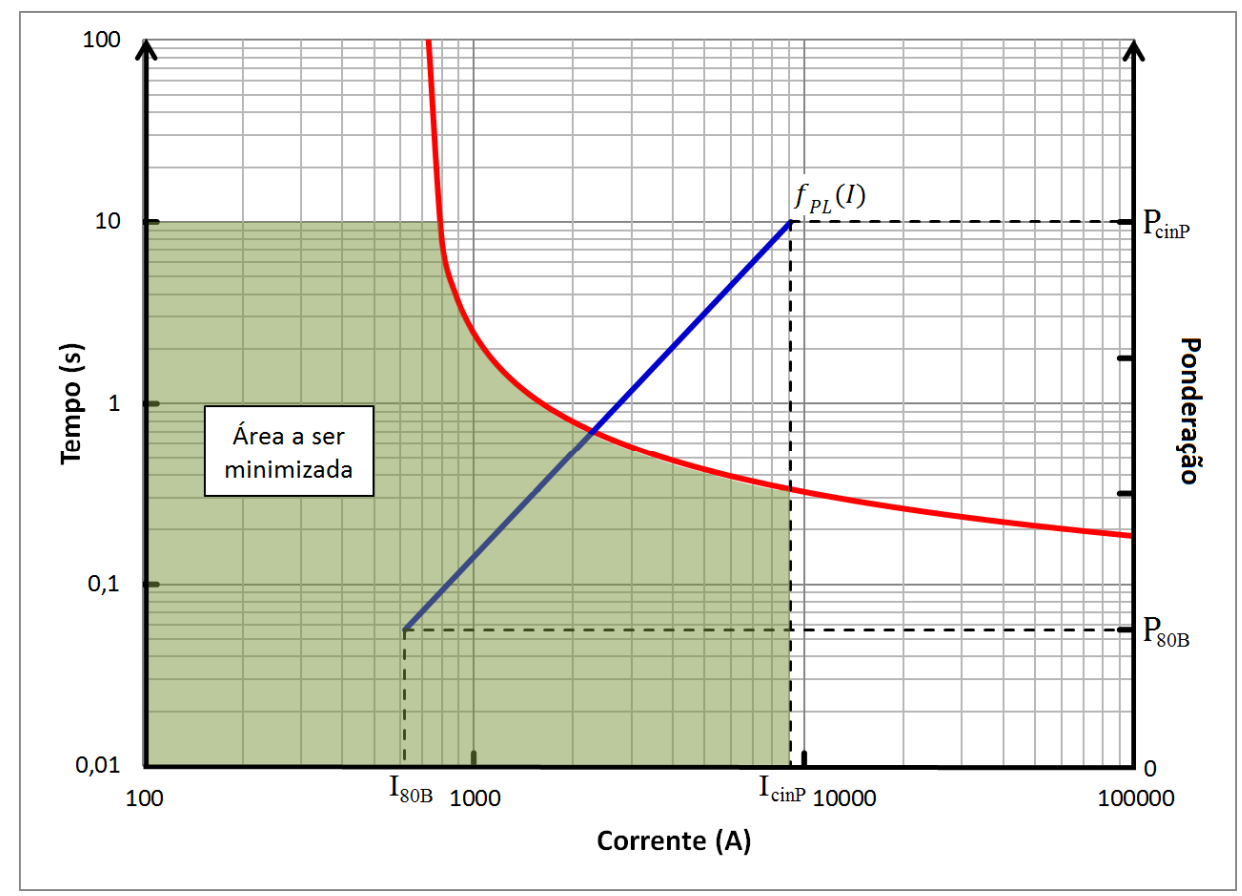

Figura 4.11 - Função de ponderação sobre a área abaixo da curva do relé.

O método da Integral Logarítmica ponderada Linearmente - ILL é aplicado sobre todas as configurações possíveis dos relés que se situam na área de ajuste, respeitando os quatro pontos de referência $\left(I_{\text {cinP }}, t_{\text {cinP }}\right),\left(I_{80 P}, t_{80 P}\right),\left(I_{\text {cinB }}, t_{\text {cinB }}\right),\left(I_{80 B}, t_{80 B}\right)$ e o ponto de limite superior $\left(I_{\text {cinP }}, t_{\text {cinP_s }}\right)$, válidos tanto para a proteção de fase (falta trifásica) quanto para a de neutro (falta monofásica-terra). Assim, analisa-se cada padrão de curva e calcula-se a área ponderada, obtendo como resposta o ajuste que produz uma curva acima dos quatro pontos de referência, abaixo do ponto de limite superior e cuja área logarítmica ponderada seja a menor dentre todas as possíveis. O fluxograma da Figura 4.12 descreve o método ILL. Inicialmente calculam-se as constantes de ponderação segundo a fórmula (4.16). Em seguida, são definidos os intervalos de integração, sendo o valor máximo $\mathrm{I}_{\text {cinP }}$ e o mínimo o valor da corrente para o tempo de atuação de 10 segundos. Para $n$ divisões da área a ser calculada, o passo é calculado, conforme a equação (4.12). O valor da integral então é inicialmente calculado como a área entre $\mathrm{I}_{\min }$ e o eixo do tempo. Para isso, multiplica-se a corrente pelo tempo, porém deverá ser aplicada a função logarítmica sobre ambos e, sobre a corrente, deverá ser aplicado o peso através da função de ponderação, conforme a equação (4.16). Além disso, como a função logarítmica de um número menor que 1 resulta em um valor negativo, para a área ser corretamente calculada os valores devem ser corrigidos. O critério para este caso são os limites inferiores dos valores de corrente e de tempo de atuação do relé. Considerando como menor corrente o valor de $10 \mathrm{~A}$ e como menor tempo $0,01 \mathrm{~s}$, a correção sobre o logaritmo da corrente será $-1(\log 10=1)$ e sobre o logaritmo do tempo será +2 
$(\log 0,01=-2)$, como pode ser verificado no fluxograma. Em seguida a próxima corrente é calculada incrementando-se o passo logarítmico conforme a equação (4.13). Para a nova corrente, o tempo de atuação do relé é calculado através de sua equação de atuação, seja ele um relé padronizado ou não. $\mathrm{O}$ próximo passo é atualizar o valor da integral com a área do trapézio, conforme a equação (4.14), porém corrigindo os valores da corrente somando-se -1 e do tempo somando-se +2 , conforme justificado. A área é então atualizada até que todas as $n$ divisões sejam somadas.

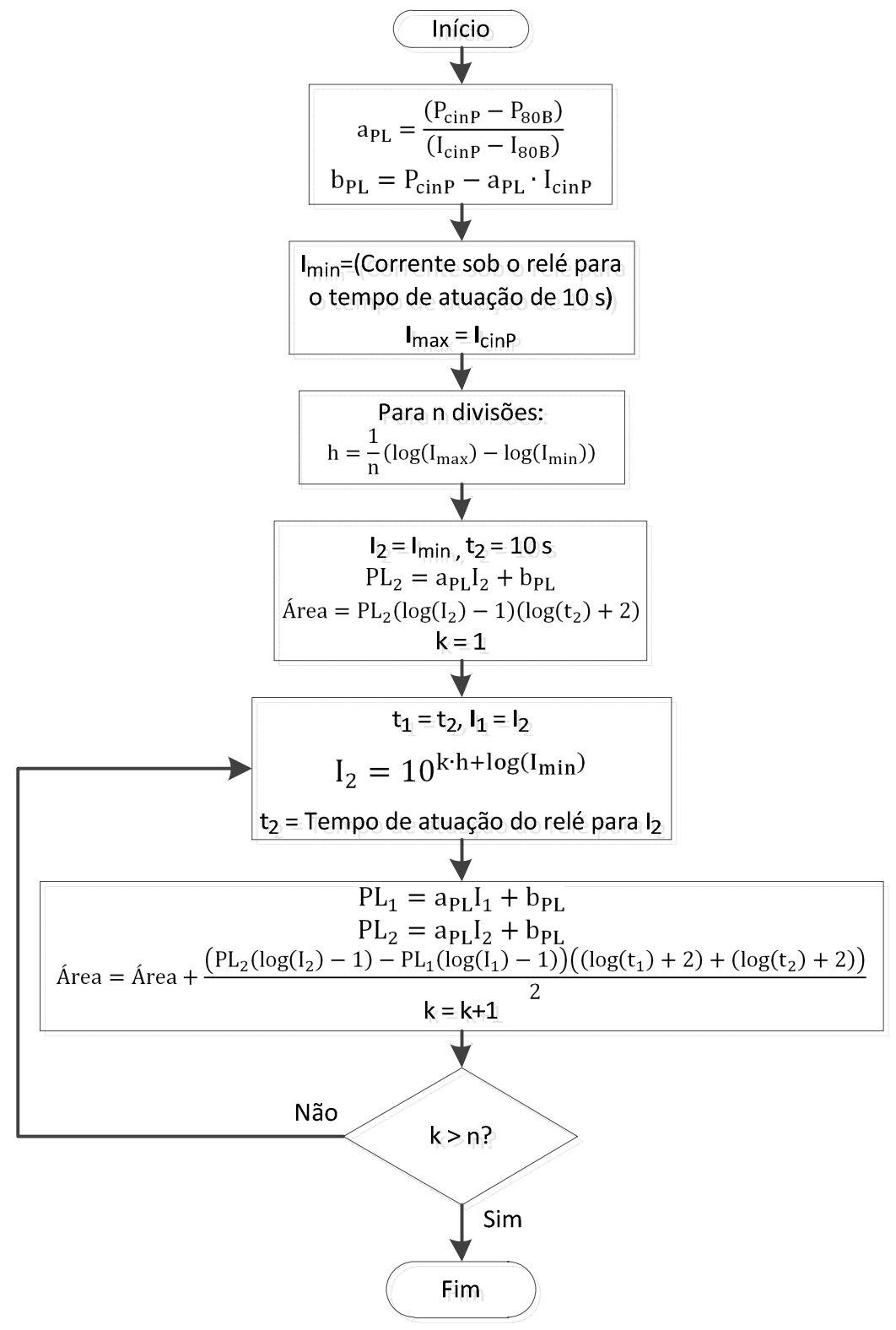

Figura 4.12 - Fluxograma do método ILL.

O método é aplicado para todas as configurações de ajustes possíveis para o relé em análise que produzam uma curva dentro da área de ajuste definida pela Figura 4.7, comparando o valor da integral calculada em cada arranjo e tomando apenas o menor valor. Ao final, o ajuste que produza a menor área será o otimizado. Como exemplo, toma-se um relé fictício cujos pontos de referência são $(13532,3 ; 0,2)$, $(230,7 ; 0,5),(141,1 ; 0,6)$ e $(111,5 ; 0,7)$, e a faixa da corrente de pick-up está entre 400 e 4300 A. A 
utilização do método ME levaria a uma resposta com corrente de pick-up bastante elevada e uma curva com grande inclinação, como na Figura 4.13. Aplicando o método ILL a resposta seria mais coerente, com uma curva de baixa declividade, baixa corrente de pick-up e ainda assim baixo tempo de atuação para a corrente $I_{\operatorname{cinP}}$, como pode ser visto na Figura 4.14.

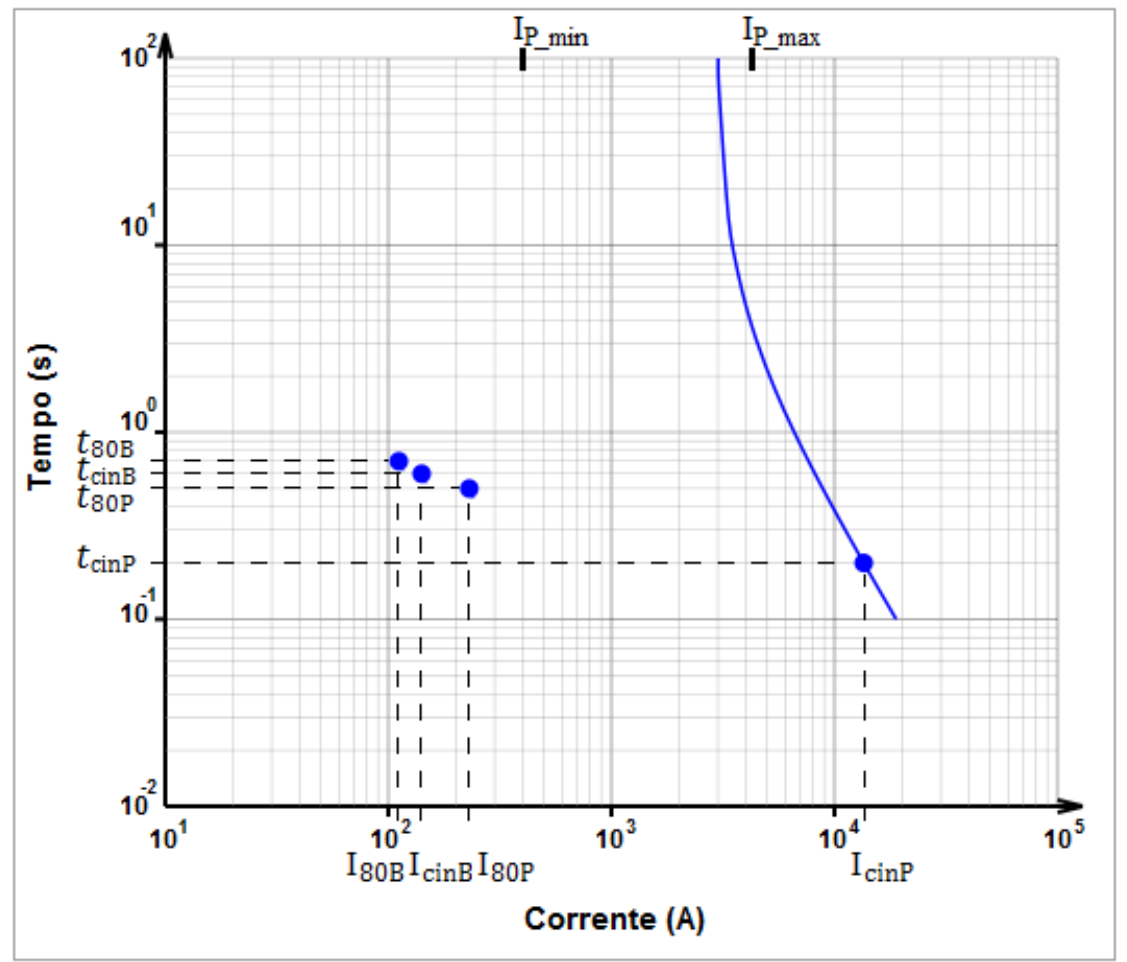

Figura 4.13 - Exemplo de solução pelo método ME, com apenas uma corrente de referência sensibilizada pelo relé.

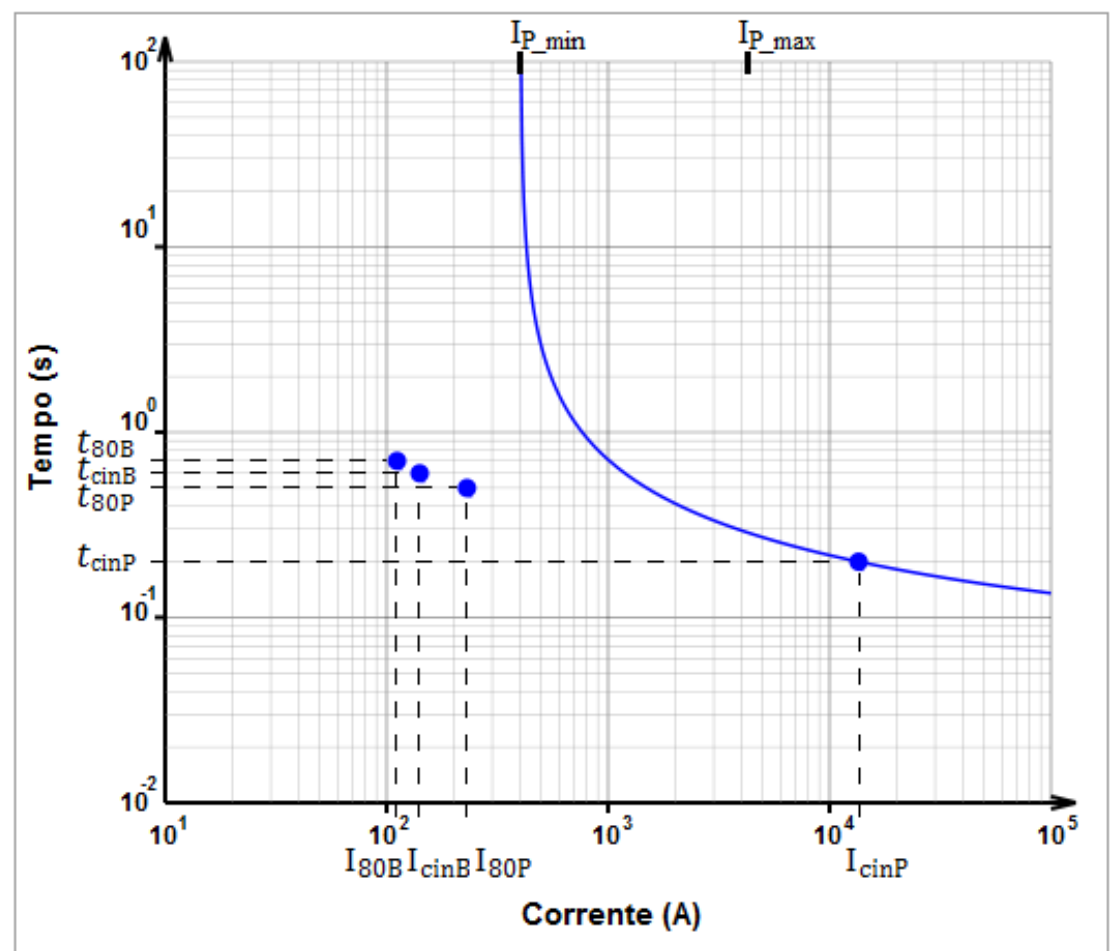

Figura 4.14 - Exemplo de solução pelo método ILL, com apenas uma corrente de referência sensibilizada pelo relé. 


\subsubsection{MÉTODO INTEGRADO ME-ILL}

Como visto na Figura 4.14, mesmo tomando apenas um ponto de referência (corrente para uma falta close-in), a resposta obtida pelo método ILL foi muito satisfatória. Isso traz a dúvida: porque não utilizar sempre apenas um ponto, como empregado em outras metodologias de coordenação, e aplicar o método ILL?

O método ILL tenta reduzir o tempo de atuação ao máximo para todas as correntes. Deste modo, utiliza-lo sem a informação da atuação do relé como backup pode causar violações na coordenação, sendo necessária uma etapa de testes sucessivos entre os pares de relés para garantir a coordenação. Ou seja, o método reduziria tanto o tempo de atuação para correntes de baixa amplitude que poderia violar as restrições de coordenação. Nos casos em que $I_{80 P}, I_{c i n B}$ e $I_{80 B}$ são baixos o suficientes para não sensibilizar o relé, tem-se como consequência justamente que o ajuste mais correto do relé é aquele que implica em um menor tempo de atuação para correntes de baixa amplitude. Desse modo justifica-se a escolha do método ILL para casos em que nem todas as correntes de referência sensibilizam o relé.

Através de diversos testes utilizando os dois métodos, chega-se à conclusão que, em casos em que todas as quatro correntes de referência sensibilizam o relé, a aplicação do ME ou ILL produz resultados bastante similares, muitas vezes iguais. Porém, o método da integral logarítmica possui um esforço computacional maior. Assim definiu-se um novo método que une os lados positivos dos dois métodos anteriormente apresentados. Para situações em que todas as correntes de referência sensibilizam o relé, é utilizado o método ME. Para casos em que uma ou mais correntes de referência não sensibilizam o relé é utilizado o método ILL. Com isso, o método de otimização resultante, ME-ILL, consegue tratar todos os casos de coordenação pelo melhor ajuste local, garantindo confiabilidade e agilidade na resposta.

\subsection{DADOS DE ENTRADA}

A metodologia de ajuste proposta é tal que não são necessários dados sobre a topologia do sistema para realizar a análise, de modo que estes são considerados nos dados sobre as correntes de curtocircuito. Os dados foram separados em dados de sistema e dados de equipamentos, para a proteção de fase e de neutro. Assim sendo, tanto para os dados de fase quanto para os de neutro, os dados de sistema são:

- Local do relé;

- Valores das correntes de curto-circuito, compreendendo $\mathrm{I}_{\text {cinP }}, \mathrm{I}_{80 \mathrm{P}}, \mathrm{I}_{\mathrm{cinB}}$, e $\mathrm{I}_{80 \mathrm{~B}}$ descritos na seção 4.3 , sendo $I_{3 f_{-} \text {cinP }}, I_{3 f_{-} 80 P}, I_{3 f_{-} \text {cinB }}$, e $I_{3 f_{-} 80 B}$ para a proteção de fase e $I_{3 i o \_c i n P}$,

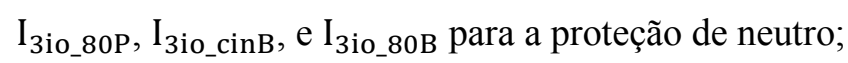

- Tempos de referência para a atuação do relé, compreendendo $t_{\text {cinP }}, t_{\text {cinP_s }}, t_{80 P}, t_{c i n B}, e$ $t_{80 B}$ descritos na seção 4.3 , sendo $t_{3 f_{-} \text {cinP }}, t_{3 f_{-} c i n P_{-} s}, t_{3 f_{-} 80 P}, t_{3 f_{-} \text {cinB }}$ e $t_{3 f_{-} 80 B}$ para a 
proteção de fase e $t_{3 i i_{-} \text {cinP }}, t_{3 i o_{-} \text {cinP_s }}, t_{3 i_{-} 80 P}, t_{3 i o_{-} \text {cinB }}, e t_{3 i o_{-} 80 B}$ para a proteção de neutro;

- Faixa de ajuste da corrente de pick-up de acordo com o sistema, compreendendo $I_{P_{-}} \min \mathrm{e}$ $I_{P_{-} \text {max }}$ descritos na seção 4.3 , sendo $\mathrm{I}_{\mathrm{P}_{-} f f_{-} \text {min }} \mathrm{e} \mathrm{I}_{\mathrm{P}_{\_} f f_{-} \max }$ para a proteção de fase e $\mathrm{I}_{\mathrm{P}_{-} \mathrm{ft} \_ \text {min }}$ e $\mathrm{I}_{\mathrm{P}_{-} \mathrm{ft} \_ \text {max }}$ para a proteção de neutro.

Os dados necessários dos relés, da proteção de fase e de neutro, são:

- Índice numérico para identificação do relé;

- Tipo e fabricante do relé, assim como a linha em que ele se encontra instalado e o número do circuito. Estes dados são apenas para a identificação do relé;

- Faixa de ajuste do multiplicador de tempo do relé (TDS) para os padrões ANSI e IEC, sendo necessários os valores dos limites inferior, superior e o passo da variação;

- Faixa de ajuste da corrente de pick-up do relé, compreendendo os limites inferior e superior, e o passo da variação;

- Relação de transformação do transformador de corrente (TC) do relé, com os valores da corrente nominal (em Ampères) no primário e no secundário do TC.

\subsection{DEFINIÇÃO AUTOMÁTICA DOS AJUSTES}

Com base no que foi descrito até então, o fluxograma da Figura 4.15 resume o funcionamento da metodologia proposta. Inicialmente faz-se a leitura dos dados dos relés juntamente com os valores de $\mathrm{I}_{\text {cinP }}, \mathrm{t}_{\text {cinP }}, \mathrm{t}_{\text {cinP_s }}, \mathrm{I}_{80 \mathrm{P}}, \mathrm{t}_{80 \mathrm{P}}, \mathrm{I}_{\text {cinB }}, \mathrm{t}_{\text {cinB }}, \mathrm{I}_{80 \mathrm{~B}}, \mathrm{t}_{80 \mathrm{~B}}, \mathrm{I}_{\mathrm{P}_{-} \min } \mathrm{e} \mathrm{I}_{\mathrm{P}_{-} \max }$ para cada relé, para as proteções de fase e de neutro. Estes dados são salvos na memória do programa de modo dinâmico, podendo ser acessados a qualquer momento. Inicia-se então a coordenação, carregando-se os dados do primeiro relé. Em seguida variam-se todas as variáveis de ajuste do relé e verificam-se as restrições, ou seja, dentre cada configuração de ajustes formada por todas as combinações possíveis entre $I_{P}$ (variando entre $I_{P_{-} \text {min }} e$ $\mathrm{I}_{\mathrm{P}_{-} \max }$ ), $\mathrm{K}_{1}, \mathrm{~K}_{2}$ e $\mathrm{K}_{3}$ (variando dentre todas as 10 combinações de curvas padrão ANSI e IEC das tabelas 2.2 e 2.3) e TDS (entre os valores mínimo e máximo de acordo com o relé em análise), são verificadas, em cada iteração, as restrições definidas pela área de ajuste da Figura 4.7. Para isso, as variáveis (TDS, $I_{P}$ e tipo de curva) foram separadas em uma cadeia de três laços, sendo o mais externo variando $I_{P}$ e o mais interno variando TDS. Desse modo, após inicializadas as variáveis em seus valores mínimos, incrementase o passo do ajuste de TDS sucessivamente até que sejam satisfeitas as restrições ou que se atinja o seu valor máximo. Satisfeitas as restrições (curva de atuação dentro da área de ajuste da Figura 4.7) aplica-se o método de otimização ME-ILL, calculando-se a soma dos erros relativos de acordo com a seção 4.4.1 caso todas as correntes de referência sejam maiores que o maior valor da corrente de pick-up, ou 
calculando a integral logarítmica de acordo com a seção 4.4.2 caso ao menos uma corrente de referência seja menor que a máxima corrente de pick-up. Se o valor resultante (da soma ponderada ou da integral) for menor que um valor de referência (inicialmente tomado como um valor muito alto), a referência passa a ter o valor da configuração atual de ajustes. Em seguida varia-se o tipo de curva e repete-se a variação entre o mínimo e o máximo de TDS até que as restrições sejam satisfeitas, calculando novamente a soma dos erros relativos ou a integral logarítmica e salvando o menor resultado. Variadas todas as curvas, incrementa-se o passo da corrente de pick-up e volta-se ao primeiro padrão de curva e ao primeiro valor de TDS. O processo se repete até que sejam testadas todas as combinações possíveis entre os possíveis valores de $I_{P}$, todos os tipos de curvas e todos os valores possíveis de TDS que satisfazem as restrições. Após serem testadas todas as configurações válidas, o valor salvo na referência será relativo ao melhor arranjo de ajustes para o relé atual, que então recebe estes ajustes. Segue-se para a análise do próximo relé do banco de dados, repetindo-se todos os passos anteriores. Ao final, todos os relés serão ajustados com a melhor configuração possível segundo a metodologia apresentada. A metodologia é a mesma para a definição dos ajustes de fase e de neutro, com diferença nos valores de referência e na indicação de utilizar ou não a restrição de limite superior, de acordo com a presença ou ausência de relé de distância como proteção principal.

O método aproveita a própria característica das curvas inversas no tempo e assume que os relés disponíveis para análise descreverão bem o comportamento do sistema. Quando impostas as restrições do relé de distância, o método sempre encontrará uma solução otimizada e coordenada, desde que haja alguma curva que se encaixe dentro da área de ajuste da Figura 4.7. Geralmente esta curva existe porque a curva do relé de distância é a tempo definido e, portanto, desde que a atuação do relé 67 respeite o intervalo de coordenação determinado, sempre haverá coordenação entre os relés 67 e 21 . Desse modo, segundo os critérios da seção 4.2 e as figuras 4.2 e 4.7, o método garante a correta proteção da linha onde o relé está instalado (zona primária), a coordenação entre os relés 21 e 67, e a coordenação remota para uma corrente de curto-circuito close-in, que são as regiões sob interferência da restrição da atuação a tempo definido do relé de distância. A coordenação para faltas além do curto close-in das linhas adjacentes, modelada pelo ponto $\left(\mathrm{I}_{80 \mathrm{~B}}, \mathrm{t}_{80 \mathrm{~B}}\right)$, será garantida pela própria característica de corrente inversa no tempo do relé 67, pois geralmente, respeitando-se a área de ajuste da Figura 4.7, o tempo de atuação do relé para a corrente $\mathrm{I}_{80 \mathrm{~B}}$ é bem maior que $\mathrm{t}_{80 \mathrm{~B}}$.

O método também pode ser aplicado sem que seja levada em consideração a atuação do relé 21, tanto para a proteção de fase quanto para a de neutro, considerando apenas o relé de sobrecorrente direcional e sua atuação como proteção principal e como retaguarda remota, não havendo a restrição do ponto $\left(\mathrm{I}_{\text {cinP }}, \mathrm{t}_{\text {cinP_s }}\right)$, de modo a realizar a coordenação apenas entre os relés de sobrecorrente. Para esta situação, devem ser escolhidos novos critérios de tempo de atuação e consequentemente novas definições de $t_{\text {cinP }}, t_{80 P}, t_{\text {cinB }}$ e $t_{80 B}$. Assim, o método fornece como resultado o ajuste que mais se aproxima da curva idealizada, sendo esta a que tangencia os pontos $\left(\mathrm{I}_{\text {cinP }}, \mathrm{t}_{\mathrm{cinP}}\right),\left(\mathrm{I}_{80 \mathrm{P}}, \mathrm{t}_{80 \mathrm{P}}\right),\left(\mathrm{I}_{\operatorname{cinB}}, \mathrm{t}_{\operatorname{cinB}}\right)$ e $\left(\mathrm{I}_{80 \mathrm{~B}}\right.$, 
$\mathrm{t}_{80 \mathrm{~B}}$ ), e que tem como corrente de pick-up a corrente $\mathrm{I}_{\mathrm{P}_{-} \min }$, resultando em uma proteção coordenada, por respeitar as referências, ágil, por ser a mais rápida possível, e sensível, por possuir um baixo valor da corrente de pick-up. Para essa situação, em alguns casos, o relé não possui as características desejadas para seu local de instalação, não apresentando curvas de atuação que se aproximam da ideal definida através de seus pontos de referência. Casos assim são raros (menos do que 5\% dos casos testados), porém, a fim de contemplá-los, é necessária uma etapa de verificação, realizada ao final, que indica se há relés que violam as restrições de coordenação. Em caso positivo, modificam-se os pontos de referência destes relés, para que a metodologia seja reaplicada sobre eles encontrando assim uma resposta coerente. A etapa de verificação dos resultados consiste em testar todos os pares de relés principal/retaguarda (ou retaguarda local/retaguarda remota) verificando se há violações nas restrições. Caso haja, um novo conjunto de relés é definido, apenas com os pares de relés que apresentam violações. Sobre este conjunto, é realizada uma atualização nos pontos de referência de modo que os novos valores contemplem as restrições impostas pela própria curva dos relés. Assim, automaticamente são alterados os tempos de referência para o relé atuando como retaguarda remota (P3 e/ou P4), sendo que o novo valor será igual ao tempo de atuação da proteção principal para a corrente em questão adicionado do intervalo mínimo de coordenação considerado. Em seguida o processo de definição dos ajustes se repete, apenas com os relés desse novo conjunto.

A metodologia pode ser utilizada para relés com curvas não padronizadas, ou ainda, pode-se fixar o tipo de curva de um relé e desejar encontrar o melhor ajuste para seu local de instalação. Nestes casos, a metodologia é a mesma, com a diferença de que não há um laço para variar o tipo de curva. Para relés com curvas não padronizadas, pode-se utilizar a metodologia exposta no tópico 2.2.2 para a coleta e tratamento dos dados dos relés e então algum método para obtenção do tempo de operação do relé. Neste trabalho, a partir dos resultados obtidos pela metodologia do tópico 2.2.2, foi aplicada uma interpolação logarítmica sob o tempo o tempo de operação, sob os múltiplos da corrente e sob os TDSs (para casos de relés com ajustes contínuos de $\mathrm{I}_{\mathrm{P}}$ e TDS), resultando em uma função que retorna o tempo de operação do relé a partir do fornecimento de seus ajustes. Desse modo, a única diferença da aplicação da metodologia de coordenação automática proposta para relés não padronizados é a utilização da função de interpolação logarítmica ao invés da equação (2.4), utilizada em relés padronizados, além de que estes relés devem ser tratados com o pressuposto de que possuem apenas um tipo de curva. 


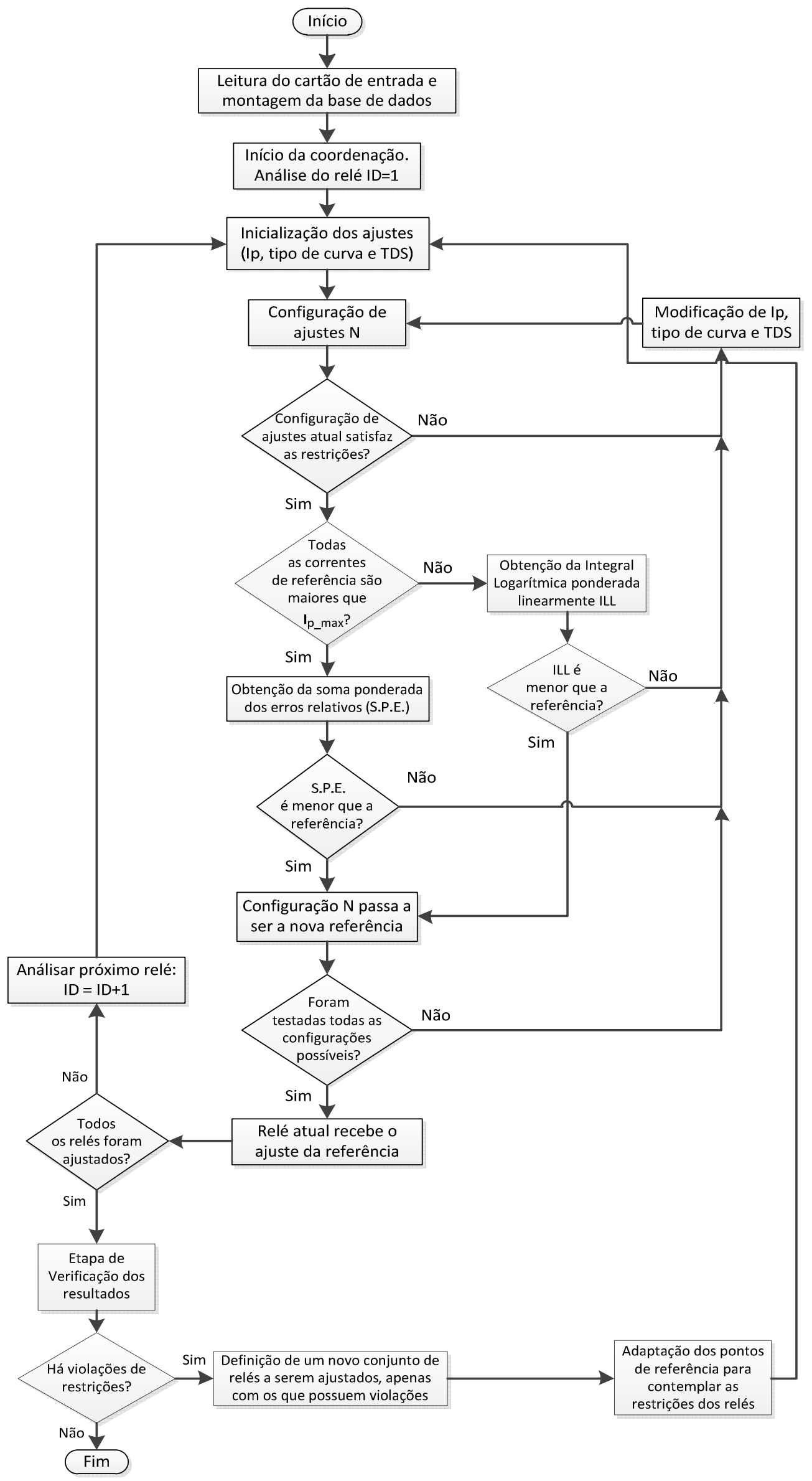

Figura 4.15 - Fluxograma geral da metodologia. 


\section{RESULTADOS}

Para efeito de demonstração a metodologia foi aplicada a dois sistemas. A seção 5.1 mostra a aplicação a um sistema real, uma porção do sistema elétrico brasileiro de transmissão com foco no estado de São Paulo. Já a seção 5.2 mostra a aplicação para o sistema teste IEEE 14 barras. Detalhes destes sistemas e os resultados obtidos serão abordados a seguir.

\subsection{APLICAÇÃO PARA UMA PORÇÃO DO SISTEMA BRASILEIRO}

A Figura 5.1 mostra o diagrama unifilar reduzido de parte do sistema elétrico brasileiro e que será utilizado neste trabalho. O diagrama e a análise das correntes de curto-circuito foram obtidos por meio do programa Computer-Aided Protection Engineering - CAPE (2013). A Tabela 5.1 mostra os dados de entrada de sistema para os ajustes dos relés de fase, com os valores das correntes para faltas trifásicas, enquanto a Tabela 5.2 mostra os dados de entrada de sistema para os relés de neutro, com os valores das correntes para faltas monofásicas-terra. Os valores de $I_{P_{-} f f \_m i n}, I_{P_{-} f f \text { max }}, I_{P_{-} f t \_m i n}$ e $I_{P_{-} f t \_m a x}$ foram calculados segundo os critérios de ajuste da corrente de pick-up descritos na seção 4.2.

Por se tratar de um sistema reduzido, o sistema da Figura 5.1 possui elementos que representam linhas equivalentes do sistema real, tais quais as linhas [19210-19280], [19280-19240] e [19210-19240], e a barra 19219, de modo que os relés R4, R5, R11, R12, R19, R20, R29 e R30 não estão presentes no sistema real. Porém, a análise do sistema elétrico com a inclusão destes relés proporciona ganhos didáticos, tais como:

- A verificação do comportamento da metodologia quando há linhas com correntes de curto-circuito que pouco varia com a distância, como o caso dos relés R4 e R5;

- A verificação do comportamento da metodologia para casos em que somente existem informações do próprio bay da linha, como no caso dos relés R11, R12, R19, R20, R29 e R30 em que há dados das correntes de curto-circuito close-in apenas. 
Tabela 5.1 - Dados de entrada para os relés de fase do sistema da Figura 5.1.

\begin{tabular}{|c|c|c|c|c|c|c|c|c|c|c|c|}
\hline ID & $\mathrm{DE}$ & PARA & Circ. & $\begin{array}{c}\mathrm{I}_{3 \mathrm{f}_{\text {_cinP }}} \\
\text { (A) }\end{array}$ & $\begin{array}{c}\mathrm{I}_{3 f_{-} 80 \mathrm{P}} \\
(\mathrm{A})\end{array}$ & $\begin{array}{c}\mathrm{I}_{3 \mathrm{f}_{\text {_cin }} \mathrm{B}} \\
\text { (A) }\end{array}$ & $\begin{array}{c}\mathrm{I}_{3 \mathrm{f} \_80 \mathrm{~B}} \\
(\mathrm{~A})\end{array}$ & $\begin{array}{c}\mathrm{TC}_{\text {PRIM }} \\
\text { (A) }\end{array}$ & $\begin{array}{c}\mathrm{TC}_{\mathrm{SEC}} \\
(\mathrm{A})\end{array}$ & $\underset{(\mathrm{A})}{\mathrm{I}_{\mathrm{P}_{\text {fff_min }}}}$ & $\frac{\mathrm{I}_{P_{-} \text {ff_max }}(\mathrm{A})}{}$ \\
\hline R1 & 19200 & 19210 & 1 & 3273,5 & 1167,0 & 472,5 & 401,1 & 600 & 1 & 475,2 & 475,2 \\
\hline $\mathrm{R} 2$ & 19210 & 19200 & 1 & 10391,2 & 2802,4 & 2250,3 & 721,4 & 600 & 1 & 475,2 & 1800,2 \\
\hline R3 & 19200 & 19219 & 1 & 3273,5 & 1502,8 & 1085,0 & 623,7 & 600 & 1 & 475,2 & 868,0 \\
\hline R4 & 19219 & 19200 & 1 & 6851,2 & 2698,8 & 2250,3 & 372,0 & 600 & 1 & 475,2 & 1800,2 \\
\hline R5 & 19219 & 19210 & 1 & 1085,0 & 623,7 & 472,5 & 401,1 & 600 & 1 & 475,2 & 475,2 \\
\hline R6 & 19210 & 19219 & 1 & 10391,2 & 7360,3 & 6851,2 & 2698,8 & 600 & 1 & 475,2 & 5481,0 \\
\hline R7 & 19210 & 33046 & 1 & 9105,0 & 2878,4 & 2420,5 & 1367,2 & 600 & 5 & 346,8 & 1936,4 \\
\hline $\mathrm{R} 8$ & 33046 & 19210 & 1 & 4563,6 & 2097,4 & 1755,6 & 1486,9 & 600 & 5 & 936,0 & 1404,5 \\
\hline R9 & 33046 & 19280 & 1 & 3203,5 & 1929,1 & 1599,2 & 0,0 & 600 & 5 & 936,0 & 1279,4 \\
\hline R10 & 19280 & 33046 & 1 & 15674,3 & 4482,7 & 3782,7 & 1674,3 & 800 & 5 & 399,6 & 3026,2 \\
\hline R11 & 19210 & 19280 & 1 & 10822,3 & 52,3 & 25,1 & 0,5 & 600 & 5 & 399,6 & 399,6 \\
\hline R12 & 19280 & 19210 & 1 & 17248,0 & 52,4 & 31,5 & 26,7 & 800 & 5 & 399,6 & 399,6 \\
\hline R13 & 19210 & 19280 & 2 & 8783,3 & 2277,5 & 1665,8 & 35,3 & 600 & 5 & 399,6 & 1332,6 \\
\hline R14 & 19280 & 19210 & 2 & 15614,9 & 2666,0 & 2088,6 & 1768,1 & 800 & 5 & 399,6 & 1670,9 \\
\hline R15 & 19210 & 19220 & 1 & 9194,6 & 4171,4 & 3210,5 & 1096,5 & 600 & 5 & 469,2 & 2568,4 \\
\hline R16 & 19220 & 19210 & 1 & 6824,8 & 2651,0 & 1660,3 & 1256,9 & 400 & 5 & 469,2 & 1328,2 \\
\hline R17 & 19210 & 19220 & 2 & 9194,6 & 4171,4 & 3210,5 & 1096,5 & 600 & 5 & 469,2 & 2568,4 \\
\hline R18 & 19220 & 19210 & 2 & 6824,8 & 2651,0 & 1660,3 & 1256,9 & 400 & 5 & 469,2 & 1328,2 \\
\hline R19 & 19210 & 19240 & 1 & 10719,4 & 229,7 & 128,5 & 47,3 & 400 & 5 & 399,6 & 399,6 \\
\hline R20 & 19240 & 19210 & 1 & 13532,3 & 230,7 & 141,1 & 111,5 & 300 & 5 & 399,6 & 399,6 \\
\hline R21 & 19240 & 33006 & 1 & 11850,2 & 6041,1 & 5373,5 & 1868,2 & 300 & 5 & 399,6 & 4298,8 \\
\hline R22 & 33006 & 19240 & 1 & 2559,8 & 1965,4 & 1807,5 & 380,7 & 300 & 5 & 456,0 & 1446,0 \\
\hline R23 & 33006 & 19220 & 1 & 5937,1 & 2115,0 & 1724,0 & 1548,9 & 400 & 5 & 456,0 & 1379,2 \\
\hline R24 & 19220 & 33006 & 1 & 8313,8 & 2417,2 & 1991,8 & 1480,4 & 400 & 5 & 543,6 & 1593,4 \\
\hline R25 & 19240 & 33032 & 1 & 12087,6 & 4350,6 & 3736,7 & 1446,1 & 300 & 5 & 399,6 & 2989,4 \\
\hline R26 & 33032 & 19240 & 1 & 2762,2 & 1806,9 & 1570,2 & 612,6 & 1600 & 5 & 624,0 & 1699,9 \\
\hline R27 & 33032 & 19220 & 1 & 4619,6 & 1829,9 & 1494,7 & 1343,7 & 1600 & 5 & 624,0 & 1195,8 \\
\hline R28 & 19220 & 33032 & 1 & 8541,8 & 2376,8 & 1972,3 & 1210,9 & 400 & 5 & 543,6 & 1577,9 \\
\hline R29 & 19280 & 19240 & 1 & 16622,2 & 915,4 & 694,2 & 348,2 & 800 & 5 & 399,6 & 534,5 \\
\hline R30 & 19240 & 19280 & 1 & 12974,3 & 900,2 & 668,1 & 178,5 & 300 & 5 & 399,6 & 555,4 \\
\hline
\end{tabular}


Tabela 5.2 - Dados de entrada para os relés de neutro do sistema da Figura 5.1.

\begin{tabular}{|c|c|c|c|c|c|c|c|c|c|c|c|}
\hline ID & $\mathrm{DE}$ & PARA & Circ. & $\begin{array}{c}\mathrm{I}_{3 \mathrm{io} \_ \text {cin }} \\
(\mathrm{A})\end{array}$ & $\begin{array}{c}\mathrm{I}_{3 \mathrm{io} / 80 \mathrm{P}} \\
(\mathrm{A})\end{array}$ & $\begin{array}{c}\mathrm{I}_{3 \mathrm{io}_{\mathrm{o}} \mathrm{cin} \mathrm{B}} \\
(\mathrm{A})\end{array}$ & $\begin{array}{c}\mathrm{I}_{3 \text { io_80B }} \\
(\mathrm{A})\end{array}$ & $\begin{array}{c}\mathrm{TC}_{\text {PRIM }} \\
(\mathrm{A})\end{array}$ & $\begin{array}{c}\mathrm{TC}_{\mathrm{SEC}} \\
(\mathrm{A})\end{array}$ & $\begin{array}{c}\mathrm{I}_{\mathrm{P}_{-} \text {ff_min }} \\
(\mathrm{A})\end{array}$ & $\begin{array}{c}\mathrm{I}_{\mathrm{P}_{-} \mathrm{ff}}(\mathrm{A}) \mathrm{max} \\
\end{array}$ \\
\hline $\mathrm{R} 1$ & 19200 & 19210 & 1 & 5058,8 & 1395,3 & 498 & 298,3 & 600 & 1 & 80 & 240 \\
\hline $\mathrm{R} 2$ & 19210 & 19200 & 1 & 10947,7 & 1343,7 & 616,6 & 44,3 & 600 & 1 & 80 & 240 \\
\hline R3 & 19200 & 19219 & 1 & 5059,1 & 1791 & 1300,4 & 721,1 & 600 & 1 & 80 & 240 \\
\hline R4 & 19219 & 19200 & 1 & 5618,3 & 1223,8 & 616,4 & 86,2 & 600 & 1 & 80 & 240 \\
\hline R5 & 19219 & 19210 & 1 & 1300,4 & 721,1 & 497,8 & 298,2 & 600 & 1 & 80 & 240 \\
\hline R6 & 19210 & 19219 & 1 & 10947,8 & 6254,2 & 5618,3 & 1223,8 & 600 & 1 & 80 & 240 \\
\hline R7 & 19210 & 33046 & 1 & 10824,5 & 2205,9 & 1762 & 1071,1 & 600 & 5 & 80 & 240 \\
\hline $\mathrm{R} 8$ & 33046 & 19210 & 1 & 2312,4 & 943,7 & 624,9 & 374,1 & 600 & 5 & 80 & 240 \\
\hline R9 & 33046 & 19280 & 1 & 1762 & 1199,3 & 903,6 & 154,2 & 600 & 5 & 80 & 240 \\
\hline R10 & 19280 & 33046 & 1 & 9528 & 2514,2 & 2043,2 & 809,9 & 800 & 5 & 80 & 240 \\
\hline R11 & 19210 & 19280 & 1 & 11439,5 & 5,9 & 2,7 & 0,4 & 600 & 5 & 80 & 240 \\
\hline R12 & 19280 & 19210 & 1 & 10952,8 & 5,9 & 1,2 & 0,8 & 800 & 5 & 80 & 240 \\
\hline R13 & 19210 & 19280 & 2 & 10544,8 & 1533 & 1162,4 & 369,2 & 600 & 5 & 80 & 240 \\
\hline R14 & 19280 & 19210 & 2 & 9254,6 & 1060,2 & 391 & 369,8 & 800 & 5 & 80 & 240 \\
\hline R15 & 19210 & 19220 & 1 & 10371,3 & 3692,5 & 2592,6 & 428,1 & 600 & 5 & 80 & 240 \\
\hline R16 & 19220 & 19210 & 1 & 6609,8 & 2244,6 & 1070 & 622,8 & 400 & 5 & 80 & 240 \\
\hline R17 & 19210 & 19220 & 2 & 10371,3 & 3692,5 & 2592,6 & 428,1 & 600 & 5 & 80 & 240 \\
\hline R18 & 19220 & 19210 & 2 & 6609,8 & 2244,6 & 1070 & 622,8 & 400 & 5 & 80 & 240 \\
\hline R19 & 19210 & 19240 & 1 & 11416,6 & 88 & 52,7 & 23,8 & 400 & 5 & 80 & 240 \\
\hline R20 & 19240 & 19210 & 1 & 8694,8 & 87 & 26,1 & 15,2 & 300 & 5 & 80 & 240 \\
\hline R21 & 19240 & 33006 & 1 & 7846,7 & 3750,8 & 3240,2 & 898,6 & 300 & 5 & 80 & 240 \\
\hline R22 & 33006 & 19240 & 1 & 1742,5 & 1091,3 & 899,3 & 262,1 & 300 & 5 & 80 & 240 \\
\hline R23 & 33006 & 19220 & 1 & 3240,2 & 898,6 & 346,1 & 670,8 & 400 & 5 & 80 & 240 \\
\hline R24 & 19220 & 33006 & 1 & 8416,7 & 1579,2 & 1396,4 & 828,1 & 400 & 5 & 80 & 240 \\
\hline R25 & 19240 & 33032 & 1 & 7951,7 & 2526,6 & 1897,8 & 412,7 & 300 & 5 & 80 & 240 \\
\hline R26 & 33032 & 19240 & 1 & 1758,7 & 687,4 & 442,7 & 68,5 & 1600 & 5 & 80 & 240 \\
\hline R27 & 33032 & 19220 & 1 & 2189,7 & 519,2 & 243,9 & 146,5 & 1600 & 5 & 80 & 240 \\
\hline R28 & 19220 & 33032 & 1 & 8814,4 & 2110,5 & 1382,3 & 405,6 & 400 & 5 & 80 & 240 \\
\hline R29 & 19280 & 19240 & 1 & 10889,1 & 133,8 & 68,7 & 32,2 & 800 & 5 & 80 & 240 \\
\hline R30 & 19240 & 19280 & 1 & 8679,7 & 134,1 & 68,9 & 5,9 & 300 & 5 & 80 & 240 \\
\hline
\end{tabular}




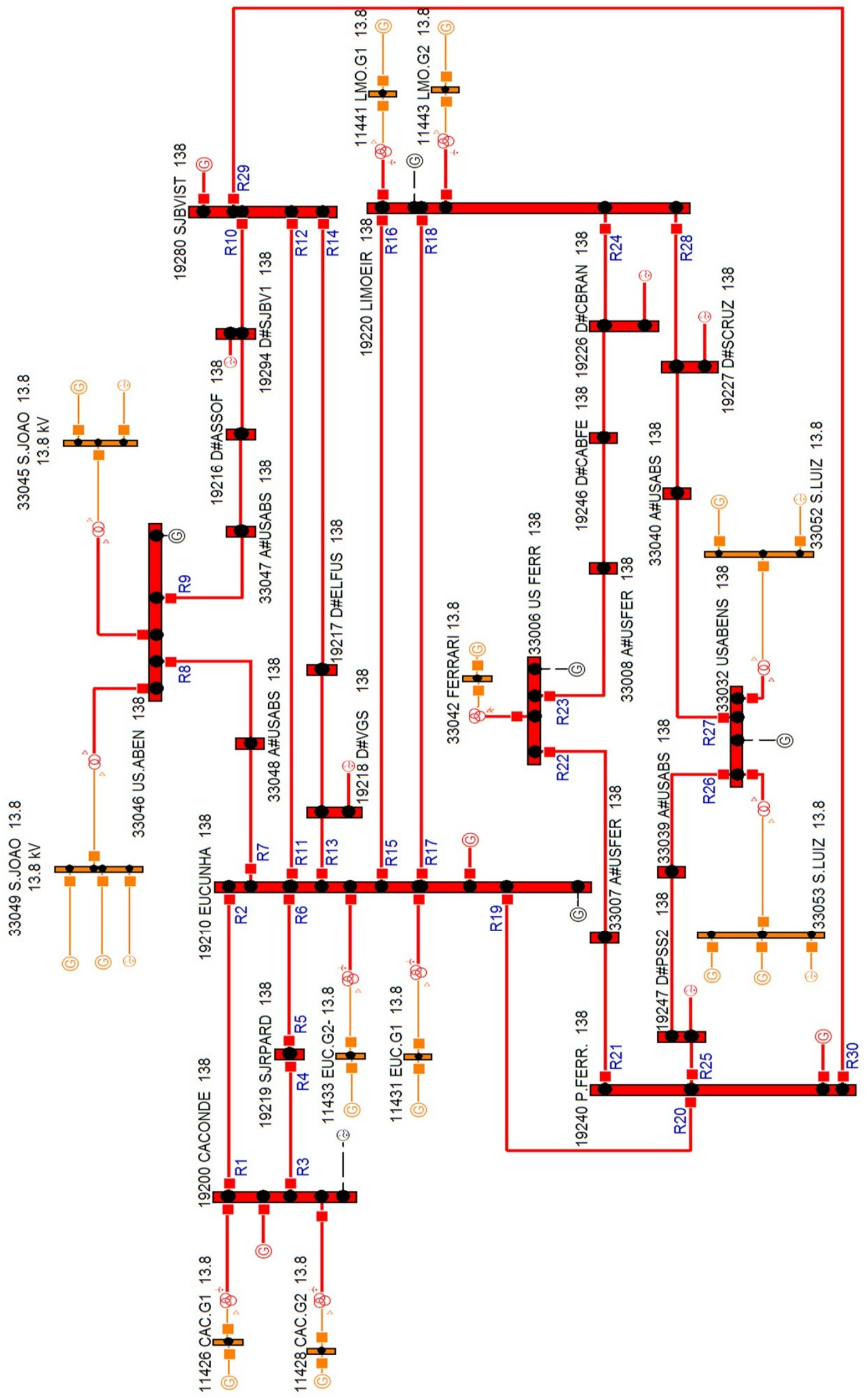

Figura 5.1 - Diagrama unifilar reduzido de parte do sistema brasileiro, com foco no estado de São Paulo. 
Foram adotadas para todos os relés as características de atuação da Tabela 5.3.

Tabela 5.3 - Características dos relés.

\begin{tabular}{|c|c|c|c|c|c|c|c|c|}
\hline \multicolumn{3}{|c|}{ TDS (ANSI) } & \multicolumn{3}{c|}{ TDS (IEC) } & \multicolumn{3}{c|}{$\begin{array}{c}\text { Corrente de pick- } \\
\text { up (A) }\end{array}$} \\
\hline LI & Passo & LS & LI & Passo & LS & LI & Passo & LS \\
\hline 0,5 & 0,01 & 15 & 0,05 & 0,01 & 1 & 0,25 & 0,01 & 16 \\
\hline
\end{tabular}

LI: Limite Inferior LS: Limite Superior

Como padronização da indicação do local do relé, na Tabela 5.2 têm-se as barras DE e PARA indicando a linha em que o relé se encontra, sendo que a barra DE indica o local do qual o relé está mais próximo. Por exemplo, o relé R1 está na linha entre as barras 19200 e 19210, próximo à barra 19200, no circuito 1 .

Toma-se como exemplo o relé R1 para a proteção de fase, logo verificam-se as correntes trifásicas francas. Seguindo a regra descrita na seção 4.1, R1 é proteção de retaguarda remota de R6, R7, R11, R13, R15, R17 e R19. Para R1 atuando como proteção de retaguarda local deve-se analisar a corrente de curto-circuito para as faltas do tipo close-in e a 80\% da linha [19200-19210]. Utilizando o programa CAPE, obtém-se como valores destas correntes 3273,5 A e 1167 A, respectivamente, como se pode ver na Tabela 5.1 em $\mathrm{I}_{3 \mathrm{f}_{-} \text {cinP }}$ e $\mathrm{I}_{3 \mathrm{f}}$ 80P. Aplicando-se uma falta na linha em que R6 é retaguarda local, o valor sensibilizado por R1 é de 472,5 A para um curto-circuito do tipo close-in, e para um curtocircuito a $80 \%$ da linha, R1 não é sensibilizado (o sentido da corrente é inverso ao do relé direcional). Repetindo-se a simulação da falta nas linhas em que os relés R7, R11, R13, R15, R17 e R19 são retaguardas locais (relés dos quais R1 é proteção de retaguarda remota), tem-se a Tabela 5.4 como resultado. Nela pode-se verificar o valor da amplitude das correntes que são medidas por R1 quando este atua como proteção de retaguarda remota. Na tabela, c. 1 indica o circuito 1 da linha, enquanto c. 2 indica o circuito 2. NS indica que o relé não foi sensibilizado.

Tabela 5.4 - Corrente de curto-circuito sobre R1 para sua atuação como proteção de retaguarda remota.

\begin{tabular}{|c|c|c|}
\hline Local da Falta & $\begin{array}{c}\text { Corrente medida por R1 em } \\
\text { uma falta close-in (A) }\end{array}$ & $\begin{array}{c}\text { Corrente medida por R1 em uma } \\
\text { falta a 80\% da linha (A) }\end{array}$ \\
\hline$[19210-19219]$ c. 1 (R6) & 472,5 & NS \\
\hline$[19210-33046]$ c.1 (R7) & 472,5 & 172,3 \\
\hline$[19210-19280]$ c.1 (R1) & 472,5 & 4,6 \\
\hline$[19210-19280]$ c.2 (R13) & 472,5 & 169,1 \\
\hline$[19210-19220]$ c.1 (R15) & 472,5 & 401,1 \\
\hline$[19210-19220]$ c. 2 (R17) & 472,5 & 401,1 \\
\hline$[19210-19240]$ c. 1 (R19) & 472,5 & 20,1 \\
\hline
\end{tabular}

NS: valor não significativo. 
Observa-se que os maiores valores das correntes são 472,5 A para uma falta close-in e 401,1 A para uma falta a $80 \%$ da linha. Estes serão os valores de referência para a atuação do relé R1 como proteção de retaguarda remota. Deste modo, os valores das correntes de curto-circuito de referência são:

$$
\mathrm{I}_{3 \mathrm{f}_{-} \text {cinP }}=3273,5 \mathrm{~A} \quad \mathrm{I}_{3 \mathrm{f}_{-} 80 \mathrm{P}}=1167,0 \mathrm{~A} \quad \mathrm{I}_{3 \mathrm{f}_{-} \text {cinB }}=472,5 \mathrm{~A} \quad \mathrm{I}_{3 \mathrm{f}_{-} 80 \mathrm{~B}}=401,1 \mathrm{~A} .
$$

Estes valores podem ser notados na entrada de dados descrita pela Tabela 5.1. Acrescentando os valores de tempo de coordenação padrão descritos na seção 4.3, os quatro pontos de referência para o ajuste do relé R1 serão:

$$
\mathrm{P} 1=(3273,5 ; 0,200) \quad \mathrm{P} 2=(1167,0 ; 0,500) \quad \mathrm{P} 3=(472,5 ; 0,600) \quad \mathrm{P} 4=(401,1 ; 0,700) .
$$

Admitiu-se neste trabalho que a corrente de pick-up deve variar entre $120 \%$ da corrente que limita o carregamento da linha até $80 \%$ da corrente medida pelo relé para um curto-circuito trifásico na barra remota, como descrito na seção 4.3. Para o relé R1, a corrente de curto-circuito trifásico na barra remota tem um valor de $472,5 \mathrm{~A}$, e aplicando o fator de $80 \%$ o valor máximo da corrente de pick-up passa a ser 378,0 A. Como este valor é menor do que $120 \%$ da corrente que limita o carregamento da linha (475,2 A, descrito na Tabela 5.1), o valor máximo da corrente de pick-up passa a ter o mesmo valor do mínimo e, portanto, o ajuste deve ser fixado em 475,2 A. Este critério foi utilizado, pois se entende que o menor valor que a corrente de pick-up deve possuir é da corrente que limita o carregamento da linha acrescida de um fator de sobrecorrente.

Aplicando a metodologia proposta, o valor encontrado para o ajuste de fase de R1 será tal que sua curva de atuação estará posicionada a mais próxima possível dos quatro pontos de referência anteriormente descritos. A Figura 5.2 mostra a curva de atuação obtida, assim como os pontos de referência e as correntes mínima e máxima de pick-up, que são iguais para este caso. 


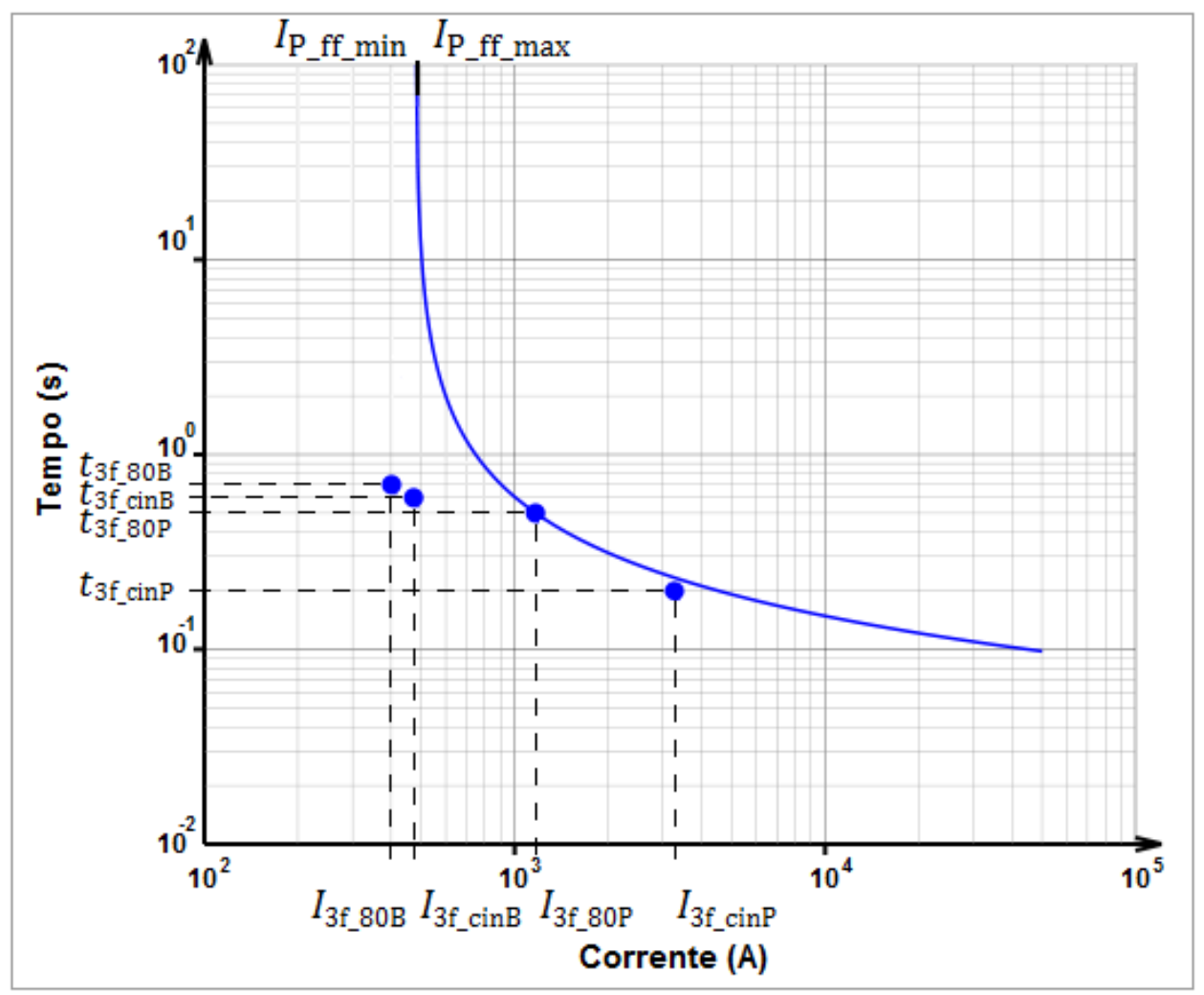

Figura 5.2 - Curva de atuação obtida para o relé R1.

O relé R4 é proteção de retaguarda remota do relé R1. Realizando a mesma análise obtém-se um ajuste para R4 que está automaticamente coordenado com R1. A Figura 5.3 mostra a coordenação entre os relés R4 e R1, além dos pontos de referência para cada relé e os ajustes encontrados. Assim como na Figura 5.2, os valores de referência são facilmente identificados, pois a relação entre as correntes é sempre a mesma: $I_{\operatorname{cin} P}>I_{80 P}>I_{\operatorname{cin} B}>I_{80 B}$. Do mesmo modo: $t_{\operatorname{cin} P}<t_{80 P}<t_{\operatorname{cin} B}<t_{80 B}$. 


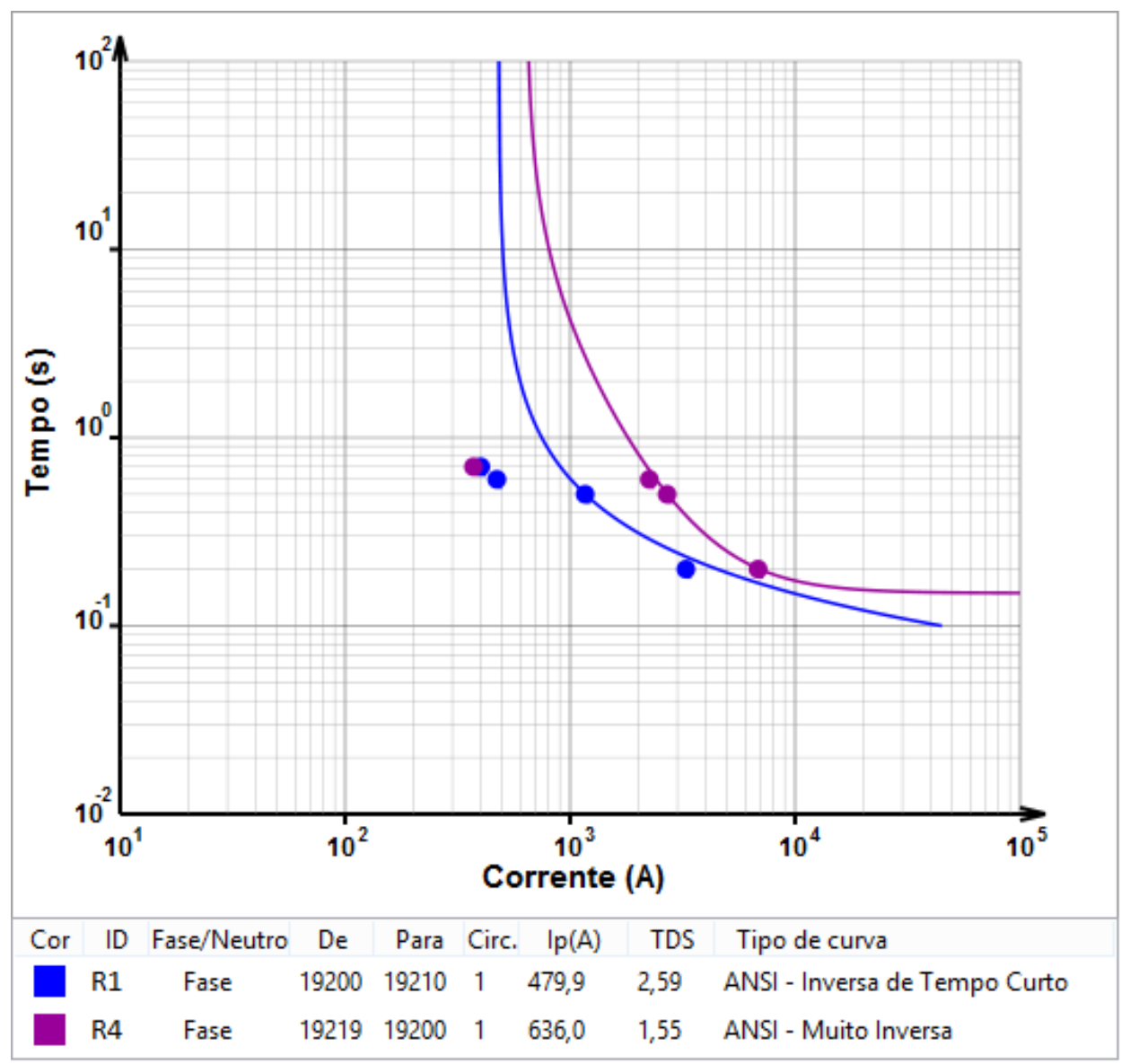

Figura 5.3 - Coordenação entre os relés R1 e R4 de fase.

Tanto para R1 quanto para R4, como há pontos de referência com correntes menores do que o máximo valor da corrente de pick-up, o método de otimização utilizado foi o critério da Integral Logarítmica.

Uma análise mais detalhada da Figura 5.3 mostra que, para uma falta trifásica franca close-in na linha [19200-19210] em que o relé R1 é proteção local, ele é sensibilizado por uma corrente de 3273,5 A, enquanto o relé R4 seria sensibilizado por uma corrente de 2250,3 A. Nestas condições, o tempo de atuação de R1 seria 233 ms e de relé R4 671 ms. Logo ambos estão coordenados por um intervalo de 438 ms. Para uma falta trifásica franca a 80\% da linha [19200-19210], partindo de 19200, o relé R1 é sensibilizado por uma corrente de 1167,0 A, enquanto o relé R4 é sensibilizado por uma corrente baixa, de 372,0 A. Neste caso, o tempo de atuação de R1 seria 501 ms, enquanto R4 não é sensibilizado. Logo, novamente os relés estariam coordenados, com um intervalo de coordenação considerado infinito.

A metodologia também foi aplicada para a proteção de neutro, considerando o arranjo de proteção com proteção de distância de neutro, ou seja, com restrição de limite superior e com os tempos de

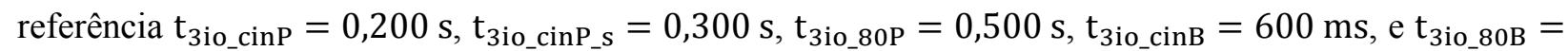
0,700 s. Para o mesmo par R1/R4, o resultado pode ser visto na Figura 5.4. Neste caso, para R1 de neutro foi utilizado o método do Menor Erro, pois todas as correntes de referência são maiores que o máximo da 
corrente de pick-up. Para R4 foi utilizado o método de otimização da Integral Logarítmica, pois, neste caso, $\mathrm{I}_{3 \text { io_cinB }}<\mathrm{I}_{\mathrm{P}_{-} \mathrm{ft} \_ \text {max }}$.

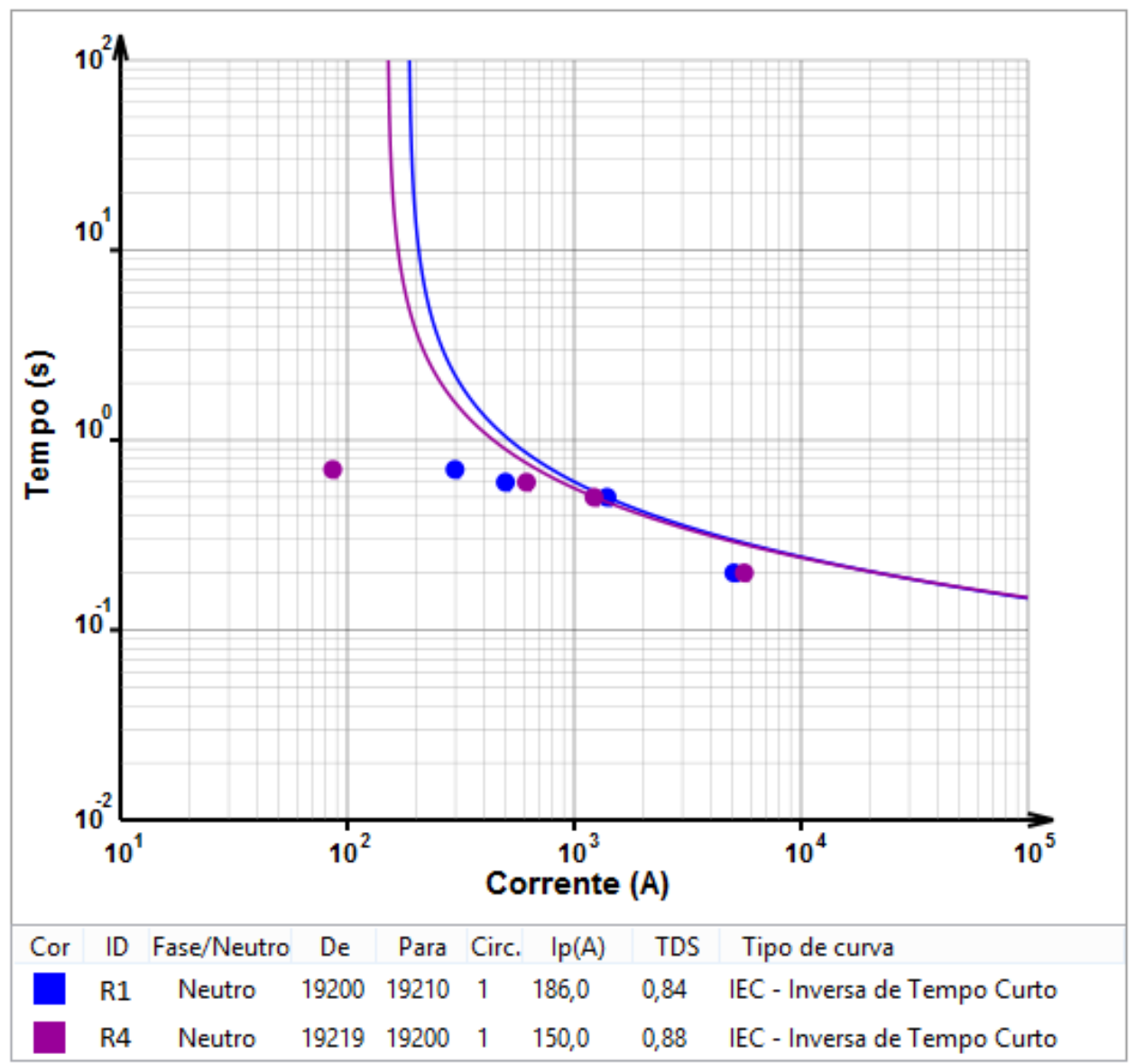

Figura 5.4 - Coordenação entre os relés R1 e R4 de neutro.

$\mathrm{Na}$ proteção de neutro a corrente de pick-up pode assumir valores menores, pois valores consideráveis de correntes de sequência zero somente estão presentes no sistema em caso de faltas envolvendo a terra. Na Figura 5.4, apesar de a curva do relé R1 (principal) estar acima da curva de R4 (retaguarda) eles estão corretamente coordenados, pois as curvas estão acima dos respectivos pontos de referência. Uma análise mais detalhada mostra que, para uma falta monofásica-terra franca close-in na linha [19200-19210] em que o relé R1 é proteção local, ele é sensibilizado por uma corrente de 5058,8 A, enquanto o relé R4 seria sensibilizado por uma corrente de 616,4 A. Nestas condições, o tempo de atuação de R1 seria 297 ms e de relé R4 757 ms. Logo ambos estão coordenados por um intervalo de 460 ms. Para uma falta trifásica franca a $80 \%$ da linha [19200-19210], partindo de 19200, o relé R1 é sensibilizado por uma corrente de 1395,3 A, enquanto o relé R4 é sensibilizado por uma corrente de 86,2 A. Neste caso, o tempo de atuação de R1 seria 500 ms, enquanto R4 não é sensibilizado, confirmando a correta coordenação dos relés.

Outro exemplo interessante de coordenação é dos relés das duas linhas entre as barras 19210 e 19220. As duas linhas paralelas são idênticas, fato que dificultaria a análise topológica em algumas 
metodologias no que diz respeito da garantia de coordenação entre os pares R15/R18 e R16/R17. Porém, realizando uma análise de curto-circuito para os relés atuando tanto como proteção de retaguarda local quanto retaguarda remota, tem-se a garantia da manutenção dos requisitos de coordenação. A Tabela 5.1 mostra que as correntes de referência de fase medidas pelos relés R15 e R17 são maiores do que as correntes de referência sobre os relés R16 e R18, tanto na atuação como retaguarda local quanto na proteção de retaguarda remota. Logo os relés R15 e R17 devem possuir curvas de atuação acima das curvas dos relés R16 e R18. Como as correntes de referência dos relés R15 e R17 são idênticas, devido à simetria do sistema, os ajustes de ambos os relés também irão coincidir. Este fato também é válido para os relés R16 e R18. A figura 5.5 mostra os ajustes de fase dos relés R15, R16, R17 e R18, obtidos após a aplicação do método proposto.

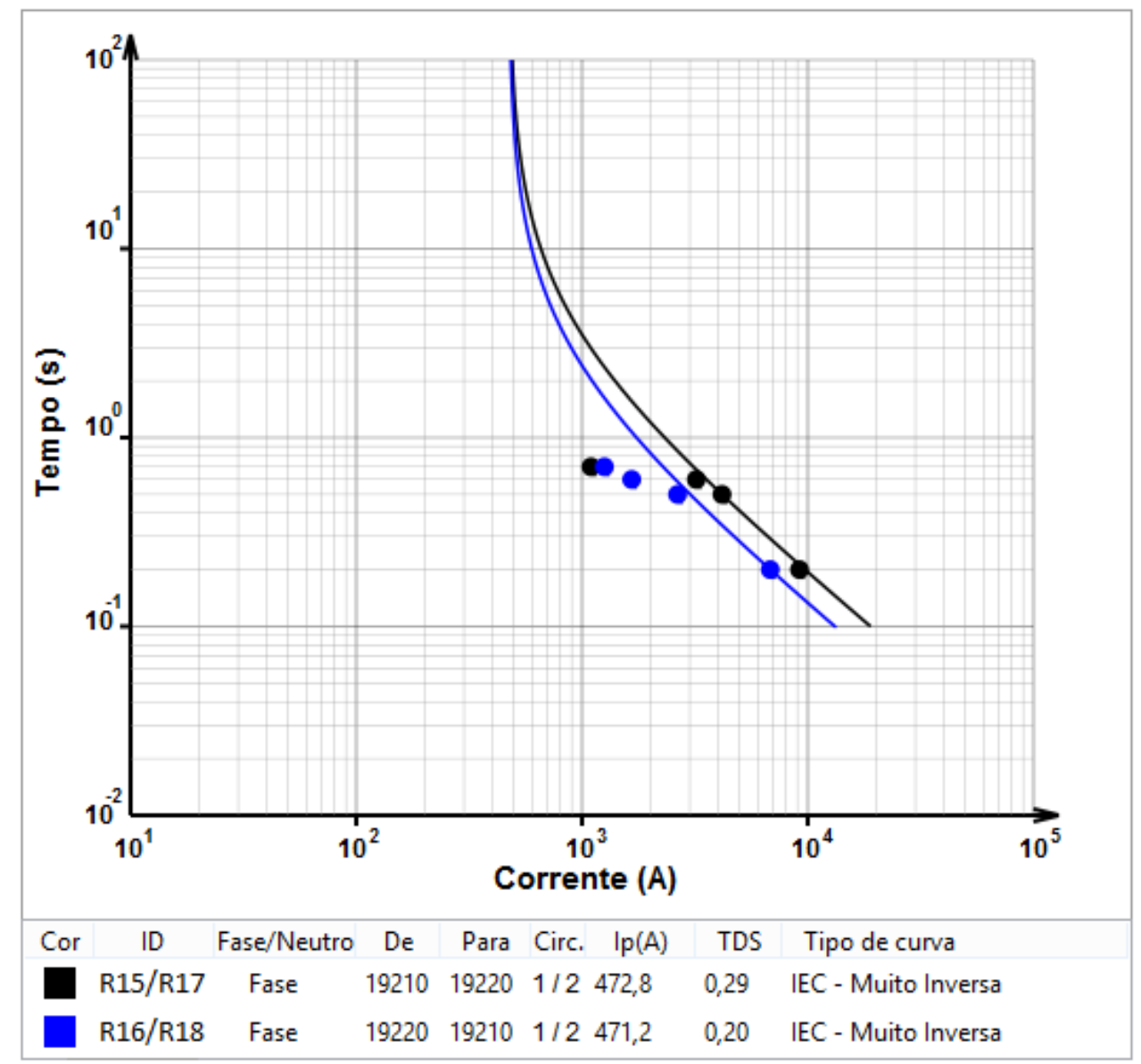

Figura 5.5 - Curvas de atuação dos relés R15, R18, R16 e R17 de fase.

Para uma falta no circuito 2 da linha [19210-19220], os relés R17 e R18 atuam como proteção de retaguarda local e os relé R15 e R16 atuam como retaguarda remota (pares R17-R16 e R18-R15). Para esta situação, verifica-se visualmente na Figura 5.5 que o resultado obtido garante a coordenação. Os pontos de referência de fase indicados para os relés R15 e R17 são $(9194,6 ; 0,200)$, (4171,4;0,500), $(3210,5 ; 0,600)$ e $(1096,5 ; 0,700)$, enquanto que os pontos para os relés R16 e R18 são $(6824,8 ; 0,200)$, $(2651,0 ; 0,500),(1660,3 ; 0,600)$ e $(1256,9 ; 0,700)$. 
Para uma falta no circuito 1 da linha [19210-19220], próximo à barra 19210, a corrente de falta trifásica sentida pelo relé R15 é de 9194,6 A e o tempo de atuação do relé R15 pela solução dada é de 212 ms. Desse modo, o intervalo de coordenação de R15 com o relé 21 instalado no mesmo local (atuando como proteção principal) é de $112 \mathrm{~ms}$, respeitando o intervalo mínimo de $100 \mathrm{~ms}$ definido na seção 4.2. Além disso, os relés de distância nos mesmos locais de R1, R5, R8, R12, R14, R18 e R20, que são os que possuem o local de instalação do relé R15 como segunda zona de proteção (relé de distância retaguarda de R15, 21B no exemplo da Figura 4.2) possuem um intervalo de coordenação de 188 ms para com R15, respeitando os $100 \mathrm{~ms}$ desejados. Para a mesma falta close-in para R15, a corrente medida sob o relé R18 é de 1660,3 A, e o tempo de atuação do relé R18 para esta corrente é de 1,070 s. Logo o intervalo de coordenação entre os relés R18 e R15 foi de 858 ms, e o intervalo de coordenação entre R18 e a segunda zona do relé de distância instalado no mesmo local de R15 é de 670 ms, respeitando o mínimo de $200 \mathrm{~ms}$ definido na seção 4.2 .

Para uma falta trifásica a 80\% da linha [19210-19220] partindo-se da barra 19210, a corrente medida pelo relé R15 é de 4171,4 A e o tempo de atuação pela solução dada é de 500 ms, respeitando o intervalo mínimo de $100 \mathrm{~ms}$ para com a atuação de segunda zona do relé de distância instalado no mesmo local de R15. Para esta mesma falta, o relé R18 não é sensibilizado, pois o sentido da corrente é inverso ao do relé direcional. Como R18 nunca atuará para esta falta, pode-se considerar que ele está corretamente coordenado com R15 e com a proteção de distância para esta situação. Desse modo verificase que, embora seja difícil perceber visualmente que a coordenação está correta, nos dois casos a atuação da proteção de retaguarda remota é corretamente coordenada com a proteção de retaguarda local, além de ser coordenada com a proteção de distância, confirmando a exatidão da metodologia. A mesma análise vale para os ajustes de R17 e R16, cujos ajustes e referências são iguais aos relés R15 e R18 respectivamente.

Aplicando a metodologia para a proteção de neutro dos mesmos relés, os pontos de referência para os relés R15 e R17 são (10371,3; 0,200), (3692,5;0,500), (2592,6;0,600) e (428,1;0,700), enquanto que os pontos para os relés R16 e R18 são (6609,8; 0,200), (3692,5;0,500), $(2592,6 ; 0,600)$ e $(428,1 ; 0,700)$. Os resultados obtidos podem ser vistos na Figura 5.6. Para uma falta monofásica-terra close-in nas respectivas linhas, o intervalo de coordenação obtido entre os relés R15 e R18 (e também R17 e R16) é de 1,127 s, enquanto que, para o mesmo tipo de falta, o par R16 e R17 (e também o par R18 e R15) possui um intervalo de 626 ms. Já para uma falta monofásica-terra a $80 \%$ das respectivas linhas, o intervalo de coordenação obtido entre os relés R15 e R18 (e também R17 e R16) é de 1,857 s, enquanto que, para o mesmo tipo de falta, o par R16 e R17 (e também o par R18 e R15) possui um intervalo de $5,462 \mathrm{~s}$, confirmando a exatidão do método. 


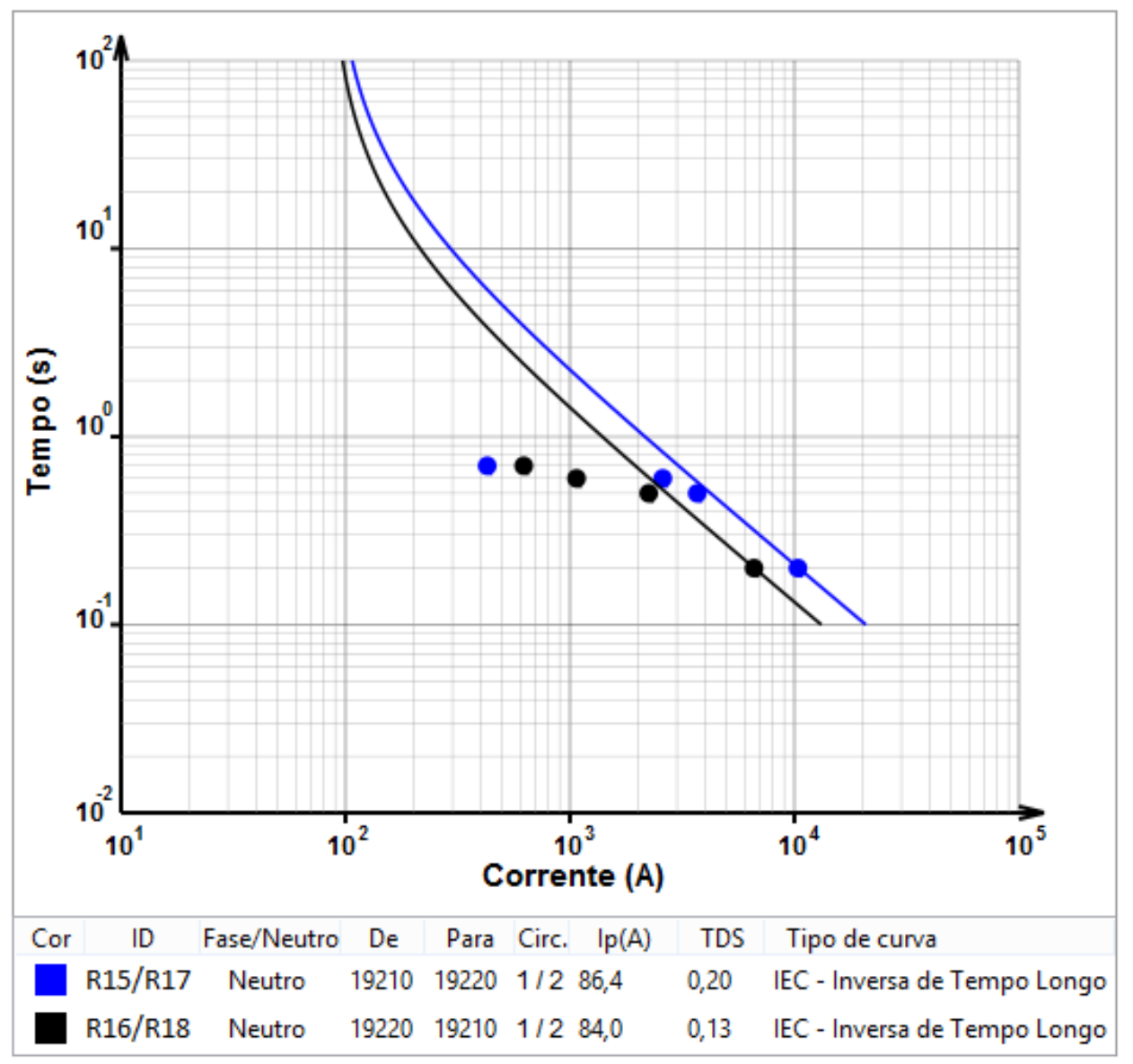

Figura 5.6 - Curvas de atuação dos relés R15, R18, R16 e R17 de neutro.

Outra situação de interessante ocorre quando as restrições de corrente de pick-up impõem que o relé de proteção de retaguarda remota tenha um ajuste de Ip menor do que o relé de proteção de retaguarda local, implicando que as curvas de atuação dos dispositivos se cruzem em determinado momento. A Figura 5.7 mostra um exemplo desta situação para as curvas de atuação dos relés R7 e R9, instalados respectivamente nas linhas [19210-33048] e [33046-33047]. A faixa de ajuste da corrente de pick-up de R9 é de 936,0 a 1279,4 A, enquanto que R7 tem faixa de ajuste entre 346,8 e 1936,6 A. Pelo diagrama do sistema percebe-se que R7 é proteção de retaguarda de R9. Desse modo, apesar de que a corrente de pick-up de $\mathrm{R} 7$ possa assumir valores menores do que a de $\mathrm{R} 9$, os ajustes devem ser tal que a coordenação seja garantida.

Para um curto-circuito trifásico close-in na linha [33046-19280] (próximo ao relé R9), a corrente medida pelo relé R9 é de 3203,5 A, sendo que o tempo de atuação do relé R9 para esta corrente é de 295 ms de acordo com a solução dada pela metodologia. Desse modo, o intervalo de coordenação de R9 com o relé 21 instalado no mesmo local (atuando como proteção principal) é de $195 \mathrm{~ms}$, respeitando o intervalo mínimo de $100 \mathrm{~ms}$ definido na seção 4.2. Além disso, o relé 21 instalado no mesmo local de R7 e que possui o local de instalação do relé R9 como segunda zona de proteção (relé de distância retaguarda de R9, 21B no exemplo da Figura 4.2) possui um intervalo de coordenação de 105 ms para com R9, 
respeitando os $100 \mathrm{~ms}$ desejados. Para a mesma condição de falta, a corrente medida pelo relé R7 é de 2420,5 A, sendo que o tempo de atuação do relé R7 para esta corrente é de $648 \mathrm{~ms}$. Logo o intervalo de coordenação entre os relés R7 e R9 foi de 353 ms, e o intervalo de coordenação entre R7 e a segunda zona do relé de distância instalado no mesmo local de R9 é de $248 \mathrm{~ms}$, respeitando o mínimo de $200 \mathrm{~ms}$ definidos na seção 4.2 .

Para um curto-circuito trifásico na barra remota da linha [33046-19280] (próximo ao relé R10), a corrente medida pelo relé R9 é de 1599,2 A, sendo que o tempo de atuação do relé R9 para esta corrente é de $676 \mathrm{~ms}$, possuindo um intervalo de coordenação de $276 \mathrm{~ms}$ para com a segunda zona do relé de distância instalado no mesmo local de R9, e respeitando o intervalo mínimo de 200 ms. Para esta última situação de falta, a corrente medida pelo relé R7 é de 1040,8 A, sendo que o tempo de atuação do relé R7 para esta corrente é de 3,933 s. Ou seja, nesta última condição o relé R7 também está coordenado com o relé R9 e com a proteção de distância, possuindo um intervalo de 3,257 s para com a atuação de R9. Com estas informações, verifica-se que a coordenação entre o par R9-R7 está garantida para toda a linha em que o relé R9 é retaguarda local. Através apenas do gráfico das curvas de atuação dos relés não se pode visualizar esta informação, porém, com a visualização dos pontos de referência adotados para coordenação percebe-se facilmente a qualidade da resposta obtida.

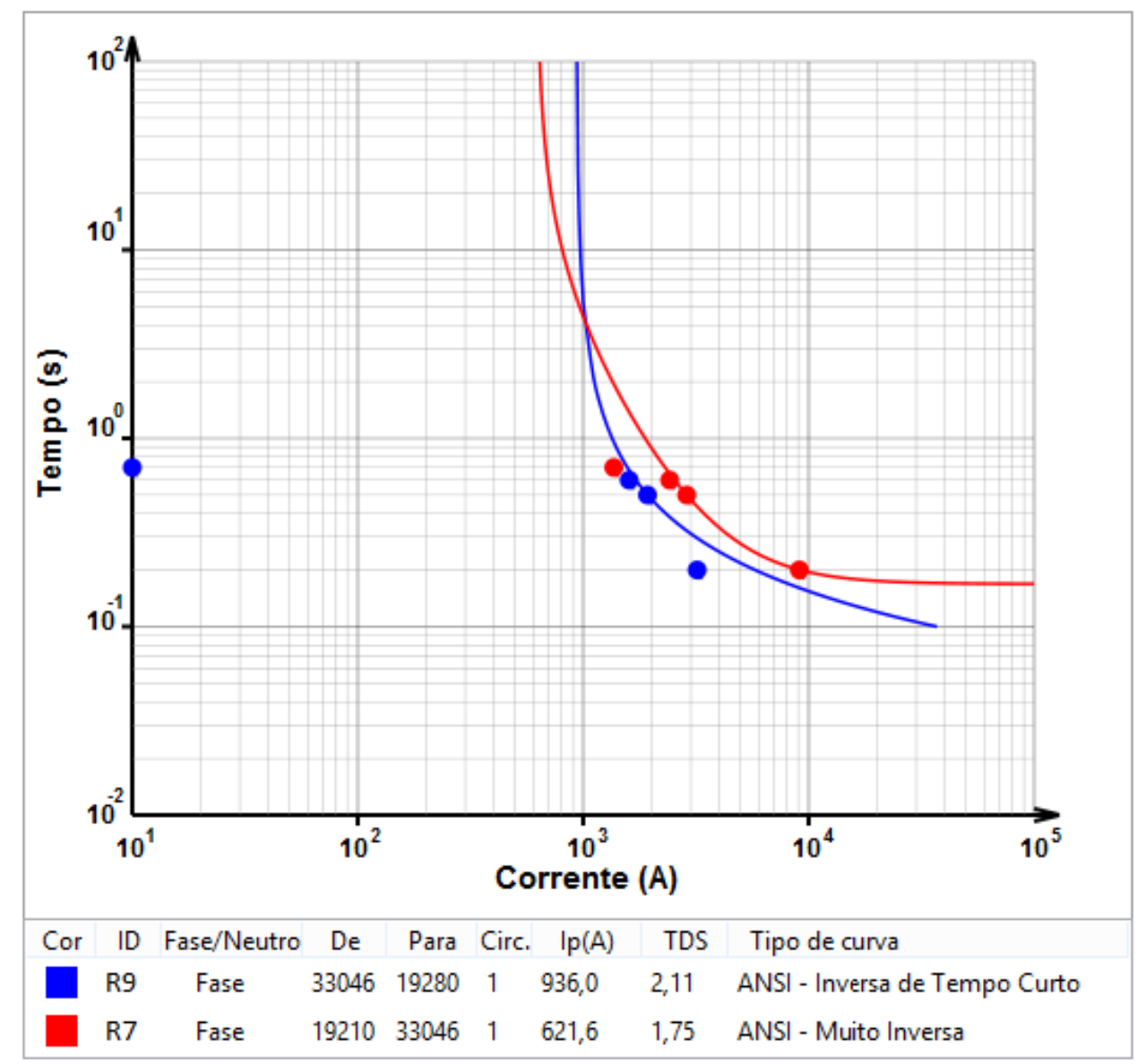

Figura 5.7 - Curvas de atuação dos relés R9 e R7 de fase, sendo o relé R7 retaguarda remota do relé R9. 
Aplicando a metodologia para a proteção de neutro dos relés R7 e R9, os pontos de referência de R7 são (10824,5 ; 0,200), (2205,9; 0,500), (1762,0 ; 0,600) e (2071,1 ; 0,700), enquanto para R9 (1762,0 ; 0,200), (1199,3;0,500), (903,6;0,600) e $(154,2 ; 0,700)$. Os resultados obtidos podem ser vistos na Figura 5.8. Para uma falta monofásica-terra close-in na linha [33046-19280] (próximo ao relé R9), o intervalo de coordenação entre os relés é de $381 \mathrm{~ms}$. Já para uma falta monofásica-terra a $80 \%$ da linha [33046-19280], com relação a R9, o intervalo de coordenação obtido entre os relés é de 1,06 s.

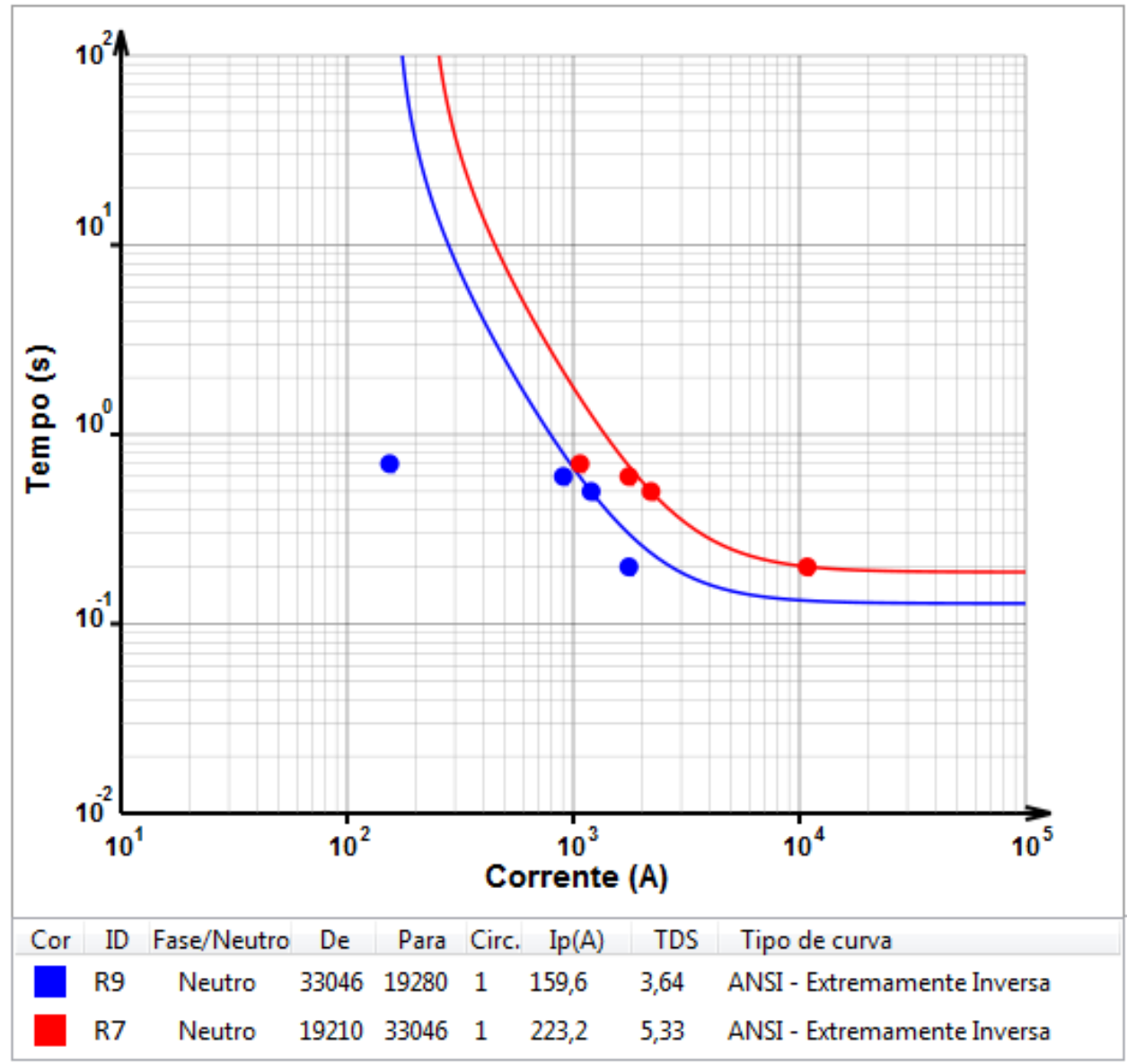

Figura 5.8 - Curvas de atuação dos relés R9 e R7 de neutro, sendo o relé R7 retaguarda remota do relé R9.

A metodologia pode ser aplicada sem que seja considerado o relé de distância, desde que os critérios sejam corretamente adequados. Como exemplo, o algoritmo foi executado para o mesmo sistema de modo que, considerando a ausência de um relé 21 de neutro, os tempos de referência adotados para a

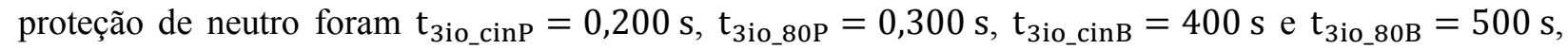
sem restrição de limite superior, conforme a seção 4.3. A Figura 5.9 mostra os resultados obtidos para a proteção de neutro dos relés R1 e R4. 


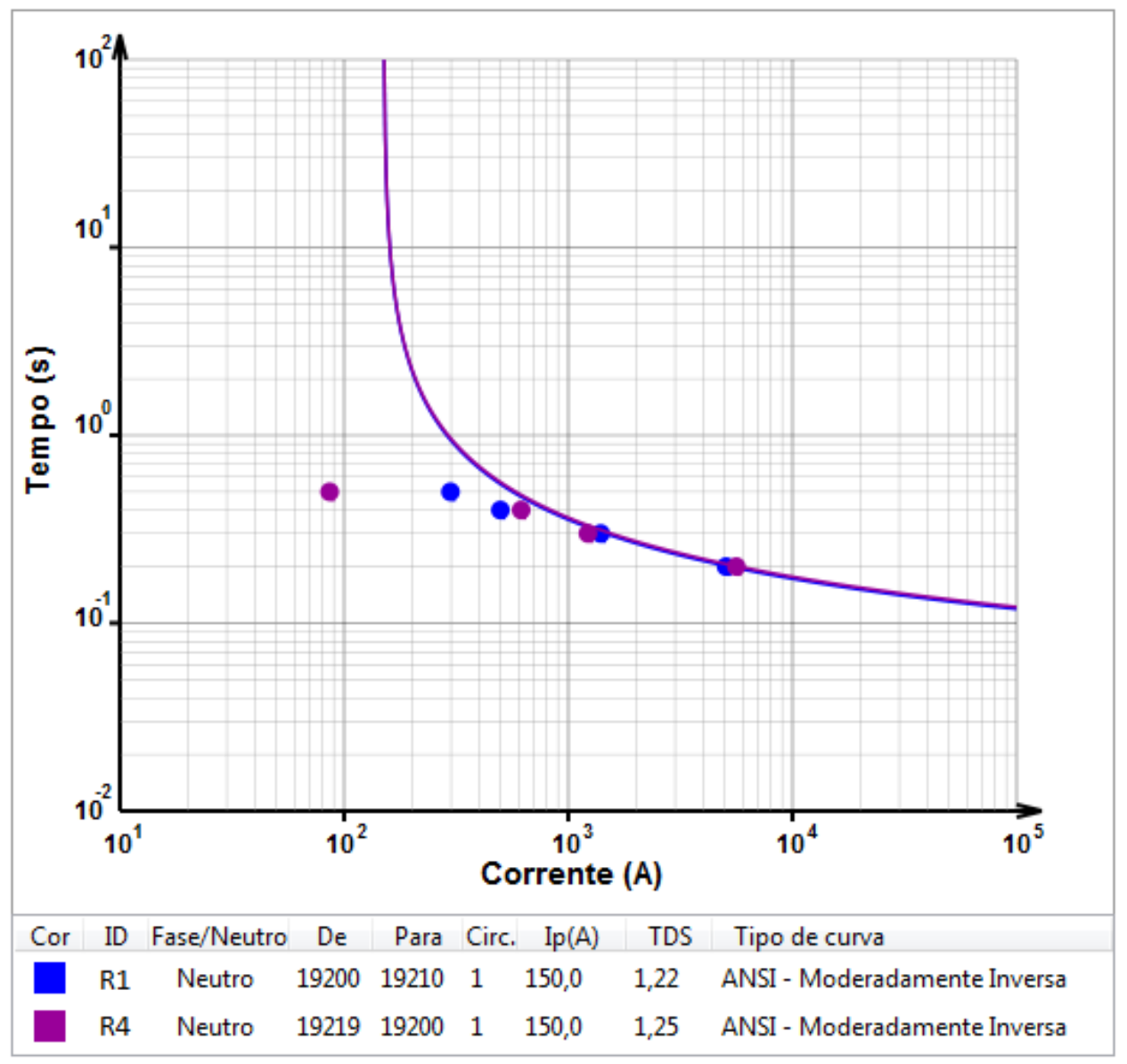

Figura 5.9 - Coordenação entre os relés R1 e R4 de neutro, sem considerar relé 21 como proteção principal.

Neste caso, sem a restrição de limite superior, o algoritmo fica livre para encontrar o melhor ajuste de acordo com o método de otimização utilizado. No caso, sobre R1 utilizou-se o Menor Erro e sobre R4 a Integral Logarítmica. A Tabela 5.5 resume as análises para este par de relés, sendo R1 o principal e R4 o de retaguarda. Nela, T OP é o tempo de operação do relé. A partir dos resultados verificase a exatidão e versatilidade do método.

Tabela 5.5 - Resultados para R1 e R4 como proteção de neutro, sem considerar relé 21 como proteção principal.

\begin{tabular}{|c|c|c|c|c|c|}
\hline $\begin{array}{c}\text { Tipo de falta na } \\
\text { linha [19200-19210] }\end{array}$ & $\begin{array}{c}\text { Corrente } \\
\text { Medida em } \\
\text { R1 (A) }\end{array}$ & $\begin{array}{c}\text { ToP de R1 } \\
\text { (s) }\end{array}$ & $\begin{array}{c}\text { Corrente } \\
\text { Medida em } \\
\text { R4 (A) }\end{array}$ & $\begin{array}{c}\text { ToP de R4 } \\
\text { (s) }\end{array}$ & $\begin{array}{c}\text { Intervalo de } \\
\text { Coordenação (s) }\end{array}$ \\
\hline Close-in & 5058,8 & 0,202 & 616,4 & 0,482 & 0,280 \\
\hline $80 \%$ da linha & 1395,3 & 0,306 & 86,2 & infinito & infinito \\
\hline
\end{tabular}




\subsection{APLICAÇÃO PARA O SISTEMA IEEE 14 BARRAS}

A topologia do sistema teste IEEE de 14 barras é apresentada na Figura 5.10. Ele é composto de 14 barras, 20 ramos e 3 transformadores. Os dados deste sistema se encontram no Apêndice A. Para aplicação da metodologia foram definidos 30 relés dispostos pelas 15 linhas do sistema, conforme a Figura 5.11.

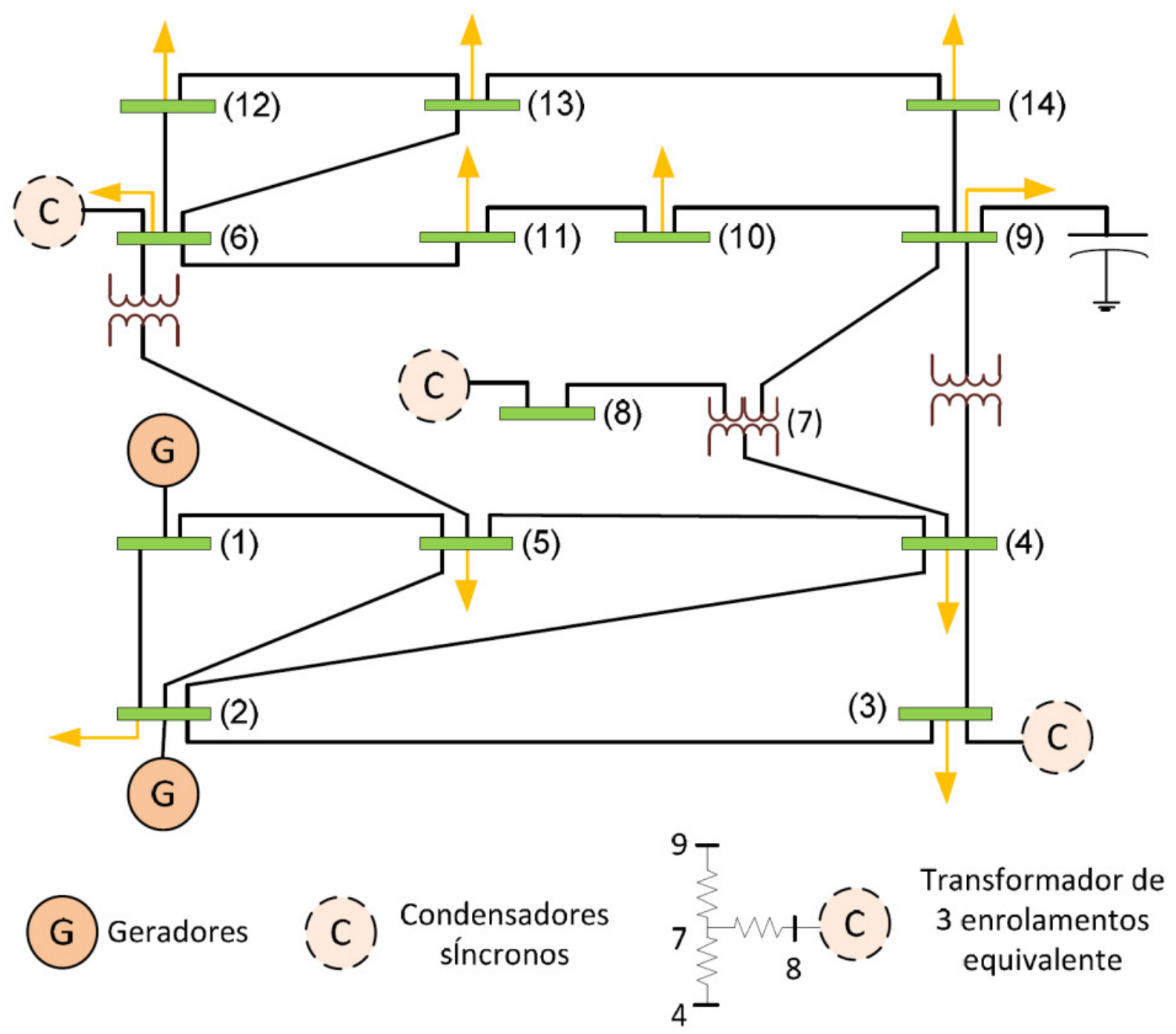

Figura 5.10 - Representação do sistema IEEE 14 barras. 


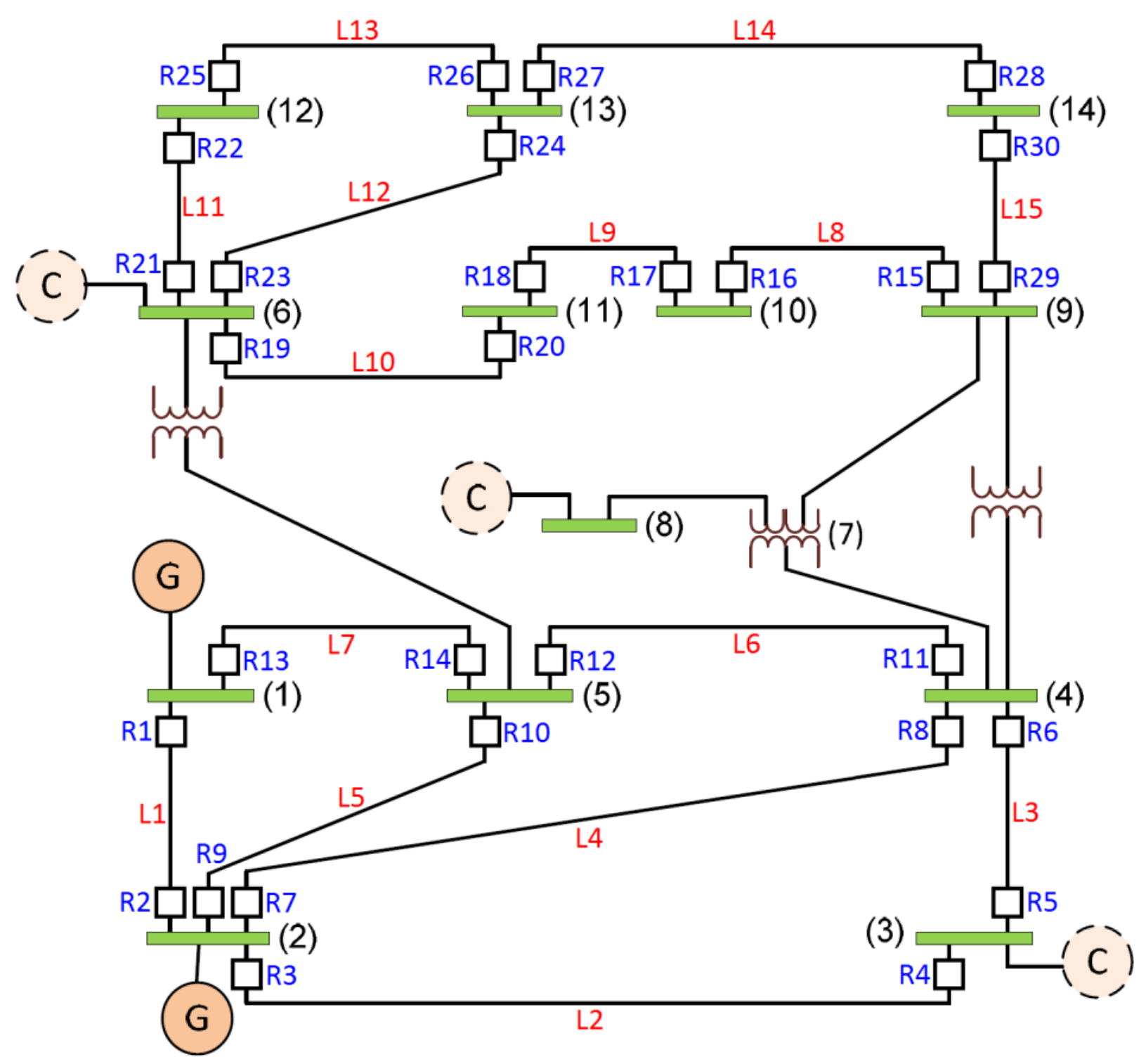

Figura 5.11 - Sistema IEEE 14 barras para a aplicação da metodologia

Sobre este sistema foi realizada uma análise de curto-circuito para obtenção das correntes de referência que são dados de entrada para a metodologia, conforme descrito na seção 4.2. A Tabela 5.6 resume os dados de entrada de fase (faltas trifásicas) enquanto que a Tabela 5.7 mostra os dados de entrada para a proteção de neutro (faltas fase-terra). Para esta análise foi considerado que a unidade direcional somente aceita correntes com ângulos entre $-150^{\circ}$ e $30^{\circ}$ (ou entre $0^{\circ}$ e $30^{\circ}$ e entre $210^{\circ}$ e $360^{\circ}$ ).

Nesse estudo, os TCs foram dimensionados de modo a suportar a faixa de ajuste da corrente de pick-up, levando em consideração a faixa de ajuste de Ip pelo relé descrita na Figura 5.8. Por exemplo, para o relé R1 a faixa de ajuste de Ip pela Tabela 5.6 é entre 1000 e 7979,3 A. Assim, para respeitar a faixa da corrente de pick-up do relé (entre 0,25 e 16 A no secundário pela Tabela 5.8), a relação do TC deve ser no mínimo 498,7 e no máximo 4000. 
Tabela 5.6 - Dados de entrada para os relés de fase do sistema da Figura 5.11.

\begin{tabular}{|c|c|c|c|c|c|c|c|c|c|c|c|}
\hline ID & $\mathrm{DE}$ & PARA & Circ. & $\begin{array}{c}\mathrm{I}_{3 \mathrm{f}_{\text {_cin }} \mathrm{P}} \\
(\mathrm{A})\end{array}$ & $\begin{array}{c}\mathrm{I}_{3 f_{-} 80 \mathrm{P}} \\
(\mathrm{A})\end{array}$ & $\begin{array}{c}\mathrm{I}_{3 \mathrm{f}_{\text {_cin B }} \mathrm{B}} \\
\text { (A) }\end{array}$ & $\begin{array}{c}\mathrm{I}_{3 f_{-} 80 \mathrm{~B}} \\
(\mathrm{~A})\end{array}$ & $\begin{array}{c}\mathrm{TC}_{\text {PRIM }} \\
(\mathrm{A})\end{array}$ & $\begin{array}{c}\mathrm{TC}_{\text {SEC }} \\
(\mathrm{A})\end{array}$ & 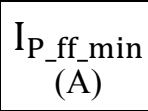 & $\underset{\left(\mathrm{A}_{-}\right)}{\mathrm{I}_{\mathrm{P}_{\text {_ffmax }}}}$ \\
\hline R1 & 1 & 2 & 1 & 11918 & 10357 & 9974,1 & 9430,2 & 500 & 1 & 1000 & 7979,3 \\
\hline $\mathrm{R} 2$ & 2 & 1 & 1 & 6654,9 & 5030 & 4696,7 & 0 & 500 & 1 & 500 & 3757,4 \\
\hline $\mathrm{R} 3$ & 2 & 3 & 1 & 12758 & 10415 & 9911 & 2863,7 & 500 & 1 & 500 & 7929 \\
\hline $\mathrm{R} 4$ & 3 & 2 & 1 & 3068,8 & 1942,5 & 1662,8 & 1569,1 & 300 & 1 & 300 & 1330,3 \\
\hline R5 & 3 & 4 & 1 & 11752 & 2295,6 & 673,41 & 549 & 500 & 1 & 500 & 538,73 \\
\hline R6 & 4 & 3 & 1 & 13015 & 2611,6 & 1118,3 & 142,67 & 500 & 1 & 500 & 894,65 \\
\hline R7 & 2 & 4 & 1 & 13701 & 6985 & 5528,8 & 4275,7 & 500 & 1 & 500 & 4423,1 \\
\hline $\mathrm{R} 8$ & 4 & 2 & 1 & 8239,9 & 2101,1 & 847,61 & 1374,6 & 500 & 1 & 500 & 678,08 \\
\hline R9 & 2 & 5 & 1 & 13536 & 6461,2 & 4913,6 & 4041,5 & 500 & 1 & 500 & 3930,9 \\
\hline $\mathrm{R} 10$ & 5 & 2 & 1 & 8792,8 & 2227,6 & 742,23 & 994,97 & 500 & 1 & 500 & 593,79 \\
\hline R11 & 4 & 5 & 1 & 6476,5 & 4545,3 & 4076,3 & 1517,6 & 500 & 1 & 500 & 3261,1 \\
\hline $\mathrm{R} 12$ & 5 & 4 & 1 & 9796,6 & 7845,5 & 7375 & 2779,2 & 500 & 1 & 500 & 5900 \\
\hline R13 & 1 & 5 & 1 & 13665 & 7105 & 5631,7 & 5103,3 & 600 & 1 & 600 & 4505,3 \\
\hline R14 & 5 & 1 & 1 & 8316,4 & 2166 & 1411 & 0 & 500 & 1 & 500 & 1128,8 \\
\hline $\mathrm{R} 15$ & 9 & 10 & 1 & 11309 & 9583,9 & 9205,9 & 6453,6 & 500 & 1 & 500 & 7364,7 \\
\hline R16 & 10 & 9 & 1 & 2990,4 & 2027,4 & 1779,1 & 926,53 & 300 & 1 & 300 & 1423,3 \\
\hline R17 & 10 & 11 & 1 & 8335,4 & 5507 & 4934,6 & 2745,9 & 500 & 1 & 500 & 3947,7 \\
\hline R18 & 11 & 10 & 1 & 6505,5 & 4297,5 & 3786,2 & 2879,1 & 500 & 1 & 500 & 3029 \\
\hline R19 & 6 & 11 & 1 & 10468 & 6825,7 & 6149 & 3937,9 & 500 & 1 & 500 & 4919,2 \\
\hline $\mathrm{R} 20$ & 11 & 6 & 1 & 5297,5 & 3160,3 & 2645,6 & 1829,7 & 500 & 1 & 500 & 2116,5 \\
\hline R21 & 6 & 12 & 1 & 12751 & 6848,2 & 5900 & 2675,7 & 500 & 1 & 500 & 4720 \\
\hline $\mathrm{R} 22$ & 12 & 6 & 1 & 4270,8 & 1201,6 & 267,46 & 54,333 & 200 & 1 & 200 & 213,97 \\
\hline R23 & 6 & 13 & 1 & 11836 & 7973,6 & 7205,9 & 4122,3 & 500 & 1 & 500 & 5764,7 \\
\hline R24 & 13 & 6 & 1 & 4379,3 & 1856,2 & 1188,9 & 162,83 & 400 & 1 & 400 & 951,12 \\
\hline R25 & 12 & 13 & 1 & 5878,4 & 2609,3 & 1817,8 & 1008,8 & 500 & 1 & 500 & 1454,2 \\
\hline R26 & 13 & 12 & 1 & 9760,7 & 5086 & 4313,8 & 1260,7 & 500 & 1 & 500 & 3451,1 \\
\hline R27 & 13 & 14 & 1 & 8979,4 & 4941,8 & 4232 & 2147,9 & 500 & 1 & 500 & 3385,6 \\
\hline R28 & 14 & 13 & 1 & 6283,3 & 3253,6 & 2589,2 & 1757,5 & 200 & 1 & 200 & 2071,4 \\
\hline R29 & 9 & 14 & 1 & 11673 & 7200,4 & 6453,5 & 3556,8 & 500 & 1 & 500 & 5162,9 \\
\hline R30 & 14 & 9 & 1 & 4075,6 & 1905,5 & 1302,8 & 844,74 & 400 & 1 & 400 & 1042,3 \\
\hline
\end{tabular}


Tabela 5.7 - Dados de entrada para os relés de neutro do sistema da Figura 5.11.

\begin{tabular}{|c|c|c|c|c|c|c|c|c|c|c|c|}
\hline ID & $\mathrm{DE}$ & PARA & Circ. & $\underset{(\mathrm{A})}{\mathrm{I}_{3 \text { io_cinP }}}$ & $\underset{(\mathrm{A})}{\mathrm{I}_{3 \mathrm{io}_{-} 8 \mathrm{P}}}$ & $\underset{\text { (A) }}{\mathrm{I}_{3 \text { io_cinB }}}$ & $\underset{(\mathrm{A})}{\mathrm{I}_{3 \mathrm{io} 80 \mathrm{~B}}}$ & $\begin{array}{c}\mathrm{TC}_{\text {PRIM }} \\
\text { (A) }\end{array}$ & $\begin{array}{c}\mathrm{TC}_{\text {SEC }} \\
(\mathrm{A})\end{array}$ & $\begin{array}{l}\mathrm{I}_{P_{-} f f}(\mathrm{~A}) \\
\text { (A) }\end{array}$ & $\underset{(\mathrm{A})}{\mathrm{I}_{P_{-} f f(\max }}$ \\
\hline R1 & 1 & 2 & 1 & 4091 & 2358,5 & 1917,5 & 819,46 & 80 & 1 & 80 & 240 \\
\hline $\mathrm{R} 2$ & 2 & 1 & 1 & 12174 & 9987,2 & 9495,4 & 2844,9 & 80 & 1 & 80 & 240 \\
\hline $\mathrm{R} 3$ & 2 & 3 & 1 & 9876,3 & 4552 & 3379,5 & 0 & 80 & 1 & 80 & 240 \\
\hline R4 & 3 & 2 & 1 & 9763,6 & 5347,5 & 4214,9 & 3770,7 & 80 & 1 & 80 & 240 \\
\hline R5 & 3 & 4 & 1 & 8605,7 & 3848,1 & 3455,5 & 2899,5 & 80 & 1 & 80 & 240 \\
\hline R6 & 4 & 3 & 1 & 10323 & 4742,6 & 4477,2 & 135,52 & 80 & 1 & 80 & 240 \\
\hline $\mathrm{R} 7$ & 2 & 4 & 1 & 10543 & 3291,8 & 1632,5 & 566,47 & 80 & 1 & 80 & 240 \\
\hline $\mathrm{R} 8$ & 4 & 2 & 1 & 12170 & 5177,9 & 3562,4 & 2829,8 & 80 & 1 & 80 & 240 \\
\hline R9 & 2 & 5 & 1 & 11066 & 3720,4 & 2053,6 & 1054,2 & 80 & 1 & 80 & 240 \\
\hline R10 & 5 & 2 & 1 & 11683 & 4670,5 & 3029,3 & 2090,6 & 80 & 1 & 80 & 240 \\
\hline R11 & 4 & 5 & 1 & 10321 & 8105,4 & 7572,7 & 4132,9 & 80 & 1 & 80 & 240 \\
\hline R12 & 5 & 4 & 1 & 6207,8 & 4044,4 & 3513,1 & 1038,6 & 80 & 1 & 80 & 240 \\
\hline R13 & 1 & 5 & 1 & 9518,7 & 2863 & 1292,5 & 666,1 & 80 & 1 & 80 & 240 \\
\hline R14 & 5 & 1 & 1 & 12452 & 5560 & 4065,1 & 2337,1 & 80 & 1 & 80 & 240 \\
\hline R15 & 9 & 10 & 1 & 10422 & 8702,8 & 8325,5 & 5526,2 & 80 & 1 & 80 & 240 \\
\hline R16 & 10 & 9 & 1 & 3894,3 & 2935,3 & 2686,2 & 1020,9 & 80 & 1 & 80 & 240 \\
\hline R17 & 10 & 11 & 1 & 8899,8 & 6024,2 & 5447,8 & 3276 & 80 & 1 & 80 & 240 \\
\hline R18 & 11 & 10 & 1 & 6088 & 3846,4 & 3321,1 & 2381,7 & 80 & 1 & 80 & 240 \\
\hline R19 & 6 & 11 & 1 & 10237 & 6558,7 & 5877,5 & 3654,1 & 80 & 1 & 80 & 240 \\
\hline $\mathrm{R} 20$ & 11 & 6 & 1 & 5658,7 & 3471,3 & 2932,4 & 2111,2 & 80 & 1 & 80 & 240 \\
\hline $\mathrm{R} 21$ & 6 & 12 & 1 & 12395 & 6465,8 & 5517,5 & 2237 & 80 & 1 & 80 & 240 \\
\hline R22 & 12 & 6 & 1 & 4777,6 & 1691,9 & 752,97 & 458,05 & 80 & 1 & 80 & 240 \\
\hline R23 & 6 & 13 & 1 & 10868 & 6986,8 & 6216,1 & 3115,2 & 80 & 1 & 80 & 240 \\
\hline R24 & 13 & 6 & 1 & 5491,8 & 2952,9 & 2280,3 & 1237,9 & 80 & 1 & 80 & 240 \\
\hline $\mathrm{R} 25$ & 12 & 13 & 1 & 5821,7 & 2531 & 1737,3 & 920,31 & 80 & 1 & 80 & 240 \\
\hline R26 & 13 & 12 & 1 & 9942,7 & 5220,4 & 4441,3 & 1363,8 & 80 & 1 & 80 & 240 \\
\hline R27 & 13 & 14 & 1 & 8710,7 & 4647,2 & 3930,1 & 1810,9 & 80 & 1 & 80 & 240 \\
\hline R28 & 14 & 13 & 1 & 6678,6 & 3625,6 & 2962,3 & 2125,6 & 80 & 1 & 80 & 240 \\
\hline R29 & 9 & 14 & 1 & 11093 & 6593,7 & 5841,8 & 2885,5 & 80 & 1 & 80 & 240 \\
\hline R30 & 14 & 9 & 1 & 4769,2 & 2614,1 & 2020,8 & 1490,9 & 80 & 1 & 80 & 240 \\
\hline
\end{tabular}

Para todos os relés foram adotadas as características de configuração da Tabela 5.8.

Tabela 5.8 - Características dos relés.

\begin{tabular}{|c|c|c|c|c|c|c|c|c|}
\hline \multicolumn{3}{|c|}{ TDS (ANSI) } & \multicolumn{3}{c|}{ TDS (IEC) } & \multicolumn{3}{c|}{ Corrente de pick- } \\
\hline LI & Passo & LS & LI & Passo & LS & LI & Passo & LS \\
\hline 0,5 & 0,01 & 15 & 0,05 & 0,01 & 1 & 0,25 & 0,01 & 16 \\
\hline
\end{tabular}

LI: Limite Inferior LS: Limite Superior 
Neste sistema as correntes variam pouco com a distância, como pode ser visto nas correntes de referência das tabelas 5.6 e 5.7. Desse modo surgem problemas de coordenação ao se admitir a coordenação com o relé de distância, pois, devido ao limite superior de atuação a ser respeitado pelo relé 67, em alguns casos não há solução sem violação das restrições. Devido a esta característica, a metodologia foi aplicada sem a restrição de limite superior em ambas as proteções, de fase e de neutro. Os tempos de referência utilizados para este sistema são mostrados na Tabela 5.9.

Tabela 5.9 - Tempos de referência para a coordenação utilizados no sistema da Figura 5.11.

\begin{tabular}{|c|c|c|c|c|}
\cline { 2 - 5 } \multicolumn{1}{c|}{} & $\mathrm{t}_{\text {cinP }}(\mathrm{s})$ & $\mathrm{t}_{80 \mathrm{P}}(\mathrm{s})$ & $\mathrm{t}_{\text {cinB }}(\mathrm{s})$ & $\mathrm{t}_{80 \mathrm{~B}}(\mathrm{~s})$ \\
\hline Fase & 0,200 & 0,500 & 0,600 & 0,700 \\
\hline Neutro & 0,200 & 0,300 & 0,400 & 0,500 \\
\hline \hline $\begin{array}{c}\text { Intervalo de } \\
\text { Coordenação (s) }\end{array}$ & 0,200 & \multicolumn{3}{|c}{} \\
\hline
\end{tabular}

Os relés 4, 8 e 10 são retaguardas do relé 2. As figuras 5.12 a 5.17 mostram os resultados obtidos para a coordenação dos pares 2-4, $2-8$ e 2-10, nas proteções de fase e de neutro. Nestas figuras também são indicados os pontos de referência. Devido ao baixo decaimento da corrente com a distância neste sistema, a etapa de verificação indica que os tempos de referência tomados como base, de acordo com a Tabela 5.9, nem sempre são suficientes para garantir a coordenação, corrigindo-os automaticamente quando necessário. Por este motivo, em alguns casos os pontos de referência não apresentam os tempos utilizados como base, e sim os valores corrigidos.

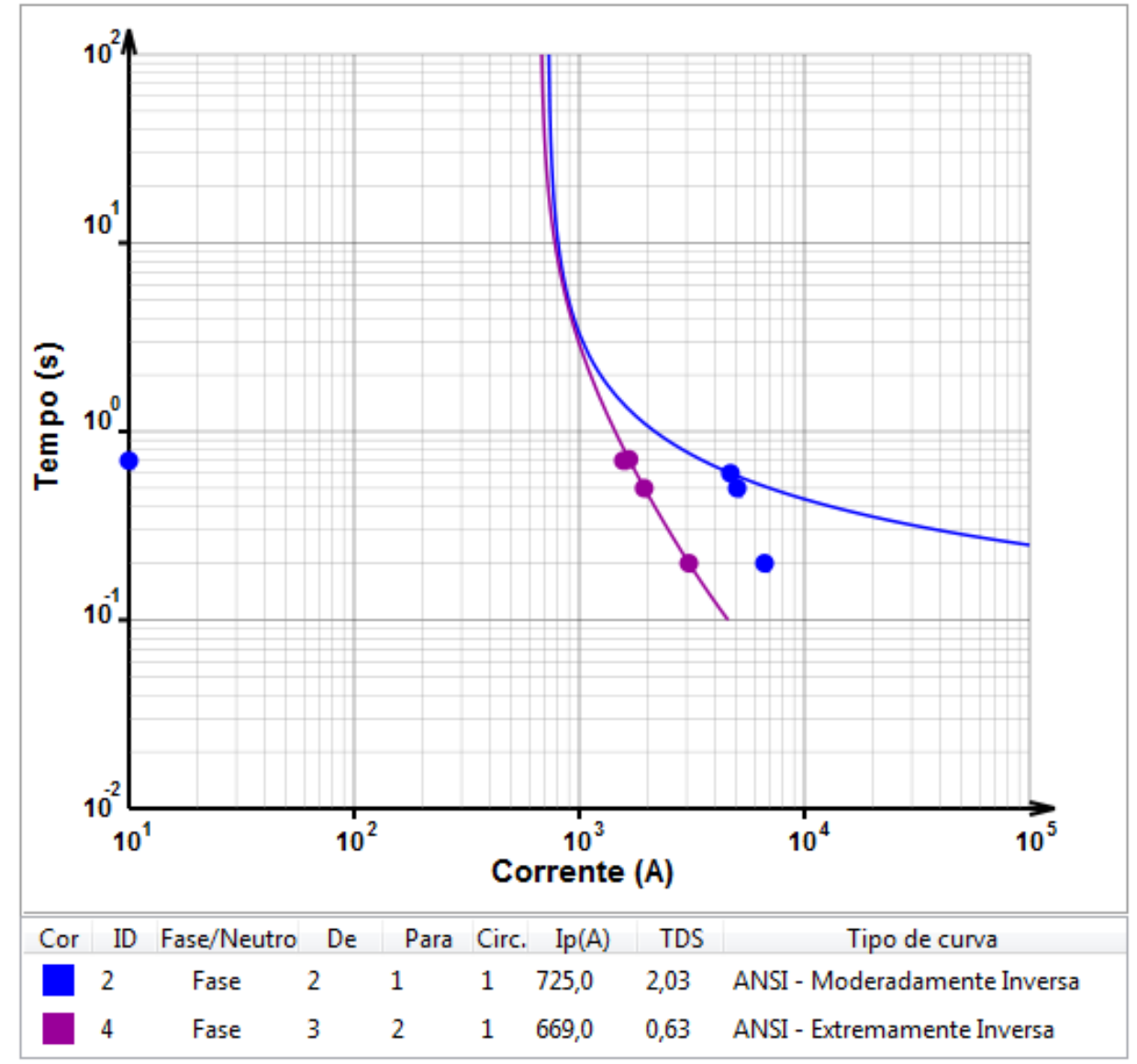

Figura 5.12 - Coordenação entre os relés 2 e 4 de fase. 


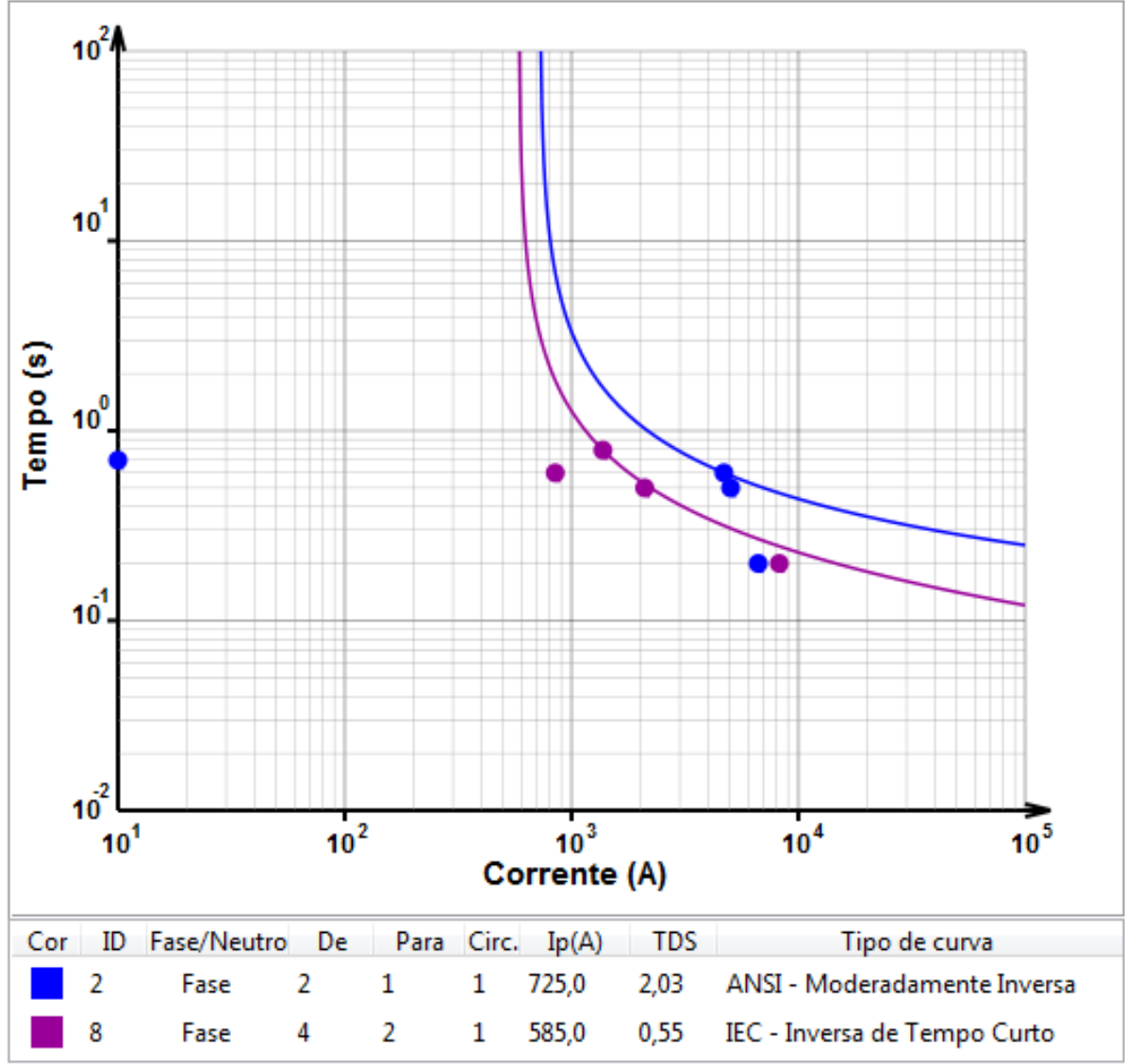

Figura 5.13 - Coordenação entre os relés 2 e 8 de fase.

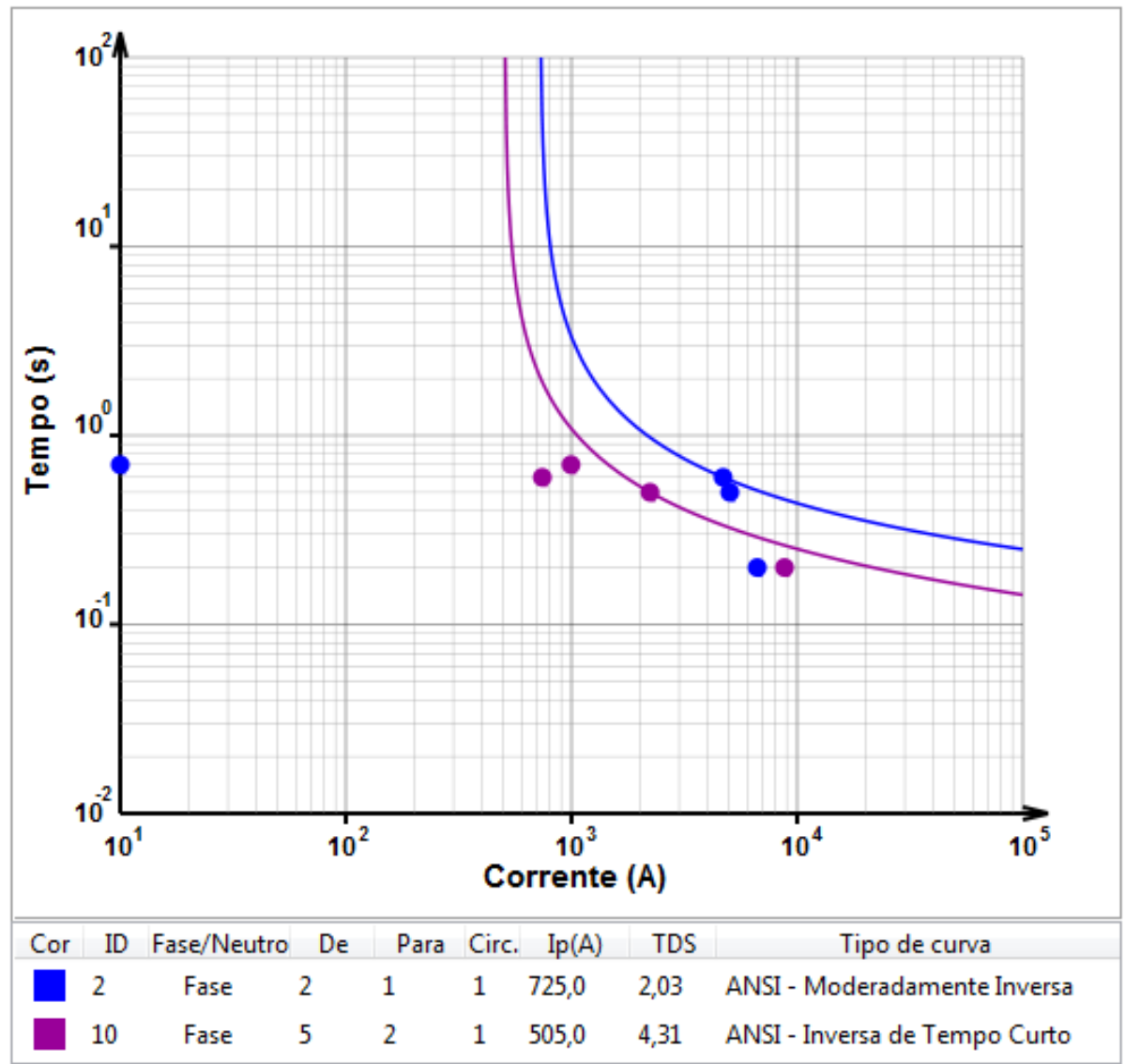

Figura 5.14 - Coordenação entre os relés 2 e 10 de fase. 


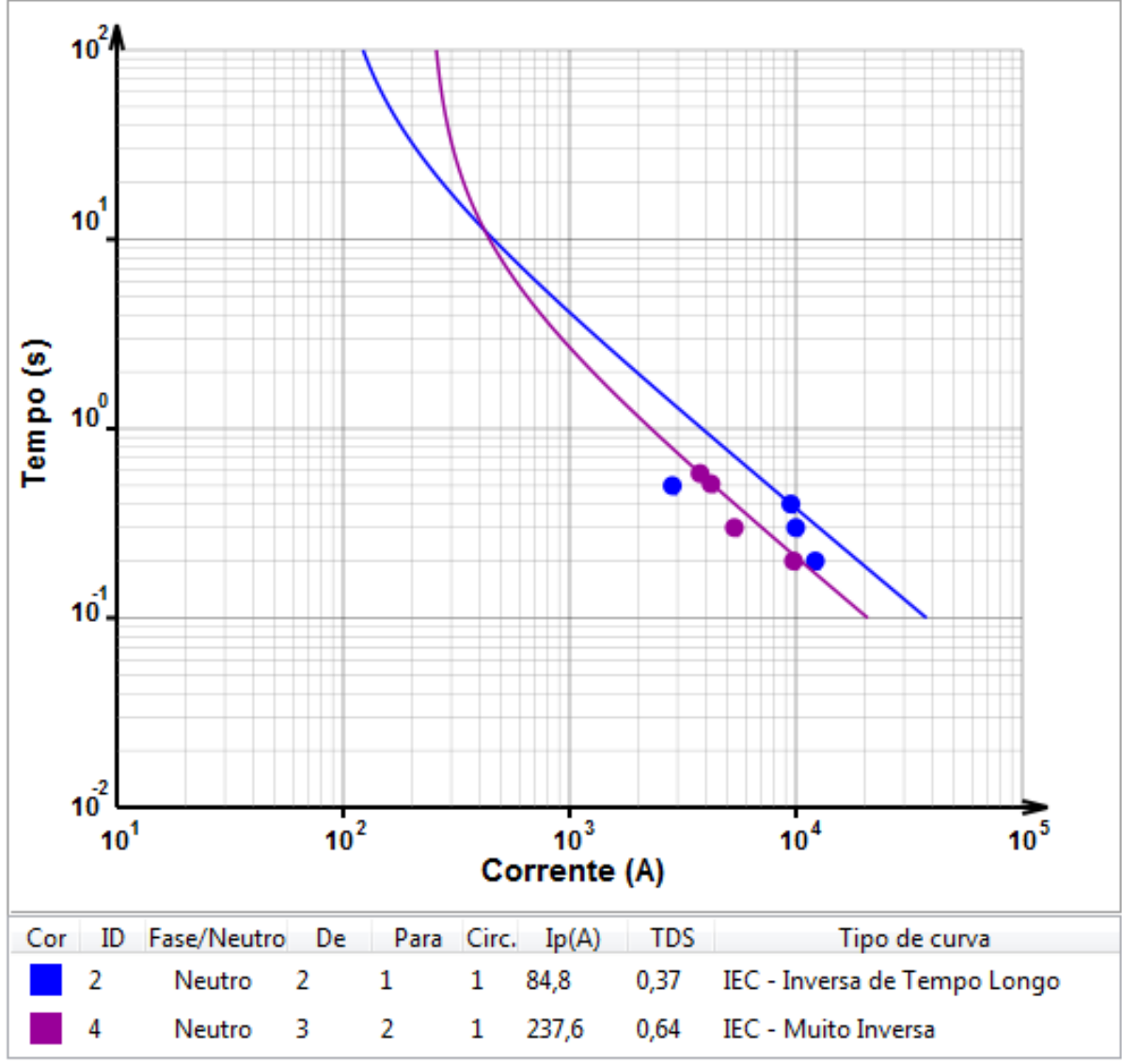

Figura 5.15 - Coordenação entre os relés 2 e 4 de neutro.

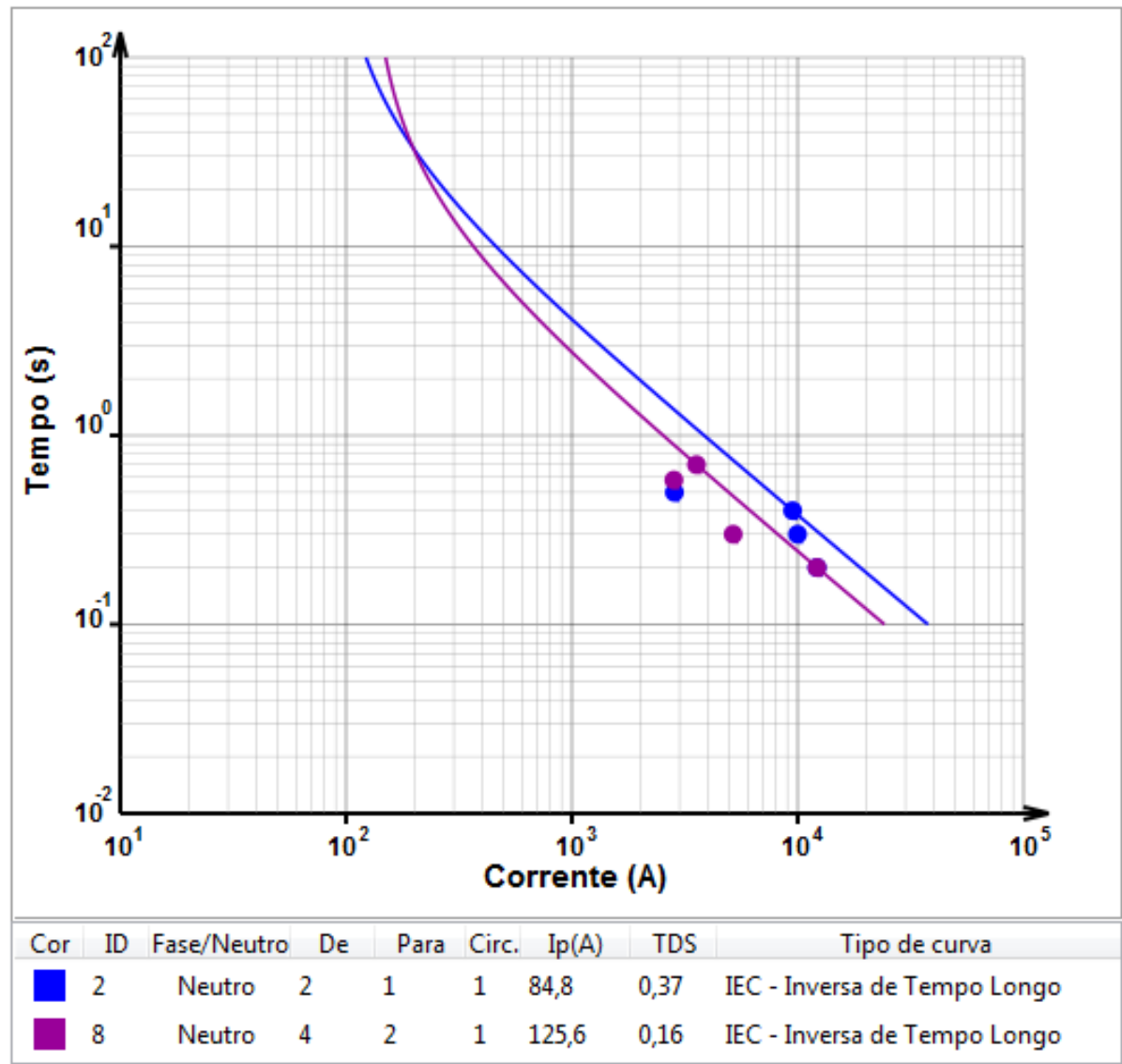

Figura 5.16 - Coordenação entre os relés 2 e 8 de neutro. 


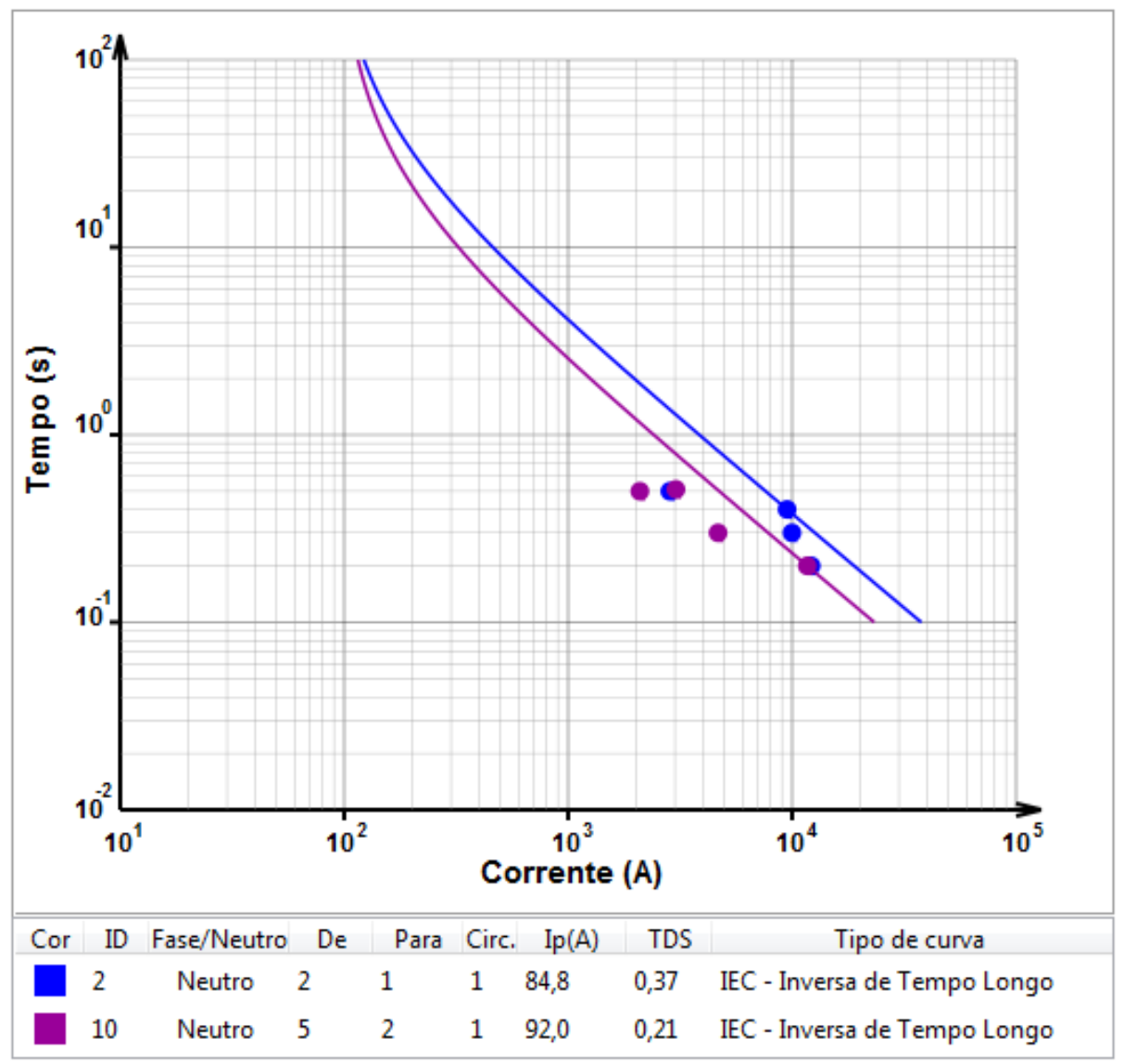

Figura 5.17 - Coordenação entre os relés 2 e 10 de neutro.

As tabelas 5.10 e 5.11 resumem os resultados da atuação dos relés do sistema para proteção de fase e de neutro respectivamente. Nestas tabelas $\mathrm{P}$ indica o relé principal, $\mathrm{R}$ o relé de retaguarda e ITC o intervalo de coordenação obtido para o par em análise. 
Tabela 5.10 - Resultados de fase do sistema IEEE 14 barras: correntes sobre os relés e respectivos tempos de atuação.

\begin{tabular}{|c|c|c|c|c|c|c|c|c|c|c|c|c|}
\hline & \multicolumn{2}{|c|}{ Par } & \multicolumn{5}{|c|}{ Falta close-in } & \multicolumn{5}{|c|}{ Falta a $80 \%$ da linha } \\
\hline ID & $P$ & $\mathrm{R}$ & $\begin{array}{l}\text { Corrente } \\
\text { no } \\
\text { principal } \\
\text { (A) }\end{array}$ & $\begin{array}{l}\text { Atuação } \\
\text { do } \\
\text { principal } \\
\text { (s) }\end{array}$ & $\begin{array}{c}\text { Corrente } \\
\text { no } \\
\text { retaguarda } \\
\text { (A) }\end{array}$ & \begin{tabular}{|} 
Atuação \\
do \\
retaguarda \\
(s)
\end{tabular} & ITC & $\begin{array}{l}\text { Corrente } \\
\text { no } \\
\text { principal } \\
\text { (A) }\end{array}$ & $\begin{array}{l}\text { Atuação } \\
\text { do } \\
\text { principal } \\
\text { (s) }\end{array}$ & $\begin{array}{c}\text { Corrente } \\
\text { no } \\
\text { retaguarda } \\
\text { (A) }\end{array}$ & $\begin{array}{c}\text { Atuação } \\
\text { do } \\
\text { retaguarda } \\
\text { (s) }\end{array}$ & ITC \\
\hline 1 & 1 & 14 & 11918,0 & 0,522 & 1411,0 & 1,025 & 0,503 & 10357,0 & 0,698 & 0,0 & Inf. & Inf. \\
\hline 2 & 2 & 4 & 6654,9 & 0,512 & 1662,8 & 0,712 & 0,201 & 5030,0 & 0,580 & 1569,1 & 0,816 & 0,235 \\
\hline 3 & 2 & 8 & 6654,9 & 0,512 & 847,6 & 1,840 & 1,329 & 5030,0 & 0,580 & 1374,6 & 0,791 & 0,211 \\
\hline 4 & 2 & 10 & 6654,9 & 0,512 & 742,2 & 1,918 & 1,406 & 5030,0 & 0,580 & 995,0 & 1,091 & 0,510 \\
\hline 5 & 3 & 1 & 12758,0 & 0,554 & 9974,1 & 0,755 & 0,201 & 10415,0 & 0,590 & 9430,2 & 0,849 & 0,258 \\
\hline 6 & 3 & 8 & 12758,0 & 0,554 & 847,6 & 1,840 & 1,286 & 10415,0 & 0,590 & 1374,6 & 0,791 & 0,201 \\
\hline 7 & 3 & 10 & 12758,0 & 0,554 & 742,2 & 1,918 & 1,364 & 10415,0 & 0,590 & 995,0 & 1,091 & 0,500 \\
\hline 8 & 4 & 6 & 3068,8 & 0,200 & 1118,3 & 2,631 & 2,430 & 1942,5 & 0,503 & 142,7 & Inf. & Inf. \\
\hline 9 & 5 & 3 & 11752,0 & 0,254 & 9911,0 & 0,600 & 0,346 & 2295,6 & 0,502 & 2863,7 & 1,022 & 0,521 \\
\hline 10 & 6 & 7 & 13015,0 & 0,200 & 5528,8 & 0,661 & 0,461 & 2611,6 & 0,526 & 4275,7 & 0,911 & 0,385 \\
\hline 11 & 6 & 12 & 13015,0 & 0,200 & 7375,0 & 0,600 & 0,399 & 2611,6 & 0,526 & 2779,2 & 1,824 & 1,298 \\
\hline 12 & 7 & 1 & 13701,0 & 0,237 & 9974,1 & 0,755 & 0,518 & 6985,0 & 0,501 & 9430,2 & 0,849 & 0,348 \\
\hline 13 & 7 & 4 & 13701,0 & 0,237 & 1662,8 & 0,712 & 0,475 & 6985,0 & 0,501 & 1569,1 & 0,816 & 0,315 \\
\hline 14 & 7 & 10 & 13701,0 & 0,237 & 742,2 & 1,918 & 1,681 & 6985,0 & 0,501 & 995,0 & 1,091 & 0,590 \\
\hline 15 & 8 & 5 & 8239,9 & 0,246 & 673,4 & 2,536 & 2,289 & 2101,1 & 0,524 & 549,0 & 8,676 & 8,152 \\
\hline 16 & 8 & 12 & 8239,9 & 0,246 & 7375,0 & 0,600 & 0,354 & 2101,1 & 0,524 & 2779,2 & 1,824 & 1,299 \\
\hline 17 & 9 & 1 & 13536,0 & 0,219 & 9974,1 & 0,755 & 0,536 & 6461,2 & 0,501 & 9430,2 & 0,849 & 0,348 \\
\hline 18 & 9 & 4 & 13536,0 & 0,219 & 1662,8 & 0,712 & 0,493 & 6461,2 & 0,501 & 1569,1 & 0,816 & 0,315 \\
\hline 19 & 9 & 8 & 13536,0 & 0,219 & 847,6 & 1,840 & 1,621 & 6461,2 & 0,501 & 1374,6 & 0,791 & 0,290 \\
\hline 20 & 10 & 11 & 8792,8 & 0,262 & 4076,3 & 0,602 & 0,340 & 2227,6 & 0,501 & 1517,6 & 2,211 & 1,710 \\
\hline 21 & 10 & 13 & 8792,8 & 0,262 & 5631,7 & 0,752 & 0,490 & 2227,6 & 0,501 & 5103,3 & 0,904 & 0,403 \\
\hline 22 & 11 & 5 & 6476,5 & 0,358 & 673,4 & 2,536 & 2,178 & 4545,3 & 0,531 & 549,0 & 8,676 & 8,145 \\
\hline 23 & 11 & 7 & 6476,5 & 0,358 & 5528,8 & 0,661 & 0,303 & 4545,3 & 0,531 & 4275,7 & 0,911 & 0,380 \\
\hline 24 & 12 & 9 & 9796,6 & 0,443 & 4913,6 & 0,697 & 0,254 & 7845,5 & 0,562 & 4041,5 & 0,895 & 0,334 \\
\hline 25 & 12 & 13 & 9796,6 & 0,443 & 5631,7 & 0,752 & 0,309 & 7845,5 & 0,562 & 5103,3 & 0,904 & 0,342 \\
\hline 26 & 13 & 2 & 13665,0 & 0,200 & 4696,7 & 0,600 & 0,400 & 7105,0 & 0,500 & 0,0 & Inf. & Inf. \\
\hline 27 & 14 & 9 & 8316,4 & 0,200 & 4913,6 & 0,697 & 0,497 & 2166,0 & 0,503 & 4041,5 & 0,895 & 0,393 \\
\hline 28 & 14 & 11 & 8316,4 & 0,200 & 4076,3 & 0,602 & 0,402 & 2166,0 & 0,503 & 1517,6 & 2,211 & 1,708 \\
\hline 29 & 15 & 30 & 11309,0 & 0,396 & 1302,8 & 1,023 & 0,626 & 9583,9 & 0,553 & 844,7 & 3,184 & 2,630 \\
\hline 30 & 16 & 18 & 2990,4 & 0,227 & 3786,2 & 0,648 & 0,421 & 2027,4 & 0,501 & 2879,1 & 1,142 & 0,641 \\
\hline 31 & 17 & 15 & 8335,4 & 0,218 & 9205,9 & 0,600 & 0,383 & 5507,0 & 0,501 & 6453,6 & 1,235 & 0,734 \\
\hline 32 & 18 & 19 & 6505,5 & 0,216 & 6149,0 & 0,617 & 0,401 & 4297,5 & 0,500 & 3937,9 & 1,524 & 1,023 \\
\hline 33 & 19 & 22 & 10468,0 & 0,212 & 267,5 & 31,616 & 31,405 & 6825,7 & 0,500 & 54,3 & Inf. & Inf. \\
\hline 34 & 19 & 24 & 10468,0 & 0,212 & 1188,9 & 1,142 & 0,931 & 6825,7 & 0,500 & 162,8 & Inf. & Inf. \\
\hline 35 & 20 & 17 & 5297,5 & 0,201 & 4934,6 & 0,625 & 0,424 & 3160,3 & 0,501 & 2745,9 & 2,071 & 1,570 \\
\hline 36 & 21 & 20 & 12751,0 & 0,264 & 2645,6 & 0,713 & 0,449 & 6848,2 & 0,510 & 1829,7 & 1,595 & 1,085 \\
\hline 37 & 21 & 24 & 12751,0 & 0,264 & 1188,9 & 1,142 & 0,878 & 6848,2 & 0,510 & 162,8 & Inf. & Inf. \\
\hline 38 & 22 & 26 & 4270,8 & 0,200 & 4313,8 & 0,604 & 0,404 & 1201,6 & 0,836 & 1260,7 & 3,077 & 2,240 \\
\hline 39 & 23 & 20 & 11836,0 & 0,226 & 2645,6 & 0,713 & 0,487 & 7973,6 & 0,500 & 1829,7 & 1,595 & 1,095 \\
\hline 40 & 23 & 22 & 11836,0 & 0,226 & 267,5 & 31,616 & 31,390 & 7973,6 & 0,500 & 54,3 & Inf. & Inf. \\
\hline 41 & 24 & 25 & 4379,3 & 0,200 & 1817,8 & 0,831 & 0,631 & 1856,2 & 0,503 & 1008,8 & 2,165 & 1,662 \\
\hline 42 & 24 & 28 & 4379,3 & 0,200 & 2589,2 & 0,669 & 0,468 & 1856,2 & 0,503 & 1757,5 & 1,154 & 0,651 \\
\hline 43 & 25 & 21 & 5878,4 & 0,203 & 5900,0 & 0,600 & 0,397 & 2609,3 & 0,518 & 2675,7 & 1,498 & 0,980 \\
\hline 44 & 26 & 23 & 9760,7 & 0,248 & 7205,9 & 0,613 & 0,365 & 5086,0 & 0,502 & 4122,3 & 1,906 & 1,404 \\
\hline 45 & 26 & 28 & 9760,7 & 0,248 & 2589,2 & 0,669 & 0,420 & 5086,0 & 0,502 & 1757,5 & 1,154 & 0,652 \\
\hline 46 & 27 & 23 & 8979,4 & 0,261 & 7205,9 & 0,613 & 0,352 & 4941,8 & 0,503 & 4122,3 & 1,906 & 1,404 \\
\hline 47 & 27 & 25 & 8979,4 & 0,261 & 1817,8 & 0,831 & 0,570 & 4941,8 & 0,503 & 1008,8 & 2,165 & 1,663 \\
\hline 48 & 28 & 29 & 6283,3 & 0,233 & 6453,5 & 0,658 & 0,425 & 3253,6 & 0,500 & 3556,8 & 2,211 & 1,711 \\
\hline 49 & 29 & 16 & 11673,0 & 0,200 & 1779,1 & 0,656 & 0,456 & 7200,4 & 0,528 & 926,5 & 2,673 & 2,145 \\
\hline 50 & 30 & 27 & 4075,6 & 0,201 & 4232,0 & 0,600 & 0,399 & 1905,5 & 0,500 & 2147,9 & 1,398 & 0,898 \\
\hline
\end{tabular}


Tabela 5.11 - Resultados de neutro do sistema IEEE 14 barras: correntes sobre os relés e respectivos tempos de atuação.

\begin{tabular}{|c|c|c|c|c|c|c|c|c|c|c|c|c|}
\hline & \multicolumn{2}{|c|}{ Par } & \multicolumn{5}{|c|}{ Falta close-in } & \multicolumn{5}{|c|}{ Falta a $80 \%$ da linha } \\
\hline ID & $\mathrm{P}$ & $\mathrm{R}$ & $\begin{array}{l}\text { Corrente } \\
\text { no } \\
\text { principal } \\
\text { (A) }\end{array}$ & $\begin{array}{l}\text { Atuação } \\
\text { do } \\
\text { principal } \\
\text { (s) }\end{array}$ & \begin{tabular}{|} 
Corrente \\
no \\
retaguarda \\
(A)
\end{tabular} & $\begin{array}{c}\text { Atuação } \\
\text { do } \\
\text { retaguarda } \\
\text { (s) }\end{array}$ & ITC & $\begin{array}{l}\text { Corrente } \\
\text { no } \\
\text { principal } \\
\text { (A) }\end{array}$ & $\begin{array}{l}\text { Atuação } \\
\text { do } \\
\text { principal } \\
\text { (s) }\end{array}$ & $\begin{array}{l}\text { Corrente } \\
\text { no } \\
\text { retaguarda } \\
\text { (A) }\end{array}$ & \begin{tabular}{|} 
Atuação \\
do \\
retaguarda \\
(s)
\end{tabular} & ITC \\
\hline 1 & 1 & 14 & 4091,0 & 0,306 & 4065,1 & 0,622 & 0,316 & 2358,5 & 0,555 & 2337,1 & 1,100 & 0,545 \\
\hline 2 & 2 & 4 & 12174,0 & 0,311 & 4214,9 & 0,516 & 0,205 & 9987,2 & 0,380 & 3770,7 & 0,581 & 0,201 \\
\hline 3 & 2 & 8 & 12174,0 & 0,311 & 3562,4 & 0,702 & 0,390 & 9987,2 & 0,380 & 2829,8 & 0,892 & 0,512 \\
\hline 4 & 2 & 10 & 12174,0 & 0,311 & 3029,3 & 0,789 & 0,478 & 9987,2 & 0,380 & 2090,6 & 1,160 & 0,780 \\
\hline 5 & 3 & 1 & 9876,3 & 0,500 & 1917,5 & 0,701 & 0,201 & 4552,0 & 0,594 & 819,5 & 2,007 & 1,413 \\
\hline 6 & 3 & 8 & 9876,3 & 0,500 & 3562,4 & 0,702 & 0,202 & 4552,0 & 0,594 & 2829,8 & 0,892 & 0,298 \\
\hline 7 & 3 & 10 & 9876,3 & 0,500 & 3029,3 & 0,789 & 0,289 & 4552,0 & 0,594 & 2090,6 & 1,160 & 0,566 \\
\hline 8 & 4 & 6 & 9763,6 & 0,216 & 4477,2 & 0,476 & 0,260 & 5347,5 & 0,402 & 135,5 & Inf. & Inf. \\
\hline 9 & 5 & 3 & 8605,7 & 0,216 & 3379,5 & 0,691 & 0,474 & 3848,1 & 0,501 & 0,0 & Inf. & Inf. \\
\hline 10 & 6 & 7 & 10323,0 & 0,200 & 1632,5 & 0,492 & 0,292 & 4742,6 & 0,448 & 566,5 & 1,113 & 0,665 \\
\hline 11 & 6 & 12 & 10323,0 & 0,200 & 3513,1 & 0,400 & 0,200 & 4742,6 & 0,448 & 1038,6 & 1,476 & 1,029 \\
\hline 12 & 7 & 1 & 10543,0 & 0,241 & 1917,5 & 0,701 & 0,460 & 3291,8 & 0,356 & 819,5 & 2,007 & 1,651 \\
\hline 13 & 7 & 4 & 10543,0 & 0,241 & 4214,9 & 0,516 & 0,275 & 3291,8 & 0,356 & 3770,7 & 0,581 & 0,225 \\
\hline 14 & 7 & 10 & 10543,0 & 0,241 & 3029,3 & 0,789 & 0,548 & 3291,8 & 0,356 & 2090,6 & 1,160 & 0,804 \\
\hline 15 & 8 & 5 & 12170,0 & 0,200 & 3455,5 & 0,561 & 0,361 & 5177,9 & 0,477 & 2899,5 & 0,678 & 0,201 \\
\hline 16 & 8 & 12 & 12170,0 & 0,200 & 3513,1 & 0,400 & 0,200 & 5177,9 & 0,477 & 1038,6 & 1,476 & 0,999 \\
\hline 17 & 9 & 1 & 11066,0 & 0,201 & 1917,5 & 0,701 & 0,499 & 3720,4 & 0,300 & 819,5 & 2,007 & 1,706 \\
\hline 18 & 9 & 4 & 11066,0 & 0,201 & 4214,9 & 0,516 & 0,315 & 3720,4 & 0,300 & 3770,7 & 0,581 & 0,281 \\
\hline 19 & 9 & 8 & 11066,0 & 0,201 & 3562,4 & 0,702 & 0,500 & 3720,4 & 0,300 & 2829,8 & 0,892 & 0,592 \\
\hline 20 & 10 & 11 & 11683,0 & 0,200 & 7572,7 & 0,400 & 0,200 & 4670,5 & 0,506 & 4132,9 & 0,752 & 0,246 \\
\hline 21 & 10 & 13 & 11683,0 & 0,200 & 1292,5 & 0,444 & 0,244 & 4670,5 & 0,506 & 666,1 & 720 & 0,213 \\
\hline 22 & 11 & 5 & 10321,0 & 0,291 & 3455,5 & 0,561 & 0,270 & 8105,4 & 0,373 & 2899,5 & 0,678 & 0,305 \\
\hline 23 & 11 & 7 & 10321,0 & 0,291 & 1632,5 & 0,492 & 0,201 & 8105,4 & 0,373 & 566,5 & 1,113 & 0,739 \\
\hline 24 & 12 & 9 & & & & & & & 0,346 & & 1,636 & 1,290 \\
\hline 25 & 12 & 13 & 6207,8 & 0,223 & 1292,5 & 0,444 & 0,221 & 4044,4 & 0,346 & 666,1 & 0,720 & 0,374 \\
\hline 26 & 13 & 2 & 9518,7 & 0,200 & 9495,4 & 0,400 & 0,200 & 2863,0 & 0,301 & 2844,9 & 1,364 & 1,063 \\
\hline 27 & 14 & 9 & & & & & & & 0,452 & & 1,636 & 1,184 \\
\hline 28 & 14 & 11 & 12452,0 & 0,200 & 7572,7 & 0,400 & 0,200 & 5560,0 & 0,452 & 4132,9 & 0,752 & 0,300 \\
\hline 29 & 15 & 30 & 10422,0 & 0,448 & 2020,8 & 1,129 & 0,681 & 8702,8 & 0,539 & 1490,9 & 2,099 & 1,560 \\
\hline 30 & 16 & 18 & & & & & 0,366 & & 353 & & 0,814 & 0,461 \\
\hline 31 & 17 & 15 & 8899,8 & 0,284 & 8325,5 & 0,564 & 0,280 & 6024,2 & 0,425 & 5526,2 & 0,863 & 0,438 \\
\hline 32 & 18 & 19 & 6088,0 & 0,298 & 5877,5 & 0,498 & 0,200 & 3846,4 & 0,483 & 3654,1 & 0,823 & 0,339 \\
\hline 33 & 19 & 22 & 10237,0 & 0,281 & 753,0 & 0,545 & 0,264 & 6558,7 & 0,445 & 458,1 & 0,974 & 0,529 \\
\hline 34 & 19 & 24 & 10237,0 & 0,281 & 2280,3 & 0,526 & 0,245 & 6558,7 & 0,445 & 1237,9 & 1,072 & 0,628 \\
\hline 35 & 20 & 17 & 5658,7 & 0,271 & 5447,8 & 0,472 & 0,200 & 3471,3 & 0,454 & 3276,0 & 0,809 & 0,354 \\
\hline 36 & 21 & 20 & 12395,0 & 0,200 & 2932,4 & 0,545 & 0,345 & 6465,8 & 0,386 & 2111,2 & 0,783 & 0,397 \\
\hline 37 & 21 & 24 & 12395,0 & 0,200 & 2280,3 & 0,526 & 0,326 & 6465,8 & 0,386 & 1237,9 & 1,072 & 0,686 \\
\hline 38 & 22 & 26 & 4777,6 & 0,201 & 4441,3 & 0,454 & 0,253 & 1691,9 & 0,314 & 1363,8 & 1,543 & 1,229 \\
\hline 39 & 23 & 20 & 10868,0 & 0,293 & 2932,4 & 0,545 & 0,252 & 6986,8 & 0,462 & 2111,2 & 0,783 & 0,321 \\
\hline 40 & 23 & 22 & 10868,0 & 0,293 & 753,0 & 0,545 & 0,251 & 6986,8 & 0,462 & 458,1 & 0,974 & 0,512 \\
\hline 41 & 24 & 25 & 5491,8 & 0,205 & 1737,3 & 0,523 & 0,318 & 2952,9 & 0,396 & 920,3 & 1,473 & 1,077 \\
\hline 42 & 24 & 28 & 5491,8 & 0,205 & 2962,3 & 0,460 & 0,255 & 2952,9 & 0,396 & 2125,6 & 0,648 & 0,252 \\
\hline 43 & 25 & 21 & 5821,7 & 0,200 & 5517,5 & 0,454 & 0,254 & 2531,0 & 0,335 & 2237,0 & 1,150 & 0,815 \\
\hline 44 & 26 & 23 & 9942,7 & 0,201 & 6216,1 & 0,522 & 0,321 & 5220,4 & 0,385 & 3115,2 & 1,082 & 0,697 \\
\hline 45 & 26 & 28 & 9942,7 & 0,201 & 2962,3 & 0,460 & 0,259 & 5220,4 & 0,385 & 2125,6 & 0,648 & 0,263 \\
\hline 46 & 27 & 23 & 8710,7 & 0,201 & 6216,1 & 0,522 & 0,321 & 4647,2 & 0,379 & 3115,2 & 1,082 & 0,703 \\
\hline 47 & 27 & 25 & 8710,7 & 0,201 & 1737,3 & 0,523 & 0,322 & 4647,2 & 0,379 & 920,3 & 1,473 & 1,094 \\
\hline 48 & 28 & 29 & 6678,6 & 0,201 & 5841,8 & 0,401 & 0,200 & 3625,6 & 0,374 & 2885,5 & 0,848 & 0,474 \\
\hline 49 & 29 & 16 & 11093,0 & 0,207 & 2686,2 & 0,422 & 0,215 & 6593,7 & 0,353 & 1020,9 & 3,020 & 2,667 \\
\hline 50 & 30 & 27 & 4769,2 & 0,200 & 3930,1 & 0,450 & 0,250 & 2614,1 & 0,671 & 1810,9 & 1,002 & 0,331 \\
\hline
\end{tabular}


A Figura 5.18 mostra os intervalos de coordenação obtidos para a proteção de fase e de neutro para os pares de relés descritos nas tabelas 5.10 e 5.11. Na Figura, ITC_cin é o intervalo para faltas closein e ITC_80 o intervalo para faltas a 80\% da linha. ITC_min representa o intervalo mínimo admitido para este sistema, que é de $200 \mathrm{~ms}$. Verifica-se que todos os pares apresentam intervalo de coordenação acima do mínimo.

a) Intervalos de coordenação para a proteção de fase

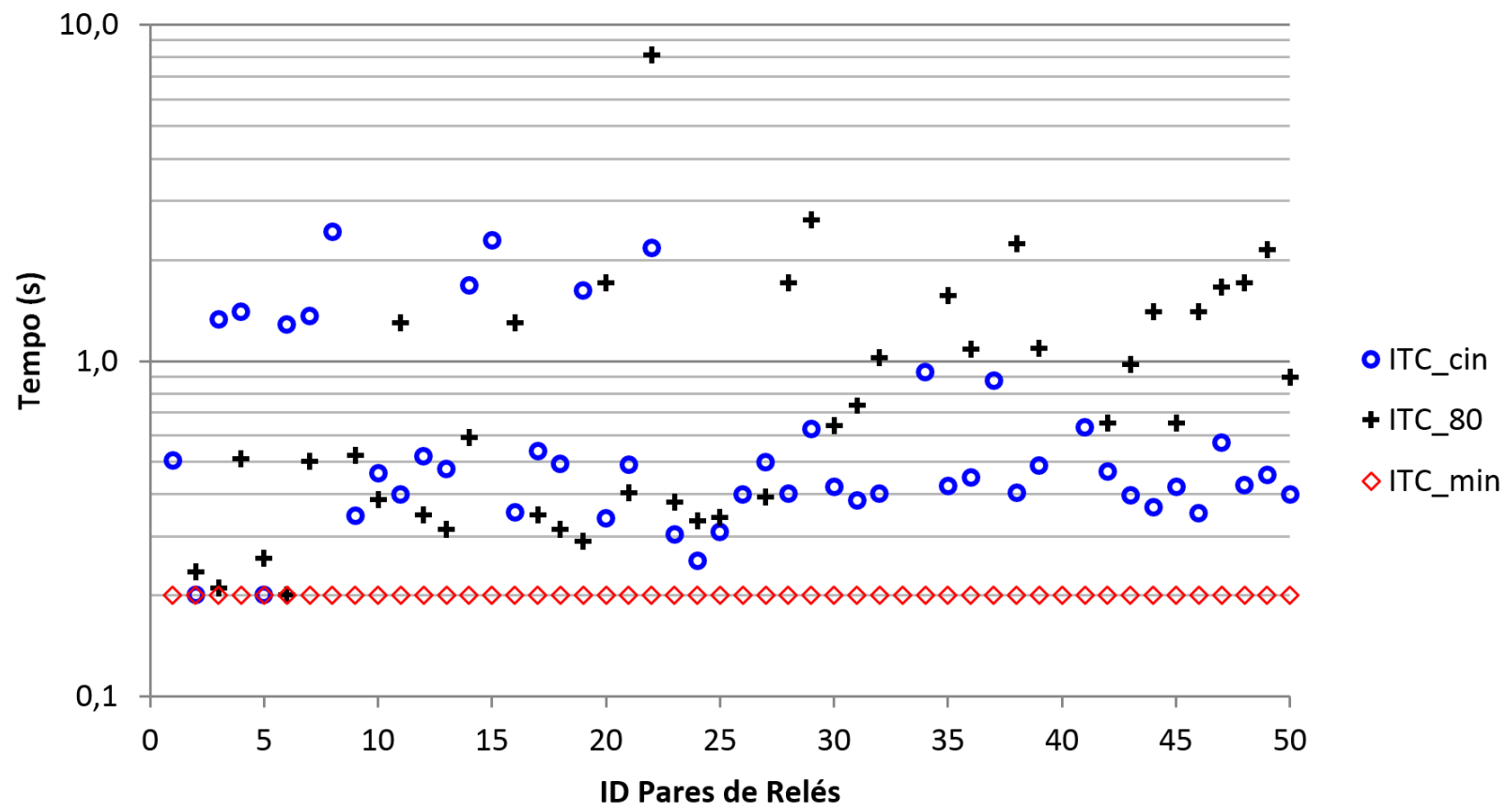

b) Intervalos de coordenação para a proteção de neutro

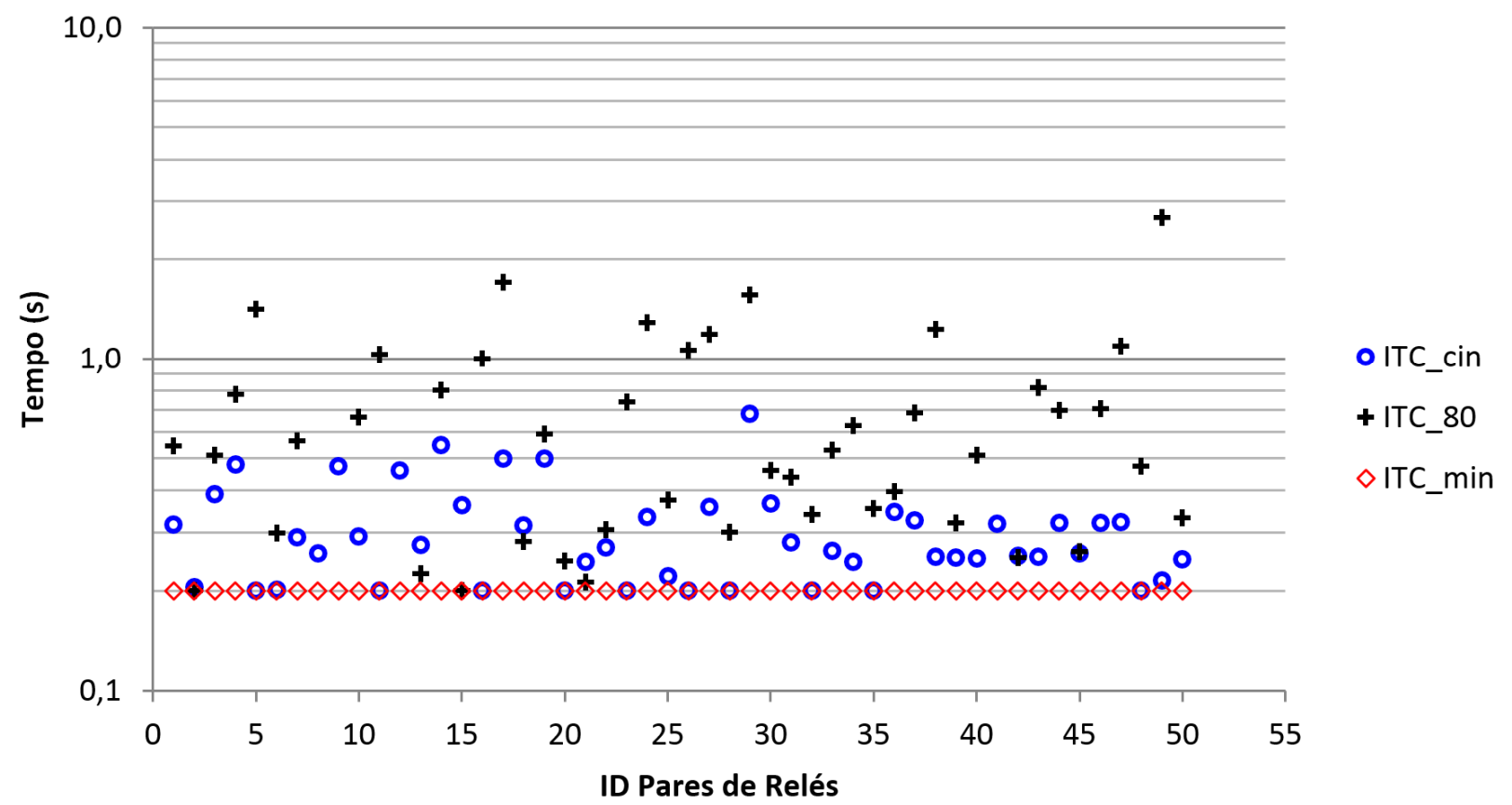

Figura 5.18 - Intervalos de coordenação para o sistema IEEE 14 barras para a proteção de fase a) e de neutro b). 
As tabelas 5.12 e 5.13 mostram os ajustes dos obtidos pela metodologia para as proteções de fase e de neutro, respectivamente. Nas tabelas, Ip_sec indica a corrente de pick-up no secundário do TC.

Tabela 5.12 - Ajustes de fase obtidos para o sistema IEEE 14 barras.

\begin{tabular}{|l|c|c|c|c|c|c|l|}
\hline ID & DE & PARA & circ. & Ip_sec & Ip (A) & TDS & \multicolumn{1}{|c|}{ Padrão } \\
\hline R1 & 1 & 2 & 1 & 3,96 & 1980 & 0,23 & IEC - Extremamente Inversa \\
\hline R2 & 2 & 1 & 1 & 1,45 & 725 & 2,03 & ANSI - Moderadamente Inversa \\
\hline R3 & 2 & 3 & 1 & 1,01 & 505 & 10,28 & ANSI - Inversa de Tempo Curto \\
\hline R4 & 3 & 2 & 1 & 2,23 & 669 & 0,63 & ANSI - Extremamente Inversa \\
\hline R5 & 3 & 4 & 1 & 1,01 & 505 & 1,39 & ANSI - Moderadamente Inversa \\
\hline R6 & 4 & 3 & 1 & 1,19 & 595 & 1,04 & ANSI - Inversa \\
\hline R7 & 2 & 4 & 1 & 1,94 & 970 & 0,23 & IEC - Muito Inversa \\
\hline R8 & 4 & 2 & 1 & 1,17 & 585 & 0,55 & IEC - Inversa de Tempo Curto \\
\hline R9 & 2 & 5 & 1 & 1,94 & 970 & 0,21 & IEC - Muito Inversa \\
\hline R10 & 5 & 2 & 1 & 1,01 & 505 & 4,31 & ANSI - Inversa de Tempo Curto \\
\hline R11 & 4 & 5 & 1 & 1,12 & 560 & 0,28 & IEC - Muito Inversa \\
\hline R12 & 5 & 4 & 1 & 1,05 & 525 & 0,58 & IEC - Muito Inversa \\
\hline R13 & 1 & 5 & 1 & 1,94 & 1164 & 2,61 & ANSI - Extremamente Inversa \\
\hline R14 & 5 & 1 & 1 & 1,89 & 945 & 0,78 & ANSI - Moderadamente Inversa \\
\hline R15 & 9 & 10 & 1 & 1,87 & 935 & 0,72 & IEC - Extremamente Inversa \\
\hline R16 & 10 & 9 & 1 & 1,1 & 330 & 0,23 & IEC - Extremamente Inversa \\
\hline R17 & 10 & 11 & 1 & 1,03 & 515 & 0,71 & IEC - Extremamente Inversa \\
\hline R18 & 11 & 10 & 1 & 1,19 & 595 & 0,32 & IEC - Extremamente Inversa \\
\hline R19 & 6 & 11 & 1 & 1,14 & 570 & 0,89 & IEC - Extremamente Inversa \\
\hline R20 & 11 & 6 & 1 & 1,53 & 765 & 1,29 & ANSI - Extremamente Inversa \\
\hline R21 & 6 & 12 & 1 & 1,04 & 520 & 0,46 & IEC - Muito Inversa \\
\hline R22 & 12 & 6 & 1 & 1,01 & 202 & 4,18 & ANSI - Extremamente Inversa \\
\hline R23 & 6 & 13 & 1 & 1,31 & 655 & 0,92 & IEC - Extremamente Inversa \\
\hline R24 & 13 & 6 & 1 & 1,26 & 504 & 0,77 & ANSI - Inversa \\
\hline R25 & 12 & 13 & 1 & 1,01 & 505 & 0,16 & IEC - Muito Inversa \\
\hline R26 & 13 & 12 & 1 & 1,03 & 515 & 0,33 & IEC - Muito Inversa \\
\hline R27 & 13 & 14 & 1 & 1,16 & 580 & 0,28 & IEC - Muito Inversa \\
\hline R28 & 14 & 13 & 1 & 3,06 & 612 & 0,16 & IEC - Muito Inversa \\
\hline R29 & 9 & 14 & 1 & 1,19 & 595 & 0,96 & IEC - Extremamente Inversa \\
\hline R30 & 14 & 9 & 1 & 1,38 & 552 & 0,69 & ANSI - Inversa \\
\hline & & & & & & & \\
\hline
\end{tabular}


Tabela 5.13 - Ajustes de neutro obtidos para o sistema IEEE 14 barras.

\begin{tabular}{|l|c|c|c|c|c|c|l|}
\hline ID & DE & PARA & circ. & Ip_sec & Ip (A) & TDS & \multicolumn{1}{|c|}{ Padrão } \\
\hline R1 & 1 & 2 & 1 & 2,88 & 230,4 & 0,38 & IEC - Muito Inversa \\
\hline R2 & 2 & 1 & 1 & 1,06 & 84,8 & 0,37 & IEC - Inversa de Tempo Longo \\
\hline R3 & 2 & 3 & 1 & 2,24 & 179,2 & 13,49 & ANSI - Extremamente Inversa \\
\hline R4 & 3 & 2 & 1 & 2,97 & 237,6 & 0,64 & IEC - Muito Inversa \\
\hline R5 & 3 & 4 & 1 & 2,89 & 231,2 & 0,58 & IEC - Muito Inversa \\
\hline R6 & 4 & 3 & 1 & 2,92 & 233,6 & 0,64 & IEC - Muito Inversa \\
\hline R7 & 2 & 4 & 1 & 2,96 & 236,8 & 0,79 & IEC - Inversa de Tempo Curto \\
\hline R8 & 4 & 2 & 1 & 1,57 & 125,6 & 0,16 & IEC - Inversa de Tempo Longo \\
\hline R9 & 2 & 5 & 1 & 2,81 & 224,8 & 5,36 & ANSI - Extremamente Inversa \\
\hline R10 & 5 & 2 & 1 & 1,15 & 92 & 0,21 & IEC - Inversa de Tempo Longo \\
\hline R11 & 4 & 5 & 1 & 2,78 & 222,4 & 0,98 & IEC - Muito Inversa \\
\hline R12 & 5 & 4 & 1 & 1,48 & 118,4 & 0,85 & IEC - Muito Inversa \\
\hline R13 & 1 & 5 & 1 & 2,76 & 220,8 & 0,65 & IEC - Inversa de Tempo Curto \\
\hline R14 & 5 & 1 & 1 & 1,12 & 89,6 & 0,23 & IEC - Inversa de Tempo Longo \\
\hline R15 & 9 & 10 & 1 & 2,97 & 237,6 & 0,16 & IEC - Inversa de Tempo Longo \\
\hline R16 & 10 & 9 & 1 & 2,47 & 197,6 & 0,97 & IEC - Extremamente Inversa \\
\hline R17 & 10 & 11 & 1 & 2,92 & 233,6 & 0,78 & IEC - Muito Inversa \\
\hline R18 & 11 & 10 & 1 & 2,99 & 239,2 & 0,54 & IEC - Muito Inversa \\
\hline R19 & 6 & 11 & 1 & 2,99 & 239,2 & 0,87 & IEC - Muito Inversa \\
\hline R20 & 11 & 6 & 1 & 2,9 & 232 & 0,47 & IEC - Muito Inversa \\
\hline R21 & 6 & 12 & 1 & 1,22 & 97,6 & 0,21 & IEC - Inversa de Tempo Longo \\
\hline R22 & 12 & 6 & 1 & 3 & 240 & 0,51 & IEC - Inversa de Tempo Curto \\
\hline R23 & 6 & 13 & 1 & 2,89 & 231,2 & 1 & IEC - Muito Inversa \\
\hline R24 & 13 & 6 & 1 & 2,93 & 234,4 & 0,34 & IEC - Muito Inversa \\
\hline R25 & 12 & 13 & 1 & 2,46 & 196,8 & 4,8 & ANSI - Extremamente Inversa \\
\hline R26 & 13 & 12 & 1 & 1,03 & 82,4 & 0,2 & IEC - Inversa de Tempo Longo \\
\hline R27 & 13 & 14 & 1 & 1,06 & 84,8 & 0,17 & IEC - Inversa de Tempo Longo \\
\hline R28 & 14 & 13 & 1 & 1,06 & 84,8 & 0,13 & IEC - Inversa de Tempo Longo \\
\hline R29 & 9 & 14 & 1 & 2,97 & 237,6 & 0,7 & IEC - Muito Inversa \\
\hline R30 & 14 & 9 & 1 & 2,98 & 238,4 & 1 & IEC - Extremamente Inversa \\
\hline & & & & & & & \\
\hline
\end{tabular}

A metodologia pode ser aplicada a este mesmo sistema de modo que a proteção de distância seja considerada, porém requer algumas particularidades. Para a proteção de fase, adotando os tempos de referência da Tabela 5.9 e com a restrição de limite superior de $300 \mathrm{~ms}$ para a corrente de falta close-in, a metodologia não encontra solução para os relés 1, 3, 12 e 15. Isso acontece pois as correntes de referência são muito próximas umas das outras, fazendo com que os relés tenham tempos de atuação relativamente altos para altas correntes e violando assim a restrição de limite superior imposta para faltas close-in. Em casos como estes há algumas alternativas para a manutenção da coordenação com o relé de distância. Pode-se, por exemplo, alterar os tempos de referência, aumentando o intervalo mínimo de coordenação e/ou o tempo utilizado no limite superior $\left(t_{c i n P_{-} s}\right)$. Uma alternativa interessante é a utilização da unidade de sobrecorrente instantânea do relé direcional. Para isso é necessária uma pequena alteração no método, 
de modo que, nos relés indicados como possuindo ajuste instantâneo, sejam utilizadas apenas as correntes de referência que possuam valores abaixo da corrente de ajuste da unidade instantânea $\left(I_{I N S T}\right)$. Assim, caso todas as quatro correntes de referência $\left(I_{c i n P}, I_{80 P}, I_{c i n B}\right.$, e $\left.I_{80 B}\right)$ sejam menores que $I_{I N S T}$, o critério ME será utilizado, caso contrário, o método ILL será aplicado para a definição do melhor ajuste, do mesmo modo como descrito na seção 4.4.3.

Configurando a unidade instantânea com um valor abaixo da corrente de curto close-in, o ponto de referência $\left(I_{\operatorname{cinP}}, t_{\operatorname{cinP}}\right)$ será ignorado, resolvendo o problema da restrição do limite superior. Uma prática comum é ajustar o instantâneo do relé para tratar faltas em até $80 \%$ da linha, assim como no relé de distância. A Figura 5.19 a) mostra o resultado obtido para o relé 1 de fase aplicando a metodologia admitindo o relé de distância e com a unidade instantânea do relé direcional de retaguarda local ajustada com o valor da corrente de uma falta trifásica a $80 \%$ da linha, ou seja, $I_{I N S T}=I_{\operatorname{cinB}}$. Como comparação, a Figura 5.19 b) mostra o resultado obtido para o relé 1 sem que seja considerado o relé 21 e sem a unidade instantânea do relé 67.

a)

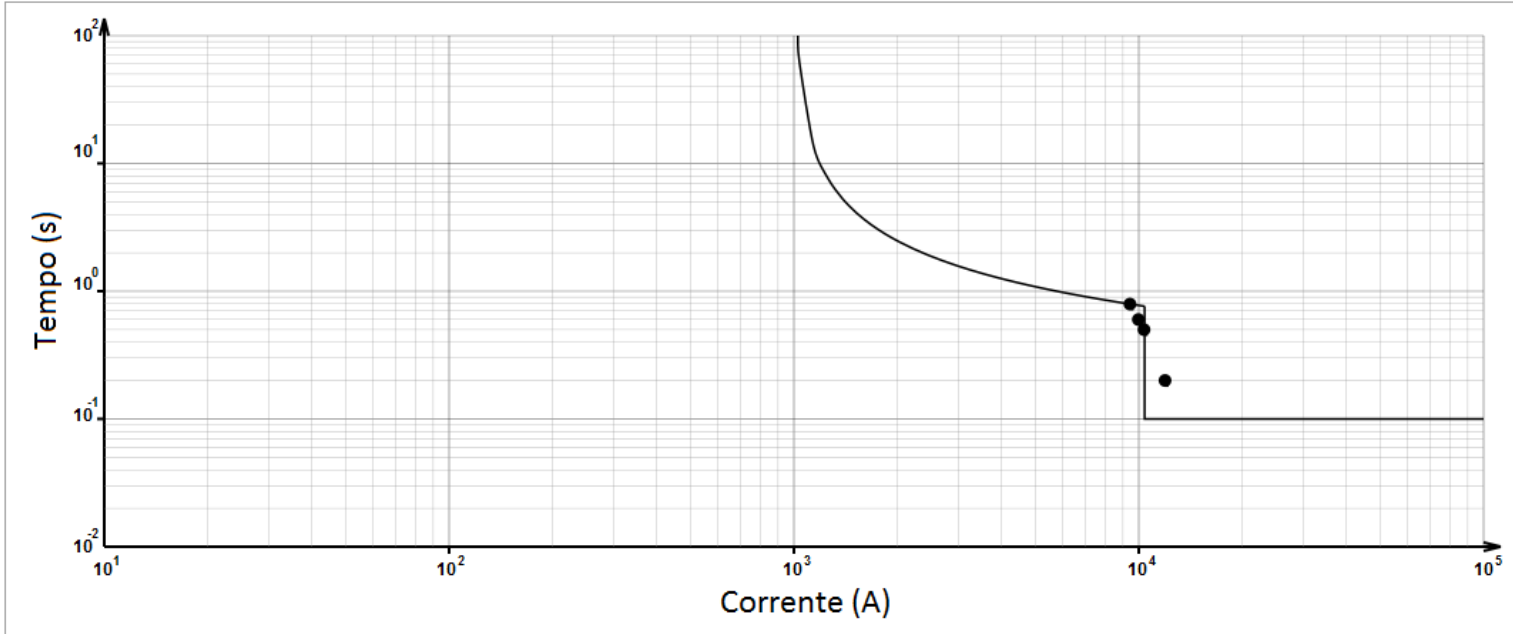

b)

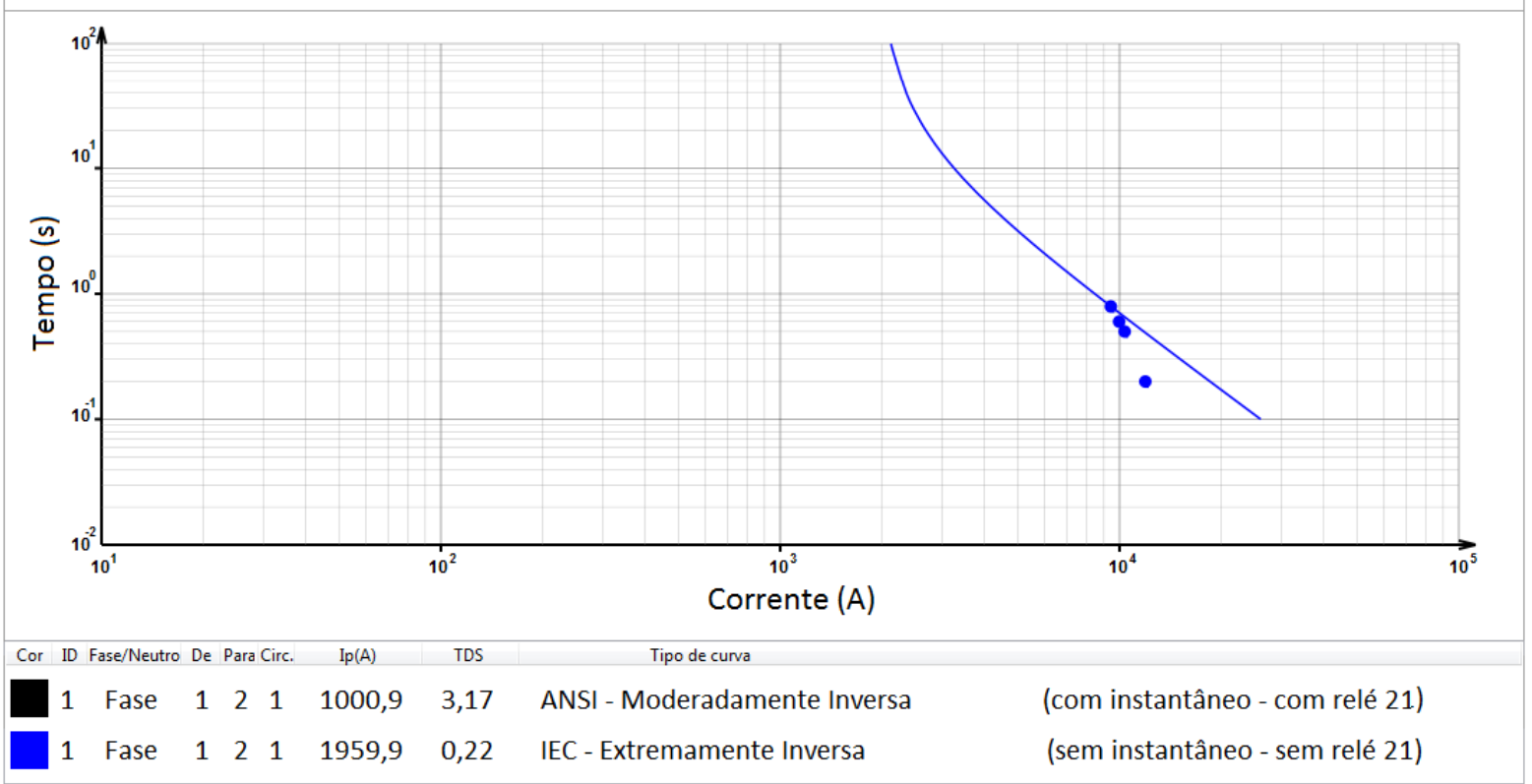

Figura 5.19 - Comparação entre resultados para o relé 1 com (a) e sem (b) unidade instantânea. 
Analisando a Figura 5.19 percebe-se que a inclusão da unidade instantânea melhorou os requisitos de agilidade e sensibilidade, fornecendo uma resposta com menor tempo de atuação para correntes acima de $I_{I N S T}$, além de uma menor corrente de pick-up. Porém, somente uma análise mais detalhada dos requisitos do próprio sistema levaria a uma conclusão sob qual dos dois ajustes (Figura 5.19a ou 5.19b) seria mais adequado, pois como as correntes de referência estão muito próximas umas das outras, por questões de segurança a unidade instantânea poderia ser desativada, evitando atuações indevidas, como por exemplo, para faltas além da linha protegida.

Reforça-se aqui a versatilidade e exatidão da metodologia proposta, fornecendo bons resultados mesmo para situações não usuais e sistemas com diversas particularidades.

\subsection{DESEMPENHO COMPUTACIONAL}

A metodologia foi implementada utilizando a linguagem de programação $\mathrm{C}++$, com uma interface desenvolvida com o toolkit gratuito Gtk+ (GTK PROJECT, 2014). Foi utilizada programação orientada a objeto, com classes de funções para realizar as seguintes tarefas:

- Adição de dados a partir do cartão de entrada: foi utilizada alocação dinâmica através de lista encadeada, deixando a programação mais eficiente e segura;

- Modificação da base de dados: foram utilizadas funções para a modificação de algum valor da base de dados, assim como exclusão de termos;

- Realização da coordenação dos relés: esta é a função que verifica as restrições impostas e identifica, dentre todas as opções disponíveis, quais dos ajustes produzem uma curva de atuação que se situe dentro da área de ajuste descrita pela Figura 4.6;

- Otimização pelo método ME-ILL: esta função aplica o método ME-ILL sobre os ajustes separados pela função anterior e identifica qual o melhor ajuste possível para o relé;

- Saída gráfica: após a definição dos ajustes, esta função escreve os pontos relativos às curvas de atuação (corrente versus tempo) de cada relé em arquivos texto, sendo possível posteriormente construir os coordenogramas a partir de qualquer editor de planilha;

- Saída resumida dos ajustes: com esta função tem-se uma saída com a resposta final do algoritmo, composta apenas pelos ajustes finais de cada relé: Ip, TDS e padrão de curva adotado. Também é mostrada a soma dos desvios dos tempos de atuação de todos os relés para com o ponto $\left(I_{\operatorname{cinP}}, t_{\operatorname{cin} P}\right)$, ou seja, se todos os relés tiverem o tempo de atuação $t_{c i n P}$ para suas respectivas correntes $I_{c i n P}$, a soma dos desvios será zero. O APÊNDICE B mostra um exemplo dessa saída resumida;

- Funções relativas ao funcionamento da interface desenvolvida. 
A interface visa facilitar o tratamento do problema pelo usuário, sendo de grande importância pois fornece os resultados graficamente, mostrando os coordenogramas que são importantes para a visualização da eficácia da coordenação. Na interface há uma lista de relés da proteção fase-fase, lista de relés da proteção fase-terra, lista dos pares de relés da proteção principal/retaguarda (ou retaguarda local/retaguarda remota), uma área para mostrar os gráficos das curvas de atuação dos relés e, uma lista com o resumo dos ajustes dos relés mostrados atualmente na área gráfica. Há a possibilidade de comparar os resultados obtidos com os ajustes de outras configurações salvas anteriormente. Além disso, pode-se ativar ou desativar a visualização dos pontos de referência. A Figura 5.10 mostra uma imagem da interface do programa desenvolvido com base na metodologia.

Para efeito de desempenho, o sistema teste foi executado em um computador com as seguintes características: processador Intel $^{(\mathrm{R})}$ Core2Quad Q9550 2,83GHz, memória RAM de 4GB, sistema operacional Windows 7๑ 64bits. Para o sistema da Figura 5.1 o tempo médio de execução do programa foi de 21 segundos, ou em média $350 \mathrm{~ms}$ por relé (sem levar em consideração o estudo de curto-circuito), demonstrando-se eficiente do ponto de vista computacional, considerando que o algoritmo testa todas as possibilidades de curvas, e ainda há grandes faixas de variação da corrente de pick-up. Ressalta-se que o desempenho do método é altamente dependente desta faixa, pois a corrente de pick-up é variada no loop mais externo do algoritmo.

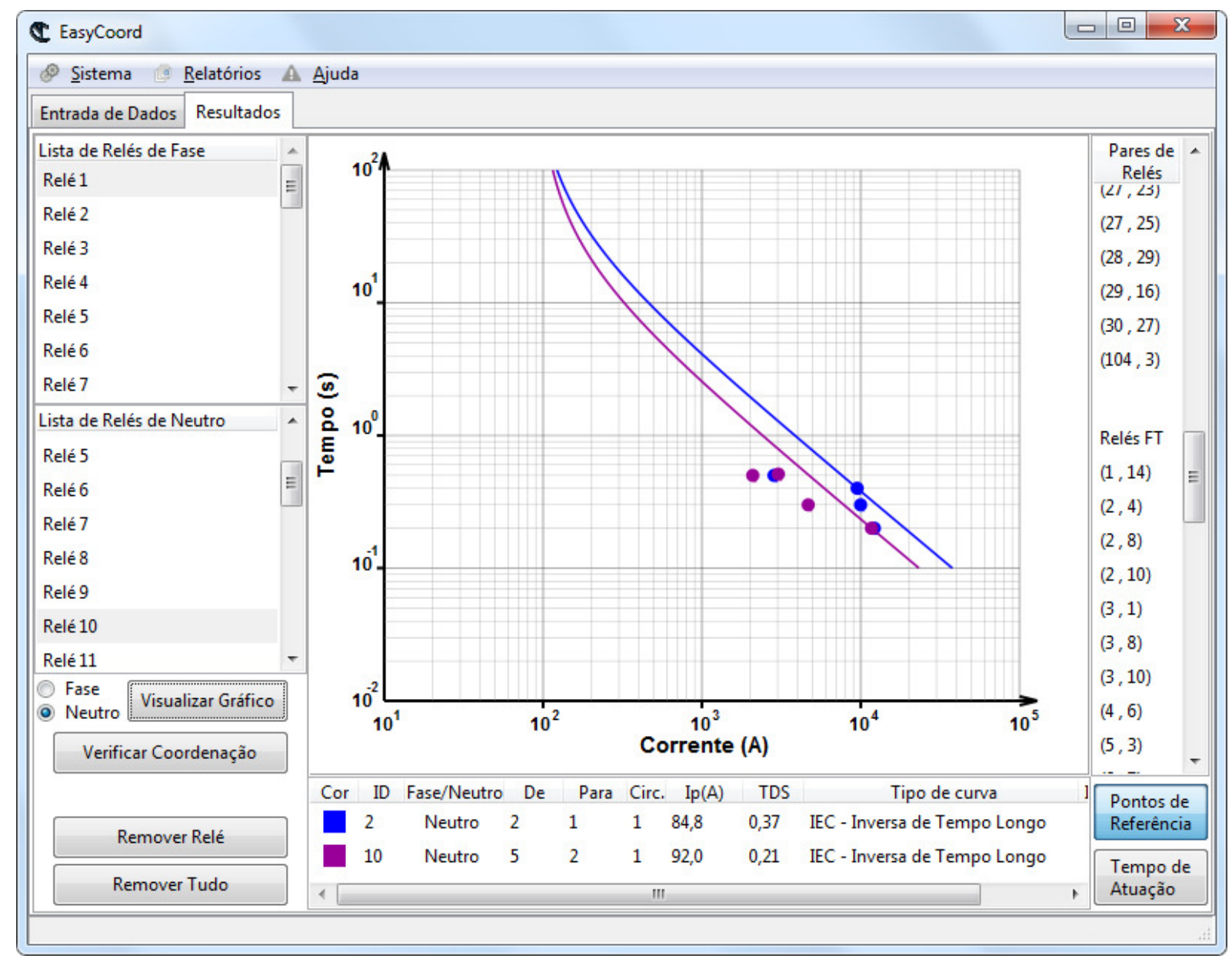

Figura 5.20 - Imagem da interface do programa desenvolvido. 


\section{ANÁLISE DA COORDENAÇÃO DOS RELÉS DIRECIONAIS FRENTE A ALTERAÇÕES TOPOLÓGICAS}

Sabe-se que é requisito de segurança de um sistema o critério N-1, o qual impõe que o sistema deve ser capaz de operar normalmente, sem interrupção do fornecimento de energia, perda de estabilidade, violações dos limites operativos normais e sem sobrecargas mesmo com a indisponibilidade de um elemento do sistema, ou seja, durante uma contingência simples. Para linhas de transmissão, o critério indica que o sistema de proteção deve estar ajustado de modo a manter a coordenação e os requisitos de proteção mesmo quando houver uma linha fora de operação, atuando corretamente no caso de uma situação indesejada durante essa contingência.

O método do melhor ajuste local utiliza informações de curto-circuito do sistema para encontrar a coordenação entre os elementos. Desse modo, alterações topológicas não influenciam na aplicabilidade da metodologia, e sim nos dados de entrada para a mesma. As curvas de atuação devem sempre ficar acima dos pontos definidos pelas correntes de referência e pelos tempos mínimos de atuação determinados pelo usuário. Assim, tomando como referência sempre a maior corrente garante-se a coordenação mesmo quando há contingências. De modo geral, as correntes de entrada da metodologia podem ser definidas do seguinte modo:

- $I_{\text {cinP }}$ : Corrente sobre o relé atuando como proteção local para uma falta close-in. Caso haja diversas topologias do sistema a serem consideradas, deverá ser tomada a maior corrente dentre todos os casos, incluindo o caso base, com todos os disjuntores do sistema fechados. Para a proteção de fase considera-se uma falta trifásica, enquanto que para a proteção de neutro a falta analisada é monofásica-terra;

- $I_{80 P}$ : Corrente sobre o relé atuando como proteção local para uma falta a $80 \%$ da linha. Caso haja diversas topologias do sistema a serem consideradas, deverá ser tomada a maior corrente dentre todos os casos, incluindo o caso base, com todos os disjuntores do sistema fechados. Para a proteção de fase considera-se uma falta trifásica, enquanto que para a proteção de neutro a falta analisada é monofásica-terra;

- $I_{c i n B}$ : Corrente sobre o relé atuando como proteção de retaguarda remota para uma falta close-in sob a proteção principal. Deverá ser tomada a maior corrente sobre o relé dentre todos os casos em que ele é proteção de retaguarda. Além disso, caso haja alterações topológicas a ser consideradas, a corrente de referência será a maior sobre o relé dentre todos os casos. Para a proteção de fase considera-se uma falta trifásica, enquanto que para a proteção de neutro a falta analisada é monofásica-terra;

- $I_{80 B}$ : Corrente sobre o relé atuando como proteção de retaguarda remota para uma falta a $80 \%$ da linha da proteção principal. Deverá ser tomada a maior corrente sobre o relé dentre todos os casos em que ele é proteção de retaguarda. Além disso, caso haja 
alterações topológicas a serem consideradas, a corrente de referência será a maior sobre o relé dentre todos os casos. Para a proteção de fase considera-se uma falta trifásica, enquanto que para a proteção de neutro a falta analisada é monofásica-terra.

Em resumo, as correntes de referência estão relacionadas sempre o pior cenário na ótica do relé em análise, tanto em sua atuação como proteção local quanto de retaguarda remota. A análise da coordenação considerando alterações topológicas pode ser feita basicamente de três modos, cada um seguindo um determinado critério:

1. Definição de cenários recorrentes. Neste tipo de análise são definidos alguns cenários de contingências que ocorrem com mais frequência e/ou envolvendo linhas mais importantes do sistema. Desse modo, a análise de curto-circuito será feita apenas para o caso base e para contingências neste conjunto de linhas consideradas como casos mais importantes, recorrentes ou fator de segurança. Esta análise é feita geralmente em sistemas de grande porte, em que o esforço para uma análise N-1 real é muito grande;

2. Consideração de contingências em linhas paralelas. Uma situação mais comum de contingência é a retirada de uma linha que pertence a um conjunto de linhas paralelas, seja para manutenção ou mesmo em uma condição de falta. Neste caso, as linhas restantes devem ser capazes de manter o fluxo de potência entre seus terminais, aumentando o carregamento. Dessa forma, é importante que o sistema de proteção seja capaz de manter a correta operação durante uma contingência em uma das linhas paralelas, sendo este um critério bastante utilizado nos estudos de coordenação. Para este caso, inicialmente os circuitos paralelos devem ser identificados, geralmente com base nos dados de impedâncias mútuas do sistema. Assim, o estudo de curto-circuito é feito para o caso base e para contingências nestes circuitos, de modo que, para cada relé, são identificadas as linhas paralelas com relação à linha em que a proteção em análise está instalada. Então, são tomadas como referência as maiores correntes entre o caso base e a situação das linhas paralelas (com relação ao relé em análise) abertas. Este critério é bastante utilizado, pois fornece resultados satisfatórios e um esforço menor que a análise N-1.

3. Análise N-1 real. Nesta análise, para cada relé, o estudo de curto-circuito é feito para o caso base e para contingências em cada linha do sistema, fornecendo resultados totalmente confiáveis, garantindo realmente o critério N-1. Entretanto, este estudo demanda muito tempo, pois multiplica a quantidade de faltas analisadas no caso base pela quantidade de linhas do sistema, chegando facilmente na casa de milhares de tipos de faltas. 
Vale a pena reforçar que, independentemente do critério admitido para a análise de coordenação, a metodologia é sempre válida, pois somente os dados de entrada mudam de acordo com o tipo de estudo de curto-circuito realizado.

Como exemplo de aplicação da metodologia frente a alterações topológicas, foram testados os critérios de contingências em linhas paralelas e a análise N-1 real para o sistema da Figura 5.1. Nesta análise foram considerados 22 relés do sistema da Figura 5.1, sendo ignoradas as proteções dos relés R4, R5, R11, R12, R19, R20, R29 e R30. A seguir serão apresentados os passos do estudo de alterações topológicas segundo os dois critérios considerados.

\subsection{CONTINGÊNCIAS EM LINHAS PARALELAS}

Para este critério são identificadas, para cada relé, as linhas paralelas presentes no sistema através dos dados de impedância mútua. A análise de curto-circuito é então realizada de modo que, para cada relé, são aplicados os curtos-circuitos do tipo close-in e a $80 \%$ da linha considerando os casos: todos os disjuntores fechados e; linhas paralelas abertas e aterradas, uma a uma.

A Tabela 6.1 mostra todas as linhas que serão abertas para cada relé, considerando o sistema elétrico da Figura 5.1. Nota-se que não necessariamente as linhas identificadas têm o mesmo destino da linha protegida pelo relé; havendo algum trecho em que elas estão acopladas mutuamente já indica que a abertura da linha afetará o estudo de curto-circuito e, portanto, deve ser considerada. Na tabela, c1 indica circuito 1 e c2 circuito 2 .

Para cada relé serão aplicadas as seguintes faltas:

- Curto-circuito close-in, com valor das correntes de falta franca trifásica e monofásica terra no relé principal e nos relés de retaguarda, para o caso base do sistema;

- Curto-circuito a $80 \%$ da linha do relé em análise, com valor das correntes de falta franca trifásica e monofásica terra no relé principal e nos relés de retaguarda, para o caso base do sistema;

- Curto-circuito trifásico na barra remota com a corrente medida sobre o relé em análise, para o caso base do sistema;

- Curto-circuito close-in, com valor das correntes de falta franca trifásica e monofásica terra no relé principal e nos relés de retaguarda, abrindo as linhas com trechos paralelos identificados uma a uma, ou seja, uma falta aplicada por linha aberta;

- Curto-circuito a $80 \%$ da linha do relé em análise, com valor das correntes de falta franca trifásica e monofásica terra no relé principal e nos relés de retaguarda, abrindo as linhas com trechos paralelos identificados uma a uma, ou seja, uma falta aplicada por linha aberta; 
- Curto-circuito trifásico na barra remota, com a corrente medida sobre o relé em análise, abrindo as linhas com trechos paralelos identificados uma a uma, ou seja, uma falta aplicada por linha aberta.

As faltas na barra remota são necessárias para identificar o valor da máxima corrente de pick-up admitida na metodologia, enquanto as outras faltas são necessárias para a coordenação dos relés. Assim sendo, para este sistema é necessário calcular 3 tipos de falta para cada relé para o caso base, mais 3 faltas por linha aberta, totalizando 192 faltas. Para curtos-circuitos close-in e a $80 \%$ da linha são tomadas correntes trifásicas e monofásicas-terra, enquanto que para curtos na barra remota só é tomada a corrente trifásica. Assim sendo, chega-se a um total de 320 correntes para serem analisadas, enquanto que, caso só fosse considerado o caso base, seriam 110 correntes consideradas. Estes números só consideram as correntes nos relés principais, porém, exceto para faltas na barra remota, são necessários os valores sob os relés de retaguarda, aumentando consideravelmente a quantidade total de valores tratados. 
Tabela 6.1 - Localização dos relés em estudo e as respectivas linhas com trechos paralelos.

\begin{tabular}{|c|c|c|c|c|c|c|c|}
\hline ID & De & Para & Circ. & $1^{\mathrm{a}}$ linha aberta & $2^{\mathrm{a}}$ linha aberta & $3^{\mathrm{a}}$ linha aberta & $4^{\mathrm{a}}$ linha aberta \\
\hline $\mathrm{R} 1$ & 19200 & 19210 & 1 & $\begin{array}{c}19200-19219-19210 \\
\text { c1 }\end{array}$ & & & \\
\hline $\mathrm{R} 2$ & 19210 & 19200 & 1 & $\begin{array}{c}\text { 19200-19219-19210 } \\
\text { c1 }\end{array}$ & & & \\
\hline $\mathrm{R} 3$ & 19200 & 19219 & 1 & $19200-1210 \mathrm{c} 1$ & & & \\
\hline R6 & 19210 & 19219 & 1 & $19200-1210 \mathrm{c} 1$ & & & \\
\hline R7 & 19210 & 33046 & 1 & $\begin{array}{c}19210-19218-19217- \\
19280 \mathrm{c} 1\end{array}$ & $\begin{array}{c}19210-19218-19217- \\
14247 \mathrm{c} 1\end{array}$ & & \\
\hline $\mathrm{R} 8$ & 33046 & 19210 & 1 & $\begin{array}{c}19210-19218-19217- \\
19280 \mathrm{c} 1\end{array}$ & $\begin{array}{c}19210-19218-19217- \\
14247 \mathrm{c} 1\end{array}$ & & \\
\hline R9 & 33046 & 19280 & 1 & $\begin{array}{c}19210-19218-19217- \\
19280 \mathrm{c} 1\end{array}$ & $\begin{array}{c}19210-19218-19217- \\
14247 \mathrm{c} 1\end{array}$ & $\begin{array}{c}14247-19217-19280 \\
\text { c1 }\end{array}$ & \\
\hline R10 & 19280 & 33046 & 1 & $\begin{array}{c}19210-19218-19217- \\
19280 \mathrm{c} 1\end{array}$ & $\begin{array}{c}19210-19218-19217- \\
14247 \mathrm{c} 1\end{array}$ & $\begin{array}{c}14247-19217-19280 \\
\text { c1 }\end{array}$ & \\
\hline R13 & 19210 & 19280 & 1 & $\begin{array}{c}14509-19294-19216- \\
33047-33046 \mathrm{c} 1\end{array}$ & $\begin{array}{c}\text { 19280-19294-19216- } \\
33047-33046 \mathrm{c} 1\end{array}$ & $\begin{array}{c}33046-33048-19210 \\
\text { c1 }\end{array}$ & $\begin{array}{c}14509-19294-19280 \\
\text { c1 }\end{array}$ \\
\hline R14 & 19280 & 19210 & 1 & $\begin{array}{c}14509-19294-19216- \\
33047-33046 \mathrm{cl}\end{array}$ & $\begin{array}{c}\text { 19280-19294-19216- } \\
33047-33046 \mathrm{cl}\end{array}$ & $\begin{array}{c}33046-33048-19210 \\
\text { c1 }\end{array}$ & $\begin{array}{c}14509-19294-19280 \\
\text { c1 }\end{array}$ \\
\hline R15 & 19210 & 19220 & 1 & $19210-19220 \mathrm{c} 2$ & & & \\
\hline R16 & 19220 & 19210 & 1 & $19210-19220 \mathrm{c} 2$ & & & \\
\hline R17 & 19210 & 19220 & 2 & $19210-19220$ c1 & & & \\
\hline R18 & 19220 & 19210 & 2 & $19210-19220 \mathrm{c} 1$ & & & \\
\hline R23 & 33006 & 19220 & 1 & $\begin{array}{c}19220-19227-14493 \\
\text { c1 }\end{array}$ & $\begin{array}{c}19220-19227-33040- \\
33032 \mathrm{c} 1 \\
\end{array}$ & $\begin{array}{c}14493-19227-33040- \\
33032 \mathrm{c} 1 \\
\end{array}$ & $\begin{array}{c}33032-33039-19247- \\
19240 \mathrm{c} 1 \\
\end{array}$ \\
\hline R24 & 19220 & 33006 & 1 & $\begin{array}{c}19220-19227-14493 \\
\text { c1 }\end{array}$ & $\begin{array}{c}19220-19227-33040- \\
33032 \mathrm{c} 1\end{array}$ & $\begin{array}{c}14493-19227-33040- \\
33032 \mathrm{c} 1 \\
\end{array}$ & $\begin{array}{c}33032-33039-19247- \\
19240 \mathrm{c} 1\end{array}$ \\
\hline R21 & 19240 & 33006 & 1 & $\begin{array}{c}\text { 33032-33039-19247- } \\
19240 \mathrm{c} 1 \\
\end{array}$ & & & \\
\hline R22 & 33006 & 19240 & 1 & $\begin{array}{c}33032-33039-19247- \\
19240 \mathrm{c} 1\end{array}$ & & & \\
\hline R27 & 33032 & 19220 & 1 & $\begin{array}{c}\text { 33006-33008-19246- } \\
19226-19220 \mathrm{c} 1\end{array}$ & & & \\
\hline R28 & 19220 & 33032 & 1 & $\begin{array}{c}33006-33008-19246- \\
19226-19220 \mathrm{cl}\end{array}$ & & & \\
\hline R25 & 19240 & 33032 & 1 & $\begin{array}{c}19240-33007-33006 \\
\text { c1 }\end{array}$ & $\begin{array}{c}\text { 33006-33008-19246- } \\
19226-19220 \mathrm{c} 1\end{array}$ & & \\
\hline R26 & 33032 & 19240 & 1 & $\begin{array}{c}19240-33007-33006 \\
\text { c1 }\end{array}$ & $\begin{array}{c}\text { 33006-33008-19246- } \\
19226-19220 \mathrm{c} 1 \\
\end{array}$ & & \\
\hline
\end{tabular}

Para entrada da metodologia é necessária a maior corrente de todos os casos, seja para o relé atuando como proteção principal e também como proteção de retaguarda. Para isso, para cada relé, varrem-se os resultados tomando sempre o maior valor da corrente dentre cada situação de topologia do sistema. Isso é feito para as faltas close-in, a $80 \%$ da linha e na barra remota, sendo que, nas duas primeiras, toma-se também o maior valor de corrente nos relés de retaguarda para cada uma das alterações topológicas. 
Para as faltas close-in e a $80 \%$ da linha, procuram-se também, para cada relé, todos os casos em que ele atua como proteção de retaguarda, tomando sempre o maior valor de corrente como referência. Para a maior das correntes de faltas trifásicas na barra remota será aplicado um fator de segurança, admitido de $80 \%$, e o resultado será o valor máximo da corrente de pick-up de fase. Para o ajuste de neutro, a faixa de pick-up não necessita de uma análise de curto-circuito sendo definida geralmente por porcentagens dos valores nominais dos equipamentos do vão da linha do relé, como o TC. Como já descrito, para este trabalho foi admitida a faixa de 80 a 240 A para o ajuste de pick-up dos relés de neutro.

Ao final da análise tem-se o maior valor das correntes para o relé atuando como proteção principal e proteção de retaguarda, além da faixa da corrente de pick-up. A Tabela 6.2 resume estes dados para a proteção de fase, e a Tabela 6.3 mostra os resultados para a proteção de neutro. Estes serão os dados de entrada da metodologia.

Tabela 6.2 - Resultados de fase da análise de curto-circuito trifásico considerando circuitos paralelos.

\begin{tabular}{|c|c|c|c|c|c|c|c|c|c|}
\hline ID & De & Para & Circ. & $\begin{array}{c}I_{3 f \text { _cinP }} \\
\text { (A) }\end{array}$ & $\begin{array}{c}\mathrm{I}_{3 \mathrm{f} \_80 \mathrm{P}} \\
\text { (A) }\end{array}$ & $\begin{array}{c}I_{3 f \text { _cinB }} \\
\text { (A) }\end{array}$ & $\begin{array}{c}I_{3 f_{3} 80 \mathrm{~B}} \\
(\mathrm{~A})\end{array}$ & $\begin{array}{c}\mathrm{I}_{\mathrm{P}_{\text {_ff_min }}} \\
(\overline{\mathrm{A}})\end{array}$ & $\begin{array}{c}\mathrm{I}_{\mathrm{P}_{\mathrm{P} f f} \text { max }} \\
(\mathrm{A})\end{array}$ \\
\hline R1 & 19200 & 19210 & 1 & 3273,6 & 1167,1 & 472,44 & 401,09 & 475,2 & 475,2 \\
\hline R2 & 19210 & 19200 & 1 & 10392 & 3387,6 & 2250,3 & 372,04 & 475,2 & 1800,3 \\
\hline R3 & 19200 & 19219 & 1 & 3273,6 & 1167,2 & 472,44 & 401,09 & 475,2 & 475,2 \\
\hline R6 & 19210 & 19219 & 1 & 10392 & 3387,6 & 2250,3 & 372,08 & 475,2 & 1800,3 \\
\hline R7 & 19210 & 33046 & 1 & 9105,3 & 2866,1 & 2420,7 & 1579,9 & 346,8 & 1903,1 \\
\hline R8 & 33046 & 19210 & 1 & 4564,3 & 2262,1 & 1755,8 & 1487,2 & 936 & 1404,7 \\
\hline R9 & 33046 & 19280 & 1 & 3203,6 & 2114,1 & 1599,1 & 143,61 & 936 & 1279,4 \\
\hline $\mathrm{R} 10$ & 19280 & 33046 & 1 & 15685 & 4474 & 3783,4 & 1871,8 & 399,6 & 3026,7 \\
\hline R13 & 19210 & 19280 & 1 & 8783,5 & 2390,2 & 1665,9 & 33,509 & 399,6 & 1332,7 \\
\hline $\mathrm{R} 14$ & 19280 & 19210 & 1 & 15625 & 2791,7 & 2089 & 1768,5 & 399,6 & 1671,2 \\
\hline $\mathrm{R} 15$ & 19210 & 19220 & 1 & 9195,4 & 5901 & 3210,7 & 1121,8 & 469,2 & 2568,6 \\
\hline R16 & 19220 & 19210 & 1 & 6825,1 & 3178,3 & 1660,3 & 756,28 & 469,2 & 1328,3 \\
\hline $\mathrm{R} 17$ & 19210 & 19220 & 2 & 9195,4 & 5901 & 3210,7 & 1121,8 & 469,2 & 2568,6 \\
\hline $\mathrm{R} 18$ & 19220 & 19210 & 2 & 6825,1 & 3178,3 & 1660,3 & 756,28 & 469,2 & 1328,3 \\
\hline $\mathrm{R} 23$ & 33006 & 19220 & 1 & 5937,2 & 2250,5 & 1724,1 & 1549 & 456 & 1379,3 \\
\hline R24 & 19220 & 33006 & 1 & 8314,2 & 2464,2 & 2099,1 & 1709,6 & 543,6 & 1593,5 \\
\hline R21 & 19240 & 33006 & 1 & 11851 & 6041,3 & 5373,6 & 2025,2 & 399,6 & 4107,9 \\
\hline R22 & 33006 & 19240 & 1 & 2666,4 & 2182,5 & 1807,6 & 381,49 & 456 & 1446,1 \\
\hline R27 & 33032 & 19220 & 1 & 4519,6 & 1964 & 1494,8 & 1343,8 & 624 & 1195,8 \\
\hline $\mathrm{R} 28$ & 19220 & 33032 & 1 & 8542,1 & 2378,3 & 2026,9 & 1423,2 & 543,6 & 1577,9 \\
\hline $\mathrm{R} 25$ & 19240 & 33032 & 1 & 12088 & 4354,5 & 3736,8 & 1611,5 & 399,6 & 2924,3 \\
\hline R26 & 33032 & 19240 & 1 & 2816,8 & 1995,4 & 1570,2 & 612,57 & 624 & 1256,2 \\
\hline
\end{tabular}


Tabela 6.3 - Resultados de neutro da análise de curto-circuito monofásico-terra considerando circuitos paralelos.

\begin{tabular}{|c|c|c|c|c|c|c|c|c|c|}
\hline ID & De & Para & Circ. & $\begin{array}{c}\mathrm{I}_{3 \mathrm{io} \_ \text {cinP }} \\
(\mathrm{A})\end{array}$ & $\begin{array}{c}\mathrm{I}_{\text {3io_80P }} \\
(\mathrm{A})\end{array}$ & $\begin{array}{c}\mathrm{I}_{3 \mathrm{io} \_ \text {_in B }} \\
(\mathrm{A})\end{array}$ & $\begin{array}{c}\mathrm{I}_{3 \mathrm{iio} 80 \mathrm{~B}} \\
(\mathrm{~A})\end{array}$ & $\begin{array}{c}\mathrm{I}_{\text {Pfttmin }_{\text {ft.m }}} \\
(\mathrm{A})\end{array}$ & $\begin{array}{c}\mathrm{I}_{\mathrm{P}_{\text {_ft_max }}}(\mathrm{A}) \\
\text { (A) }\end{array}$ \\
\hline $\mathrm{R} 1$ & 19200 & 19210 & 1 & 5058,8 & 1508,4 & 497,96 & 315,16 & 80 & 240 \\
\hline R2 & 19210 & 19200 & 1 & 10948 & 1639,4 & 616,55 & 0 & 80 & 240 \\
\hline $\mathrm{R} 3$ & 19200 & 19219 & 1 & 5059,1 & 1525,3 & 497,84 & 315,08 & 80 & 240 \\
\hline R6 & 19210 & 19219 & 1 & 10948 & 1708,2 & 616,4 & 0 & 80 & 240 \\
\hline R7 & 19210 & 33046 & 1 & 10825 & 2646,8 & 2029,1 & 1459,6 & 80 & 240 \\
\hline R8 & 33046 & 19210 & 1 & 2312,5 & 945,18 & 624,96 & 395,3 & 80 & 240 \\
\hline R9 & 33046 & 19280 & 1 & 2029,1 & 1459,6 & 903,87 & 156,35 & 80 & 240 \\
\hline R10 & 19280 & 33046 & 1 & 9530,2 & 2507,7 & 2043,3 & 811,31 & 80 & 240 \\
\hline R13 & 19210 & 19280 & 1 & 10545 & 1525,3 & 1162,7 & 369,1 & 80 & 240 \\
\hline R14 & 19280 & 19210 & 1 & 9256,5 & 1062,9 & 391 & 247,07 & 80 & 240 \\
\hline R15 & 19210 & 19220 & 1 & 10372 & 5884,9 & 2592,7 & 806,79 & 80 & 240 \\
\hline R16 & 19220 & 19210 & 1 & 6610,1 & 2463,9 & 1070 & 284,98 & 80 & 240 \\
\hline R17 & 19210 & 19220 & 2 & 10372 & 5884,9 & 2592,7 & 806,79 & 80 & 240 \\
\hline R18 & 19220 & 19210 & 2 & 6610,1 & 2463,9 & 1070 & 284,98 & 80 & 240 \\
\hline R23 & 33006 & 19220 & 1 & 3649,3 & 983,55 & 346,07 & 670,66 & 80 & 240 \\
\hline R24 & 19220 & 33006 & 1 & 8416,6 & 2092,4 & 1396,4 & 1097,2 & 80 & 240 \\
\hline R21 & 19240 & 33006 & 1 & 7846,8 & 3950,9 & 3649,3 & 983,55 & 80 & 240 \\
\hline R22 & 33006 & 19240 & 1 & 1742,5 & 1377,4 & 899,34 & 264,32 & 80 & 240 \\
\hline R27 & 33032 & 19220 & 1 & 2189,7 & 718,38 & 243,86 & 148,33 & 80 & 240 \\
\hline R28 & 19220 & 33032 & 1 & 8814,3 & 2502,1 & 1958,1 & 1346,4 & 80 & 240 \\
\hline R25 & 19240 & 33032 & 1 & 7951,7 & 2707,6 & 1897,7 & 626,64 & 80 & 240 \\
\hline R26 & 33032 & 19240 & 1 & 2282,9 & 1525,6 & 442,67 & 68,456 & 80 & 240 \\
\hline
\end{tabular}

\subsection{CONTINGÊNCIAS APLICANDO O CRITÉRIO N-1}

Neste critério, a análise de curto-circuito é feita considerando dois casos: com todos os disjuntores fechados (caso base) e; abrindo, uma a uma, todas as linhas do sistema, com exceção da própria linha protegida pelo relé. Em cada situação são aplicados os curtos close-in e a $80 \%$ da linha, com valores de corrente medidas sobre o relé principal e o de retaguarda remota. Como sempre, para a proteção de fase analisa-se uma falta trifásica franca, enquanto que para a proteção de neutro a análise é feita sobre uma falta fase-terra franca.

Assim, para cada relé serão aplicadas as seguintes faltas:

- Curto-circuito close-in, com valor das correntes de falta franca trifásica e monofásica terra no relé principal e nos relés de retaguarda, para o caso base do sistema;

- Curto-circuito a $80 \%$ da linha do relé em análise, com valor das correntes de falta franca trifásica e monofásica terra no relé principal e nos relés de retaguarda, para o caso base do sistema;

- Curto-circuito trifásico na barra remota com a corrente medida sobre o relé em análise, para o caso base do sistema; 
- Curto-circuito close-in, com valor das correntes de falta franca trifásica e monofásica terra no relé principal e nos relés de retaguarda, abrindo uma a uma todas as linhas do sistema, exceto a do próprio relé em análise;

- Curto-circuito a $80 \%$ da linha do relé em análise, com valor das correntes de falta franca trifásica e monofásica terra no relé principal e nos relés de retaguarda, abrindo uma a uma todas as linhas do sistema, exceto a do próprio relé em análise;

- Curto-circuito trifásico na barra remota, com a corrente medida sobre o relé em análise, abrindo uma a uma todas as linhas do sistema, exceto a do próprio relé em análise.

São necessárias três faltas para cada relé para o caso base, mais três faltas por linha aberta. Considerando que existem $n$ linhas no sistema e em cada uma há dois relés, como para cada relé são abertas $n-1$ linhas, o total de faltas aplicadas é $6 n^{2}$. Portanto, para este sistema de 11 linhas serão aplicadas 726 faltas, chegando a 1210 correntes, considerando apenas os relés principais, sendo necessárias também, para cada caso, as correntes sobre os relés de retaguarda.

O processo de obtenção das correntes de referência é o mesmo para o caso em que apenas linhas paralelas são abertas: sobre o relé principal e sobre os de retaguarda, toma-se sempre a maior corrente entre o caso base e cada situação de linha aberta. Em seguida, para cada relé, verifica-se sua atuação como retaguarda e obtém-se a maior corrente dentre todos os casos. Esse processo é feito para as faltas close-in e a $80 \%$ da linha. Para faltas na barra remota não é necessário verificar correntes nos relés de retaguarda, pois este caso analisa apenas o limite superior da corrente de pick-up da proteção de fase.

Ao final da análise tem-se o maior valor das correntes para o relé atuando como proteção principal e proteção de retaguarda, além da faixa da corrente de pick-up. A Tabela 6.4 resume estes dados para a proteção de fase, e a Tabela 6.5 mostra os resultados para a proteção de neutro. Estes serão os dados de entrada da metodologia. 
Tabela 6.4 - Resultados de fase da análise de curto-circuito considerando o critério N-1.

\begin{tabular}{|c|c|c|c|c|c|c|c|c|c|}
\hline ID & De & Para & Circ. & $\begin{array}{c}I_{3 f \_c i n P} \\
(A)\end{array}$ & $\begin{array}{c}\mathrm{I}_{3 \mathrm{f} \_80 \mathrm{P}} \\
(\mathrm{A})\end{array}$ & $\begin{array}{c}I_{3 f \_c i n B} \\
\text { (A) }\end{array}$ & $\begin{array}{c}I_{3 f \_80 B} \\
(A)\end{array}$ & $\begin{array}{c}\mathrm{I}_{P_{-} \text {ff_min }} \\
(\mathrm{A})\end{array}$ & 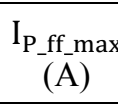 \\
\hline R1 & 19200 & 19210 & 1 & 3273,6 & 1167,1 & 851,55 & 723,94 & 475,2 & 475,2 \\
\hline $\mathrm{R} 2$ & 19210 & 19200 & 1 & 10392 & 3387,6 & 2250,3 & 372,04 & 475,2 & 1635,7 \\
\hline R3 & 19200 & 19219 & 1 & 3273,6 & 1167,2 & 851,55 & 723,94 & 475,2 & 475,2 \\
\hline R6 & 19210 & 19219 & 1 & 10392 & 3387,6 & 2250,3 & 372,08 & 475,2 & 1635,7 \\
\hline R7 & 19210 & 33046 & 1 & 9333,3 & 3031,9 & 2420,7 & 1579,9 & 346,8 & 1838,4 \\
\hline $\mathrm{R} 8$ & 33046 & 19210 & 1 & 4564,3 & 2262,1 & 1998,3 & 1753,8 & 936 & 936 \\
\hline R9 & 33046 & 19280 & 1 & 3203,6 & 2114,1 & 1599,1 & 143,61 & 936 & 936 \\
\hline $\mathrm{R} 10$ & 19280 & 33046 & 1 & 15991 & 4654,9 & 3783,4 & 1871,8 & 399,6 & 3026,7 \\
\hline R13 & 19210 & 19280 & 1 & 8783,5 & 2390,2 & 1957,1 & 569,7 & 399,6 & 1240,8 \\
\hline R14 & 19280 & 19210 & 1 & 15625 & 2819,4 & 2329,2 & 2030,3 & 399,6 & 1671,2 \\
\hline R15 & 19210 & 19220 & 1 & 9195,4 & 5901 & 5594,2 & 2047,2 & 469,2 & 2020,2 \\
\hline R16 & 19220 & 19210 & 1 & 6825,1 & 3178,3 & 3081,1 & 1421,3 & 469,2 & 800,25 \\
\hline R17 & 19210 & 19220 & 2 & 9195,4 & 5901 & 5594,2 & 2047,2 & 469,2 & 2020,2 \\
\hline R18 & 19220 & 19210 & 2 & 6825,1 & 3178,3 & 3081,1 & 1421,3 & 469,2 & 800,25 \\
\hline R23 & 33006 & 19220 & 1 & 5937,2 & 2250,5 & 1935,4 & 1786,1 & 456 & 456 \\
\hline R24 & 19220 & 33006 & 1 & 8549,2 & 2599,5 & 2099,1 & 1709,6 & 543,6 & 1496,2 \\
\hline $\mathrm{R} 21$ & 19240 & 33006 & 1 & 12155 & 6259,2 & 5373,6 & 2025,2 & 399,6 & 4107,9 \\
\hline R22 & 33006 & 19240 & 1 & 2666,4 & 2182,5 & 2040,9 & 748,05 & 456 & 456 \\
\hline $\mathrm{R} 27$ & 33032 & 19220 & 1 & 4519,6 & 1964 & 1709,2 & 1585,6 & 624 & 624 \\
\hline $\mathrm{R} 28$ & 19220 & 33032 & 1 & 8753,7 & 2530,9 & 2026,9 & 1423,2 & 543,6 & 1491,6 \\
\hline R25 & 19240 & 33032 & 1 & 12355 & 4528,3 & 3736,8 & 1611,5 & 399,6 & 2924,3 \\
\hline R26 & 33032 & 19240 & 1 & 2816,8 & 1995,4 & 1827,2 & 940,98 & 624 & 624 \\
\hline
\end{tabular}


Tabela 6.5 - Resultados de neutro da análise de curto-circuito considerando o critério N-1

\begin{tabular}{|c|c|c|c|c|c|c|c|c|c|}
\hline ID & De & Para & Circ. & $\begin{array}{c}\mathrm{I}_{3 \mathrm{io} \_ \text {cinP }} \\
(\mathrm{A})\end{array}$ & $\begin{array}{c}\mathrm{I}_{3 \mathrm{io} \_80 \mathrm{P}} \\
(\mathrm{A})\end{array}$ & $\begin{array}{c}\mathrm{I}_{3 \mathrm{io} / \mathrm{A} \text { Bin }} \\
(\mathrm{A})\end{array}$ & $\begin{array}{c}\mathrm{I}_{3 \mathrm{io} \_80 \mathrm{~B}} \\
(\overline{\mathrm{A}})\end{array}$ & $\begin{array}{c}\mathrm{I}_{P_{\text {fft_min }}} \\
(\mathrm{A})\end{array}$ & $\begin{array}{c}\mathrm{I}_{\mathrm{P}_{-} \mathrm{ft}} \text { (A) } \\
(\mathrm{A})\end{array}$ \\
\hline $\mathrm{R} 1$ & 19200 & 19210 & 1 & 5058,8 & 1525 & 1283,2 & 766,52 & 80 & 240 \\
\hline $\mathrm{R} 2$ & 19210 & 19200 & 1 & 10948 & 1708,4 & 616,55 & 0 & 80 & 240 \\
\hline $\mathrm{R} 3$ & 19200 & 19219 & 1 & 5059,1 & 1525,3 & 1283,2 & 766,5 & 80 & 240 \\
\hline R6 & 19210 & 19219 & 1 & 10948 & 1708,2 & 616,4 & 0 & 80 & 240 \\
\hline $\mathrm{R} 7$ & 19210 & 33046 & 1 & 10825 & 2618,3 & 1991,8 & 1376,5 & 80 & 240 \\
\hline $\mathrm{R} 8$ & 33046 & 19210 & 1 & 2312,5 & 945,18 & 624,96 & 395,3 & 80 & 240 \\
\hline R9 & 33046 & 19280 & 1 & 1991,8 & 1376,5 & 903,87 & 163,98 & 80 & 240 \\
\hline $\mathrm{R} 10$ & 19280 & 33046 & 1 & 9758,5 & 2658,8 & 2043,3 & 811,31 & 80 & 240 \\
\hline R13 & 19210 & 19280 & 1 & 10545 & 1525,3 & 1162,7 & 373,72 & 80 & 240 \\
\hline $\mathrm{R} 14$ & 19280 & 19210 & 1 & 9256,5 & 1062,9 & 500,28 & 307,5 & 80 & 240 \\
\hline $\mathrm{R} 15$ & 19210 & 19220 & 1 & 10372 & 5884,9 & 5588,9 & 928,42 & 80 & 240 \\
\hline R16 & 19220 & 19210 & 1 & 6610,1 & 2463,9 & 2308,8 & 603,93 & 80 & 240 \\
\hline R17 & 19210 & 19220 & 2 & 10372 & 5884,9 & 5588,9 & 928,42 & 80 & 240 \\
\hline R18 & 19220 & 19210 & 2 & 6610,1 & 2463,9 & 2308,8 & 603,93 & 80 & 240 \\
\hline R23 & 33006 & 19220 & 1 & 3649,3 & 983,55 & 956,31 & 1232,1 & 80 & 240 \\
\hline R24 & 19220 & 33006 & 1 & 8416,6 & 2092,4 & 2300,2 & 1614,3 & 80 & 240 \\
\hline R21 & 19240 & 33006 & 1 & 8474,6 & 4490,2 & 3649,3 & 983,55 & 80 & 240 \\
\hline R22 & 33006 & 19240 & 1 & 2696,3 & 1893,4 & 1727 & 1480,9 & 80 & 240 \\
\hline $\mathrm{R} 27$ & 33032 & 19220 & 1 & 2504 & 778,64 & 789,52 & 829,89 & 80 & 240 \\
\hline R28 & 19220 & 33032 & 1 & 8814,3 & 2502,1 & 1958,1 & 1346,4 & 80 & 240 \\
\hline $\mathrm{R} 25$ & 19240 & 33032 & 1 & 8490,8 & 3254 & 2252,1 & 699,82 & 80 & 240 \\
\hline R26 & 33032 & 19240 & 1 & 2282,9 & 1525,6 & 1331,4 & 1197,8 & 80 & 240 \\
\hline
\end{tabular}




\subsection{ANÁLISE DE RESULTADOS}

Através dos resultados pode-se analisar a viabilidade de aplicação entre um critério e outro. Para isso, as tabelas 6.6 a 6.8 comparam os dados obtidos para os pontos de referência nos três casos analisados: o caso base, a consideração de linhas paralelas e o critério N-1. Os resultados mostram o desvio porcentual entre os valores de corrente. Valores iguais a zero indicam que os resultados foram iguais para os dois casos, enquanto valores apresentados como inf. indicam que o caso de referência possui corrente igual a zero. Por exemplo: о valor $\mathrm{I}_{3 \text { іо_80в }}$ para R1 nо caso base foi de 298,33 A, para о caso de linhas paralelas foi de 315,16, e para o caso N-1 foi de 766,52. Assim, para este caso, o desvio percentual entre o critério de linhas paralelas e o caso base foi de 5,6\%, o desvio entre o critério $\mathrm{N}-1$ e o caso base foi de $156,9 \%$ e, o desvio entre o critério N-1 e o de linhas paralelas foi de $143,2 \%$.

Tabela 6.6 - Comparação dos resultados entre o critério de linhas paralelas e o caso base.

\begin{tabular}{|c|c|c|c|c|c|c|c|c|}
\hline \multirow[b]{2}{*}{ ID } & \multicolumn{4}{|c|}{ Fase } & \multicolumn{4}{|c|}{ Neutro } \\
\hline & $\mathrm{I}_{3 \mathrm{f}_{-} \text {cinP }}$ & $\mathrm{I}_{3 \mathrm{f} \_80 \mathrm{P}}$ & $\mathrm{I}_{3 \mathrm{f}_{-} \text {cinB }}$ & $\mathrm{I}_{3 \mathrm{f} \_80 \mathrm{~B}}$ & $\mathrm{I}_{3 \mathrm{io} \_ \text {cinP }}$ & $\mathrm{I}_{3 \mathrm{io} \_80 \mathrm{P}}$ & $\mathrm{I}_{3 \mathrm{io} \_ \text {cinB }}$ & $\mathrm{I}_{3 \mathrm{io} \_80 \mathrm{~B}}$ \\
\hline R1 & $0 \%$ & $0 \%$ & $0 \%$ & $0 \%$ & $0 \%$ & $8,1 \%$ & $0 \%$ & $5,6 \%$ \\
\hline $\mathrm{R} 2$ & $0 \%$ & $20,9 \%$ & $0 \%$ & $0 \%$ & $0 \%$ & $22,0 \%$ & $0 \%$ & $0 \%$ \\
\hline R3 & $0 \%$ & $0 \%$ & $0 \%$ & $0 \%$ & $0 \%$ & $9,3 \%$ & $0 \%$ & $5,6 \%$ \\
\hline R6 & $0 \%$ & $20,9 \%$ & $0 \%$ & $0 \%$ & $0 \%$ & $27,2 \%$ & $0 \%$ & $0 \%$ \\
\hline R7 & $0 \%$ & $0 \%$ & $0 \%$ & $15,8 \%$ & $0 \%$ & $20,7 \%$ & $15,2 \%$ & $36,5 \%$ \\
\hline $\mathrm{R} 8$ & $0 \%$ & $7,7 \%$ & $0 \%$ & $0 \%$ & $0 \%$ & $0 \%$ & $0 \%$ & $5,7 \%$ \\
\hline $\mathrm{R} 9$ & $0 \%$ & $9,8 \%$ & $0 \%$ & inf. & $15,2 \%$ & $36,5 \%$ & $0 \%$ & $0 \%$ \\
\hline $\mathrm{R} 10$ & $0 \%$ & $0 \%$ & $0 \%$ & $11,6 \%$ & $0 \%$ & $0 \%$ & $0 \%$ & $0 \%$ \\
\hline R13 & $0 \%$ & $5,4 \%$ & $0 \%$ & $0 \%$ & $0 \%$ & $0 \%$ & $0 \%$ & $0 \%$ \\
\hline R14 & $0 \%$ & $4,6 \%$ & $0 \%$ & $0 \%$ & $0 \%$ & $0 \%$ & $0 \%$ & $5,7 \%$ \\
\hline $\mathrm{R} 15$ & $0 \%$ & $41,4 \%$ & $0 \%$ & $2,3 \%$ & $0 \%$ & $59,4 \%$ & $0 \%$ & $88,4 \%$ \\
\hline R16 & $0 \%$ & $19,9 \%$ & $0 \%$ & $0 \%$ & $0 \%$ & $9,8 \%$ & $0 \%$ & $2,7 \%$ \\
\hline R17 & $0 \%$ & $41,4 \%$ & $0 \%$ & $2,3 \%$ & $0 \%$ & $59,4 \%$ & $0 \%$ & $88,4 \%$ \\
\hline $\mathrm{R} 18$ & $0 \%$ & $19,9 \%$ & $0 \%$ & $0 \%$ & $0 \%$ & $9,8 \%$ & $0 \%$ & $2,7 \%$ \\
\hline R23 & $0 \%$ & $6,4 \%$ & $0 \%$ & $0 \%$ & $12,6 \%$ & $9,4 \%$ & $0 \%$ & $0 \%$ \\
\hline R24 & $0 \%$ & $1,9 \%$ & $5,4 \%$ & $15,5 \%$ & $0 \%$ & $32,5 \%$ & $0 \%$ & $32,5 \%$ \\
\hline $\mathrm{R} 21$ & $0 \%$ & $0 \%$ & $0 \%$ & $8,4 \%$ & $0 \%$ & $5,3 \%$ & $12,6 \%$ & $9,4 \%$ \\
\hline R22 & $4,2 \%$ & $11,0 \%$ & $0 \%$ & $0 \%$ & $0 \%$ & $26,2 \%$ & $0 \%$ & $0 \%$ \\
\hline $\mathrm{R} 27$ & $0 \%$ & $7,3 \%$ & $0 \%$ & $0 \%$ & $0 \%$ & $38,4 \%$ & $0 \%$ & $1,2 \%$ \\
\hline R28 & $0 \%$ & $0 \%$ & $2,8 \%$ & $17,6 \%$ & $0 \%$ & $18,5 \%$ & $41,7 \%$ & $232,3 \%$ \\
\hline R25 & $0 \%$ & $0 \%$ & $0 \%$ & $11,4 \%$ & $0 \%$ & $7,0 \%$ & $0 \%$ & $51,9 \%$ \\
\hline R26 & $2,0 \%$ & $10,5 \%$ & $0 \%$ & $0 \%$ & $29,8 \%$ & $122,1 \%$ & $0 \%$ & $0 \%$ \\
\hline
\end{tabular}


Tabela 6.7 - Comparação dos resultados entre o critério N-1 e o caso base.

\begin{tabular}{|c|c|c|c|c|c|c|c|c|}
\hline & \multicolumn{4}{|c|}{ Fase } & \multicolumn{4}{|c|}{ Neutro } \\
\hline ID & $\mathrm{I}_{3 \mathrm{f} \_ \text {cinP }}$ & $\mathrm{I}_{3 \mathrm{f}_{2} 80 \mathrm{P}}$ & $\mathrm{I}_{3 \mathrm{f}_{\text {_cinB }}}$ & $\mathrm{I}_{3 \mathrm{f}_{2} 80 \mathrm{~B}}$ & $\mathrm{I}_{3 \text { io_cinP }}$ & $\mathrm{I}_{3 \mathrm{io} \_80 \mathrm{P}}$ & $\mathrm{I}_{3 \mathrm{io} \_\mathrm{cinB}}$ & $\mathrm{I}_{3 \mathrm{io} \_80 \mathrm{~B}}$ \\
\hline $\mathrm{R} 1$ & $0 \%$ & $0 \%$ & $80,2 \%$ & $80,5 \%$ & $0 \%$ & $\mathbf{9 , 3 \%}$ & $157,7 \%$ & $156,9 \%$ \\
\hline R2 & $0 \%$ & $20,9 \%$ & $0 \%$ & $0 \%$ & $0 \%$ & $27,1 \%$ & $0 \%$ & $0 \%$ \\
\hline R3 & $0 \%$ & $0 \%$ & $80,2 \%$ & $80,5 \%$ & $0 \%$ & $9,3 \%$ & $157,7 \%$ & $157,0 \%$ \\
\hline R6 & $0 \%$ & $20,9 \%$ & $0 \%$ & $0 \%$ & $0 \%$ & $27,2 \%$ & $0 \%$ & $0 \%$ \\
\hline R7 & $2,5 \%$ & $5,8 \%$ & $0 \%$ & $15,8 \%$ & $0 \%$ & $19,4 \%$ & $13,0 \%$ & $28,8 \%$ \\
\hline R8 & $0 \%$ & $7,7 \%$ & $13,8 \%$ & $17,9 \%$ & $0 \%$ & $0 \%$ & $0 \%$ & $5,7 \%$ \\
\hline R9 & $0 \%$ & $9,8 \%$ & $0 \%$ & inf. & $13,0 \%$ & $28,8 \%$ & $0 \%$ & $4,9 \%$ \\
\hline R10 & $2,0 \%$ & $4,0 \%$ & $0 \%$ & $11,6 \%$ & $2,4 \%$ & $6,0 \%$ & $0 \%$ & $0 \%$ \\
\hline R13 & $0 \%$ & $5,4 \%$ & $17,5 \%$ & $1600,1 \%$ & $0 \%$ & $0 \%$ & $0 \%$ & $1,3 \%$ \\
\hline R14 & $0 \%$ & $5,6 \%$ & $11,5 \%$ & $14,8 \%$ & $0 \%$ & $0 \%$ & $27,9 \%$ & $31,5 \%$ \\
\hline R15 & $0 \%$ & $41,4 \%$ & $74,2 \%$ & $86,7 \%$ & $0 \%$ & $59,4 \%$ & $115,6 \%$ & $116,9 \%$ \\
\hline R16 & $0 \%$ & $19,9 \%$ & $85,6 \%$ & $87,9 \%$ & $0 \%$ & $9,8 \%$ & $115,8 \%$ & $117,6 \%$ \\
\hline R17 & $0 \%$ & $41,4 \%$ & $74,2 \%$ & $86,7 \%$ & $0 \%$ & $59,4 \%$ & $115,6 \%$ & $116,9 \%$ \\
\hline R18 & $0 \%$ & $19,9 \%$ & $85,6 \%$ & $87,9 \%$ & $0 \%$ & $9,8 \%$ & $115,8 \%$ & $117,6 \%$ \\
\hline R23 & $0 \%$ & $6,4 \%$ & $12,3 \%$ & $15,3 \%$ & $12,6 \%$ & $9,4 \%$ & $176,3 \%$ & $83,7 \%$ \\
\hline R24 & $2,8 \%$ & $7,5 \%$ & $5,4 \%$ & $15,5 \%$ & $0 \%$ & $32,5 \%$ & $64,7 \%$ & $94,9 \%$ \\
\hline R21 & $2,6 \%$ & $3,6 \%$ & $0 \%$ & $8,4 \%$ & $8,0 \%$ & $19,7 \%$ & $12,6 \%$ & $9,4 \%$ \\
\hline R22 & $4,2 \%$ & $11,0 \%$ & $12,9 \%$ & $96,1 \%$ & $54,7 \%$ & $73,5 \%$ & $92,0 \%$ & $460,3 \%$ \\
\hline R27 & $0 \%$ & $7,3 \%$ & $14,3 \%$ & $18,0 \%$ & $14,4 \%$ & $50,0 \%$ & $223,8 \%$ & $466,3 \%$ \\
\hline R28 & $2,5 \%$ & $6,4 \%$ & $2,8 \%$ & $17,6 \%$ & $0 \%$ & $18,5 \%$ & $41,7 \%$ & $232,3 \%$ \\
\hline R25 & $2,2 \%$ & $4,0 \%$ & $0 \%$ & $11,4 \%$ & $6,8 \%$ & $28,6 \%$ & $18,7 \%$ & $69,6 \%$ \\
\hline R26 & $2,0 \%$ & $10,5 \%$ & $16,4 \%$ & $53,6 \%$ & $29,8 \%$ & $122,1 \%$ & $200,8 \%$ & $1649,7 \%$ \\
\hline
\end{tabular}

Tabela 6.8 - Comparação dos resultados entre o critério N-1 e o critério de linhas paralelas.

\begin{tabular}{|c|c|c|c|c|c|c|c|c|}
\hline & \multicolumn{4}{|c|}{ Fase } & \multicolumn{4}{|c|}{ Neutro } \\
\hline ID & $\mathrm{I}_{3 \mathrm{f}_{\text {cinP }}}$ & $\mathrm{I}_{3 \mathrm{f}_{-} 80 \mathrm{P}}$ & $\mathrm{I}_{3 \mathrm{f}_{-} \operatorname{cinB}}$ & $\mathrm{I}_{3 \mathrm{f}_{-} 80 \mathrm{~B}}$ & $\mathrm{I}_{\text {3io_cinP }}$ & $\mathrm{I}_{3 \mathrm{io} \_80 \mathrm{P}}$ & $\mathrm{I}_{\text {3io_cinB }}$ & $\mathrm{I}_{\text {3io_80B }}$ \\
\hline R1 & $0 \%$ & $0 \%$ & $80,2 \%$ & $80,5 \%$ & $0 \%$ & $1,1 \%$ & $157,7 \%$ & $143,2 \%$ \\
\hline R2 & $0 \%$ & $0 \%$ & $0 \%$ & $0 \%$ & $0 \%$ & $4,2 \%$ & $0 \%$ & $0 \%$ \\
\hline R3 & $0 \%$ & $0 \%$ & $80,2 \%$ & $80,5 \%$ & $0 \%$ & $0 \%$ & $157,8 \%$ & $143,3 \%$ \\
\hline R4 & $0 \%$ & $0 \%$ & $0 \%$ & $0 \%$ & $0 \%$ & $0 \%$ & $0 \%$ & $0 \%$ \\
\hline R7 & $2,5 \%$ & $5,8 \%$ & $0 \%$ & $0 \%$ & $0 \%$ & $0 \%$ & $0 \%$ & $0 \%$ \\
\hline R8 & $0 \%$ & $0 \%$ & $13,8 \%$ & $17,9 \%$ & $0 \%$ & $0 \%$ & $0 \%$ & $0 \%$ \\
\hline R9 & $0 \%$ & $0 \%$ & $0 \%$ & $0 \%$ & $0 \%$ & $0 \%$ & $0 \%$ & $4,9 \%$ \\
\hline $\mathrm{R} 10$ & $2,0 \%$ & $4,0 \%$ & $0 \%$ & $0 \%$ & $2,4 \%$ & $6,0 \%$ & $0 \%$ & $0 \%$ \\
\hline $\mathrm{R} 13$ & $0 \%$ & $0 \%$ & $17,5 \%$ & $1600,1 \%$ & $0 \%$ & $0 \%$ & $0 \%$ & $1,3 \%$ \\
\hline $\mathrm{R} 14$ & $0 \%$ & $1,0 \%$ & $11,5 \%$ & $14,8 \%$ & $0 \%$ & $0 \%$ & $27,9 \%$ & $24,5 \%$ \\
\hline $\mathrm{R} 15$ & $0 \%$ & $0 \%$ & $74,2 \%$ & $82,5 \%$ & $0 \%$ & $0 \%$ & $115,6 \%$ & $15,1 \%$ \\
\hline R16 & $0 \%$ & $0 \%$ & $85,6 \%$ & $87,9 \%$ & $0 \%$ & $0 \%$ & $115,8 \%$ & $111,9 \%$ \\
\hline R17 & $0 \%$ & $0 \%$ & $74,2 \%$ & $82,5 \%$ & $0 \%$ & $0 \%$ & $115,6 \%$ & $15,1 \%$ \\
\hline R18 & $0 \%$ & $0 \%$ & $85,6 \%$ & $87,9 \%$ & $0 \%$ & $0 \%$ & $115,8 \%$ & $111,9 \%$ \\
\hline $\mathrm{R} 23$ & $0 \%$ & $0 \%$ & $12,3 \%$ & $15,3 \%$ & $0 \%$ & $0 \%$ & $176,3 \%$ & $83,7 \%$ \\
\hline $\mathrm{R} 24$ & $2,8 \%$ & $5,5 \%$ & $0 \%$ & $0 \%$ & $0 \%$ & $0 \%$ & $64,7 \%$ & $47,1 \%$ \\
\hline $\mathrm{R} 21$ & $2,6 \%$ & $3,6 \%$ & $0 \%$ & $0 \%$ & $8,0 \%$ & $13,7 \%$ & $0 \%$ & $0 \%$ \\
\hline R22 & $0 \%$ & $0 \%$ & $12,9 \%$ & $96,1 \%$ & $54,7 \%$ & $37,5 \%$ & $92,0 \%$ & $460,3 \%$ \\
\hline R27 & $0 \%$ & $0 \%$ & $14,3 \%$ & $18,0 \%$ & $14,4 \%$ & $8,4 \%$ & $223,8 \%$ & $459,5 \%$ \\
\hline $\mathrm{R} 28$ & $2,5 \%$ & $6,4 \%$ & $0 \%$ & $0 \%$ & $0 \%$ & $0 \%$ & $0 \%$ & $0 \%$ \\
\hline $\mathrm{R} 25$ & $2,2 \%$ & $4,0 \%$ & $0 \%$ & $0 \%$ & $6,8 \%$ & $20,2 \%$ & $18,7 \%$ & $11,7 \%$ \\
\hline R26 & $0 \%$ & $0 \%$ & $16,4 \%$ & $53,6 \%$ & $0 \%$ & $0 \%$ & $200,8 \%$ & $1649,7 \%$ \\
\hline
\end{tabular}


Observando os resultados pode-se chegar a algumas conclusões. Em primeiro lugar, pelas tabelas 6.6 e 6.7 percebe-se que a consideração apenas do caso base certamente resultará em violações do critério de segurança N-1 do sistema, pois há uma grande quantidade de correntes de referência com valores maiores do que no caso base. Desse modo, ajustes considerando apenas a análise do caso base levariam a atuação indevida de dispositivos de proteção caso alguma linha do sistema saia de operação.

Um resultado interessante é que a maioria dos valores das correntes para faltas close-in na atuação do relé como proteção principal apresentaram resultados bem próximos entre o caso base, o critério de linhas paralelas e o critério N-1 real, tanto para faltas trifásicas quanto para monofásicas-terra. Isso indica que, para faltas close-in, a maior corrente ocorrerá, na maioria das vezes, quando todos os disjuntores do sistema estiverem fechados. Esta característica pode mascarar os resultados em metodologias que utilizam apenas faltas close-in para realizar a coordenação de sobrecorrente, dando a impressão equivocada de que o sistema está corretamente coordenado para casos de alterações topológicas.

Quanto à escolha do critério a ser utilizado, o mais correto seria o $\mathrm{N}-1$, pois, pela própria formulação, analisa todas as possíveis alterações topológicas N-1 do sistema, porém exige-se um grande esforço durante o estudo de curto-circuito. Como citado, são 1210 diferentes tipos de faltas analisadas no critério N-1 contra 320 do critério de linhas paralelas e 110 do caso base, sendo viável apenas caso seja realizada uma automatização da análise de curto-circuito. Já a análise considerando linhas paralelas pode ser considerada viável, produzindo bons resultados dependendo da confiabilidade desejada. Os casos em que o critério N-1 produz resultados mais realistas (correntes de referência maiores) do que no critério de linhas paralelas em um fator de $10 \%$ ou mais são detalhados nas tabelas 6.9 e 6.10 . O caso base considera todos os disjuntores das linhas do sistema fechados. 
Tabela 6.9 - Casos em que o critério N-1 fornece resultados mais realistas do que o critério de linhas paralelas, para a proteção de fase.

\begin{tabular}{|c|c|c|c|}
\hline $\begin{array}{l}\text { ID } \\
\text { Relé }\end{array}$ & Corrente & $\begin{array}{l}\text { Condição para a maior corrente no critério } \\
\text { "N-1" }\end{array}$ & $\begin{array}{c}\text { Condição para a maior corrente no critério } \\
\text { "Linhas Paralelas" }\end{array}$ \\
\hline R1 & $\mathrm{I}_{3 \mathrm{f}_{-} \operatorname{cin} B}$ & Linha [19200-19219-19210 c1] aberta & Caso Base \\
\hline $\mathrm{R} 1$ & $\mathrm{I}_{3 \mathrm{f}} 80 \mathrm{~B}$ & Linha [19200-19219-19210 c1] aberta & Caso Base \\
\hline R3 & $\mathrm{I}_{3 \mathrm{f}_{-} \operatorname{cin} B}$ & Linha $[19200-19210 \mathrm{c} 1]$ aberta & Caso Base \\
\hline R3 & $\mathrm{I}_{3 \mathrm{f} \_80 \mathrm{~B}}$ & Linha $[19200-19210 \mathrm{c} 1]$ aberta & Caso Base \\
\hline $\mathrm{R} 8$ & $\mathrm{I}_{3 \mathrm{f}_{-} \operatorname{cin} B}$ & Linha [19210-19218-19217-19280 c1] aberta & Caso Base \\
\hline $\mathrm{R} 8$ & $\mathrm{I}_{3 \mathrm{f} \_80 \mathrm{~B}}$ & Linha [19210-19218-19217-19280 c1] aberta & Caso Base \\
\hline $\mathrm{R} 13$ & $\mathrm{I}_{3 \mathrm{f}_{-} \operatorname{cin} B}$ & Linha [19210-33048-33046 c1] aberta & Caso Base \\
\hline R13 & $\mathrm{I}_{3 \mathrm{f} \_80 \mathrm{~B}}$ & Linha [19210-33048-33046 c1] aberta & Caso Base \\
\hline R14 & $I_{3 f_{-} \operatorname{cinB}}$ & Linha [19210-33048-33046 c1] aberta & Caso Base \\
\hline R14 & $\mathrm{I}_{3 \mathrm{f} \_80 \mathrm{~B}}$ & Linha [19210-33048-33046 c1] aberta & Caso Base \\
\hline $\mathrm{R} 15$ & $\mathrm{I}_{3 \mathrm{f}_{-} \operatorname{cinB}}$ & Linha [19210-19220 c2] aberta & Caso Base \\
\hline R15 & $\mathrm{I}_{3 \mathrm{f} \_80 \mathrm{~B}}$ & Linha [19210-19220 c2] aberta & Linha $[33032-33040-19227-19220 \mathrm{c} 1]$ aberta \\
\hline R16 & $\mathrm{I}_{3 \mathrm{f}_{-} \operatorname{cinB} B}$ & Linha [19210-19220 c2] aberta & Caso Base \\
\hline R16 & $\mathrm{I}_{3 \mathrm{f} \_80 \mathrm{~B}}$ & Linha [19210-19220 c2] aberta & Caso Base \\
\hline R17 & $\mathrm{I}_{3 \mathrm{f}_{-} \operatorname{cinB}}$ & Linha $[19210-19220 \mathrm{c} 1]$ aberta & Caso Base \\
\hline R17 & $\mathrm{I}_{3 \mathrm{f} \_80 \mathrm{~B}}$ & Linha $[19210-19220 \mathrm{c} 1]$ aberta & Linha $[33032-33040-19227-19220 \mathrm{c} 1]$ aberta \\
\hline $\mathrm{R} 18$ & $\mathrm{I}_{3 \mathrm{f}_{-} \operatorname{cin} B}$ & Linha $[19210-19220 \mathrm{c} 1]$ aberta & Caso Base \\
\hline R18 & $\mathrm{I}_{3 \mathrm{f}_{-} 80 \mathrm{~B}}$ & Linha $[19210-19220 \mathrm{c} 1]$ aberta & Caso Base \\
\hline $\mathrm{R} 23$ & $\mathrm{I}_{3 \mathrm{f}_{-} \operatorname{cin} B}$ & Linha [33032-33040-19227-19220 c1] aberta & Caso Base \\
\hline $\mathrm{R} 23$ & $\mathrm{I}_{3 \mathrm{f} \_80 \mathrm{~B}}$ & Linha [33032-33040-19227-19220 c1] aberta & Caso Base \\
\hline R22 & $\mathrm{I}_{3 f_{-} \operatorname{cinB}}$ & Linha [33032-33040-19227-19220 c1] aberta & Caso Base \\
\hline R22 & $\mathrm{I}_{3 \mathrm{f}_{-} 80 \mathrm{~B}}$ & Linha [33032-33040-19227-19220 c1] aberta & Caso Base \\
\hline R27 & $I_{3 f_{-} \operatorname{cinB}}$ & $\begin{array}{l}\text { Linha [33006-33008-19246-19226-19220 c1] } \\
\text { aberta }\end{array}$ & Caso Base \\
\hline R27 & $\mathrm{I}_{3 \mathrm{f}-80 \mathrm{~B}}$ & $\begin{array}{l}\text { Linha [33006-33008-19246-19226-19220 c1] } \\
\text { aberta }\end{array}$ & Caso Base \\
\hline R26 & $I_{3 f \_c i n B}$ & $\begin{array}{l}\text { Linha [33006-33008-19246-19226-19220 c1] } \\
\text { aberta }\end{array}$ & Caso Base \\
\hline R26 & $\mathrm{I}_{3 \mathrm{f}-80 \mathrm{~B}}$ & $\begin{array}{l}\text { Linha [33006-33008-19246-19226-19220 c1] } \\
\text { aberta }\end{array}$ & Caso Base \\
\hline
\end{tabular}


Tabela 6.10 - Casos em que o critério N-1 fornece resultados melhores do que o critério de linhas paralelas, para a proteção de neutro.

\begin{tabular}{|c|c|c|c|}
\hline ID & Corrente & $\begin{array}{l}\text { Condição para a maior corrente no critério } \\
\text { "N-1" }\end{array}$ & $\begin{array}{c}\text { Condição para a maior corrente no critério } \\
\text { "Linhas Paralelas" }\end{array}$ \\
\hline R1 & $\mathrm{I}_{3 i \mathrm{o}_{-} \operatorname{cin} B}$ & Linha [19200-19219-19210 c1] aberta & Caso Base \\
\hline $\mathrm{R} 1$ & $\mathrm{I}_{3 \mathrm{io \_} \_80 \mathrm{~B}}$ & Linha [19200-19219-19210 c1] aberta & Linha [19210-19220 c2] aberta \\
\hline R3 & $\mathrm{I}_{3 \mathrm{io} \_ \text {cinB }}$ & Linha [19200-19210 c1] aberta & Caso Base \\
\hline R3 & $\mathrm{I}_{3 \mathrm{io} \_80 \mathrm{~B}}$ & Linha [19200-19210 c1] aberta & Linha [19210-19220 c2] aberta \\
\hline $\mathrm{R} 14$ & $\mathrm{I}_{3 \mathrm{io \_} \operatorname{cin} B}$ & $\begin{array}{l}\text { Linha [33046-33047-19216-19294-19280 c1] } \\
\text { aberta }\end{array}$ & Caso Base \\
\hline $\mathrm{R} 14$ & $\mathrm{I}_{3 \mathrm{io} \_80 \mathrm{~B}}$ & $\begin{array}{l}\text { Linha [33046-33047-19216-19294-19280 c1] } \\
\text { aberta }\end{array}$ & Linha [19210-19220 c2] aberta \\
\hline $\mathrm{R} 15$ & $\mathrm{I}_{3 \mathrm{io} \_ \text {cin } B}$ & Linha [19210-19220 c2] aberta & Caso Base \\
\hline $\mathrm{R} 15$ & $\mathrm{I}_{3 \mathrm{io} \_80 \mathrm{~B}}$ & Linha [19210-19220 c2] aberta & $\begin{array}{l}\text { Linha [33006-33008-19246-19226-19220 c1] } \\
\text { aberta }\end{array}$ \\
\hline R16 & $\mathrm{I}_{3 i o_{-} \operatorname{cin} B}$ & Linha [19210-19220 c2] aberta & Caso Base \\
\hline R16 & $\mathrm{I}_{3 \mathrm{io} \_80 \mathrm{~B}}$ & Linha [19210-19220 c2] aberta & Linha [19210-19218-19217-19280 c1] aberta \\
\hline $\mathrm{R} 17$ & $\mathrm{I}_{3 \mathrm{io \_} \text { cinB }}$ & Linha [19210-19220 c1] aberta & Caso Base \\
\hline $\mathrm{R} 17$ & $\mathrm{I}_{3 \mathrm{io} \_80 \mathrm{~B}}$ & Linha [19210-19220 c1] aberta & $\begin{array}{l}\text { Linha [33006-33008-19246-19226-19220 c1] } \\
\text { aberta }\end{array}$ \\
\hline $\mathrm{R} 18$ & $\mathrm{I}_{3 \mathrm{io \_} \operatorname{cin} \mathrm{B}}$ & Linha $[19210-19220 \mathrm{c} 1]$ aberta & Caso Base \\
\hline $\mathrm{R} 18$ & $\mathrm{I}_{3 \mathrm{io} \_80 \mathrm{~B}}$ & Linha [19210-19220 c1] aberta & Linha [19210-19218-19217-19280 c1] aberta \\
\hline $\mathrm{R} 23$ & $\mathrm{I}_{3 \mathrm{iio} \_ \text {cinB }}$ & Linha [33032-33040-19227-19220 c1] aberta & Caso Base \\
\hline $\mathrm{R} 23$ & $\mathrm{I}_{3 \mathrm{iio} \_80 \mathrm{~B}}$ & Linha [19240-19247-33039-33032 c1] aberta & Caso Base \\
\hline R24 & $\mathrm{I}_{3 \mathrm{iio} \_ \text {cinB }}$ & Linha $[33032-33040-19227-19220 \mathrm{c} 1]$ aberta & Caso Base \\
\hline $\mathrm{R} 24$ & $\mathrm{I}_{3 \mathrm{io} \_80 \mathrm{~B}}$ & Linha [33032-33040-19227-19220 c1] aberta & Linha [19240-19247-33039-33032 c1] aberta \\
\hline $\mathrm{R} 21$ & $\mathrm{I}_{3 \mathrm{io} \_80 \mathrm{P}}$ & $\begin{array}{l}\text { Linha [33006-33008-19246-19226-19220 c1] } \\
\text { aberta }\end{array}$ & Linha [19240-19247-33039-33032 c1] aberta \\
\hline $\mathrm{R} 22$ & $\mathrm{I}_{3 i o \_c i n P}$ & Linha [33032-33040-19227-19220 c1] aberta & Caso Base \\
\hline $\mathrm{R} 22$ & $\mathrm{I}_{3 \mathrm{io} \_80 \mathrm{P}}$ & Linha $[33032-33040-19227-19220 \mathrm{c} 1]$ aberta & Linha [19240-19247-33039-33032 c1] aberta \\
\hline R22 & $\mathrm{I}_{3 \text { io_cinB }}$ & Linha [33032-33040-19227-19220 c1] aberta & Caso Base \\
\hline $\mathrm{R} 22$ & $\mathrm{I}_{3 \mathrm{io} \_80 \mathrm{~B}}$ & Linha [33032-33040-19227-19220 c1] aberta & Caso Base \\
\hline $\mathrm{R} 27$ & $\mathrm{I}_{3 \mathrm{io} \_ \text {cinP }}$ & Linha [19240-33007-33006 c1] aberta & Caso Base \\
\hline $\mathrm{R} 27$ & $\mathrm{I}_{3 \mathrm{io} \_\operatorname{cin} \mathrm{B}}$ & $\begin{array}{l}\text { Linha [33006-33008-19246-19226-19220 c1] } \\
\text { aberta }\end{array}$ & Caso Base \\
\hline $\mathrm{R} 27$ & $\mathrm{I}_{3 \mathrm{io} \_80 \mathrm{~B}}$ & Linha [19240-33007-33006 c1] aberta & Linha [19210-19220 c2] aberta \\
\hline $\mathrm{R} 25$ & $\mathrm{I}_{3 \mathrm{io} \_80 \mathrm{P}}$ & Linha [33032-33040-19227-19220 c1] aberta & Linha [19240-33007-33006 c1] aberta \\
\hline $\mathrm{R} 25$ & $\mathrm{I}_{3 \mathrm{io}_{-} \mathrm{cin} B}$ & Linha [19240-33007-33006 c1] aberta & Caso Base \\
\hline $\mathrm{R} 25$ & $\mathrm{I}_{3 \mathrm{io} \_80 \mathrm{~B}}$ & Linha [19240-33007-33006 c1] aberta & $\begin{array}{l}\text { Linha [33006-33008-19246-19226-19220 c1] } \\
\text { aberta }\end{array}$ \\
\hline $\mathrm{R} 26$ & $\mathrm{I}_{3 \mathrm{io} \_ \text {cinB }}$ & $\begin{array}{l}\text { Linha [33006-33008-19246-19226-19220 c1] } \\
\text { aberta }\end{array}$ & Caso Base \\
\hline R26 & $\mathrm{I}_{3 \mathrm{io \_} 80 \mathrm{~B}}$ & $\begin{array}{l}\text { Linha [33006-33008-19246-19226-19220 c1] } \\
\text { aberta }\end{array}$ & Caso Base \\
\hline
\end{tabular}


Para exemplificar os resultados, a coordenação foi realizada para os três tipos de estudo. Toma-se o par de relés principal-retaguarda R24-R15. Considerando os resultados do caso base para a proteção de fase, para uma falta close-in a corrente no relé principal é de 8314,2 A, enquanto seu tempo de atuação é de 201 ms. No relé de retaguarda a corrente medida é de 3210,7, atuando em 676ms. Porém, para a mesma falta, caso a linha [19210-19220] circuito 2 esteja aberta, a corrente sobre o principal será de 7490,6 A e no retaguarda 5594,2 A, de modo que, com os ajustes obtidos no caso base, o relé R24 atuaria em 207 ms e o relé R15 em 361 ms, resultando em um intervalo de 154 ms, abaixo do mínimo admitido de 200 ms. Para esta mesma situação, ainda com a linha 19210-19220-2 aberta, a atuação dos relés R24 e R15 com os resultados da análise considerando linhas paralelas é de $213 \mathrm{~ms}$ e $539 \mathrm{~ms}$ respectivamente, resultando em um intervalo de coordenação de $326 \mathrm{~ms}$, acima dos $200 \mathrm{~ms}$ admitidos e, portanto, correta.

A Figura 6.1 mostra os resultados obtidos para a coordenação dos relés R24 e R15 para a proteção de fase considerando a análise de curto circuito com todos os disjuntores fechados. Já as figuras 6.2 e 6.3 mostram os resultados para as análises considerando linhas paralelas a análise N-1, respectivamente. Percebe-se claramente a evolução da curva do relé R15 entre os três gráficos, tornandose mais inclinada para manter os requisitos de coordenação e não violar os pontos de referência. Para o sistema com todos os disjuntores fechados, o tempo de atuação para faltas close-in é praticamente o mesmo nos três tipos de análise, pois o método busca justamente minimizar esse valor. A diferença está para a atuação dos relés como proteção de retaguarda, que é mais longa nos critérios N-1 e de linhas paralelas para adequar os requisitos de coordenação. 


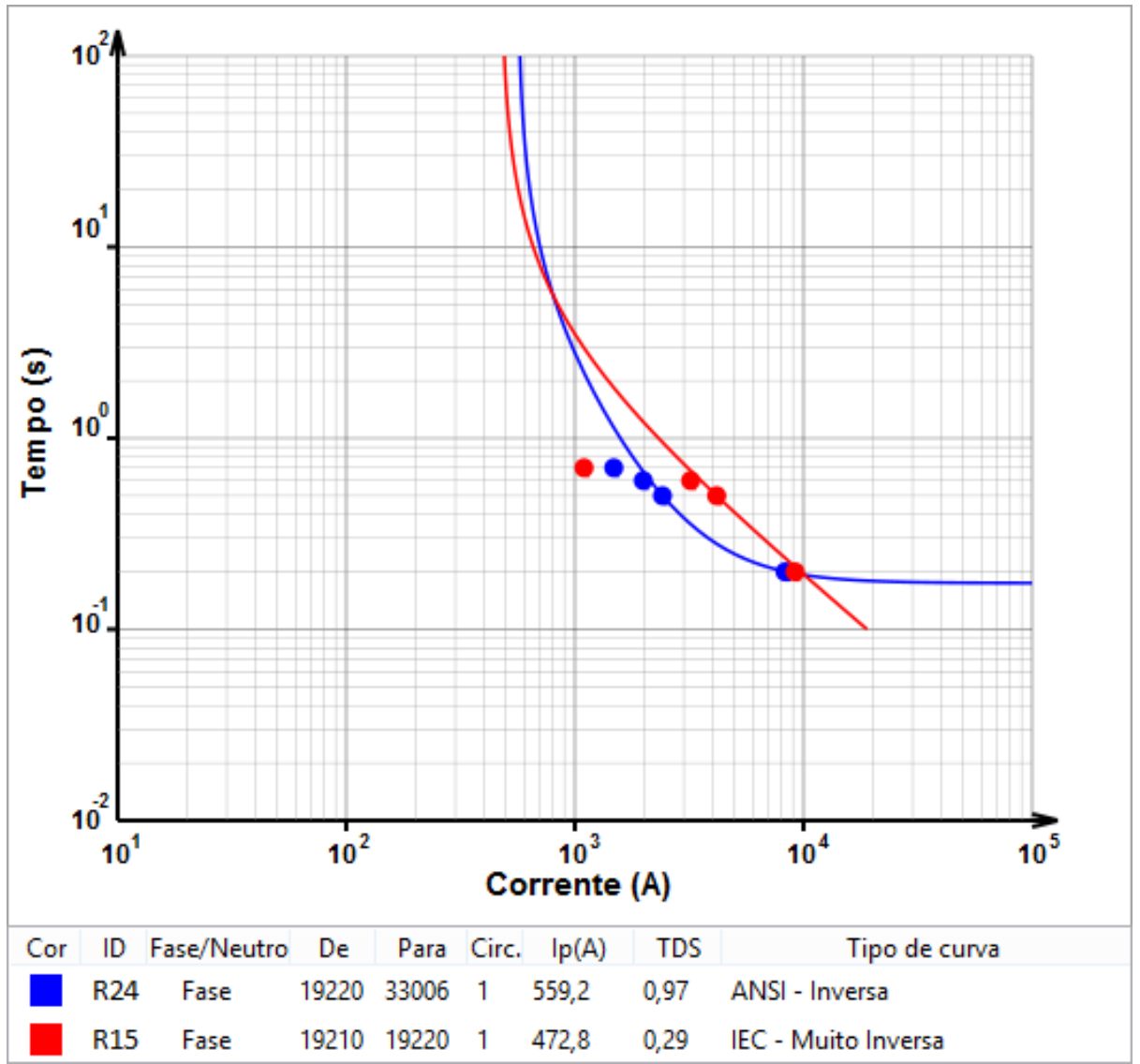

Figura 6.1 - Coordenação de fase entre os relés R24 e R15 considerando a análise para o caso base.

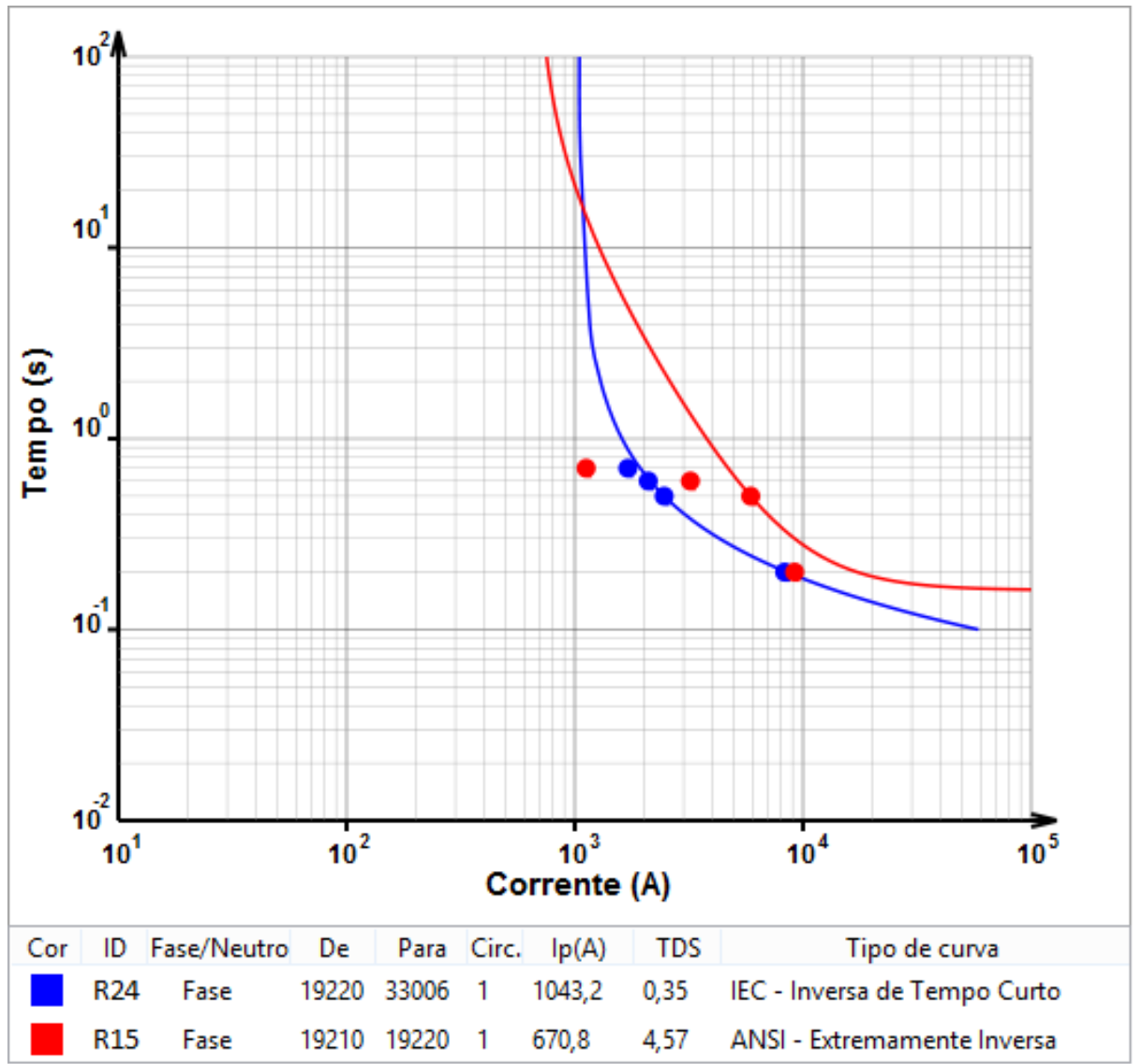

Figura 6.2 - Coordenação de fase entre os relés R24 e R15 considerando a análise de linhas paralelas. 


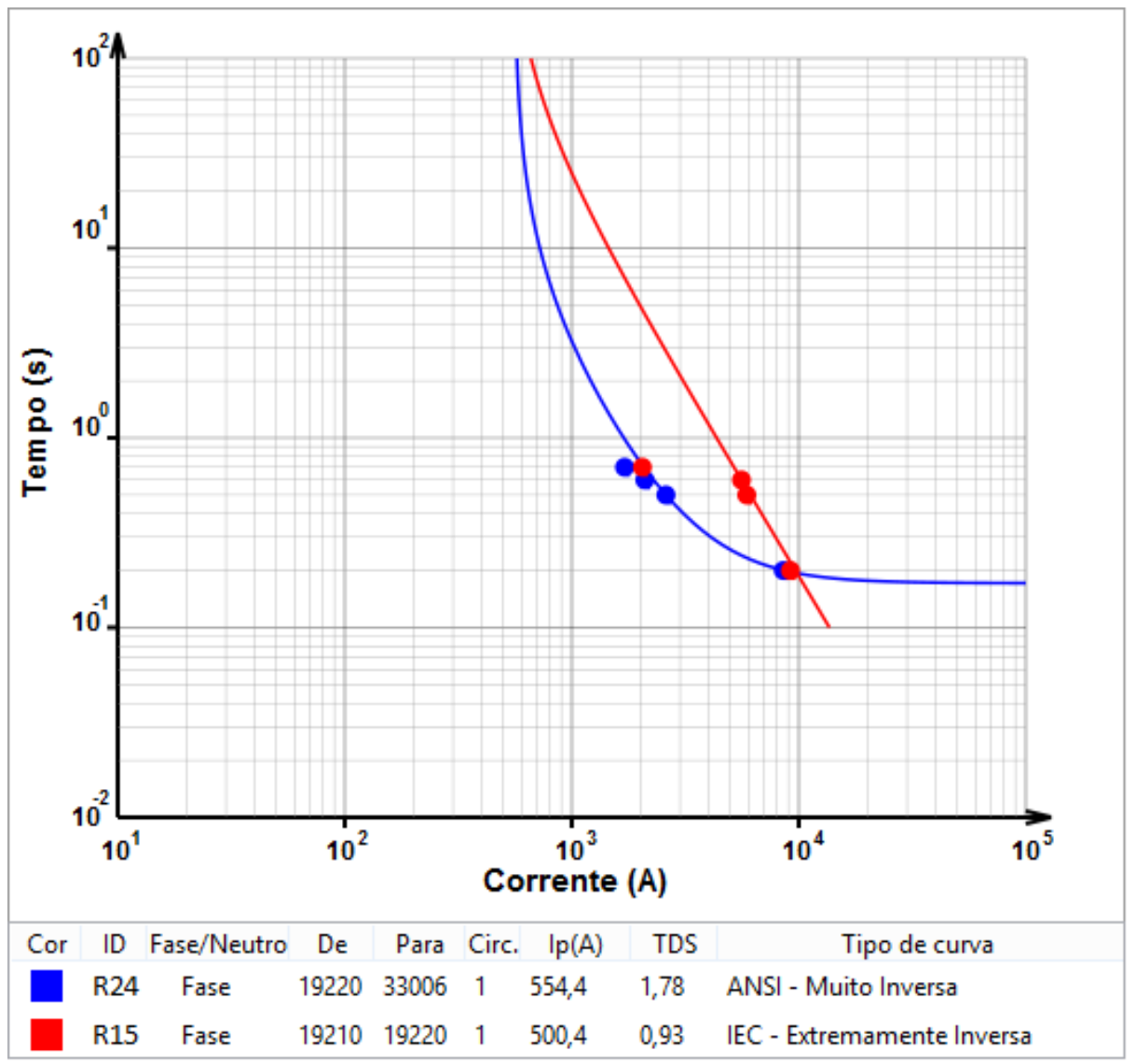

Figura 6.3 - Coordenação de fase entre os relés R24 e R15 considerando a análise N-1.

Considere agora a proteção de neutro do par principal-retaguarda R22-R24, sem levar em consideração os relés de distância. Para uma falta close-in, considerando os resultados com abertura de linhas paralelas, a corrente no relé principal é de 1742,5 A, e seu tempo de atuação é de 235 ms. No relé de retaguarda a corrente medida é de 1396,4 A, atuando em 522 ms. Porém, para a mesma falta, caso a linha [33032-33040] esteja aberta, a corrente sobre o relé principal será de 2696,3 A, atuando em 149 ms, abaixo do limite inferior admitido de 200 ms. Além disso, a corrente no relé de retaguarda será de 2300,2 A, atuando em $312 \mathrm{~ms}$, o que resulta em um intervalo de $163 \mathrm{~ms}$, abaixo do mínimo admitido. Para esta mesma situação, com a linha 33032-33040 aberta, a atuação dos relés R22 e R24 com os resultados da análise considerando o critério $\mathrm{N}-1$ é de $265 \mathrm{~ms}$ e $466 \mathrm{~ms}$ respectivamente, resultando em um intervalo de coordenação de 326 ms, acima dos 200 ms admitidos e, portanto, correta.

As figuras 6.4, 6.5 e 6.6 mostram os resultados obtidos para a coordenação dos relés R22 e R24 para a proteção de neutro considerando a análise de curto circuito no caso base, considerando linhas paralelas e considerando o critério $\mathrm{N}-1$, respectivamente. Percebe-se que há pouca diferença entre os resultados do caso base para o caso de linhas paralelas. Porém, na análise N-1 os ajustes mudam consideravelmente, tanto para o relé R22 quanto para o R24, revelando a carência da consideração apenas de linhas paralelas nos estudos de coordenação. 


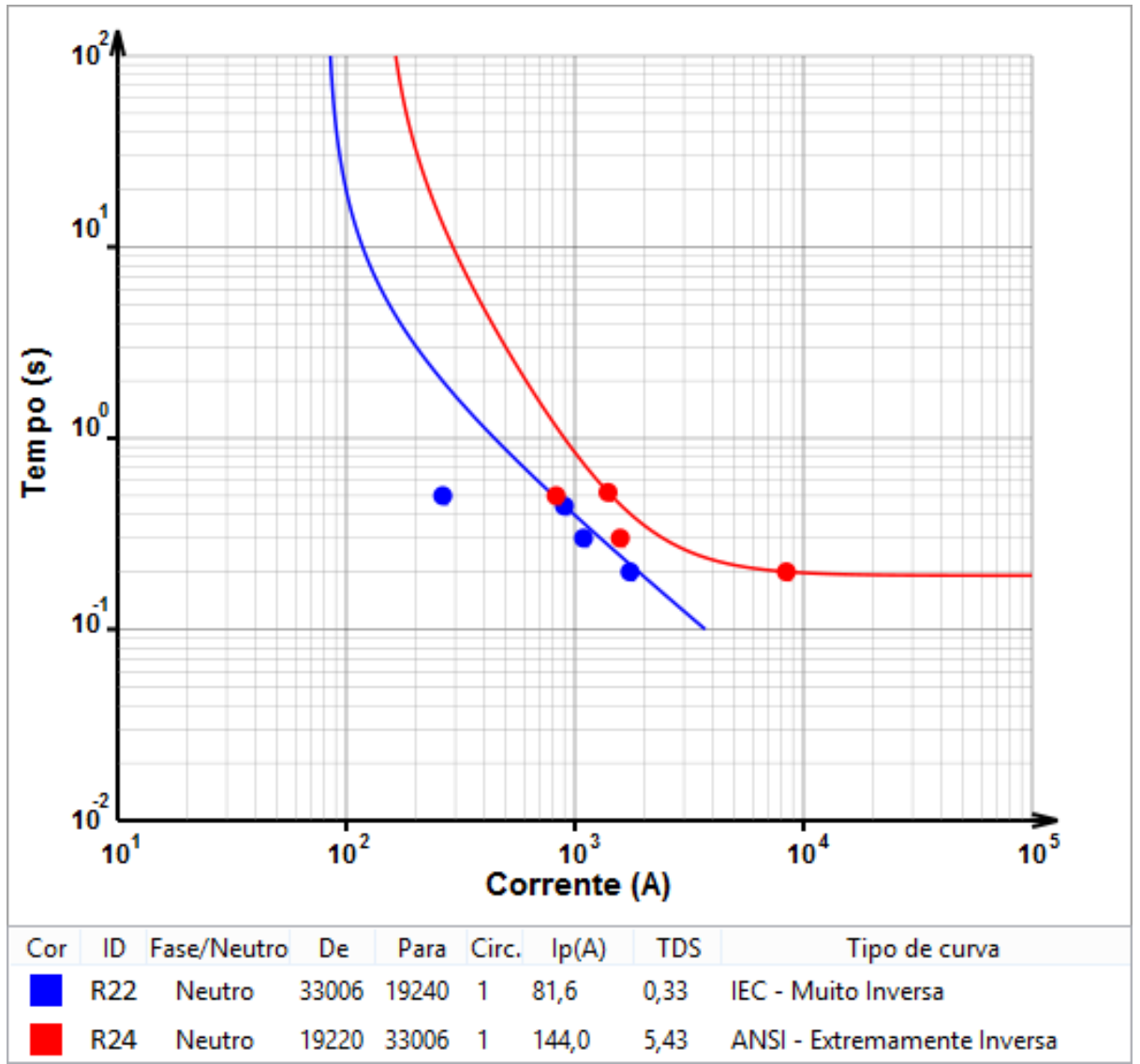

Figura 6.4 - Coordenação de neutro entre os relés R22 e R24 considerando a análise para o caso base.

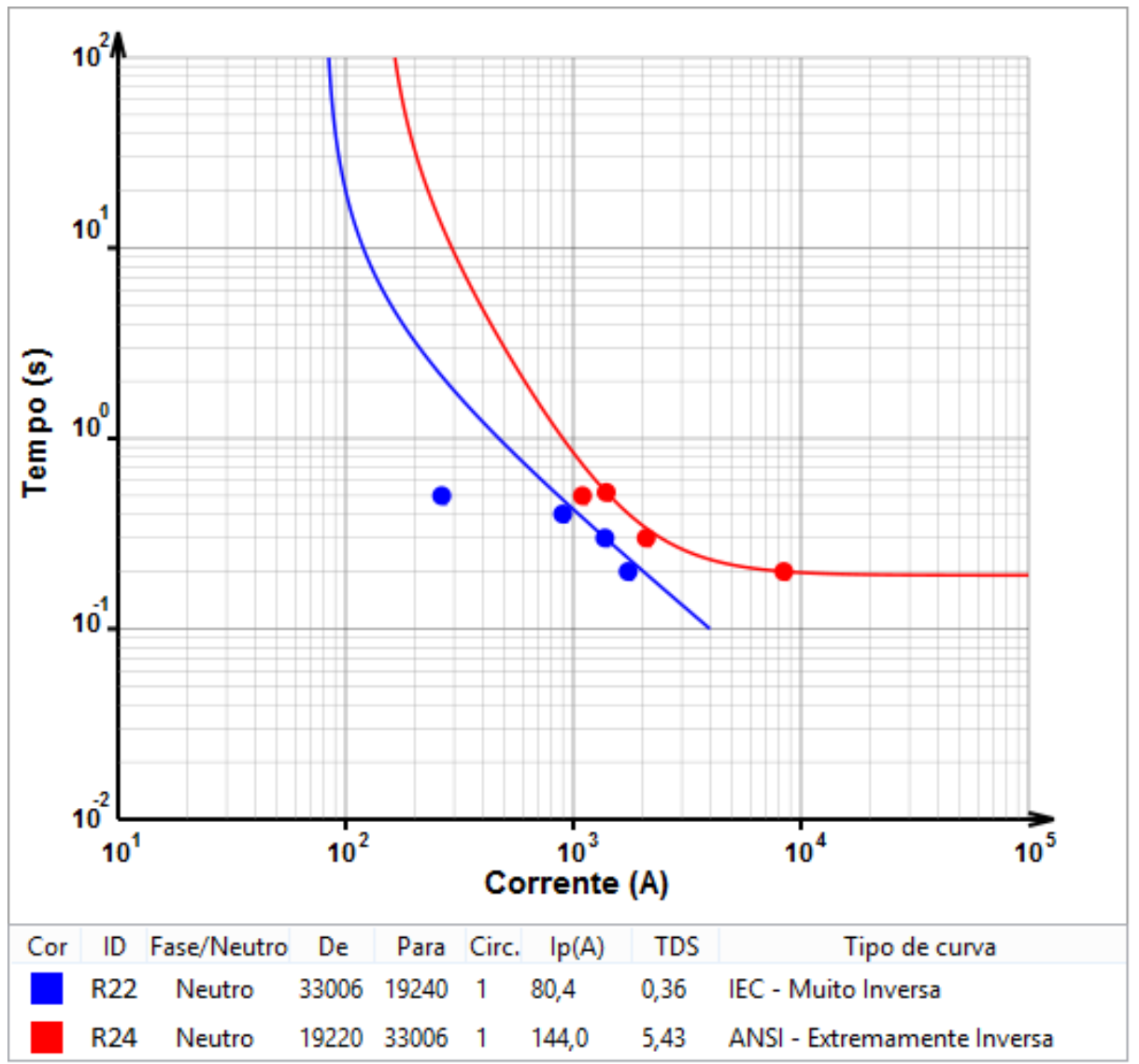

Figura 6.5 - Coordenação de neutro entre os relés R22 e R24 considerando a análise de linhas paralelas. 


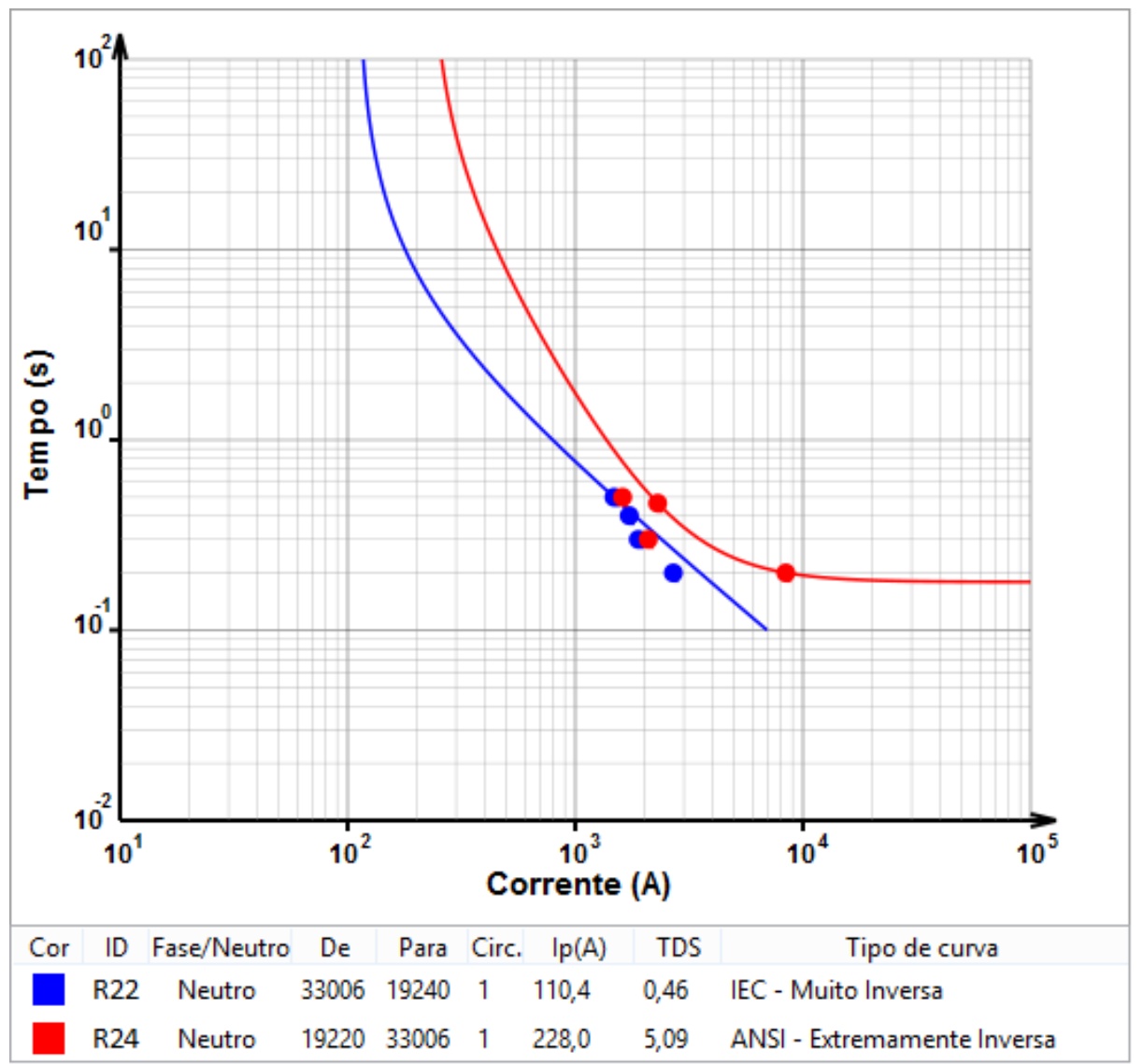

Figura 6.6 - Coordenação de neutro entre os relés R22 e R24 considerando a análise N-1.

\subsection{CONSIDERAÇÕES FINAIS SOBRE O CAPÍTULO}

Nesta seção foi realizada uma análise de curto-circuito mediante a alterações topológicas em um sistema de transmissão real. Para realizar a coordenação da proteção de sobrecorrente faz-se necessário tomar como referência a maior corrente dentre todas as condições analisadas, pois se o sistema de proteção respeita a pior situação então respeitará todas as outras. Logo, uma análise de curto-circuito deve ser realizada visando testar todas as hipóteses de alterações no sistema base e tomando como referência para a coordenação as maiores correntes obtidas para cada local de instalação dos relés.

Neste contexto, a consideração do critério N-1 é um modo de se garantir que a proteção atuará corretamente e de modo seletivo mesmo com a perda de uma linha do sistema. Porém, como demonstrado, o estudo N-1 real pode demandar muito tempo devido a grande quantidade de informações a serem tratadas, tornando-se inviável sem uma ferramenta que permita a automatização desta análise. Sem a automatização, a alternativa mais exequível seria a análise de cenários, em que são compostas diversas situações com uma maior probabilidade de ocorrer determinando uma lista de contingência de linhas. Ao final da análise têm-se os dados de entrada para o estudo de proteção, que dá origem a conjuntos de ajustes que respeitam as contingências consideradas.

Um seguimento interessante desse estudo é a proteção adaptativa, em que são definidos diversos conjuntos de ajustes relacionados a determinadas topologias do sistema. Desse modo, em dada 
contingência, um conjunto de ajustes específico para aquele caso seria carregado no relé automaticamente, mantendo o sistema de proteção otimizado. 


\section{CONCLUSÃO}

Neste trabalho foi proposta uma metodologia que define uma nova abordagem para o problema de coordenação de relés direcionais de sobrecorrente. Por meio da obtenção de informações da atuação do relé tanto como proteção principal como proteção de retaguarda (ou retaguarda local e retaguarda remota, no caso de se considerar o relé de distância como proteção principal), simplifica-se o problema de coordenação, além de que, pela própria concepção da abordagem, garante-se que os critérios de coordenação sejam obedecidos.

A metodologia é tal que os dados sobre a topologia do sistema em análise são resumidos nos dados sobre as correntes de curto-circuito, eliminando a etapa de testes sucessivos entre proteções principal/retaguarda (ou retaguarda local/retaguarda remota), aumentando a eficiência do algoritmo. Os dados sobre a forma em que o sistema se interconecta tal como definições de pares de relés principal/retaguarda estarão embutidos nas correntes de curto-circuito que são dados de entrada para a metodologia. Em sistemas que utilizam relés de distância, o método sempre garante a coordenação entre estes e os relés direcionais, pois os ajustes devem respeitar a atuação do relé 21 , que pode ser considerado como um dispositivo com curva de atuação a tempo definido, para efeito da coordenação com o relé 67. Logo, apenas por configurar os ajustes de modo que as curvas de atuação dos relés se situem na área de ajuste definida pela metodologia (Figura 4.7) já se garante a correta coordenação dos relés direcionais e relés de distância. Já para estudos considerando apenas relés direcionais de sobrecorrente a proposta do método é definir uma curva de atuação ideal, através de pontos de referência para coordenação. A partir disso, o método de otimização encontra, dentre as curvas disponíveis dos relés reais, qual mais se aproxima da ideal, assumindo que as curvas disponíveis são capazes de caracterizar corretamente o sistema. Para os casos em que não se consegue alcançar a coordenação, o método modifica automaticamente os pontos de referência para então obter resultados coerentes.

A metodologia proposta requer a obtenção de correntes de curto-circuito através de um programa externo. As simulações de faltas e a identificação de quais correntes seriam tomadas como referência fazem parte de um estudo prévio que, apesar de simples, demanda tempo do usuário. Porém, incluindo-se um módulo interno de cálculo de curto-circuito, é fácil programá-lo para obter diretamente as quatro correntes de referência que são entrada para a metodologia. Desse modo todo o processo ficaria automatizado, cabendo ao usuário apenas a determinação dos critérios a serem utilizados e a análise final dos resultados.

Como as correntes de falta são entrada para a metodologia, as análises de alterações topológicas podem ser feitas sem influenciar a aplicabilidade do método. A partir dos resultados obtidos no Capítulo 6 conclui-se que a realização da coordenação considerando apenas o caso em que todos os disjuntores estão fechados não garante a correta coordenação do sistema, sendo necessárias análises específicas de alterações topológicas. A consideração de cenários com linhas paralelas abertas traz um benefício 
significativo no sentido de segurança do sistema, porém ainda não garante o critério $\mathrm{N}-1$, o que pode causar operações indevidas quando houver linhas fora de operação. Devido ao grande esforço da análise N-1 real, que exige um número de dados quase quatro vezes maior que da análise com linhas paralelas, a melhor opção seria uma definição de cenários recorrentes, abrangendo linhas mais carregadas, com maior manutenção ou em locais de maior risco, o que, embora não garanta a coordenação para o critério N-1, é mais viável para os estudos de curto-circuito.

De modo geral, podem-se citar as seguintes vantagens da metodologia:

- Simplificação do tratamento do problema, ganhando-se em eficiência computacional e em aplicação na prática;

- Clareza dos resultados, sendo que o usuário sabe exatamente como a resposta final foi encontrada e qual a implicação caso haja variação dos critérios de coordenação. Isto é importante para a adaptação da metodologia a diferentes sistemas e sua aplicação na prática. De posse dos quatro pontos tomados como referência para a definição dos ajustes, o usuário sabe, analisando a curva de atuação, o que acontece caso na prática algum ajuste seja diferente do valor encontrado pela metodologia;

- Ganho visual com a resposta diretamente dada em curvas de atuação dos relés;

- Considera a coordenação com relés de distância.

Como contribuições à área de proteção podem-se citar:

- Desenvolvimento de um novo método de coordenação: o Melhor Ajuste Local, definindo uma área de ajuste do relé direcional de sobrecorrente;

- Desenvolvimento do critério de otimização ME - Menor Erro, determinando o melhor ajuste do relé a partir da curva de atuação que mais se aproxima dos pontos de referência;

- Desenvolvimento do critério de otimização ILL - Integral Logarítmica ponderada Linearmente, que determina o melhor ajuste do relé a partir da curva de atuação que possui a menor área em escala logarítmica;

- Análise das implicações ao estudo de coordenação com a utilização outros relés que não sejam o direcional de sobrecorrente, como no caso de restrições impostas pelo relé de distância;

- Análise detalhada das implicações nos casos de alterações topológicas e do critério de segurança N-1. 
A metodologia é promissora e pode ser expandida para outros segmentos do sistema elétrico. Abaixo seguem algumas possibilidades de trabalhos futuros nessa mesma linha de pesquisa:

- Estender a análise para sistemas de distribuição e sistemas industriais, adicionando outros elementos de proteção como fusíveis e Disjuntores de Baixa Tensão;

- Adicionar a definição da proteção de transformadores;

- Permitir a possibilidade de coordenação com a proteção de outros equipamentos, como reatores, banco de capacitores e cargas. 


\section{REFERÊNCIAS BIBLIOGRÁFICAS}

ABB Live Tank Circuit Breakers - Buyer's Guide. ABB AB High Voltage Products, 2009. Disponível em: http://www.abb.com/product/pt/9aac710019.aspx. Acesso em 25 de janeiro de 2014.

ABB Type CO Circuit Opening Overcurrent Relay. Instruction Leaflet. Maio 1984. Disponível em: http://www.abb.com/product/db0003db004281/c12573e700330419c1256e7e003223e5.aspx. Acesso em 22 de outubro de 2013.

ANDERSON, P. M. Power system protection. New York: Ed. McGraw-Hill, 1999.

CAPE - Computer-Aided Protection Engineering. Electrocon International Incoporated. Disponível em http://www.electrocon.com/capeintro.html. Acesso em 26 de agosto de 2013.

CORREAA, Rafael. Otimização da coordenação de relés de sobrecorrente direcionais em sistemas elétricos de potência utilizando a programação inteira binária. Dissertação (Mestrado em Engenharia Elétrica) - Universidade Federal de Santa Maria, Santa Maria, 91 p., 2012.

COURY, D. V.; OLESKOVICZ, M.; GIOVANINI, R. Proteção digital de sistemas elétricos de potência: dos relés eletromecânicos aos microprocessados inteligentes. São Carlos: Ed. da EESC USP, 2007.

DARWISH, H. A.; RAHMAN, M. A.; TAALAB, A.I.; SHAABAN, H. Digital model of overcurrent Relay characteristics. In: Industry Applications Conference, 1995. v. 2. Pages 11871192.

ELMORE, W. A. Protective relaying theory and applications. New York: ABB Power T\&D Company Inc., 1994.

EZZEDDINE, M.; KACZMAREK, R.; IFTIKHAR, M.U. Coordination of directional overcurrent relays using a novel method to select their settings. IET Generation, Transmission \& Distribution. v. 5, Jul. 2011, p. 743-750.

GEC MEASUREMENTS - CDG-13 Catalog. Overcurrent very inverse time relay.

GTK PROJECT. Disponível em http://www.gtk.org. Acesso em 24 de janeiro de 2014.

HENROTTE, F.; NICOLET, A.; HÉDIA, H.; GENON, A.; LEGROS, W. Modelling of electromechanical relays taking into account movement and electric circuits. IEEE Transactions on magnetics, vol. 30, no. 5, 1994.

HEWITSON, L. G.; BROWN, M.; BALAKRISHNAN, R. Practical Power Systems Protection. Elsevier - Newnes, 2004.

INSTITUTE OF ELECTRICAL AND ELECTRONICS ENGINEERS. IEEE Std. C37.112: IEEE standard inverse time characteristic equations for overcurrent relays. 1996.

INTERNATIONAL ELECTROTECHNICAL COMISSION. IEC 60255-3: electrical relays - part 3: single input energizing quantity measuring relays with dependent or independent time", 1989.

KAWAHARA, K.; SASAKI, H.; SUGIHARA, H. An application of rule based system to the coordination of directional overcurrent relays. In: Developments in Power System Protection, Sixth International Conference on (Conf. Publ. No. 434), 1997, p. 58-61. 
KLOCK JR., O. S. Programa Computacional para a Verificação da Coordenação e Auxílio na Determinação dos Ajustes de Relés Direcionais de Sobrecorrente de Neutro de Linhas de Transmissão. Dissertação (Mestrado em Engenharia Elétrica) - Universidade Federal de Santa Catarina, Florianópolis, 85 p., 2002.

MANSOUR, M. M.; MEKHAMER, S. F.; EL-KHARBAWE, N. E. A modified particle swarm optimizer for the coordination of directional overcurrent relays. IEEE Transactions on Power Delivery, v. 22, n. 3, jul. 2007, p. 1400-1410.

MASON, C. R. The art and Science of Protective Relaying. John Wiley and Sons, Inc. New York, 1956.

PÉREZ, L. G.; URDANETA, A. J. Optimal coordination of directional overcurrent relays considering definite time backup relaying. IEEE Transactions on Power Delivery, v. 14, n. 4, out. 1999, p. 1276-1284.

PHADKE, A. G.; THORP, J. S. Computer Relaying for Power Systems. Research Studies Press LTD, 1990.

SIEMENS, High-Voltage Circuit Breakers, From $72.5 \mathrm{kV}$ up to $800 \mathrm{kV}$ - Portfolio CircuitBreakers. Siemens AG, Energy Sector, 2012. Disponível em: http://www.energy.siemens.com/hq/en/power-transmission/high-voltage-products/circuitbreaker/\#content=Drive\%20Systems. Acesso em 25 de janeiro de 2014.

TLEIS, N. D. Power Systems Modelling and Fault Analysis - Theory and Practice. Elsevier Ltd, Oxford, UK. 2008.

URDANETA, A. J.; NADIRA, R.; JIMÉNEZ, L. G. P. Optimal coordination of directional overcurrent relays in interconnected power systems. IEEE Transactions on Power Delivery. v. 3, n. 3, jul. 1988, p. 903-911.

WU, FENG-JIH; CHOU, CHIH-JU; LU, YING; CHUNG, JARM-LONG. Modeling electromechanical overcurrent relays using singular value decomposition. Journal of applied mathematics. Hindawi publishing corporation. Volume 2012, article ID 104952, 18 pages. 2012.

ZEINELDIN, H.; EL-SAADANY, E. F.; SALAMA, M. A. A novel problem formulation for directional overcurrent relay coordination. large engineering systems. In: Conference on Power Engineering (LESCOPE-04), Proceedings... Jul. 2004, p. 48-51.

ZEINELDIN, H.; EL-SAADANY, E. F.; SALAMA, M. A. Optimal coordination of directional overcurrent relay coordination. In: Power Engineering Society General Meeting, Proceedings... v. 2, 2005, p. $1101-1106$.

ZIEGLER, GERHARD. Numerical distance protection - Principles and applications. 3rd edition. SIEMENS, 2008. 


\section{APÊNDICE A: DADOS DO SISTEMA IEEE 14 BARRAS}

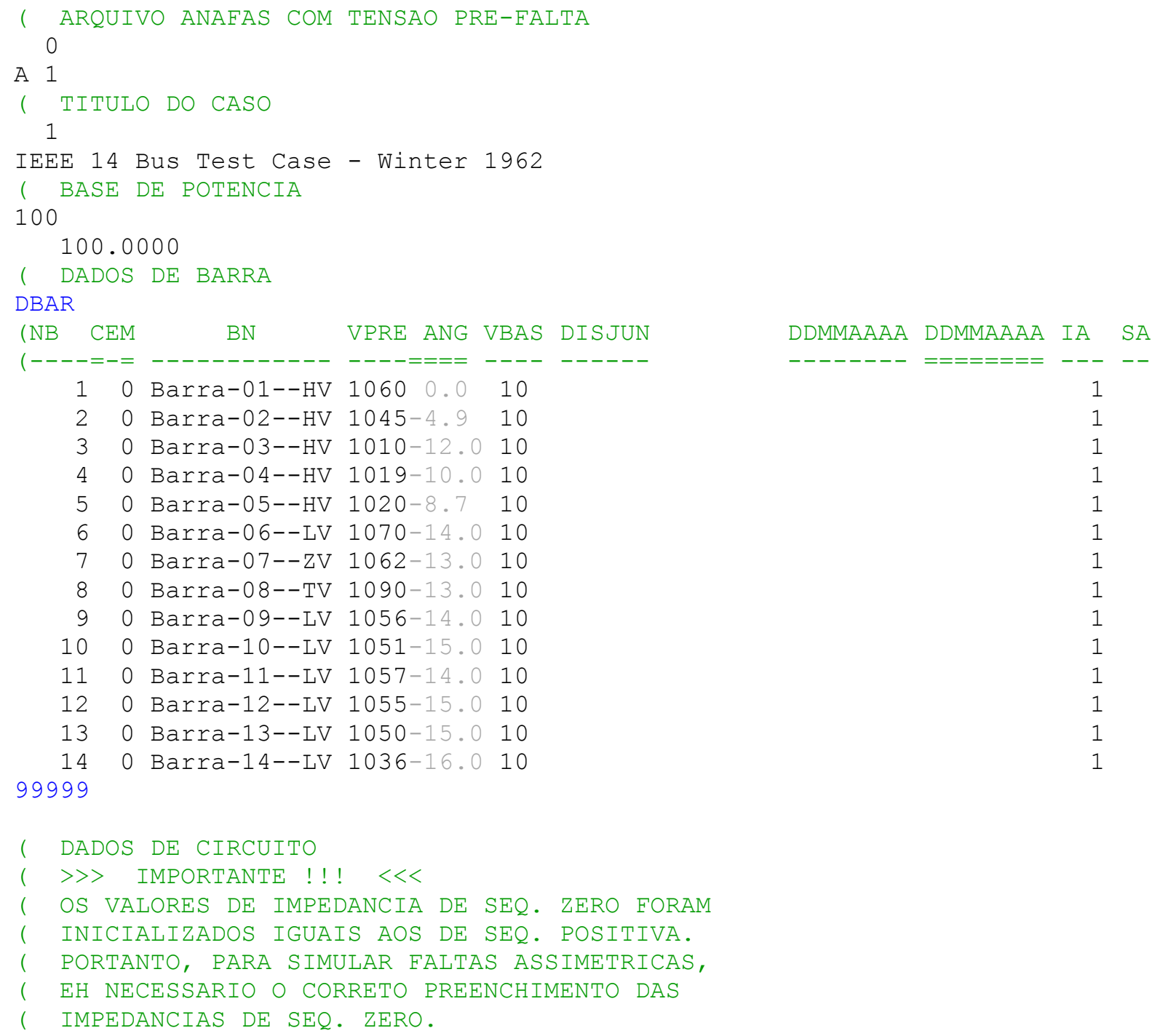

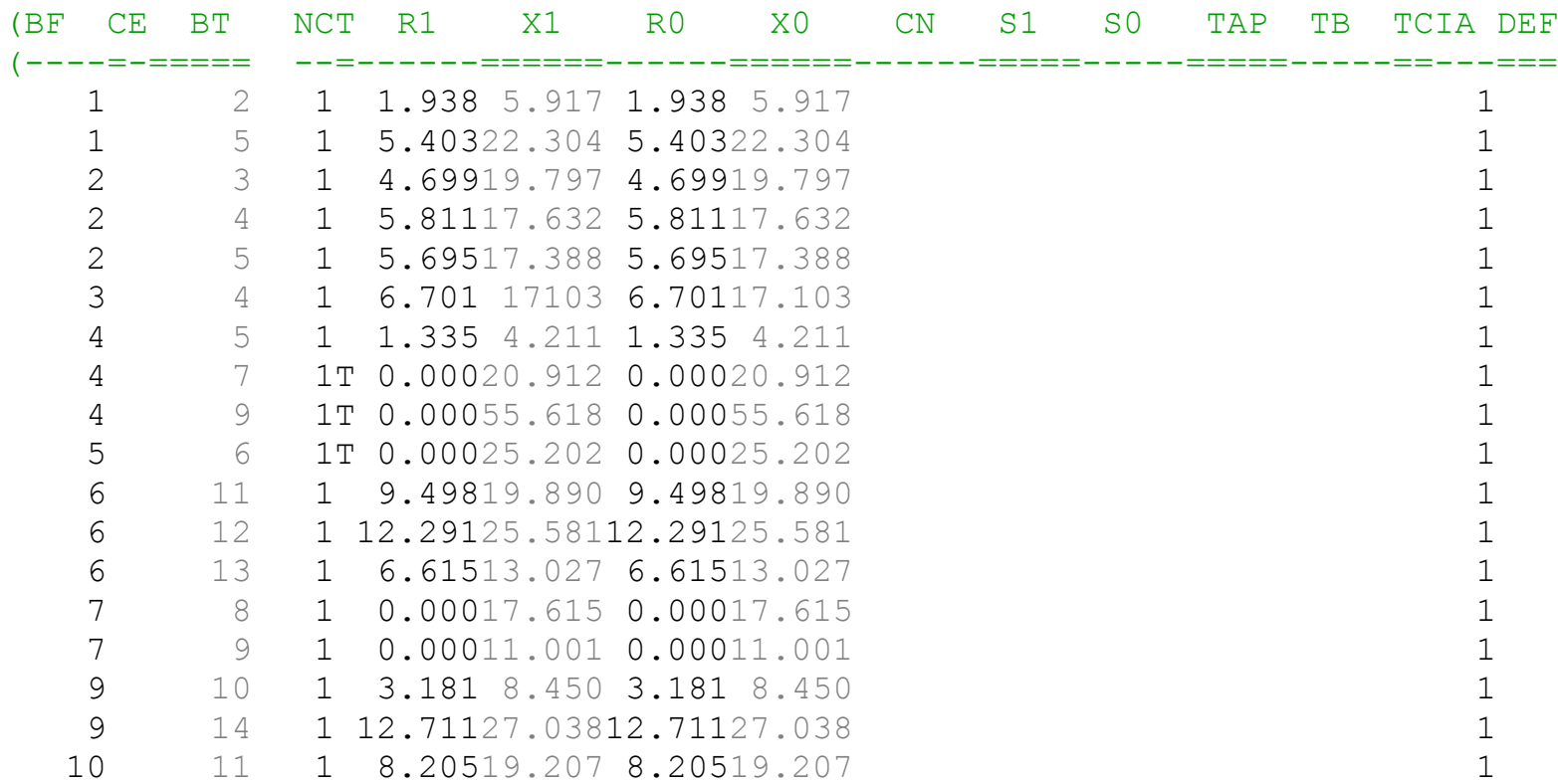




\begin{tabular}{|c|c|c|c|}
\hline 12 & 13 & 122.09219 .98822 .09219 .988 & 1 \\
\hline 13 & 14 & 117.09334 .80217 .09334 .802 & \\
\hline 0 & 9 & $\begin{array}{lll}\mathrm{H} & -52632 & -52632\end{array}$ & \\
\hline 0 & 2 & C $3748421938 \quad 3748421938$ & \\
\hline 0 & 3 & C $1040620.988 \quad 1040620.988$ & \\
\hline 0 & 4 & C $21579-1761 \quad 21579-1761$ & $\perp$ \\
\hline 0 & 5 & C131085 2759713108527597 & 1 \\
\hline 0 & 6 & C $70576 \quad 47260 \quad 70576 \quad 47260$ & $\perp$ \\
\hline 0 & 9 & C $28710 \quad 16156 \quad 28710 \quad 16156$ & $\perp$ \\
\hline 0 & 10 & C $86718 \quad 55885 \quad 86718 \quad 55885$ & \\
\hline 0 & 11 & C252445129829252445129829 & \\
\hline 0 & 12 & C170718 $44778170718 \quad 44778$ & 1 \\
\hline 0 & 13 & C 68941296196894129619 & \\
\hline 0 & 14 & C $64743 \quad 21726 \quad 64743 \quad 21726$ & 1 \\
\hline 0 & 1 & G $\quad 999998 \quad 999998$ & \\
\hline 0 & 2 & 999998 & \\
\hline 0 & 3 & 999998 & $\perp$ \\
\hline 0 & 6 & 999998 & \\
\hline 0 & 8 & 999998 & \\
\hline
\end{tabular}

99999 


\section{APÊNDICE B: EXEMPLO DE SAIIDA RESUMIDA DOS RESULTADOS}

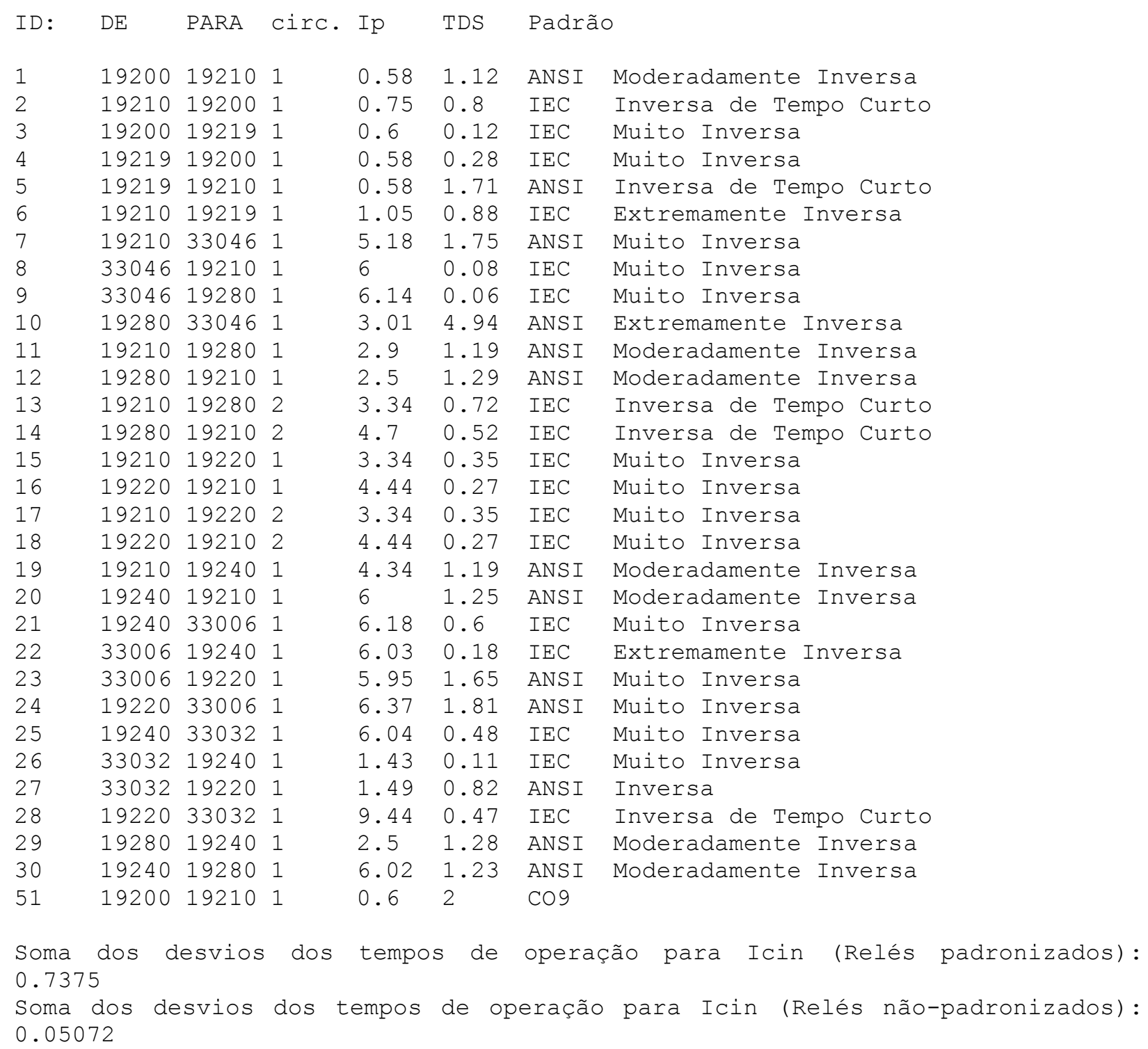

